\title{
Essays on Trust, Mobile Phones, And Nutrition Among Pastoralists in Northern Kenya
}

\author{
Dissertation \\ to attain the doctoral degree (Dr. rer. pol) \\ of the Faculty of Agricultural Sciences \\ Georg-August-University Göttingen \\ Submitted by \\ Martin Christoph Parlasca \\ born on the 25.06.1990 in Göttingen, Germany
}

Göttingen, September 2020 
Name of supervisor: Prof. Dr. Oliver Mußhoff Name of co-supervisor: Prof. Dr. Matin Qaim Name of co-supervisor: Prof. Dr. Robert Finger Date of oral examination: 19.05.2020 


\section{Summary}

The arid and semi-arid lands (ASAL) cover close to 90 per cent of Kenya's landmass and are home to nearly 30 per cent of its population. Historically, the ASAL have however suffered from limited political representation, weak integration into social services, and low infrastructure investments. This marginalization has caused affected communities to fall behind in economic development and overall welfare.

This thesis contributes to the understanding of two important aspects in the lives of the predominantly pastoralist communities that inhabit Northern Kenya's ASAL. The first aspects relates to social trust, which is considered a fundamental component of economic interaction and growth. The second aspect relates to nutrition, which is considered to be a fundamental component of human and economic development. In particular, this thesis aims at showing that increases in social trust and improvements of nutrition among pastoralist communities can be achieved through the use of mobile phones.

This dissertation is composed of three papers, each highlighting a particular component of the overall analysis. The first paper of this thesis in chapter II, is titled: "A Radius of Trust? Contrasting Insights from Experiments and Survey Data". It provides insights into the trust culture of pastoralist communities in Turkana County, Northern Kenya. The analysis is based on primary data collected in July/August 2018. We conducted an incentivized version of the canonical trust game by Berg et al. (1995) with 402 participants. Using a between-subject design, trust was measured for three treatments: trust towards people from one's own village, trust towards people from a neighboring village, and trust towards city dwellers from the county capital. While fellow villager and people from a neighboring village are equally trusted, experimental data show that participants place statistically significantly less trust into city dwellers from the county capital. We argue that this phenomenon can be explained with the concept of the radius of trust. The experiment is then contrasted with self-reported trust levels. Survey data differ from the experimental data in the aspect that fellow villagers seem to be more trusted than people from a neighboring village. A potential cause of this discrepancy lies in overstatements of trust towards fellow villagers in the survey due to a social-desirability bias.

The second paper of this dissertation in chapter III, "Can Mobile Phones Build Social Trust? Insights from Rural Kenya" utilizes the same data set as the aforementioned paper. The effect of mobile phone use on trust is the focal point of this second study. The experiment is used here as a measurement for social trust. However, the source of variation 
exploited in this study is based on mobile phone usage of the participants rather than the difference between the three treatment groups. To deal with bias due to unobserved heterogeneity of users and non-users, we use a control function approach with mobile phone reception as an instrumental variable. The results suggest that mobile phones might help increase trust towards people that live far ways, namely towards people from the county capital. No statistically significant effects are found with regard to trust towards people who live closer, namely towards fellow villagers and people from a neighboring village. The differential effect of mobile phones on trust could be explained by the fact that mobile phones facilitate communication particularly between people that are distant from each other.

The third paper of this dissertation in chapter IV is called "Can mobile phones improve nutrition among pastoral communities? Panel data evidence from Northern Kenya". This study presents an impact assessment of the effect of mobile phone use and mobile phone ownership on two indicators of dietary diversity. The study is based on six rounds of secondary panel data collected from 2009 to 2015 in Marsabit County in the North of Kenya. We show that the region is characterized by relatively low levels of dietary diversity. At the same time, mobile phone usage has risen substantially in the observed time period. We argue that mobile phone use and mobile phone ownership can be associated with increases in dietary diversity. Several robustness checks suggest that easier access to markets and purchased food contribute to this increase in dietary diversity.

Based on these three papers, we draw several conclusions. Firstly, we reinforce previous alerts that pastoralist communities in Northern Kenya do indeed face several severe challenges: social trust in the region is low, and city dwellers from the county capital even face particularly low trust levels. This lack of trust can potentially hamper social interaction and economic development of the communities. Limited dietary diversity represents another critical issue that became apparent through our analysis. As a consequence of sub-optimal dietary quality, full evolvement of individuals and their skills might be constrained, thereby restricting the economic potential of affected households.

At the same time, we show that mobile phones represent a particularly powerful tool in the hands of pastoralist communities. The technology has the potential to improve important welfare dimensions. Mobile phones can be associated with increases in trust towards people from the county capital, which might help reduce some of the aforementioned challenges. Furthermore, mobile phones can be associated with more diverse diets. This improvement of a concrete and highly relevant household welfare dimension reinforces the advantages that the mobile phone technology has brought and continues to bring to pastoralist communities. 


\section{Acknowledgements}

During my entire life and especially in the last three years I was blessed to have the support of numerous people. The thesis would not exist in this form without their help. I take this opportunity to thank them and acknowledge their support.

I would like to thank my supervisor, Prof. Dr. Oliver Mußhoff, for giving me the opportunity to write this thesis under his supervision. Thank you for your valuable and exceptionally quick feedback on my work. The freedom of choosing topics that fascinate and inspire me as well as the enabling work environment that you created are highly appreciated. I would furthermore like to thank my two co-supervisors, Prof. Dr. Robert Finger and Prof. Dr. Matin Qaim, for their support and for helping me experience a pleasant and smooth dissertation process.

Several other colleagues here in Göttingen have supported me over the last three years. I thank my coauthor Daniel Hermann for many fruitful and enjoyable discussions as well as excellent input and feedback. I am aware that the positive experience I was blessed to have with all my coauthors is not to be taken for granted. I would like to thank my fellow GlobalFood colleagues, who have not hesitated to include me into their group. The coffee breaks, retreats, courses, conferences, and outside-work activities we shared together have motivated me and contributed immensely to the enjoyableness of the last three years.

I am very thankful for the people in our coordination office and in particular for Melanie Grosse. You are great colleagues and have been an immense help in organizing and managing the sometimes tedious administrative work that goes along with the dissertation procedure.

I would like to thank my wonderful office mates over the last three years, Christina Martini, and Anette Ruml. The economic profession can be glad to have two such smart, competent, and integer researchers as you two are in its ranks.

I express deepest gratitude to the Turkana people, who continue to be a great source of inspiration for my work and who have welcomed me warmly during field work. I sincerely hope that this thesis in some way may benefit their lives. In particular, my thanks go to Mr. William Ngirotin and Mr. Kalokol Emmanuel Erukudi for their excellent research assistance. The continuous learning from another that we experienced before and during field work has greatly benefited the quality of this research.

Many thanks also go to my dear friends here in Göttingen, in particular to Carla, Elias, Fiete, Filiz, Frieda, Helge, Jurij, Katharina, Katia, Mattia, and Theo. 
My family deserves my deepest gratitude as well. You have supported me in so many ways. I am deeply grateful to my parents Katharina and Christoph, and to my siblings Teresa, Thomas, Felix, and Simon. Each one of you in their own way has been and continues to be a role model to me.

My two wonderful daughters Paula and Henrieke enrich my life in so many ways. You keep showing me that this dissertation is not as important for my life as it sometimes seemed to be in the last three years.

The gratitude I feel for the support of my wife, Lena, is difficult to put into words. You support me in so many ways: building me up when things are rough, keeping me downto-earth when things go well, constantly reminding me of what really matters in life. You were never tired of reading my work and had many good ideas and useful comments. Thank you. 


\section{Contents}

$\begin{array}{ll}\text { Summary } & \text { I }\end{array}$

$\begin{array}{ll}\text { Acknowledgements } & \text { IV }\end{array}$

$\begin{array}{ll}\text { List of Tables } & \text { VIII }\end{array}$

$\begin{array}{ll}\text { List of Figures } & \text { IX }\end{array}$

$\begin{array}{ll}\text { List of Acronyms } & \text { XII }\end{array}$

1 General Introduction 1

1.1 Trust and Nutrition among Pastoralist Communities in Northern Kenya . . 2

1.2 Mobile Phones and Pastoralists . . . . . . . . . . . . . . . . . 5

1.3 Research Objectives and Outline . . . . . . . . . . . . . . . . 7

2 A Radius of Trust?

Contrasting Insights from Experiments and Survey Data 9

2.1 Introduction . . . . . . . . . . . . . . . . . . . . . . . . . . 10

2.2 Theoretical Framework . . . . . . . . . . . . . . . . . . . . . . . 11

2.2 .1 The Radius of Trust . . . . . . . . . . . . . . . . . . . . . . 11

2.2 .2 Measuring Trust . . . . . . . . . . . . . . . . . . 13

2.3 Data . . . . . . . . . . . . . . . . . . . . . 14

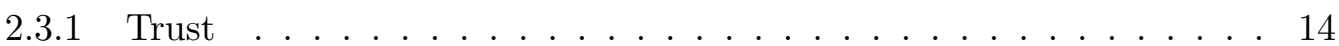

2.3 .2 Social Distance . . . . . . . . . . . . . . . . 18

2.4 Results . . . . . . . . . . . . . . . . . . . . . . . . . 19

2.4.1 Descriptive Results . . . . . . . . . . . . . . . . . . . . . . 19

2.4 .2 Comparison of Means . . . . . . . . . . . . . . . . . 21

2.4.3 Regression Analyses . . . . . . . . . . . . . . . . . . 22

2.5 Discussion . . . . . . . . . . . . . . . . . . . . 25

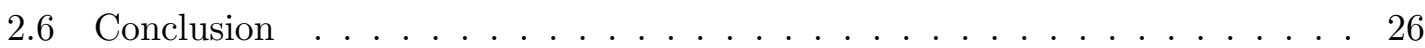


3 Can Mobile Phones Build Social Trust?

Insights from Rural Kenya $\quad 29$

3.1 Introduction . . . . . . . . . . . . . . . . . 30

3.2 Conceptual Framework . . . . . . . . . . . . . . . . . . . . . . . . 31

3.3 Data . . . . . . . . . . . . . . . . . . . . . . 35

3.3 .1 Measurement of Key Variables . . . . . . . . . . . . . . 35

3.4 Empirical Framework . . . . . . . . . . . . . . . . . . . . 38

3.4 .1 Estimation Strategy _ . . . . . . . . . . . . . . . . 38

3.4 .2 Endogeneity Tests . . . . . . . . . . . . . . . . 38

3.4.3 Robustness Checks . . . . . . . . . . . . . . . . . . . 39

3.5 Results and Discussion . . . . . . . . . . . . . . . . . . 40

3.6 Conclusion . . . . . . . . . . . . . . . . . . . . . . . 44

4 Can Mobile Phones Improve Nutrition among Pastoral Communities? $\begin{array}{ll}\text { Panel Data Evidence from Northern Kenya } & 47\end{array}$

4.1 Introduction . . . . . . . . . . . . . . . . . . . . . . . . . . 48

4.2 Conceptual Framework . . . . . . . . . . . . . . . . . . . . . . . . . . . . 49

4.3 Data and Measurement of Key Variables . . . . . . . . . . . . . . . . 51

4.3.1 Data and Sampling . . . . . . . . . . . . . . . . 51

4.3.2 Measurements of Key Variables . . . . . . . . . . . . . . . . . 52

4.4 Econometric Strategy . . . . . . . . . . . . . . . . . . . . 55

4.5 Results and Discusssion . . . . . . . . . . . . . . . . . . 58

4.5.1 Descriptive Statistics . . . . . . . . . . . . . . . . . . 58

4.5.2 Regression Results . . . . . . . . . . . . . . . . . . . 61

4.6 Conclusion . . . . . . . . . . . . . . . . . . . . . . . 69

5 General Conclusion $\quad \mathbf{7 1}$

5.1 Main Findings . . . . . . . . . . . . . . . . . . 71

5.2 Limitations and Scope for Further Research . . . . . . . . . . . . . . . . 71

5.3 Policy Recommendations . . . . . . . . . . . . . . . . . . . 73

Appendices

$\begin{array}{ll}\text { Appendix A Radius of Trust } & 91\end{array}$

$\begin{array}{lll}\text { Appendix B Can Mobile Phones Build Social Trust? } & 103\end{array}$

Appendix C Can Mobile Phones Improve Nutrition? 111

$\begin{array}{lc}\text { Declarations } & 133\end{array}$ 


\section{List of Tables}

2.1 Summary statistics for total sample $(\mathrm{N}=394) \ldots \ldots \ldots \ldots$

2.2 Frequency of interaction with neighboring villagers or city dwellers . . . . . 21

2.3 Multivariate regression analyses on the radius of trust . . . . . . . . . . 24

3.1 Summary statistics $\ldots \ldots \ldots \ldots \ldots \ldots$

3.2 Determinants of the amount sent in the trust game by the trustor . . . . . 43

3.3 Determinants of the share expected to be returned by Player B . . . . . . . 45

4.1 Share of households that use MPs among households that do not own a MP 54

4.2 Correlations between income, dietary diversity, and mobile phones $(\mathrm{N}=5,506) 59$

4.3 Socioeconomic characteristics by mobile phone ownership . . . . . . . . . . 60

4.4 Full Table for the effects of mobile phones on household dietary diversity scores (fixed effects panel model) . . . . . . . . . . . . . . . . 62

4.5 Effects of mobile phones on dietary diversity obtained from self-production and food purchases (fixed effects panel model) . . . . . . . . . . . . . 64

4.6 Effect duration of mobile phone access on dietary outcomes (fixed effects panel model $)$. . . . . . . . . . . . . . . . . . . . 66 66

4.7 Linear Probability Models for the consumption of each food groups when purchase was the main source . . . . . . . . . . . . . . 68

A1 Assignment of strategies II . . . . . . . . . . . . . . . . . 96

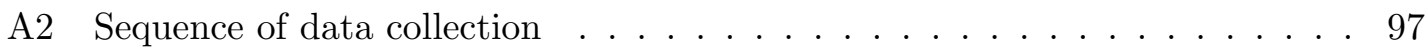

A3 Risk preference elicitation . . . . . . . . . . . . . . . . . . 98

A4 Summary statistics by treatment . . . . . . . . . . . . . . . . 99

A5 Multivariate regression analyses with explicit control variables . . . . . . . 100

B1 Deviations from the original trust game . . . . . . . . . . . . . . . 103

B2 First Stage Regressions . . . . . . . . . . . . . . . . . . . . . . . . . . 104

B3 Control function estimates for the amount sents . . . . . . . . . . . . . . 105

B4 Determinants of the amount sent in the trust game if only daily MP use is considered MP use . . . . . . . . . . . . . . . . . . 106

B5 Determinants of the amount sent in the trust game if any positive MP use is considered MP use . . . . . . . . . . . . . . . . . . . 107 
B6 Summary statistics by treatment . . . . . . . . . . . . . . . 108

B7 Two-way table of frequency counts for mobile phone use and network reception at homestead . . . . . . . . . . . . . . . . . . . 109

B8 Correlations between network coverage and access to infrastructure ( $\mathrm{N}=$

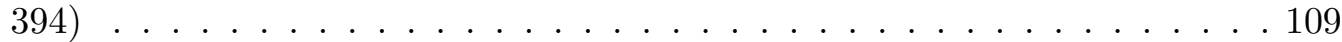

B9 Correlations between amounts sent in the trust game and network coverage for non-users of MP . . . . . . . . . . . . . . . . 110

C1 Effects of mobile phones on household dietary diversity scores (fixed effects

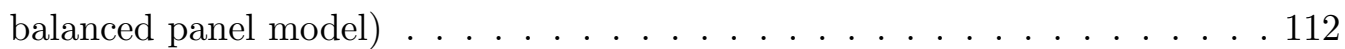

C2 Full Table for the effects of mobile phones on household dietary diversity scores (fixed effects panel model) . . . . . . . . . . . . . . . . 116

C3 Full Table for the effects of mobile phones on dietary diversity obtained from self-production and food purchases (fixed effects panel model) . . . . . 120

C4 Full Table for the effect duration of mobile phone access on dietary outcomes

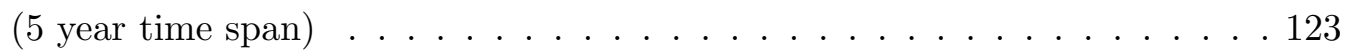

C5 Full Table for the effect duration of mobile phone access on dietary outcomes

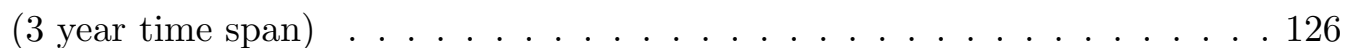

C6 Full Table for the Linear Probability Models for the consumption of each food groups when purchase was the main source . . . . . . . . . . . . 129 


\section{List of Figures}

1.1 Map of Kenya highlighting Turkana and Marsabit County . . . . . . . . . . 3

2.1 Trust levels using experiments and survey questions _ . . . . . . . . . 22

3.1 A Theory of Change for the effects of mobile phone use on general trust . . 33

4.1 Proportion of households owning at least one mobile phone in Marsabit, Kenya . . . . . . . . . . . . . . . . . 5 56

4.2 Development of mobile phone use in Marsabit, Kenya . . . . . . . . . . 56

4.3 Cumulative distribution of the Household Dietary Diversity Score in Marsabit, Kenya . . . . . . . . . . . . . . . . . . . . 59

A1 Context independent survey trust $(\mathrm{N}=394) \quad \ldots \ldots \ldots$. . . . . . . 102

A2 Context dependent survey trust $(\mathrm{N}=394) \ldots \ldots \ldots \ldots$. . . . . . . . 102 


\section{List of Acronyms}

2SLS 2 Stage Least Squares.

2SRI 2 Stage Residual Inclusion.

ASAL Arid and Semi-Arid Lands.

BDM Trust game developed by Berg et al. (1995).

CF Control Function.

CIR Censored Interval Regression.

CRRA Constant Relative Risk Aversion Coefficient.

FAO Food and Agriculture Organization of the United Nations.

FE Fixed Effects.

HDDS Household Dietary Diversity Score.

IBLI Index Based Livestock Insurance.

ICT Information and Communications Technology.

IV Instrumental Variable.

KSh Kenyan Shilling.

MP Mobile Phone.

OLS Ordinary Least Squears.

RCT Randomized Control Trial.

SMS Short Message Service.

TLU Tropical Livestock Unit. 
UN United Nations.

USD United States Dollar. 


\section{Chapter 1}

\section{General Introduction}

Rural development is a global challenge. It belongs to the Post-2015 Development Agenda set by the United Nations (UN) and constitutes political agenda in various countries. One particular rural region in sub-Saharan Africa is formed by the arid and semi-arid lands (ASAL) of Kenya. The region is predominantly inhabited by pastoralist communities and characterized by several challenges, amongst others high poverty rates, undernourishment, high child mortality, weak legal systems, as well as low levels of trust (Amwata et al., 2016; Bonfoh et al., 2016; Bauer and Mburu, 2017). Complex interdependencies between these challenges and the historic and political conditions that are at play have hampered the development of social programs that help alleviate poverty and increase welfare in the ASAL in a comprehensive and sustainable manner (Odhiambo, 2013). Neither 'trickle down' effects nor interventions based on centralized, 'top-down' approaches have shown to be effective in the past (Seid et al., 2016).

Economists can however contribute to improved policies and programs by improving the general understanding of the conditions under which the targeted population lives. Profound apprehension of smaller elements such as particular social norms, motivations, or reactions towards new technologies can reveal constraints and thereby help devise effective policies. The potential of this approach and the importance of field work and economic experiments in achieving this understanding were recently recognized through the Nobel Prize in Economics ${ }^{1}$ in 2019.

Up till now, we are lacking a sufficiently deep understanding of the communities that inhabit Northern Kenya's ASAL. This lack of understanding is also due to several radical changes to the region and its peoples over the last years: changes in land tenure systems, climate change, and the availability of new technologies such as mobile phones or the internet all have major implications on pastoralists' lives and their economic behavior (Bonfoh et al., 2016; Debsu et al., 2016; Herrero et al., 2016).

To add knowledge to the existing body of literature on pastoralist communities, this thesis presents three studies on this topic. In particular, the studies focus on a lack of trust and undernutrition as two existing challenges among pastoralist communities and

\footnotetext{
${ }^{1}$ Officially named the Sveriges Riksbank Prize in Economic Sciences in Memory of Alfred Nobel.
} 
how mobile phones can act as tools to alleviate these issues. The following section provides detailed information on the research area and the issues of trust and nutrition, as well as their relation to each other. Section 1.2 highlights the synergy between mobile phones and the pastoralist lifestyle and provides a short overview on relevant research addressing this synergy. Section 1.3 states the general research objectives and provides an outline for the remainder of this dissertation.

\subsection{Trust and Nutrition among Pastoralist Communities in Northern Kenya}

This thesis presents three studies, all of which are based on household data from Northern Kenya. Both studies laid out in chapter 2 and chapter 3 are based on primary data collected in Turkana County in 2018. The study presented in chapter 4 utilizes secondary panel data from Marsabit County covering the years from 2009 to 2015. The ASAL in Northern Kenya are a distinctive environment, which differs from other settings typically analyzed in research on rural sub-Saharan Africa. To allow a better grasp of the study environment, this section provides a brief introduction of the two regions. A special focus is given to trust and to nutrition in Northern Kenya, as these two aspects are at the core of this thesis.

Figure 1.1 shows the location of Turkana and Marsabit within Kenya. The two counties are neighbors, only separated by the Lake Turkana. They are Kenya's two largest counties in terms of surface area $\left(68,680 \mathrm{~km}^{2}\right.$ and $70,961 \mathrm{~km}^{2}$ respectively). The Survey Report on Marginalized Counties in Kenya viewed the two remote rural counties as the country's most marginalized regions (Commission on Revenue Allocation, 2012). Reliable and representative data from Turkana and Marsabit are scarce. According to the last official census in 2009, Turkana and Marsabit have a population density of 12 people per $\mathrm{km}^{2}$ and 4 people per $\mathrm{km}^{2}$ respectively. Infrastructure in the two counties is considerably weak: only $2 \%$ of the total roads in Turkana were paved in 2012. Marsabit did not have any paved roads at that time according to the Commission on Revenue Allocation (2013). Electricity is available to merely $2.4 \%$, and $7.5 \%$ of the households in the two counties. Health outcomes are critical as well. Only only $65.8 \%$ of the children between six to 60 months have adequate height for their age. In Marsabit, this figure is slightly higher at $66.9 \%$ adequate height for age (Commission on Revenue Allocation, 2013), but still indicates severe development deficiencies. ${ }^{2}$

Physical capital such as roads and electrical infrastructure foster economic development. That said, social capital is paramount for the economic development of a region as well (Woolcock and Narayan, 2000). Trust between people (also referred to as social

\footnotetext{
${ }^{2}$ It should be mentioned that the authors' impressions gained during field work in Turkana in 2018 do not fully match these figures. Especially the access to electricity and percentage of paved roads for the county of Turkana seems to have improved over the nine years between census and data collection. Nevertheless, the figures given here are the most recent official numbers that we are aware of.
} 
Figure 1.1: Map of Kenya highlighting Turkana and Marsabit County

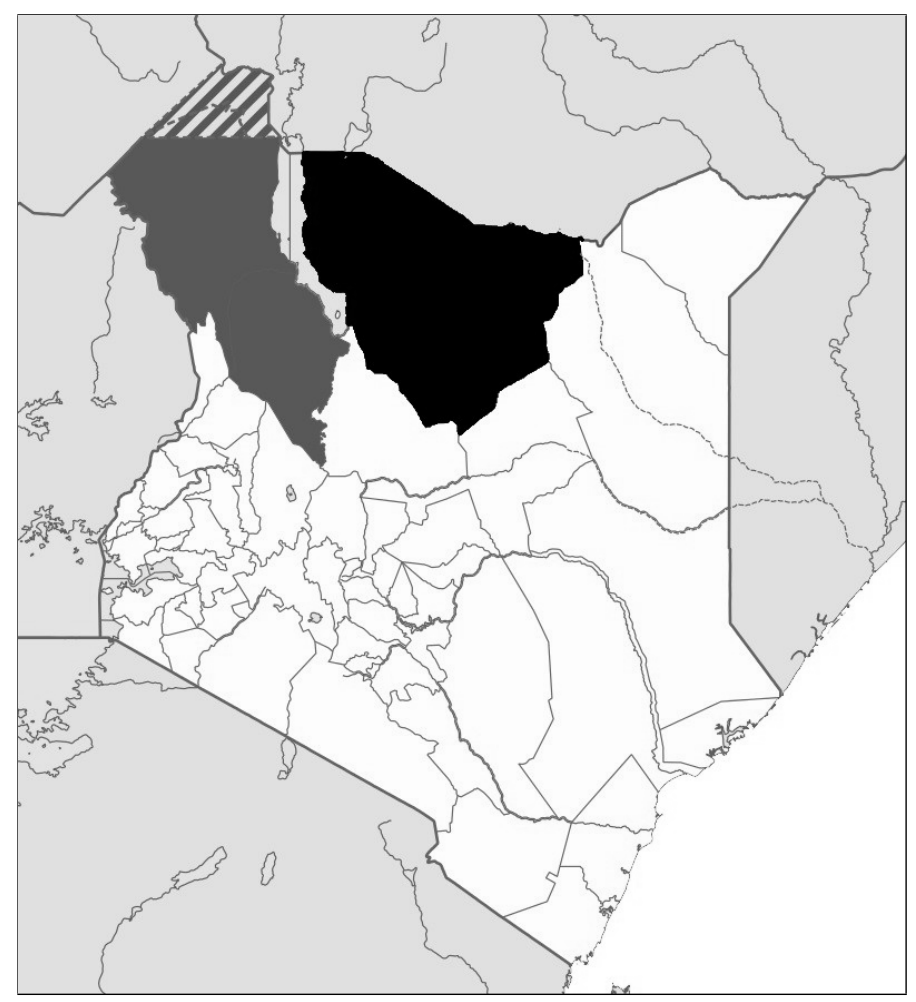

Notes: Location of Turkana County (dark grey), including the internationally disputed Elemi Triangle (diagonally striped dark grey), and location of Marsabit County (black).

Source: Own elaboration based on NordNordWest, used under license: Creative Commons by-sa-3.0 de, CC BY-SA 3.0 de,.

trust), which is a central feature of social capital (Woolcock and Narayan, 2000), facilitates collaboration and economic interactions between individuals (Arrow, 1972). Research on social trust has therefore gained considerable interest among development economists over the last few decades.

Research on social trust among pastoralist populations of low-income countries however is scarce. Apart from Cronk (2007), Ensminger (2001), and Grillos (2018), we are not aware of other studies, that focus on social trust among pastoralist communities of a low-income county. This research gap is notable, since the relevance of social trust for economic interactions is reinforced by the environment in which most pastoralist communities of low-income countries live: the weakness of legal services available to most members of pastoralist communities is one important contributor to the relevance of trust in this context. Trust is an important mechanism to overcome market failures such as imperfect contract enforcement (Karlan, 2005). Economic transactions require each partner's trust to be larger than the fear of such imperfections being exploited. The fact that Northern Kenya's population is highly scattered presents another contributor to the importance of 
trust for these communities. The low population densities in the two counties result in long physical distances between people and invoke high monitoring costs. In case these costs exceed the benefit of an economic interaction, people are required to rely solely on trust. Mobile phones and cheaper means of transportation such as motorbikes have reduced monitoring costs in recent years, but the barrier remains considerable. Northern Kenya also has a long history of violent conflicts between pastoral tribes (Bond and Mkutu, 2018). Lack of trust between tribes is both a cause and consequence of intertribal conflicts and impedes solutions to share resources peacefully and effectively (Schilling et al., 2012). Finding ways to increase trust therefore could contribute to mitigating conflicts and their adverse consequences (Noonan and Kevlihan, 2018). Due to this environment, research on trust among pastoralists in Northern Kenya is particularly important.

Beside the challenge of social trust, nutrition presents another critical issue for the pastoralist populations of Northern Kenya. The census of 2009 reveals that only two out of three children $(0.5-5$ years $)$ in Turkana and Marsabit have adequate height for their age (Commission on Revenue Allocation, 2013). This situation is worrying considering the enormous negative effects of growth failure in early life on human, social, and economic capital (Hoddinott et al., 2013).

A major reason for inadequate child growth is poor nutrition (Onyango et al., 1998; Arimond and Ruel, 2004). Nutritional challenges however also exist beyond low heightfor-age scores of children and extend to adult members of pastoralist communities as well: Pastoralists in Northern Kenya for example have also shown to exhibit inadequate intakes of Vitamin A, B 12 , and C (Iannotti and Lesorogol, 2014). Vitamin A deficiencies among mobile pastoralists have also been identified as a severe problem by Crump et al. (2017). Between 15\% and 32\% of mobile pastoralists analyzed in Crump et al. (2017) had a Vitamin A deficiency, depending on ethnic group and season.

The circumstances that cause the low nutritional status among pastoralist communities in Northern Kenya are manifold. Given that pastoralism is the main lifestyle of most people, livestock products form a large share of household food consumption. This dependency makes food availability particularly sensitive to extreme weather conditions such as droughts and floods, both of which occur frequently in Northern Kenya (Bauer and Mburu, 2017). Even for of sedentary or semi-sedentary households, food crop production is limited due to the dry climate (Mburu et al., 2017). To diversify diets, household therefore rely on food markets. In Northern Kenya, such food markets are however rare and far between (Mude et al., 2012). For example, pastoralists in Marsabit need more than three hours to reach the nearest food market (Mude et al., 2012). Research on methods to increase nutritional outcomes in Northern Kenya is therefore valuable.

How do social trust and nutrition relate? At first glance the two dimensions do not seem to have much in common. In fact, we are not aware of any study, empirical or theoretical, that links a person's social trust to her nutrition or vice versa. However, both aspects can be viewed as prerequisites - or at least as important drivers - for development. 
From a macro perspective, social trust can be seen as driving force for societies' economic development (Knack and Keefer, 1997; Zak and Knack, 2001; Algan and Cahuc, 2010). Trust even appears to be a deeper determinant of economic growth than schooling or governance (Bjørnskov, 2012). From a micro perspective, adequate nutrition too can be seen as a prerequisite for development. In this case however, development does not refer to economic growth of a region, but rather to physical and cognitive growth of individuals. Several studies suggest that malnutrition and in particular micro-nutrient deficiencies can impair cognitive development of children (Nyaradi et al., 2013) and can have adverse effects on later stages in life.

This section shows that social trust and nutrition are two critical issues among Northern Kenya's pastoralist communities. Both of these dimensions are analyzed more thoroughly in this dissertation. Mobile phone use among pastoralist communities represents the third central aspect of this thesis. The following section therefore lays out the recent adoption of mobile phones among pastoralist communities in low-income countries and sketches out chances and challenges of mobile phone use.

\subsection{Mobile Phones and Pastoralists}

Mobile phones enable fast, cheap, and convenient communication with a wide variety of people. The new possibilities of providing and acquiring information have wide-ranging implications on livelihoods, especially in rural Africa (Aker and Mbiti, 2010; Nakasone et al., 2014; Sekabira and Qaim, 2017). While mobile phones have been used in urban areas and by sedentary producers in rural areas for quite some time, we only recently observe an exceptionally rapid diffusion of this technology among pastoralists (Asaka and Smucker, 2016; Djohy et al., 2017). In Marsabit county the proportion of households using a mobile phone on a daily basis increased from $23 \%$ in 2009 to more than $70 \%$ in 2015 (Gesare et al., 2017). This adoption rate is remarkable, given that pastoralist communities are rather conservative and reluctant towards foreign technologies and innovations (Djohy et al., 2017). The substantial increase in mobile phone adoption this indicates that the technology is particularly well-suited to the lifestyle of pastoralists and able to meet crucial information and communication needs.

Pastoralists depend on communication and information for the organization of livestock and everyday life activities. We therefore explain the synergy between pastoralism and mobile phones by specific characteristics of the mobile phone technology as well as existing needs of pastoralists. These needs include information on forage availability, location of water supplies, livestock prices and volumes, current states of conflicts, onset dates of rains, flooding events, or the delivery of food aid (Rasmussen et al., 2014; Seid et al., 2016). This list is far from exhaustive and could be expanded at length. These types of information are traditionally acquired by inquiring friends, family, elders, or traditional seers (Rasmussen et al., 2014; Balehegn et al., 2019). 
Given that an urgent need for information exists, the mobile phone has several characteristics and features that comply with the situation and lifestyle of most pastoralist communities. Mobility presents a key aspect in this regard because it is at the core of many pastoralists' lives. Being mobile can be seen as a centerpiece of pastoralists' resilience (Cissé and Barrett, 2018), livelihood (Adriansen, 2008; Turner and Schlecht, 2019), and even identity (de Bruijn et al., 2016). Mobility is therefore clearly a desirable trait for a technology so that it fits well into pastoralists' lives. In opposition to landline phones for example, the mobile phone technology - even carrying the aspect in its very name - is portable and therefore meets this need.

The relative ease of acquiring and using a mobile phone presents another vital aspect that explains the synergy. Using a phone is relatively intuitive and does not require high individual capabilities. Two capabilities, namely integration into public administration and literacy, are particularly noteworthy here: Pre-paid subscriptions of mobile phones do not necessitate strong levels of integration into public administration. In most cases, users are neither required to have a bank account, a postal address, nor a steady source of income. Pre-paid contracts are therefore particularly appealing to people without such integration or regular income This is a strong advantage for the mobile phone technology, since limited integration into social services and public administration can still be observed for many pastoralists communities (Bonfoh et al., 2016).

As mobile phones allow oral communication, many pastoralists can use them relatively easily. Oral communication is still paramount for information exchange among most pastoralists (Mertz et al., 2016; Seid et al., 2016), also because the low levels of literacy observed among many pastoralist communities make other forms of communication based on written words or numbers challenging. Over the course of time, several communities have developed sophisticated oral communication traditions, such as the dagu by Afar pastoralists in Ethiopia (Seid et al., 2016; Balehegn et al., 2019), which play an important role in receiving and providing information. Communication based on spoken words or voice messages has the potential to be embedded in these informal traditions (Nilsson and Salazar, 2017) thereby facilitating the adoption and integration in already established communication practices.

Compared to other infrastructural projects that enable communication such as the construction of paved roads or the establishment of an exhaustive landline phone network, the mobile phone technology requires smaller investments by governments or private companies. In addition, most pastoralist communities inhabit vast landscapes and the large plains can facilitate signal transmission (Vidal-González and Nahhass, 2018). This further increases the cost-benefit ratio of this technology compared to other communication channels such as roads or landline phones.

The above-mentioned characteristics show that mobile phones represent a powerful and useful instrument that fits exceptionally well to the pastoralist lifestyle. Because pastoralist communities in sub-Saharan Africa still face several severe challenges and since 
most structural tickle down and 'top-down' approaches to these challenges have shown to be ineffective, the enormous potential of mobile phones has started to attract interest by researchers over the last five to ten years. Mobile phones can be used for a wide range of social and economic activities. The technology therefore has the potential to shape and influence numerous diverse aspects of pastoralists' everyday life. This is reflected in the broad range of academic disciplines in which research on this relationship has recently emerged, including research from the fields of economics, sociology, geology, environmental management, and human health. This diversity is notable, given that the overall number of studies on this topic is still relatively small.

\subsection{Research Objectives and Outline}

The previous sections highlight social trust and nutrition as two important challenges for pastoralist communities, as well as the development potential of mobile phones in this context. The next section describes the research objectives, contribution, and outline of this dissertation.

Section 1.1 shows that trust is relevant for pastoralist communities in Northern Kenya. A deeper understanding of the trust culture can therefore help comprehend economic behavior of pastoralists and improve the design of social programs in the region. The objective of chapter 2 is therefore to increase the understanding of how far pastoralists extend their trust. To do so, chapter 2 discusses results of a trust experiment (Berg et al., 1995) conducted with participants of a pastoralist community in Turkana County, Northern Kenya. We measure and compare trust towards fellow villagers, towards people from a neighboring village, and towards city dwellers from the county capital. We then test if the results can be explained by the concept of the radius of trust (Harrison, 1985; Fukuyama, 2000; Freitag and Traunmüller, 2009) and contrast the experiment to survey trust measurements. The aspect of rural development in a low-income country is kept subtle in the paper, since experimental measurements of the radius of trust are novel and relevant beyond this particular context. The paper is therefore written for a more generally interested readership.

The objective of chapter 3 is to measure the effects of mobile phones on social trust among pastoralist communities. Mobile phones have recently become available to most pastoralist communities and already affect several aspects of their lives. Mobile phones facilitate communication, which suggests that their usage might be positively associated with social trust (Buchan et al., 2006; Ben-Ner and Putterman, 2009; Labonne and Chase, 2010). At the same time, a lack of trust might restrict the potential of mobile phones (Butt, 2015; Djohy et al., 2017). Thus, a quantitative analysis of this relationship is particularly important and does - to the best of our knowledge - not exist up till now.

Chapter 4 analyses the relationship between mobile phones and nutrition. The objective of chapter 4 is to investigate the potential of mobile phones to alleviate malnutrition 
among pastoralists for example by increasing household incomes, enabling collective action for food purchases, or disseminating knowledge on places and time of food aid distribution. To do so, chapter 4 analyzes the effects of mobile phones on dietary diversity of pastoralist communities in Marsabit County, Northern Kenya. While previous research on this domain exists for rural farming households (Beuermann et al., 2012; Sekabira and Qaim, 2017), we are the first to analyze longer-term effects and the effects in a pastoralist context.

To conclude the thesis, chapter 5 provides a résumé of all three studies and connects the findings to derive more thorough policy recommendations. Potential limitations of the study and important areas of future research are also discussed. 


\title{
Chapter 2
}

\section{A Radius of Trust? \\ Contrasting Insights from Experiments and Survey Data}

\begin{abstract}
A person's reach of efficient economic activities is strongly influenced by the extent to which she grants trust towards other people. The radius of trust has recently gained interest as a concept to elucidate the underlying principles of how far a person extends her trust. However, empirical research on the radius of trust has up to now only been grounded in survey data. In this paper we use an incentivized experiment, namely the trust game, and two sets of survey questions to i) identify and localize the radius of trust and ii) contrast experimental and survey results regarding the radius of trust. To do so, we measure trust layers of 394 semi-nomadic pastoralists in rural Kenya conditional on three levels of social distance: trust towards people from one's own village, trust towards people from a neighboring village, and trust towards city dwellers from the county capital. Experimental data suggest that city dwellers are excluded from the radius of trust and face particularly low trust levels, while people from one's own village and from neighboring villages are inside the radius of trust. Survey data do not suggest any clear-cut radius of trust. Implications for development practitioners and further research on the radius of trust are discussed.
\end{abstract}

Keywords: radius of trust, social distance, trust, field experiment, pastoralism, Kenya.

JEL Codes: C93, D01, O12

\footnotetext{
This chapter is co-authored by Martin C. Parlasca (MP), Daniel Hermann (DH), and Oliver Mußhoff (OM). The contributions of each author are as follows: MP, DH, and OM developed the research questions. MP and DH designed the main experiment with assistance from OM. MP collected, analyzed, and interpreted the data. DH and OM assisted in the analyses and interpretation of the results. MP wrote the paper. DH and OM provided continuous feedback and comments during writing.
} 


\section{$2.1 \quad$ Introduction}

Trust is an essential part of economic interactions. Nearly all activities involving the exchange of goods or services require at least some degree of mutual confidence (Arrow, 1972). Since trust is fundamental for productive cooperation, trust deficits can be severe barriers for economic development (Zak and Knack, 2001; Algan and Cahuc, 2010). Recent years have therefore seen trust taken center stage of economic research.

A person's trust can be sensitive to the relationship between trustor and trustee (Karlan, 2005; Buchan et al., 2006; Etang et al., 2011; Newton and Zmerli, 2011; Burns, 2012; Ansink et al., 2017; Gupta et al., 2018). If trust is seen as a property of a specific trustortrustee interaction rather than a stable attribute or disposition, it follows that trustors can - and most likely do - exhibit different levels of trust depending on the target or object of trust. Accounting for such differentiation with respect to the object of trust is "crucial for uncovering the true role of trust as a civic force" (Delhey et al., 2011, p. 789).

One important differentiation of trust ${ }^{1}$ is described through the radius of trust (Harrison, 1985; Fukuyama, 2000; Welch et al., 2007; Freitag and Traunmüller, 2009; Etang, 2010; Delhey et al., 2011; Reeskens, 2013; Mattes and Moreno, 2018). The radius of trust indicates "the circle of people among whom cooperative norms are operative" (Fukuyama, 2000). Trust towards people within the radius of trust is generally described as "thick", while people outside of the radius face "thin" trust (Mattes and Moreno, 2018).

The radius of trust is an essential trust construct since it determines the inclusivity of the circle of cooperation for a given person or group. Civic cooperation is higher with people within the radius of trust than people outside of the radius of trust. Economic interaction between two agents can therefore be challenging if one is excluded from the other's radius. As a result, the radius of trust can have a major influence on a person's scope of economic activity. However, past economic research has focused rather on overall levels or intensities of trust. Much less attention has been devoted to analyzing its radius (van Hoorn, 2014).

The few studies that have looked at the construct of the radius of trust rely on survey questions (Welch et al., 2007; Etang, 2010; Delhey et al., 2011; Reeskens, 2013). The predictive power of such self-reported trust questions for actual economic behavior is however subject of a lively scientific debate (see Bauer and Freitag (2018) for a recent overview). Up to now it is unclear whether evidence for the radius of trust can also be drawn from experiments. We are not aware of any experimental study particularly aimed at analyzing the radius of trust. A comparison of these two methods concerning the radius of trust does ergo not exist as well.

The objective of this paper is twofold. First, we use an incentivized experiment, namely the trust game by Berg et al. (1995) to measure trust towards three different groups, each

\footnotetext{
${ }^{1}$ The literature on trust generally distinguishes between social trust and political trust (Newton, 2001). In this paper we focus solely on the former and use the term trust in the following to refer to social trust.
} 
associated with an increasing length of interactive social distance. This helps reveal if people differentiate between thick and thin trust and more importantly approximating where the line between the two types of trust is drawn. Second, we use two sets of survey trust questions that relate to the same targets of trust as the experiment to examine whether survey results regarding the radius of trust coincide with experimental findings. To our knowledge we are the first using experiments to measure the radius of trust and the first contrasting findings of an experiment and survey questions in this matter.

Our analyses focus on pastoral communities in Northern Kenya. The context of rural and remote pastoralism is in itself an interesting case for research on trust in general, and on the radius of trust in particular. The region suffers from low institutional quality and little economic modernity. Both these factors are thought to have a negative influence on the radius of trust (Delhey et al., 2011). At the same time, pastoral communities in Eastern Africa have adapted to the challenging surroundings of the region ${ }^{2}$ with close-knit networks and strong social ties (Davies and Bennett, 2007), which could point towards a more inclusive and wider radius of trust.

Despite this remarkable context, research on trust among pastoralist communities in low-income countries is scarce. We are aware of only three related studies (Cronk, 2007; Ensminger, 2001; Grillos, 2018). While the relevance of trust in this context becomes apparent in all three studies, Ensminger (2001) and Grillos (2018) both indicate that pastoralists' trust might differ substantially depending on the object of trust. Taking a closer look at pastoralists' trust culture will therefore serve as an further step in closing this research gap.

Given the context of rural pastoralism in northern Kenya, the radius of trust can have important implications for policy makers and development practitioners. Aid project or insurance programs that are targeted at rural populations and bear the potential to reduce poverty or risk exposure can suffer from lower uptake if providers of the service are not trusted (Takahashi et al., 2016; Platteau et al., 2017) or might not even be accepted at all. Providers or program officers that are aware of where the radius of trust of the targeted population begins can identify suitable trusted agents that promote the program or service and facilitate successful collaboration more easily.

\subsection{Theoretical Framework}

\subsubsection{The Radius of Trust}

A fundamental strand of trust research relates to the question if trust is unidimensional or if different dimensions of trust can be identified. While results are not entirely concordant, recent evidence converges to the proposition that (at least) two dimensions of trust exist. One type is called particular, thick, bonding, or specific trust and refers to a narrow circle

\footnotetext{
${ }^{2}$ Social challenges arise among others from frequent droughts, violent conflicts between tribes (Bond and Mkutu, 2018) as well as political and social marginalization.
} 
of people that are socially close. The other type is called general, thin, bridging, diffuse, or abstract trust and refers to people that are more socially distant and unfamiliar (Putnam et al., 1993; Yamagishi and Yamagishi, 1994; Stolle, 2002; Freitag and Traunmüller, 2009). However, interpretations about the scope of the former type of trust vary. Some scholars construe particular trust in a narrow sense and only relate it to people that are well-known such as friends, family or close neighbors (Fafchamps, 2006; Freitag and Traunmüller, 2009); others interpret particular trust more widely and also relate it to people that are not directly known but belong to the same identity group or clan (Putnam et al., 1993; Newton and Zmerli, 2011; Mattes and Moreno, 2018). In some cases, trust towards people that are not necessarily personally known, but share a common identity is referred to as identity-based-trust and treated as a third and independent trust dimension (Stolle, 2002; Freitag and Bauer, 2013).

The radius of trust emerges from this multidimensionality and can be understood as the border between two trust dimensions. Certain cooperative norms are active among people within the radius and less active or not active at all with people outside the radius (Fukuyama, 2000). We adopt Gambetta's (2000, p. 217) view that "trust [...] is a particular level of the subjective probability with which an agent assesses that another agent or group of agents will perform a particular action, both before he can monitor such action (or independently of his capacity ever to be able to monitor it) and in a context in which it affects his own action." Let $P_{X}$ and $P_{Y}$ now be the subjective probability with which a certain agent $(Z)$ assesses the likelihood of cooperation with persons $X$ and $Y$ respectively. The social distance that agent $Z$ associates with persons $X$ and $Y$ is $D_{X}$ and $D_{Y}$. The agent $Z^{\prime} s$ radius of trust is denoted as $R_{Z}$. Combining Gambetta's definition of trust with the concept of the radius of trust brings forth two deductions: First, if two persons lie within the radius of trust, they are assessed with a similar subjective probability of cooperation:

$$
D_{X} \leq R_{Z} \wedge D_{Y} \leq R_{Z} \rightarrow P_{X} \approx P_{Y}
$$

Second, if one person is inside the radius of trust and another person is not, the first person is assessed with a considerably larger probability of cooperation compared to the second person:

$$
D_{X} \leq R_{Z} \wedge D_{Y}>R_{Z} \rightarrow P_{X}>P_{Y}
$$

Several studies using both experimental and survey data present contexts in which people exhibit less trust towards people that are more socially distant (Buchan et al., 2006; Etang et al., 2011; Burns, 2012; Binzel and Fehr, 2013). The deduction presented in propositional expression (2.1) however suggests that even when a person associates two other persons with a different length of social distance, he or she might not discriminate between them in terms of trust, if both are inclusive his or her radius of trust. The second deduction implies that a third, even more socially distant person however is trusted less, if he or she is excluded from the radius of trust. 
To analyze the radius of trust it is therefore necessary to have at least three different objects of trust that are associated with varying degrees of social distance. The more trust levels for different objects of trust are specified, the more precisely the radius of trust can be located. Most experimental studies that link social distance and trust however treat social distance as a binary characteristic and define it as either zero or unity depending on whether two persons do or do not belong to the same group. While such binary comparisons are useful setups to point out ingroup/outgroup trust biases, they allow only limited conclusions on the radius of trust.

Propositions (2.1) and (2.2) consist of three elements: social distance, trust, and the radius of trust. Multiple techniques are available to measure the two former elements. The radius of trust however is unknown and also not directly measurable. It is therefore impossible to assess if the statements on the left-hand sides of propositions (2.1) and (2.2) are indeed true. Since we cannot assume logical equivalence, we can only infer with certainty from the statements on the left-hand side of propositions (2.1) and (2.2) to the statements of the right-hand side. In other words, observing a true statement on the right-hand side is not sufficient to infer that the statement on the left-hand side must be true as well. It is therefore important to note that empirical analysis cannot provide any prove for or against the existence of the radius of trust. We can however analyze if experimental and/or survey data match the model's predictions while ruling out alternative explanations. The first hypothesis therefore states:

H1: There is a radius of trust which leads to different trust levels for the in-group and out-group.

\subsubsection{Measuring Trust}

The importance of trust for interpersonal relationships is widely recognized. There is however an expansive academic discussion on how trust can be measured adequately. Experiments and survey questions present the two most popular methods to do so. The former have the advantage of revealing actual behavior and - if incentivized - bearing real economic consequences for the respondent. The latter are cheaper, easier to collect, and allow for more design flexibility. Analyses concerned with more complex dimensions of trust such as time horizons of trust or more specific trust domains are thus easier done using surveys rather than experiments. Depending on what aspects and which targets of trust are of interest, survey questions might be more convenient. The relative rigidity of trust experiments compared to survey questions is presumably a reason for the scarcity of experimental studies on more complex trust issues such as the radius of trust. Their findings should nevertheless coincide when both methods deal with the same target of trust.

Experimental data on trust is generally considered to be a decent proxy of actual trust (Bouma et al., 2008; Cárdenas and Carpenter, 2008). Correlations between experimental 
measurements and survey questions however remain widely disputed with contradicting results found in several studies (Glaeser et al., 2000; Karlan, 2005; Danielson and Holm, 2007; Etang et al., 2012; Paul et al., 2016). The divergence of results has led to the assumption that the informative value of survey questions hinges on the context in which they are used (Etang et al., 2012). This study presents two contexts, namely the sample of sub-Saharan pastoralists and the methodical focus on the radius of trust, for which a comparison of survey and experimental trust data does not exist up to now. The suitability of survey questions for either context is therefore unclear. To shed light on this aspect, we measure trust with incentivized experiments as well as survey questions and contrast the results of the two measuring methods. The second hypothesis consequently states:

H2: The measurement of the radius of trust is independent of the method used for elicitation.

\subsection{Data}

This study uses primary data collected from July to August 2018 in Turkana County, Northern Kenya. We followed a two-stage sampling approach. In the first stage, we selected five larger clusters of villages with approximately fifteen villages in each cluster. All villages lie within a one to two hours' drive from the county capital of Turkana County ${ }^{34}$. We randomly selected four to five villages from each cluster. In the second step, we obtained lists of all households living in each of the selected villages with the help of local area chiefs. Afterwards 20 to 26 households per village were randomly selected and the household head invited for participation. All but two of the invited households accepted the invitation and finished the interview. In case the household head was unavailable, the second person in charge of that household was invited. The sample includes 402 households from 17 villages.

\subsubsection{Trust}

\subsubsection{General Setup}

We conduct a variant of the trust game by Berg et al. (1995) (BDM), which has become one of the most established experiments to measure trust. The BDM involves two players, here called player A and player B. Several variations of the BDM exist, but the game is usually set up in the following way: player A is endowed with some amount of money. She can send a share of this endowment to player B. The researchers then triple whatever amount is sent. Upon receiving the tripled amount, player B can choose to send any share

\footnotetext{
${ }^{3}$ Due to intertribal conflicts involving violent raids and road blocks, one group of villages was not safely accessible. The final sampled villages were drawn from the remaining four groups.

${ }^{4}$ The county capital of Turkana County is Lodwar and has a population of approximately 48,000 people (Commission on Revenue Allocation, 2013).
} 
of this money back to player A. This transfer concludes the game. There is usually no communication allowed between the two players, before, during, or after the game and both players remain anonymous. The share of the amount sent by player A is regarded to measure his/her trust in player B; the amount returned by player B is referred to as his/her trustworthiness.

The actual players' identities are usually kept secret during and beyond the game to ensure that individual choices cannot be traced back. Experimental trust studies on social distance therefore create exogenous variation by providing some general information, socalled cues to identity about player B, for instance the player's religion, gender, ethnicity, or surname. In the study at hand, player A received information on where player B lived ${ }^{5}$. We conducted three treatments by letting the respondents play the trust game with a partner belonging to one out of three possible groups: based on a between-subject design, respondents were either paired with another fellow villager, or with a villager from a neighboring village, or with a city dweller from the county capital. We assigned treatment randomly at the individual level.

We endowed each respondent with 500 Kenyan Shillings (about 5 USD). This amount of money is substantial for most households in Turkana, since more than ninety percent of the people in that region live below the poverty line of 1.90 USD per day (Turkana County Government, 2014). The high stakes of the experiment increased the financial consequences of each decision and the attractiveness of the survey. The threat of having a biased sample in which only more trusting individuals accept the invitation to participate, while lower trusting individuals do not participate is consequently small. All payouts were realized, since random payment has shown to bias behavior in the trust game (Johnson and Mislin, 2011).

The amount sent in the trust game is generally considered a valid measurement for player A's trust in player B and has shown to explain actual behavior with regard to social capital (Cárdenas et al., 2013). Some aspects other than trust might however also affect sending decisions, most notably risk aversion, altruism, or fairness (Chetty et al., 2020; Houser et al., 2010; Brülhart and Usunier, 2012; Schechter, 2007; Cárdenas et al., 2013). While we admit that it is difficult to completely isolate the trust component of the sending decision, we designed the experiment in a way to keep other influences as small as possible.

We let respondents play both role of the sender and the receiver. The fact that every player B had also initially played the game as a player A was clearly communicated to each participant (see Appendix A.1.1.1) and should reduce sending motivations based on fairness (Schechter, 2007).

We furthermore included an incentivized Eckel and Grossman (2002) task at the end of

\footnotetext{
${ }^{5}$ Cues to identity about the approximate physical distance to player B's group are motivated by Karlan (2005). He finds that when people know the exact person with whom they are playing, more trust is placed in people who live close by.
} 
the data collection (see Table A3). This additional experiment allows the approximation of respondents' risk preferences, for which we can later adjust our analyses.

Lastly, we not only consider the sending decision of player A, but also analyze the amount that player A expected to receive back from her player B. Conditional on the pairing in the game, this variable allows capturing player A's expectations regarding the amount that either a fellow villager, or neighboring villager, or city dweller would return. This expectation is detached from other potential influences such as altruism or risk preferences. Unlike choosing to send money in the trust game however, statements about the expected return do not have any real monetary consequence for player $\mathrm{A}$, since the actual amount returned by Player B is not influenced by these statements.

\subsubsection{Specifics for Measuring the Radius of Trust}

Since player A's total payoff depends on how much player B decides to return ${ }^{6}$, player B's response conditional on player A's choice needs to be known. If player A and player $\mathrm{B}$ are both part of the same experimental session, this sequentiality is unproblematic; player A and player B not participating in the same session, however, can cause complications. Past research has dealt with this issue in different ways. Etang et al. (2011) waited with all payouts until data collection was fully completed, causing a time lag of seven days between playing the game and receiving remuneration. Gupta et al. (2018) held experimental sessions simultaneously in different villages, but transmitted information on amounts sent and received via mobile phones. It is also possible to trick respondents into believing that they play with a certain counterpart (deception), when this counterpart actually does not exist - or at least does not participate in the game - as done for example by Tanis and Postmes (2005). If player A fully believes the researchers, simulated counterparts theoretically produce the same results as real counterparts. However, people behave differently in exchange situations, when they know that they are paired with a computer rather than an actual human being (Sanfey et al., 2003). Respondents that do not fully believe the researchers are therefore likely to alter their actions. Johnson and Mislin (2011) find evidence for this bias in the trust game.

Due to the long physical distance between the county capital and our target villages, we were unable to have joined experimental sessions with both pastoralists and city dwellers. Waiting to complete the payouts until all data were collected also proved difficult due to challenges in tracking down the semi-nomadic respondents and the generally low levels of trust among the target population. We therefore employed the strategy method, which is commonly used in trust game literature (Johnson and Mislin, 2011; Sapienza et al., 2013).

The strategy method relies on asking player B how much she would like to return to a player A, given all potential amounts that player A might have sent. Player A had $500 \mathrm{KSh}$ at her disposal and could make transfers in steps of hundred Kenyan Shillings.

\footnotetext{
${ }^{6}$ Except for the case in which player A sends nothing.
} 
We therefore asked player B about her returns for all five possible positive amounts sent. Johnson and Mislin (2011) do not find that using the strategy method affects behavior of player A in the trust game. A comprehensive description of how players were matched is presented in the Appendix A.1.2 and and Table A1. Sending decisions of respondents paired with a neighboring villager made in the last session were not consequential, since there were no subsequent sessions in which the sending decision could have been used. To ensure incentive compatibility, we exclude these eight observations from the analysis (see Table A1).

Only people from the respective village were physically present in each experimental session, while city dwellers and pastoralists from neighboring villages were absent. This could result in a game-theoretical advantage of intra-village pairings over inter-village pairings and pairings with city dwellers. Several characteristics of our design ensured that this potential source of communication bias is kept to a minimum. First, we prohibited any questions or comments about the game during the explanation in the group ${ }^{7}$. We also made it very explicit that violations of this rule would lead to exclusion from the game. Two assistants, one of which was a well-known and respected elder of the region, constantly supervised the respondents. Second, we told respondents if they were paired with a fellow villager or with a neighboring villager or with a person from the county capital in private just before they made their decision. Third, we kept all decisions anonymous. If player A and player B found some way to agree on a cooperation where player A's promise to send substantially and player B promise to return substantially, each player B still has strong incentives to deviate from this agreement since his/her player A has no way to punish a contract breach.

\subsubsection{Experimental Procedure}

Since a large share of our sample is illiterate and unfamiliar with economic experiments, we opted for a single blind protocol giving respondents enough room for individual questions. Some of the respondents, especially the elderly, also suffered from reduced dexterity and required manual assistance in handling the banknotes. Our presence could have introduced some bias in the respondents' actions compared to a double blind procedure. Single blind protocols are however usually used in low income country contexts (Barr, 2003; Karlan, 2005; Schechter, 2007; Etang et al., 2011; Johansson-Stenman et al., 2013). Johnson and Mislin (2011) do not find that deviating from a double blind protocol induces significant biases in player A's behavior. The script used during the experiment is shown in the Appendix A.1.1. The sequence of all elements of the data collection is presented in Table $\mathrm{A} 2$.

With the exception of the corresponding author, all members of the research team

\footnotetext{
${ }^{7}$ We explicitly encouraged respondents to ask questions or state any uncertainties about the game later in private.
} 
directly involved in the data collection are native Turkana. One of the eight people in the team was born in the county capital, and all of them spent at least some period of their life in an urban environment. No member ever lived in one of the sampled villages.

We derive two trust variables from the experiment. The first measurement of trust is the amount sent in the trust game. As mentioned earlier, respondents could send money to player B in steps of $20 \%$ of their initial endowment. The share of the amount sent consequently has a discrete distribution, is left-censored at zero, and right-censored at $100 \%$. Our second trust measurement based on the experiment is the expected return: after respondents chose how much they wanted to send, we asked them how much money they expected to be returned by Player B. We define the expected return as the share of the amount that player A expected player B to return relative to the total amount received by player B. If player A sent nothing, we mapped her expected return to zero.

\subsubsection{Survey Questions}

After playing the trust game, we conducted short surveys with each respondent, as part of which we also asked two sets of trust related questions. One set included context independent trust questions and another set focused on trust questions within a specific context. In the former set we asked three questions: "How much do you trust people living in [A: this village? B: neighboring villages? C: the county capital?"]. Respondents could choose between the answering options "Not; a little; somewhat; a lot" as done for example by Mattes and Moreno (2018). Due to the respondents' unfamiliarity with percentages and self-evaluation on continuous numeric scales, we used discrete answering options with labels rather than continuous scales. Throughout the data collection we used the actual name of the county capital.

Our context dependent trust question depicts a concrete scenario in which respondents stated their belief regarding other people's behavior. We asked three questions: "Assume that you are walking in [A: your village; B: a neighboring village, $\mathrm{C}$ : the county capital] and 1,000 KSh (approximately 10 USD) that are yours fall out of your pocket without you realizing it. Someone else from [the village/county capital] sees that the money fell out of your pocket. He or she can pick up the money and take it as his/her own without incurring any punishment or he/she can tell you that you lost the money. How likely do you think it is that he or she will tell you that you lost the money and return it to you?" The answering options were "Very unlikely; rather unlikely; rather likely; very likely". The context dependent questions are similar to questions used by Sapienza et al. (2013) and Etang et al. (2012), who ask about the likelihood of a lost wallet being returned.

\subsubsection{Social Distance}

Social distance has a fundamental influence on interpersonal relationships and individual economic decisions (Akerlof, 1997). To conceptualize social distance it is first necessary 
to clarify which aspects of social distance are actually being targeted. This is particularly important when social distance and trust are jointly analyzed, because both concepts exhibit substantial overlap. Hoffman et al. (1996) for example define social distance as "the degree of reciprocity that subjects believe exist within a social interaction", which closely resembles many definitions of trust. To allow for a more precise differentiation between trust and social distance, this paper focuses on the dimension of social distance that is based on the interaction frequency between two persons, namely interactive social distance (Kadushin, 1962; Karakayali, 2009).

The frequency of interaction between two persons can be measured on a continuous scale; interactive social distance is therefore also likely to follow a continuous - or at least step-wise - distribution. The gradual nature of interactive social distance is in contrast to forms of social distance based on binary group identity or group affiliations, which dominate the trust literature, and makes interactive social distance a well-suited dimension to capture the radius of trust.

\subsection{Results}

This section provides the results of our analyses with the overarching objective to a) analyze if the theoretical predictions of the radius of trust are supported by experimental behavior and b) contrast if survey trust suggests the same results as the experiment. Descriptive statistics first give an overview of the sampled population's socioeconomic characteristics. Comparisons of behavior in the trust game and survey answers for the three treatments are then based on population means. Regression analyses afterwards corroborate if findings also hold conditional on the respondents' characteristics.

\subsubsection{Descriptive Results}

Table 2.1 reports summary statistics of the sample. We show characteristics that have been found to be relevant determinants of trust in previous studies, for example age, education, gender, and income. Other characteristics are relevant particularly in a pastoral setting, such as the livestock owned by the households. ${ }^{8}$ The sample is largely homogenous in terms of religion (Christianity), ethnicity (Turkana) and language (Turkana). This homogeneity is vital for trust research, since understandings and interpretations of experiment and survey trust can differ strongly depending on cultural backgrounds (Cronk, 2007; Reeskens and Hooghe, 2008; Torpe and Lolle, 2011).

Income and education levels in the sample are considerably low. More than $85 \%$ of the respondents never went to school. With 8.09 members, the average household is relatively large, which is due to several generations and other relatives often residing in one common homestead.

\footnotetext{
${ }^{8}$ Treatment in the trust game was assigned randomly. Descriptive statistics differentiated by treatment are presented in Table A4 in the Appendix.
} 
Table 2.1: Summary statistics for total sample $(\mathrm{N}=394)$

\begin{tabular}{lccc}
\hline \hline Variable & Mean/share & $\begin{array}{c}\text { Standard } \\
\text { deviation }\end{array}$ & Range \\
\hline Age [years] & 39.64 & 14.43 & {$[13 ; 80]$} \\
Constant relative risk aversion coefficient (CRRA) $^{\mathrm{a}}$ & 2.18 & 2.00 & {$[0 ; 5]$} \\
Distance to the next paved road [walking minutes] & 27.43 & 45.03 & {$[1 ; 420]$} \\
Education [years] & 1.14 & 3.01 & {$[0 ; 14]$} \\
Female & 0.51 & & \\
Herd size [TLU] & 32.80 & 35.81 & {$[0 ; 251.2]$} \\
Household size & 8.11 & 3.86 & {$[1 ; 25]$} \\
Income per year [1,000 KSh] & 5.55 & 11.45 & {$[0 ; 95]$} \\
Mobile phone user [1 = yes] & 0.81 & & \\
Religion [1 = Christian] & 0.98 & & \\
Village size [100 people] & 5.63 & 3.94 & {$[1.75 ; 15.60]$} \\
Years lived in the village [percentage of lifetime] & 0.77 & 0.32 & {$[0.02 ; 1]$} \\
\hline
\end{tabular}

Notes: CRRA $=$ Constant relative risk aversion. TLU $=$ Tropical Livestock Unit. KSh $=$ Kenyan Shillings.

${ }^{a}$ Elicitation method based on an incentivized Eckel and Grossman (2002) task (see Table A3).

${ }^{\mathrm{b}}$ One tropical livestock unit equals 1 head of cattle, or 0.7 of a camel, or 10 goats, or 10 sheep (Mburu et al., 2017).

Source: Own elaboration.

In this study, we measure trust towards three different groups: fellow villagers, people from a neighboring village, and city dwellers from the county capital. To ensure that the radius of trust lies within one's scope of analysis, it would be necessary to measure trust towards groups that are socially closest and would therefore undoubtedly lie within the circle of trust, that is spouses, best friends, or close family, as well as trust towards groups that are socially most distant and would therefore undoubtedly lie outside the circle of trust, that is unknown people with whom one shares minimal similarity. Extremely narrow or extremely wide radii might otherwise lie outside the range of analyzed trust levels. These corner solutions are however of little relevance from an economic perspective, when economic interactions with such groups occur at a low frequency.

Table 2.2 reports shows how often respondents in our sample interact with people from neighboring villages and the county capital. As expected, neighboring villages are visited considerably more often than the county capital. Only nine percent of the respondents never or at least extremely rarely visit the county capital. The other $91.12 \%$ visit the county capital at least once a year and are therefore likely to engage in situations in which trust towards city dwellers might be relevant. The three groups analyzed in this study therefore cover a wide range of interactive social distance, but still represent groups of people with whom pastoralists in a rural setting actually engage in some form of economic interaction e.g. ad hoc market interactions to purchase livestock, processed foods, or basic electronic devices. Trust towards a fellow villager thus relates to the closest possible platform of economic interaction for the respondents; trust towards a city dweller relates to the border of social distance that is still relevant for most respondents in our sample; 
Table 2.2: Frequency of interaction with neighboring villagers or city dwellers

\begin{tabular}{lcc}
\hline \hline & \multicolumn{2}{c}{ Visiting... } \\
\cline { 2 - 3 } & ...neighboring villages [\%] & ...the county capital [\%] \\
\hline ...at least once a year & 99.76 & 91.12 \\
...at least once a week & 93.91 & 20.81 \\
...every day & 75.38 & 5.58 \\
Equal interaction frequency (Wilcoxon signed-rank test) & $\mathrm{z}=16.813^{* * *}$ \\
\hline
\end{tabular}

Notes: $N=394 .{ }^{* * *} p<0.01,{ }^{* *} p<0.05,{ }^{*} p<0.1$.

Source: Own elaboration.

trust towards a person from a neighboring village relates to a middle part between these two extremes, because interactive social distance is longer compared to one's own village but shorter compared to the county capital.

\subsubsection{Comparison of Means}

Figure 2.1 shows levels of trust towards fellow villagers, towards people from a neighboring village, and towards city dwellers for four different measurements of trust. The first three bars of Subfigure 2.1a represent the share sent in the trust game. Respondents sent on average $34.5 \%$ to fellow villagers. Only slightly more was sent to people from a neighboring village, but the difference of 1.0 percentage points is not statistically significant $(p=0.61)$. City dwellers received only $26.4 \%$ on average. Mann-Whitney U tests prove the differences between the share sent to city dwellers and both fellow villagers and villagers from a neighboring village to be statistically significant at a $1 \%$ level.

The second bar triplet of Subfigure 2.1a shows the share that respondents expected player B to return. When paired with a fellow villager, respondents expected to receive back $52.5 \%$ of the amount that player $\mathrm{B}$ received. In pairings with a person from a neighboring village, respondents expected to receive 0.3 percentage points more compared to intra-village pairings. This difference is not statistically significant $(p=0.96)$. When paired with a city dweller from the county capital, respondents expected player B to send back only $45.4 \%$ of what they received. The difference between pairings with city dwellers and intra-village pairings is statistically significant at a $10 \%$ level according to a MannWhitney $\mathrm{U}$ test $(p=0.07)$. The same holds for the difference between pairings with city dwellers and inter-village pairings $(p=0.07)$.

The first set of bars of of Subfigure 2.1b shows the share of respondents that answered the context independent survey questions with either "somewhat" or "a lot". Since the survey questions were answered by the entire sample, we have 394 observations for each dimension of interactive social distance. A little more than half $(54.8 \%)$ of the respondents stated their trust towards fellow villagers. A little less than half of the respondents $(47.8 \%)$ stated to trust people from a neighboring village and only $23.1 \%$ said to trust city dwellers 
Figure 2.1: Trust levels using experiments and survey questions

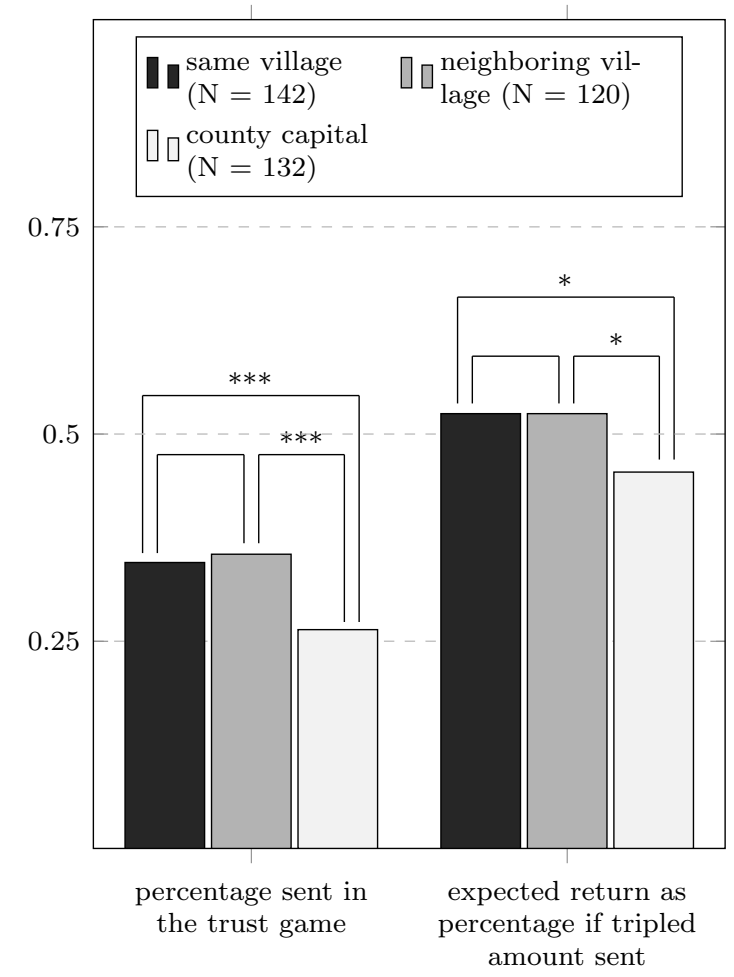

(a) experimental measurements

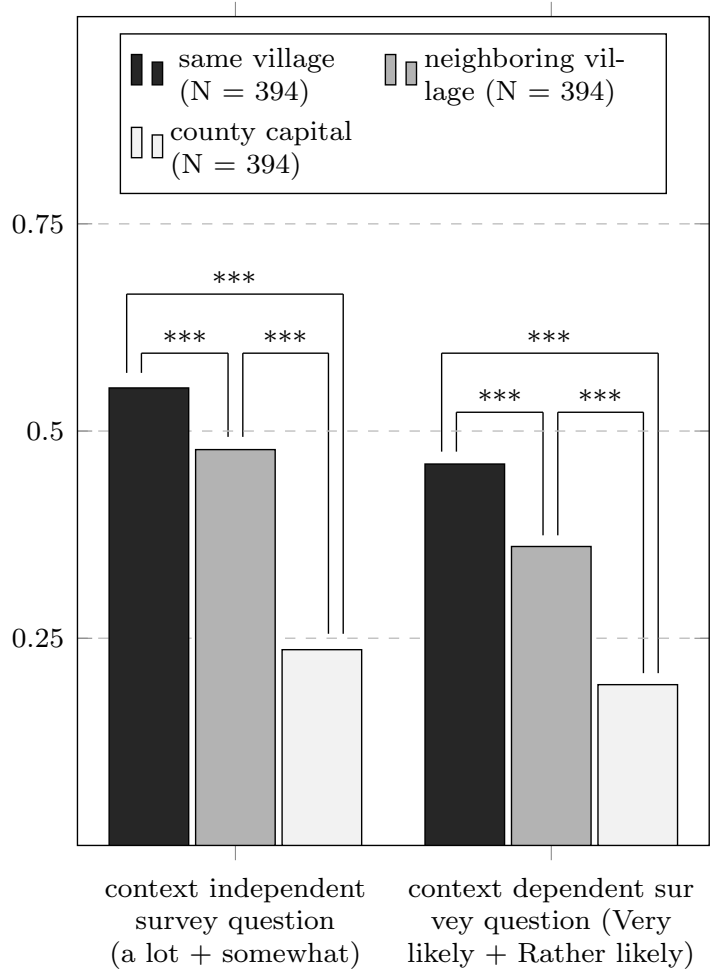

(b) survey measurements

Notes: Differences between means are tested for statistical significance using the Mann-Whitney U test (Subfigure a) and the sign test (Subfigure b). ${ }^{* * *} p<0.01,{ }^{* *} p<0.05,{ }^{*} p<0.1$.

Source: Own elaboration.

from the county capital. We use sign tests that incorporate all four possible answering options of the survey question. All differences are statistically significant at a $1 \%$ level.

The second bar triplet of of Subfigure 2.1b shows the share of respondents that answered the context dependent survey question with either "very likely" or "rather likely". The context dependent survey question regarding their own village was answered positively by $46.2 \%$. The respective values concerning a neighboring village and the county capital are $36.3 \%$ and $19.5 \%$. We again use sign tests that incorporate all four possible answering options. Similar to the context independent survey question, all differences are statistically significant at a $1 \%$ level. Disaggregated survey responses are shown in Figure A1 and Figure A2 in the Appendix.

\subsubsection{Regression Analyses}

Since treatment was assigned randomly, the comparison of means represents an unbiased method to detect differences in trust across the three treatments. To corroborate the 
stylized facts and analyze if results change when socioeconomic characteristics are included, we also employ formal regression analyses.

Multivariate regression results for the four trust variables are presented in Table 2.3. Column (1) has the amount sent as the dependent variable and coefficients are based on a censored interval estimator. Column (2) has the share expected to be returned by player $\mathrm{B}$ as the dependent variable and coefficients are based on a tobit model. Trust towards fellow villagers is the reference point.

As mentioned earlier, each respondent answered six survey questions: a context dependent and a context independent question concerning trust towards a person from a) the same village, b) a neighboring village and c) the county capital each. To compare the answers for these three levels of social distance, we combine a), b), and c) in one regression. Consequently we have only two regressions instead of six: one for context dependent survey trust and one for context independent survey trust. Since each respondent now appears in the regression with three observations, the sample size is three times as large as the original sample size. Both context dependent and context independent questions have four ordinal answering options. While the order of the answering options is unambiguous, distances between adjacent answering options are unknown and might be inconsistent. The answer "rather likely" could for example be closer to the answer "very likely" than to the answer "rather unlikely". Consequently we run ordered logistic regressions, but robustness checks show that results are robust for other estimation techniques such as ordered probit or techniques that do not account for potential differences in distances between answering options.

The results overall confirm the stylized facts presented in Figure 2.1: Respondents place significantly less trust in city dwellers compared to fellow villagers and people from a neighboring village. This is consistent for both experimental and survey measurements of trust. While the survey questions also suggest a step-wise decline of trust with regards to people from neighboring villages, outcomes of the trust game do not. In fact, raw sending decisions of the trust game even show larger shares sent to people from a neighboring village compared to fellow villagers, albeit marginal and insignificant. Regression results for the control variables' coefficient estimates can be found in Table A5 in the Appendix.

How do these findings relate to the theoretical implications of the radius of trust? As shown earlier, (interactive) social distance increases from the same village, to the neighboring village, up to the county capital. We first look at experimentally measured trust: city dwellers are trusted substantially less than fellow villagers or people from a neighboring village. Trust towards people from the same village is however very similar compared to trust towards people from neighboring villages: depending on the outcome variable, the difference between intra-village and inter-village trust ranges from -1.0 percentage points to -0.3 percentage points.

All logical statements presented in section 2.2 are true under these conditions, if the radius of trust lies between people from the neighboring village and city dwellers: social 
Table 2.3: Multivariate regression analyses on the radius of trust

\begin{tabular}{|c|c|c|c|c|}
\hline & 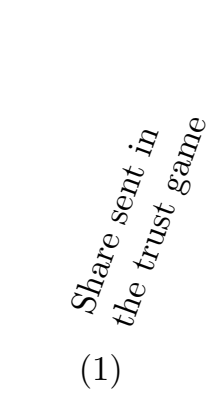 & 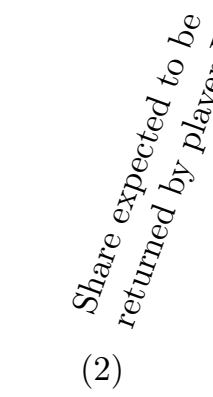 & 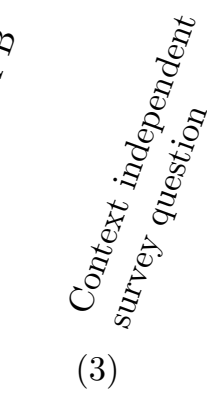 & 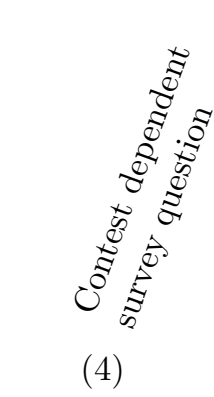 \\
\hline $\begin{array}{l}\text { Trust towards people from } \\
\text { the same village (SV) }\end{array}$ & BASELINE & BASELINE & BASELINE & BASELINE \\
\hline $\begin{array}{l}\text { Trust towards people from a } \\
\text { neighboring village }(\mathrm{NV})\end{array}$ & $\begin{array}{c}1.167 \\
(1.886)\end{array}$ & $\begin{array}{c}0.197 \\
(2.778)\end{array}$ & $\begin{array}{c}-0.305^{* * *} \\
(0.099)\end{array}$ & $\begin{array}{c}-0.186^{* *} \\
(0.082)\end{array}$ \\
\hline $\begin{array}{l}\text { Trust towards city dwellers } \\
\text { from the county capital (CD) }\end{array}$ & $\begin{array}{c}-7.889^{* * *} \\
(2.742)\end{array}$ & $\begin{array}{c}-8.361^{* *} \\
(3.661)\end{array}$ & $\begin{array}{c}-1.626^{* * *} \\
(0.142)\end{array}$ & $\begin{array}{c}-1.023^{* * *} \\
(0.104)\end{array}$ \\
\hline Control variables? & YES & YES & YES & YES \\
\hline $\mathrm{N}$ & 394 & 394 & 1,182 & 1,182 \\
\hline Wald test: $N V=C D$ & $* * *$ & * & *** & *** \\
\hline
\end{tabular}

Notes: Estimates in column (1) are based on censored interval regression. Estimates in column (2) are based on a tobit model. Estimates in columns (3) and (4) are ordered log-odds estimates from ordered logistic regression. Standard errors shown in parentheses are robust and clustered at the village level for columns (1) and (2), and clustered at the individual level for columns (3) and (4). The control variables are: age, constant relative risk aversion coefficient, distance to the next paved road, education, gender, herd size, household size, income, mobile phone use, village size, and the years lived in the village. ${ }^{* * *} p<0.01,{ }^{* *} p<0.05,{ }^{*} p<0.1$. Source: Own elaboration.

distance to fellow villagers is longer than social distance to neighboring villagers, but trust levels towards these two groups are similar. This is in accord with proposition (2.1); city dwellers are even more socially distant, and trust levels towards city dwellers are indeed substantially lower. This is in accord with proposition (2.2). The trust experiment therefore suggests that a) pastoralists do exhibit a radius of trust, and b) that this radius is drawn so that fellow villagers and people from a neighboring village are within the radius and city dwellers from the county capital are outside of the radius. We therefore confirm hypothesis 1 .

Trust levels based on the survey questions manage to reproduce the disparity of trust towards fellow villagers and trust towards city dwellers that becomes evident through the experiment. However, survey trust deviates from the experiment in the sense that the difference between intra-village and inter-village trust is substantial and statistically significant. As a result, the survey questions do not support the claim that people from a neighboring village are within the radius of trust as defined in section 2.2. We thus do not find support for hypothesis 2 . 


\subsection{Discussion}

Our analyses are - as virtually all empirical studies that employ some form of statistical tests - based on testing a statistical model incorporating the hypothesis that a particular effect has a certain size. In the study at hand we test if differences in trust between treatment groups are zero. Two aspects regarding the limits of statistical hypothesis testing deserve further discussion here.

First, statistical significance does not per se imply economic significance: effects can be statistically significant, but when effect sizes are small in absolute terms, they might not be economically relevant. As shown in Figure 1, all statistically significant differences between treatments also have a substantial effect size. Transfers sent towards city dwellers for example are on average $23.6 \%$ lower than transfers to fellow villagers, and $25.8 \%$ lower than transfers to people from a neighboring village. The pitfall of a "sizeless stare" (McCloskey and Ziliak, 1996; Hirschauer et al., 2018) can therefore be avoided in this study.

The second and far more intricate limitation is the difficulty to draw conclusions from statistically insignificant effects. A large p-value suggests that the null-hypothesis should not be rejected, but does not provide any evidence in favor of the null-hypothesis. As long as the p-value is not equal to one, there is always an alternative hypothesis that is more compatible to the data than the null-hypothesis (Greenland et al., 2016). This renders proving negatives, for example that a difference between two treatments is precisely zero, extremely difficult. Translated to our case, it means that there is no statistical certainty that experimental trust between fellow villagers and neighboring villagers is actually the same. In fact, it is rather unlikely that the difference is precisely zero. However, the theoretical framework on which we built our analysis does not necessarily require groups within the radius of trust to face strictly equal levels of trust. It is sufficient if trust towards groups within the radius is similar, thus allowing room for small potential differences.

The differences between intra-village and inter-village trust we find in the experiment are only marginal: the $95 \%$ confidence intervals for the differences in means between intervillage and intra-village pairings only range from -3.2 points to 5.2 points for the amount sent and -5.9 points to 6.4 points for the expected return. Trust towards fellow villagers is therefore sufficiently similar compared to trust towards people from a neighboring village, to support the claim that the radius of trust lies between people from a neighboring village and city dwellers from the county capital.

How can the deviation of measuring techniques regarding differences between intravillage and inter-village trust be explained? First, it is important to note that the general trends of the two measuring techniques presented here correspond to other existing studies. A monotonously falling relationship between social distance and survey trust is also seen in other studies based on survey trust (Etang, 2010; Mattes and Moreno, 2018). We are aware of only one other study that offers a comparison of experimentally measured 
trust for both intra-village and inter-village relations: Etang et al. (2011) conduct a trust experiment in two Cameroonian villages without a focus on the radius of trust and find that people send statistically significantly more to fellow villagers $(74 \%)$ than to people from the other village (63\%). We do not observe this discrimination in the study at hand. However, expected returns displayed in Etang et al. (2011) are actually very similar for intra-village pairings (46\%) and inter-village pairings (47\%). This resembles our finding that experimental trust towards fellow villagers and neighboring villages is rather similar.

An explanation for the deviation of survey trust and experimental trust could be based on an overestimation of survey trust in fellow villagers relative to trust towards more socially distant groups. Respondents might for example purposefully overstate their trust towards fellow villagers, because they want to present themselves as a particularly connected, trusting, and trustworthy member of the community and hope for some reward in the future. In an incentivized game however, trust towards fellow villagers is shown to be somewhat lower than the orally reported trust. This form of social desirability bias would then support the claim that survey trust is not a sufficiently precise predictor of actual trust in some contexts. However, the survey questions do coincide with the experiment regarding statically significantly lower trust towards city dwellers compared to fellow villagers and people form a neighboring village. This can be interpreted as support for the validity of survey trust questions.

\subsection{Conclusion}

Trust is an important mechanism to overcome market failures such as imperfect contract enforcements. Economists have therefore long argued that trust deficiencies are responsible for much of the economic underdevelopment in the world (Arrow, 1972). The radius of trust presents a key trust aspect because it indicates how far a person extends his or her trust. It thereby determines the reach of productive economic interaction within a society (van Hoorn, 2014).

Up to now, the relatively scarce research on the radius of trust exclusively relied on survey questions. In this study we have used an incentivized experiment, namely the trust game by Berg et al. (1995) and two sets of survey questions to localize the radius of trust of pastoralists in Northern Kenya and contrast the results of both measuring methods.

We find that behavior in the trust game can be well explained by the concept of the radius of trust. Pastoralists' trust towards people from the same village closely resembles trust towards people from neighboring villages, even though social distance towards the latter group is considerably longer than to the former group. This suggests that both groups are included in the radius of trust. Trust towards people from the county capital is substantially lower compared to both trust towards fellow villagers and trust towards people from neighboring villages, which suggests that city dwellers are excluded from the radius of trust. 
Survey questions in contrast do not fully coincide with the results of the incentivized experiment. This adds fuel to the fire concerning the discussion about the validity of survey trust questions. We do not give one-sided support for either side however: the survey questions manage to reproduce the disparity of trust towards fellow villagers and trust towards city dwellers that becomes evident through the experiment. This supports the validity of survey trust questions. However, the survey questions also indicate a trust difference between fellow villagers and people from a neighboring village. This difference is not statistically significant in the experiment. This deviation of survey trust and experimental trust could be based on an overestimation of survey trust in fellow villagers. The existence of a clear-cut radius of trust can therefore not be drawn from survey questions in the context at hand.

Our results suggest that experimental measuring techniques are inevitable for further research on the radius of trust and should at least complement survey data. At the same time, it is methodology desirable to measure trust towards multiple different groups, in order to localize the radius of trust as precisely as possible. The three groups presented in this paper constitute the minimal number of groups needed to draw conclusion on the radius of trust and further research based on a larger number of groups can certainly help drawing a more detailed picture. In particular it might be worthwhile to use experiments to measure trust towards very close persons such as family members or close friends. The technique of matching players presented in this paper could be useful to reduce the logistical challenges that such an extensive research design would entail.

The political situation in the analyzed region caused some constraint to our sampling procedure. Areas of Turkana County that are physically close to neighboring tribes are particularly prone to raids and conflicts. Four of the 21 villages that were initially targeted for data collection were thus inaccessible for the research team during the time of data collection. The inability to include these communities might have reduced the representativeness of the data at hand for the rest of the county's population. These areas should be included in further follow up research, when intertribal tensions reduce.

The results of this study are relevant for policy makers and development practitioners. Kenya's national policies have recently shifted their focus more towards supporting pastoral livelihoods (Odhiambo, 2013). The relative lack of trust towards people from the county capital should con-cern any person that works with pastoralists, but does not come from a Turkana village, because such trust deficits could lead to lower cooperation of pastoralists and thus hamper the implementation of development projects. The involvement of trusted agents might help overcome trust barriers and secure successful collaboration. Our results suggest that suitable agents do not necessarily need to come from each individual village, since people of neighboring villages seem to be similarly trusted. 


\title{
Chapter 3
}

\section{Can Mobile Phones Build Social Trust? Insights from Rural Kenya}

\begin{abstract}
Since trust is associated with economic development, societies could in principle reap substantial benefits from higher levels of trust. How such increases of trust within a society can be achieved, however, is hardly understood up to now. In this study, we analyze whether the usage of mobile phones can help build social trust among communities of semi-nomadic pastoralists in Northern Kenya. We measure trust with an incentivized trust game and differentiate between trust towards fellow villagers, trust towards people from a neighboring village, and trust towards city dwellers from the county capital. We analyze 394 households and employ a control function approach to account for potential endogeneity of mobile phone use. We find that using mobile phones can enhance social trust. However, such gains only occur with respect to trust towards city dwellers from the county capital. Mobile phone use does not statistically significantly increase trust towards fellow villagers or towards people from a neighboring village. This heterogeneous effect of mobile phone use on trust may be driven by the substantially longer physical distance of the respondents to city dwellers compared to the distance to fellow villagers and people from a neighboring village. Furthermore, we find that a longer duration of mobile phone ownership is associated with a reduction in trust towards city dwellers from the county capital compared to shorter durations of mobile phone ownership.
\end{abstract}

Keywords: field experiment, ICT, Kenya, mobile phones, trust.

JEL Codes: A33, C93, D90, O12, O33, Z10.

This chapter is co-authored by Martin C. Parlasca (MP), Daniel Hermann (DH), and Oliver Mußhoff $(\mathrm{OM})$. Data and code are available at The contributions of each author are as follows: MP, DH, and OM developed the research questions. MP collected, analyzed, and interpreted the data. DH and OM assisted in the analyses and interpretation of the results. MP wrote the paper. DH and OM provided continuous feedback and comments during writing. 


\subsection{Introduction}

Generalized trust, which refers to trust towards people that are not well-known (Yamagishi and Yamagishi, 1994; Stolle, 2002; Uslaner, 2002; Freitag and Traunmüller, 2009), is needed for many situations of economic interaction such as daily market activities. Considering the function of trust as a lubricant for social interaction, a lack of generalized trust can severely restrict a person's reach of efficient economic exchange. Increases of generalized trust within a society thus have the potential to create large efficiency gains (Fafchamps and Minten, 2002; Fafchamps, 2006).

Given the importance of trust for social interaction and various welfare dimensions, a growing body of economic, sociological, and psychological research has been devoted to examining the circumstances under which trust can thrive. A reoccurring notion in all three disciplines is that communication represents a key factor in the formation of trust (Lewicki et al., 2006; Glanville and Paxton, 2007). Ostrom et al. (1992) for example find that communication and sanctioning in a common pool resource experiment lead to substantially more efficient outcomes. In a laboratory setting, personal communication has shown to enhance trust (Buchan et al., 2006) and is even more powerful in creating mutually benefitting exchanges than the possibility to engage in non-binding contracts (Ben-Ner and Putterman, 2009).

In this paper, we analyze whether mobile phones - which constitute a fundamental component of modern information and communications technologies (ICT) - can help build social trust ${ }^{1}$ among pastoral communities in Northern Kenya. In most African countries, trust levels are remarkably low: out of all regions in the world, people living in sub-Sahara African countries exhibit the lowest levels of generalized trust (Mattes and Moreno, 2018). In the study region of Northern Kenya, it is particularly relevant to increase trust for several reasons. The relatively weak legal system jeopardizes contract enforcement which means that any economic interaction requires substantial amounts of trust between the contract partners. This has caused a strong reliance on trust-based relationships in Northern Kenya's livestock sector (Mahmoud, 2008; Pavanello, 2010; Roba et al., 2018). Additionally, the low population density and long physical distance between settlements in the region make communication over long distances difficult and therefore induce high monitoring costs. Lastly, low trust levels between ethnic tribes reinforce longstanding intertribal conflicts in the region and impede solutions to share resources peacefully and effectively (Schilling et al., 2012). Potential benefits of enhancing trust are therefore particularly high in the context of Northern Kenya.

Over the last decade, mobile phones have become available to most pastoralists in Northern Kenya (Butt, 2015; Asaka and Smucker, 2016; Parlasca et al., 2020). While a broad body of research has pointed out that mobile phones can help increase several

\footnotetext{
${ }^{1} \mathrm{~A}$ common distinction is often made between social trust (trust in other people) and political trust (trust in political institutions). In the following we use the term trust to refer to social trust only.
} 
economic and welfare dimensions of rural populations in sub-Saharan Africa, such as income, nutrition or gender equality (Aker and Mbiti, 2010; Sekabira and Qaim, 2017), only qualitative or anecdotal evidence of the effects of mobile phones on trust exists up to now (Molony, 2006; Overå, 2006; Molony, 2009).

In this study, we elicit trust levels with an incentivized experiment, namely the trust game by Berg et al. (1995). Experimental sessions were conducted from July 2018 to August 2018 in 17 different villages in Turkana County, Northern Kenya with a total of 402 respondents. We differentiate with regard to the object of trust by measuring trust towards fellow villagers, trust towards people from a neighboring village, and trust towards city dwellers from the county capital. Past research in rural sub-Saharan Africa indicates that smallholders exhibit less trust towards people from different villages (Etang, 2010; Etang et al., 2011) or people from the next larger city (Parlasca et al., 2019). The differentiation of the object of trust therefore allows investigating heterogeneous effects of mobile phone use on trust depending on the physical distance between trustor and trustee.

We add to the existing literature in several ways: to our knowledge, we are the first to explore the direct link between mobile phone use and trust using quantitative household data from a low-income country. We are also the first to analyze the role of geographical distance in the relationship between mobile phones and trust. Lastly, our analysis contributes to the extremely sparse literature on trust in the particular context of pastoralist communities in sub-Saharan Africa.

The reminder of the study is organized as follows. In section 3.2 , we lay out the conceptual framework that guides the analysis. The data is explained in section 3.3. We present the empirical framework in section 3.4 and discuss results in section 3.5. Section 3.6 concludes.

\subsection{Conceptual Framework}

Trust is relevant for nearly all economic activities and can help alleviate market failures (Arrow, 1972). Imperfect contract enforcement for example increases the implied costs of economic exchanges when at least one of the parties involved in a contract suspects contract breach by the other party. Sufficient trust and trustworthiness between contracting partners however can serve as a mechanism to overcome such additional costs (Fafchamps, 1996; Gambetta, 2000a). The more restricted contract enforcement is, the more partners have to rely on trust or other forms of social capital to bridge contract deficiencies. Even if monitoring is possible, it usually requires additional resources. Relying on trust rather than costly monitoring frees up resources that can be used for other activities. A positive effect of trust on economic development (Zak and Knack, 2001; Algan and Cahuc, 2010; Bjørnskov, 2012) and economic productivity (Bjørnskov and Méon, 2015) therefore finds strong and robust empirical support. 
To better understand if and how mobile phones might affect trust, it is helpful to specify which forms of trust are actually examined. Discussions on the dimensionality of social trust are part of a voluminous but dissenting body of academic research. For the course of this study, we follow the theoretical framework by Yamagishi and Yamagishi (1994) that distinguishes between knowledge-based trust and generalized trust. The former type refers to particular objects and is based on "reliable pieces of information accumulated over a long history of interactions" (Yamagishi and Yamagishi, 1994, p. 139), whereas generalized trust refers to a generic assessment of people with whom a long history of interaction is lacking. When information and knowledge concerning another person are insufficient, the social interaction will be governed by generalized trust rather than knowledge-based trust $^{2}$.

While increases in knowledge-based trust can facilitate economic activities between two agents, increases in generalized trust are more efficient in generating such benefits, because generalized trust does not need to be established for each new pair of agents (Fafchamps, 2006). Generalized trust therefore helps expand economic activities beyond already existing familiar relations (Yamagishi and Yamagishi, 1994).

We propose the Theory of Change (Weiss, 1995) presented in Figure 3.1 to show how mobile phone use can lead to increases in generalized trust. Let us assume that agent $\mathrm{A}$ and agent $\mathrm{B}$ communicate via mobile phones. Furthermore, we assume that some kind of social group $G$ exists and agent $A$ is not a member of $G$. The social group $G$ could for example be based on race, ethnicity, language, religion, group membership, or village affiliation. We now identify two pathways that lead to increases of generalized trust of $A$ towards members of $G$. If $B$ is also not a member of $G$, the communication via mobile phone can lead to increases of A's trust towards $G$, when B communicates some relevant information regarding $G$ 's members, for example by sharing a past experience or stating positive opinions regarding G. Agent A might then update her beliefs about the trustworthiness of G's members based on this indirect information and therefore place higher trust in members of this group.

In addition to this pathway, mobile phones can even provide agent $\mathrm{A}$ with direct information about group $\mathrm{G}$, should agent $\mathrm{B}$ himself be a member of that group. For example, the communication by mobile phone allows agent $\mathrm{A}$ to learn more about agent B's motivations, incentives, or norms to which agent B adheres. The mobile phone might even help agent $\mathrm{A}$ to directly experience trustworthy behavior by agent B. If agent A extrapolates parts of this information also to other members of $\mathrm{G}$, trust towards this group as a whole might rise.

Mobile phones facilitate communication between two persons, especially when they

\footnotetext{
${ }^{2}$ The widely used term particularized trust differs slightly from knowledge-based trust, since particularized trust can also be extended to unknown persons of one's own kind, whereas knowledge-based trust requires pieces of information based on actual interaction. Knowledge-based trust is rather a sub-element of particularized trust, even though both concepts exhibit substantial empirical overlap (Newton and Zmerli, 2011).
} 
Figure 3.1: A Theory of Change for the effects of mobile phone use on general trust

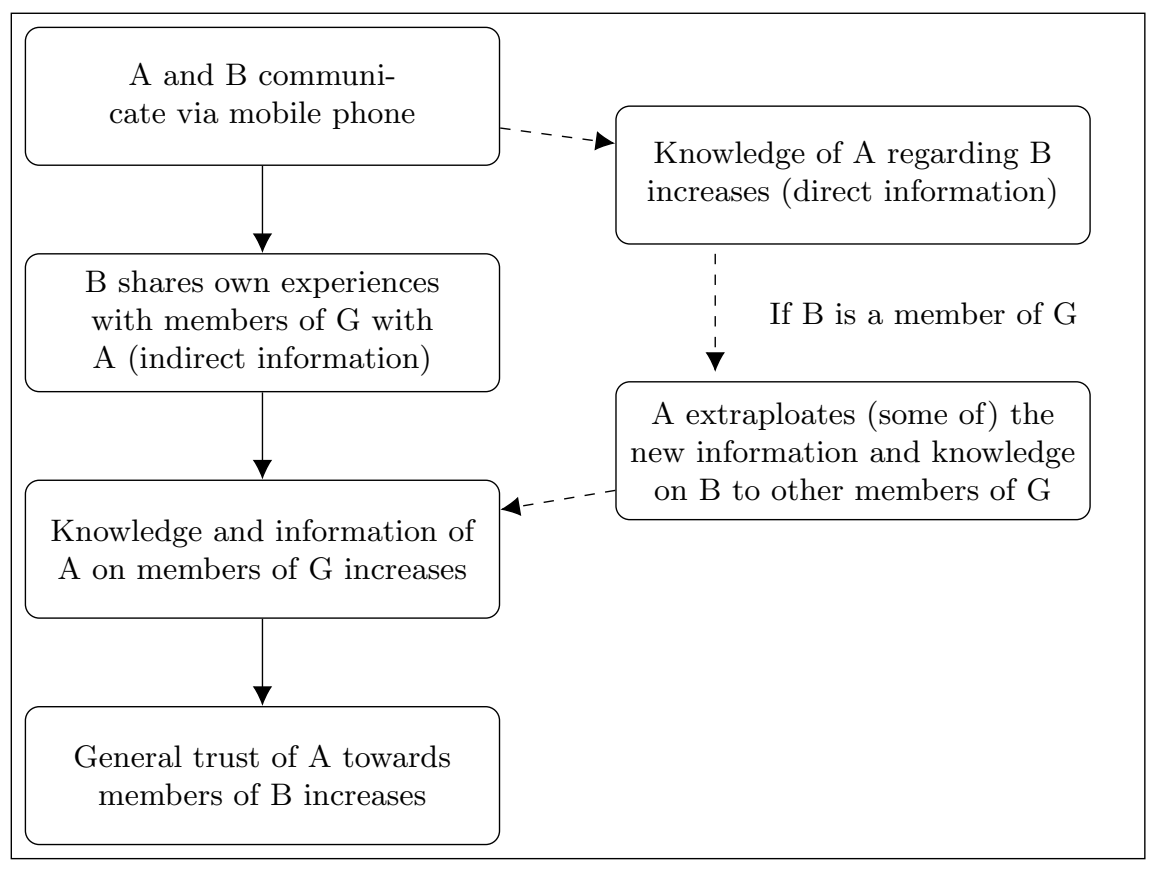

Source: Own elaboration.

are geographically apart (Nakasone et al., 2014; ?; Asaka and Smucker, 2016; Debsu et al., 2016). If the type of communication that is facilitated by mobile phones is also the type of communication that helps build knowledge-based trust, the argument that mobile phone use has the potential to increase knowledge-based trust is rather straightforward ${ }^{3}$.

Communication via mobile phones can be perceived as inferior compared to face-toface interaction (O'Doherty et al., 2007). Nilsson and Salazar (2017) however explain that Maasai pastoralists in northern Tanzania do not necessarily value the communication through mobile phones less than face-to-face communication. Mobile phones are rather integrated in the long-standing ritual of information exchange and enhance the "overall experience of sociability" (Nilsson and Salazar, 2017, p. 449) of Maasai pastoralists. That said, more knowledge of another person can potentially also lead to decreases in trust towards a person, if the newly gathered information hints towards untrustworthiness of the other person (Molony, 2006; Labonne and Chase, 2010; Butt, 2015; Djohy et al., 2017).

While there is no quantitative evidence for the direct effect of mobile phone use on knowledge-based trust, several influential studies suggest that this relationship is plausible: Overå (2006) finds that traders in Ghana benefitted from the liberalization of the

\footnotetext{
${ }^{3}$ We expect mobile phones in Northern Kenya to enable communication mostly between two people. Other forms of communication for example through the use of social media can in principle also be enhanced by mobile phones, especially in high-income countries. In the geographical context of this study, however, smart phones are rarely used and therefore render this aspect negligible.
} 
telecommunication sector, amongst others because interviewed traders argued that "the possibility to call contract partners and intermediaries, thereby communicating with them more frequently than otherwise possible, both enhances trust and renders monitoring more feasible" (Overå, 2006, p. 1312). Karlan (2005) quantified trust experimentally using the trust game by Berg et al. (1995) (BDM) where subjects played with a random person but knew the exact identity of the partner with whom they were playing. In his study, connectedness to the partner in the game increased trust levels. Respondents for example showed significantly more trust when their counterpart in the trust game lived within a 10-min walk (Karlan, 2005). Buchan et al. (2006) played a similar version of the BDM with small groups of approximately twelve people and randomly assigned groups to have either personal (non-strategy-relevant) discussions, or impersonal discussions before playing the game. They find that in groups where people shared personal information, trust levels were significantly higher than in groups where no personal communication occurred.

Up to now, there is little empirical evidence for a translation from knowledge-based trust to generalized trust (Newton and Zmerli, 2011). There is even less quantitative evidence that hints towards the existence of a positive effect of mobile phone use on generalized trust. Small country comparisons by Knack and Zak (2003) or Collier (2002), which associate the average number of phones with the average level of trust within countries, are the only quantitative study in this regard that we are aware of. Both of these studies lack clear identification. While Knack and Zak (2003) find associational evidence that countries with a higher density of mobile phones per people also are more trusting, these effects become statistically insignificant when other measures of infrastructure such as the number of paved roads are also controlled for.

However, Labonne and Chase (2010) show that road construction, and more particularly the reduction in costs of interaction due to a higher number of roads, have caused increased generalized trust among Philippine villages. Since mobile phones have also shown potential to reduce transaction costs (Jack and Suri, 2014), the finding of Labonne and Chase (2010) lend strong empirical support to our argumentation.

Given the Theory of Change presented in Figure 3.1 we therefore aim at testing the following hypothesis:

H1: Mobile phone use leads to higher levels of generalized trust.

In most of sub-Saharan Africa, generalized trust is low (Mattes and Moreno, 2018). Recent research suggests that in rural areas trust towards people that live farther away can be particularly low, because interaction and communication with such people is more challenging (Etang et al., 2011; Parlasca et al., 2019). The trust enhancing effects of mobile phone use might therefore be stronger with regard to groups that live far off, since mobile phones have the potential to increase communication especially with people that are more physically distant. Hypothesis 2 therefore states: 
H2: Gains in trust due to mobile phone use towards people that live farther away are higher than gains in trust towards people that live closer.

\subsection{Data}

Our analysis relies on primary data of 394 households collected from July 2018 to August 2018 in Turkana County, Northern Kenya. Initially, we selected five larger village groups with approximately 15 villages in each group. At the time of data collection, one of the groups was not safely accessible due to intertribal tensions in that area. We randomly selected four to five villages from the four remaining groups. All 17 villages selected for the study are located within a one to two hour drive from Turkana County's capital city. Within each village, 20 to 26 households were randomly invited to participate in the data collection. Since we worked indigenous communities, we took particularly great care in obtaining free, prior, and informed consent of all participants (FAO, 2016).

\subsubsection{Measurement of Key Variables}

We measured trust with an incentivized version of the trust game developed by Berg et al. (1995). This experiment has been widely used around the world in both laboratory and field experimental settings (Cárdenas and Carpenter, 2008; Johnson and Mislin, 2011). The BDM is played by two players: a sender and a receiver. Before the start of the game, the sender is endowed with a certain amount of money. The sender can then choose to send none, some, or all of this money to the receiver. The research team triples whatever positive amount is sent to the receiver. Upon receiving this tripled amount, the receiver can chose to return money back to the sender. This transfer is not multiplied and concludes the game. The amount sent by the sender is considered to reflect the trust of the sender towards the receiver. The amount returned by the receiver is considered to measure her trustworthiness (Wilson, 2018).

Since one of the objectives of this study is to analyze effects of mobile phone use on trust conditional on the distance between trustor and trustee, we introduce three treatments to the BDM: we randomly paired each sender to a receiver that either lives i) in the same village as the sender, or ii) in a neighboring village, or iii) in the county capital. Senders had no information on the exact identity of the person with whom they were playing, but only knew if the receiver lived in the same village, in a neighboring village, or in the county capital. These three groups capture a wide range of physical distance, but still represent groups of people with whom pastoralists in a rural setting could actually engage in situations where trust might matter (Parlasca et al., 2019).

Having revealed the general group to which the receiver belongs while having the exact identity of the receiver kept secret implies that the amounts sent in the BDM reflect 
generalized trust towards people from the respective group rather than knowledge-based trust towards a particular person. Furthermore, the anonymity of respondents' choices in the game ensured that amounts sent in the game did not get diluted by confounding factors such as concerns about reputation or the fear of retaliation by the receiver, when low amounts of money were transferred.

Numerous versions with different experimental protocols of the BDM exist. Table B1 in the Appendix demonstrates deviations from the experiment used for this study compared the original protocol used by Berg et al. (1995). The meta-analysis by Johnson and Mislin (2011) shows that the deviations from the original set-up described in Table B1 - none of which are uncommon - do not statistically significantly affect the share of the endowment sent in the trust game ${ }^{4}$. A more detailed discussion of the implications of the experimental set-up used for this study is presented in Parlasca et al. (2019).

The instructions used during the experiment are presented in the Appendix A.1.1. Appendix A.1.2 and Table A1 show the method of applying strategies. Since the sending decisions of respondents paired with a person from a neighboring village from the last session were not consequential, we drop eight observations from the sample to ensure incentive compatibility. The sequence of the data collection that was used in each village, including the BDM, payouts of earnings from the experiment, a socio-economic household survey, and an incentivized risk preference elicitation is shown in Table A2.

To measure mobile phone use and other socio-economic characteristics of the respondents and their households, we conducted a survey following the trust game. As part of this survey, we asked respondents to state their frequency of mobile phone use. Respondents could answer with one of the following options: "never; once a year; once a month; once a week; every day". We treat a household as a mobile phone user, when it used the mobile phone at least on a weekly basis. We also included other questions regarding the ownership of a mobile phone, the ownership of a smartphone, as well as the number of years of mobile phone or smart phone ownership respectively. We base the analyses on mobile phone use rather than mobile phone ownership, since pastoralists commonly share phones with non-owners (Debsu et al., 2016; Parlasca et al., 2020). We also asked whether respondents received mobile phone coverage at their homestead. Summary statistics of these variables, as well as other socio-economic characteristics of the sample are shown in Table 3.1. We test for statistical differences in means for the three treatment groups and do not find any major difference (see Table B6 in the Appendix).

The average household in our sample is considerably poor in terms of income, but has substantial livestock holdings. Educational levels are also relatively low. Despite the low levels of income, mobile phones are spread widely. An ownership rate of $81 \%$ relates to other findings of recent studies concerning mobile phones among pastoralists in Northern

\footnotetext{
${ }^{4}$ To make outcomes more comparable across studies, it is common practice to analyze the amount sent by the sender relative to her entire initial endowment, rather than the absolute monetary value of the transfer.
} 
Kenya (Parlasca et al., 2020). This rate of penetration is however still below national average (Financial Sector Deepening Kenya, 2019). A mobile phone owner in our sample has 4.24 years of experience with the phone on average. The relatively large standard deviation of 3.56 however suggests that experiences with the phone vary substantially over respondents. Smartphones are rarely used, but not completely unknown to the respondents. This supports our claim that social media use can be neglected in our context. Mobile phone reception is generally decent. Only $12 \%$ of the respondents state that network coverage is unavailable at their homestead.

Table 3.1: Summary statistics

\begin{tabular}{lccc}
\hline \hline Variable & Mean/share & $\begin{array}{c}\text { Standard } \\
\text { deviation }\end{array}$ & $\mathrm{N}$ \\
\hline Age [years] & 39.64 & 14.43 & 394 \\
Constant relative risk aversion coefficient $(\mathrm{CRRA})^{\mathrm{a}}$ & 2.18 & 2.00 & 394 \\
Distance to the next paved road [walking minutes] & 27.43 & 45.03 & 394 \\
Education [years] & 1.14 & 3.01 & 394 \\
Female & 0.51 & & 394 \\
Herd size [TLU] & 32.80 & 35.81 & 394 \\
Household size & 8.11 & 3.86 & 394 \\
Income per year [1,000KSh] (1,000 KSh $\approx$ 10 USD) & 5.55 & 11.45 & 394 \\
Mobile phone use & & & \\
$\quad$ Never & 0.19 & & 394 \\
$\quad$ Once a year & 0 & & 394 \\
$\quad$ Once a month & 0.01 & & 394 \\
$\quad$ Once a week & 0.02 & & 394 \\
$\quad$ Every day & 0.81 & & 394 \\
Mobile phone ownership [1 = yes] & 4.24 & 3.56 & 320 \\
Years of mobile phone ownership, if owner & 0.03 & & 394 \\
Smartphone ownership & 3.45 & 3.98 & 11 \\
Years of smartphone ownership, if owner & 0.88 & & 394 \\
Network reception at homestead [1=yes] & 0.93 & & 394 \\
Having relatives in neighboring villages [1= yes] & 0.62 & & 394 \\
Having relatives in the County Capital [1= yes] & 5.63 & 3.94 & 394 \\
Village size [100 people]
\end{tabular}

Notes: CRRA $=$ Constant relative risk aversion coefficient. KSh $=$ Kenyan Shillings. TLU $=$ Tropical Livestock Unit.

${ }^{a}$ Elicitation with an incentivized Eckel and Grossman (2002) task (see Table A3). Higher values imply higher risk aversion.

b One tropical livestock unit equals 1 head of cattle, or 0.7 of a camel, or 10 goats, or 10 sheep (Mburu et al., 2017).

Source: Own elaboration. 


\subsection{Empirical Framework}

\subsubsection{Estimation Strategy}

To test the hypotheses stated in section 3.2, we regress the amount sent in the trust game on the mobile phone use variable and control for various socio-economic characteristics of the household that have shown to influence trust is past studies. We are particularly interested in the mobile phone use coefficient estimates, since a statistically significant coefficient implies an effect mobile phone use on trust (Hypothesis 1). The amount sent in the trust game is left-censored at zero because people could not send less than nothing and right-censored at 100 percent because people could not send more than their entire endowment. Respondents could send money in steps of $100 \mathrm{KSh}$. The share of the endowment sent therefore has discrete steps of 20 percent. Consequently, we might not observe the actual precise amount respondents would have liked to send, but rather the interval that entails the true value. We therefore estimate a censored interval regression model (Manski and Tamer, 2002), but also report Ordinary Least Squares (OLS) estimates. While the censored interval regression accounts for the censored and discrete nature of the dependent variable, OLS is more efficient and offers a more intuitive interpretation of the coefficient estimates.

To allow for heterogeneous effects of mobile phone use on trust based on the social distance between trustor and trustee (Hypothesis 2), we estimate separate models for each of the three treatments: pairing with a fellow villager, pairing with a person from a neighboring village, or pairing with a city dweller from the county capital.

\subsubsection{Endogeneity Tests}

Since respondents were not randomly assigned to use mobile phones, it is plausible that respondents self-selected into using them. Our analysis could then suffer from statistical endogeneity based on unobserved heterogeneity across households. For example, mobile phones might be more valuable to people that have stronger social connections. At the same time, people with stronger connections might exhibit more trust towards others in general. Since we cannot directly observe, measure, and control for factors such as social connectedness, the mobile phone estimate could be biased. To examine this concern, we instrument mobile phone use with respondents' availability of mobile phone network at their homestead (see for example Labonne and Chase (2009)). The individual availability of mobile phone network is a binary variable that takes the value of unity if the household has mobile phone reception at its homestead and zero otherwise.

The control function (CF) approach, also known as 2 Stage Residual Inclusion (2SRI), relies on the inclusion of residuals of a reduced form estimation as an additional control variable in the structural equation (Terza et al., 2008; Wooldridge, 2014, 2015). The main difference of the $\mathrm{CF}$ with respect to the two-stage-least-squares (2SLS) estimation lies in 
the fact that reduced form residuals rather than fitted values from the reduced form are inserted in the structural equation. The model choice to estimate the reduced form using the CF gives more flexibility than a 2SLS approach, but also requires more distributional assumptions (Wooldridge, 2015).

In this study, mobile phone use is the potentially endogenous variable. This variable is binary. The fitted values obtained from a reduced form estimated via ordinary least squares regression would therefore be inadequate. The $\mathrm{CF}$ allows the use of a probit estimator in the reduced form, but requires that the reduced form is correctly specified ${ }^{5}$. To ensure that residuals have a mean of zero conditional on the vector of control variables, we "generalize" the residuals according to Gourieroux et al. (1987).

Another advantage of the CF lies in its potential to be applied to non-linear structural models, such as tobit or probit estimators (Wooldridge, 2010, 2014). Such applications require some nonstandard assumptions (Wooldridge, 2015) but are likely to provide decent estimates for "small amounts of endogeneity" (Wooldridge, 2015, p. 442). 2SLS is generally inconsistent under these circumstances.

Finally, the control function approach offers a rather direct test for endogeneity: Given that the standard conditions of imperfect collinearity of control variables and the rank condition for identification hold, the inclusion of the residuals in the structural equation offers a heteroskedasticity-robust Hausman test of the null-hypotheses that the potentially endogenous explanatory variable is exogenous. If the coefficient of the residual in the structural equation is statistically significantly different from zero, one can reject that the explanatory variable that is instrumented is exogenous (Wooldridge, 2015). Estimating instrumental variable (IV) models in the absence of endogeneity however leads to inflated asymptotic variances (Wooldridge, 2010; Tadesse and Bahiigwa, 2015). We therefore conduct the CF estimations, but give preference to the results of our non-IV estimations, if the $\mathrm{CF}$ approach does not detect endogeneity.

\subsubsection{Robustness Checks}

In addition to the endogeneity tests, we run several robustness checks. As mentioned in section 3.4.1, we conduct separate analyses for the three treatment groups: trust towards fellow villagers, trust towards people from a neighboring village, and trust towards a city dweller. To test if results are robust to different measurements of the key variables, we vary the measurements of the mobile phone use variable and the trust variable. First, we examine if changing the mobile phone use specification has any effect on the results. As mentioned earlier, the mobile phone use variable is binary and takes the value of unity if a respondent uses a mobile phone at least on a weekly basis and zero otherwise. To test the robustness of the three models to this specification, we also estimate the same models i) including monthly mobile phone use as part of the mobile phone use variable and ii)

\footnotetext{
${ }^{5}$ The 2SLS does not make any distributional assumptions about the reduced form (Wooldridge, 2015)
} 
only considering daily mobile phone use without weekly users. As shown in Table 3.1, the sample is largely divided into two groups: daily mobile phone users, and non-users. Only eight respondents (2.03\%) indicate that a phone was used once a week, and only 2 respondents $(0.51 \%)$ used a phone once per month. We therefore do not expect results to depend strongly on the specification of the mobile phone use variable, but conduct this exercise nevertheless, since recent research has shown that differences in mobile phone use frequency can have distinct implications for effects on household welfare (Parlasca et al., 2020).

To test the robustness of the dependent variable, we also consider an alternative trust measurement derived from the experiment, namely the amount of money that the trustor expects to get back from the trustee as a share of the tripled amount that the trustor sent to the trustee. Using the sender's expectation about the the other person's behavior as measure for trust has recently started to gain empirical support (see for example Sapienza et al. (2013)).

The sender's relative expectation ranges from zero, if the trustor expects nothing to be returned by the trustee, to 100 percent, if the trustor expects that the trustee will return all of the money she receives. If the trustor expects the same amount that she sent to be returned, the expected return is $33.33 \%$. If trustors sent nothing in the first stage of the game, we mapped their expected return to zero. Depending on the randomly assigned pairing, this variable allows capturing the sender's expectations of the average reciprocity of a fellow villager, or neighboring villager, or city dweller, detached from other potential influences such as altruism or risk preferences. Unlike choosing to send money in the trust game however, statements about the expected return do not have any real monetary consequence for the respondent, since the actual amount returned by the trustee is not influenced by these statements. We estimate models using both a tobit specification that has a lower limit of zero percent and an upper limit of one hundred percent, as well as OLS.

\subsection{Results and Discussion}

The average share sent in the trust game over the entire sample was $32.08 \%$. This value is lower than most other trust games set in African countries (Barr, 2003), but similar to comparable trust studies conducted in rural East Africa: Kenyan pastoralists analyzed by Cronk (2007) for example sent $34.25 \%$ on average and Ethiopian farmers analyzed by Ansink et al. (2017) sent $30.80 \%$.

We find differences in trust towards the three groups. On average, $34.51 \%$ was sent to fellow villagers, $35.50 \%$ was sent to people from a neighboring village, and $26.36 \%$ was sent to city dwellers from the county capital. The difference of 0.99 percentage points between intra-village and inter-village trust is not statistically significant ( $p=0.61)$. Trust towards city dwellers however is statistically significantly lower than both intra- and inter- 
village trust. A more detailed discussion on potential causes and implications of this trust disparity is presented in Parlasca et al. (2019).

In the next step, we estimate the control function to test for potential endogeneity of the mobile phone use variable due to unobserved heterogeneity. The availability of network coverage is strongly correlated with mobile phone use by the household. First stage regressions are shown in Table B2 in the Appendix. The coefficient estimates of network coverage are statistically significantly different from zero and the overall models predict mobile phone usage well.

Availability of mobile phone network is also plausibly exogenous to the outcome variable. Whether or not mobile phone network reaches the homestead of a household is not a choice variable by the household and therefore unlikely to be affected by household characteristics such as age, livestock holdings, or trust. Debsu et al. (2016), who consider pastoralist communities in a study area quite close to Turkana County, described mobile phone network coverage as "erratic" (Debsu et al., 2016, p. 57). Debsu et al. (2016) furthermore explain that in order to overcome potential problems of poor connectivity pastoralists for example walk to hills or other places where network reception is known to be decent.

These observations correspond to our experiences during the field work and are supported by the data. In Table B7 of the Appendix, we present a two-way table of frequency counts for mobile phone use and network reception at homestead. The relationship between the two variables is highly statistically significant. However, we do not find that network reception at the homestead is a necessary condition for frequent mobile phone use. To corroborate if network reception is related to other forms of infrastructure, we correlate network coverage with the household's distances to the next paved road, to the next place where potable water can be obtained, to the next local market, and to the next urban market. We do not find any statistically significant relationship between network availability and these measures of a household's physical proximity to infrastructure (see Table B8 in the Appendix). In addition, we look at correlation coefficients of the amounts sent in the trust game and network coverage for those households that do not use mobile phones to get a better understanding whether network coverage might affect trust other than through facilitated mobile phone use. We find no statistically significant correlation for either the entire sample or any of the three treatment sub-samples. Results are shown in Table B9 in the Appendix. We therefore confidentially argue that the instrumental variable is plausibly exogenous to our outcome variable.

Using the residuals from the first stage regression (results shown in Table B2) as additional control variables to our structural equation yields the control function estimates shown in Table B3. None of the residuals are statistically significantly different from zero. Consequently we cannot reject exogeneity of the mobile phone use variable and therefore rely on non-IV estimations, since they are more efficient.

We first consider the amount sent in the trust game. Table 3.2 shows the regression 
results for the three groups. Columns (1) and (2) refer to trust towards fellow villagers; columns (3) and (4) refer to trust towards people from a neighboring village, columns (5) and (6) refer to trust towards people from the county capital. We find a positive and statistically significant effect of mobile phone use on trust, but only for the group that played the trust game with a city dweller. For pairings with people that have a smaller geographical and social distance, namely fellow villagers and people from a neighboring village, the effect is not statistically significant. The effect size of the mobile phone use variable in columns (5) and (6) is also relatively large. On average, mobile phone users send ceteris paribus approximately 13 percent more of their initial endowment to city dwellers than non-users. Given that the average amount sent to city dwellers was only $26.6 \%$, this effect size is substantial.

Two other aspects of Table 3.2 deserve further discussion. While mobile phone use has no statistically significant effect on trust towards people from a neighboring village, the distance to the next paved road has a large and statistically significant negative coefficient as shown in columns (3) and (4) of Table 3.2. This suggests that living closer to a paved road might foster trust to people that live in neighboring villages. It is plausible that living near to a road has a positive effect on the interaction with neighboring villagers and - analogously to the Theory of Change presented in Figure 3.1 - therefore increases information and ultimately trust. While in the study at hand this effect is not as well identified as the effect of mobile phone use, the finding relates very closely to (Labonne and Chase, 2010) who find that road constructions led to more generalized trust in rural Philippine villages due to reduced costs of interaction between inhabitants of neighboring villages. The positive effect living in vicinity of a road on trust therefore supports our argumentation that infrastructure which facilitates communication can lead to more generalized trust. The kind of people with whom communication is enabled through the infrastructure however, has implications for the group, towards which trust is increased: proximity to roads might increase trust towards people that are not extremely near (e.g. fellow villagers), but that are also not too far away (e.g. county capital). The mobile phone technology on the other hand does not statistically significantly affect generalized trust towards people that are geographically close (e.g. fellow villager and people from a neighboring village), but does affect trust towards people that would be difficult to reach in the absence of mobile phones.

We conduct robustness checks with regard to the mobile phone use specification. In Table B4 and Table B5 in the Appendix, we show results if only daily mobile phone use is considered (Table B4) and if rare mobile phone use is considered (Table B5). As expected, results do not change much.

Table 3.3 shows the regression results, if we consider the share expected to be returned as the dependent variable rather than the share sent in the trust game. Columns (5) and (6) show that the mobile phone use variable is again positive and statistically significant for the group that is paired with city dwellers. This means that mobile phone users in this 
Table 3.2: Determinants of the amount sent in the trust game by the trustor

\begin{tabular}{|c|c|c|c|c|c|c|}
\hline & \multicolumn{2}{|c|}{$\begin{array}{l}\text { Trust towards } \\
\text { fellow villagers }\end{array}$} & \multicolumn{2}{|c|}{$\begin{array}{c}\text { Trust towards } \\
\text { people from a } \\
\text { neighboring village }\end{array}$} & \multicolumn{2}{|c|}{$\begin{array}{l}\text { Trust towards city } \\
\text { dwellers from the } \\
\text { county capital }\end{array}$} \\
\hline & $\begin{array}{l}\text { CIR } \\
(1)\end{array}$ & $\begin{array}{l}\text { OLS } \\
(2)\end{array}$ & $\begin{array}{l}\text { CIR } \\
(3)\end{array}$ & $\begin{array}{l}\text { OLS } \\
(4)\end{array}$ & $\begin{array}{l}\text { CIR } \\
(5)\end{array}$ & $\begin{array}{l}\text { OLS } \\
(6)\end{array}$ \\
\hline Mobile phone use $[1=$ yes $]$ & $\begin{array}{l}-1.448 \\
(3.448)\end{array}$ & $\begin{array}{l}-1.436 \\
(3.573)\end{array}$ & $\begin{array}{c}3.550 \\
(4.606)\end{array}$ & $\begin{array}{c}3.491 \\
(4.812)\end{array}$ & $\begin{array}{c}13.823^{* *} \\
(5.825)\end{array}$ & $\begin{array}{r}12.817^{* *} \\
(5.804)\end{array}$ \\
\hline Age [years] & $\begin{array}{c}0.053 \\
(0.117)\end{array}$ & $\begin{array}{c}0.053 \\
(0.122)\end{array}$ & $\begin{array}{c}0.057 \\
(0.091)\end{array}$ & $\begin{array}{c}0.060 \\
(0.096)\end{array}$ & $\begin{array}{l}-0.029 \\
(0.141)\end{array}$ & $\begin{array}{l}-0.032 \\
(0.138)\end{array}$ \\
\hline $\begin{array}{l}\text { Constant relative risk av- } \\
\text { ersion coefficient }(\mathrm{CRRA})^{\mathrm{a}}\end{array}$ & $\begin{array}{c}-1.610^{* *} \\
(0.698)\end{array}$ & $\begin{array}{c}-1.610^{* *} \\
(0.723)\end{array}$ & $\begin{array}{l}-0.094 \\
(0.699)\end{array}$ & $\begin{array}{l}-0.100 \\
(0.731)\end{array}$ & $\begin{array}{l}-1.049 \\
(1.374)\end{array}$ & $\begin{array}{c}-0.994 \\
(1.363)\end{array}$ \\
\hline $\begin{array}{l}\text { Distance to next road } \\
\text { [log of walking minutes] }\end{array}$ & $\begin{array}{l}-1.920 \\
(1.227)\end{array}$ & $\begin{array}{l}-1.884 \\
(1.259)\end{array}$ & $\begin{array}{c}-2.862^{* * *} \\
(1.006)\end{array}$ & $\begin{array}{c}-2.875^{* *} \\
(1.052)\end{array}$ & $\begin{array}{c}1.398 \\
(1.229)\end{array}$ & $\begin{array}{l}1.403 \\
(1.221)\end{array}$ \\
\hline Education [years] & $\begin{array}{c}0.929 * * \\
(0.395)\end{array}$ & $\begin{array}{c}0.923 * * \\
(0.411)\end{array}$ & $\begin{array}{c}0.030 \\
(0.861)\end{array}$ & $\begin{array}{c}0.032 \\
(0.903)\end{array}$ & $\begin{array}{l}-0.380 \\
(0.580)\end{array}$ & $\begin{array}{l}-0.354 \\
(0.562)\end{array}$ \\
\hline $\begin{array}{l}\text { Having family in neigh- } \\
\text { boring villagers }[1=\text { yes }]\end{array}$ & & & $\begin{array}{c}1.972 \\
(5.896)\end{array}$ & $\begin{array}{c}1.982 \\
(6.132)\end{array}$ & & \\
\hline $\begin{array}{l}\text { Having family in the } \\
\text { county capital }[1=\text { yes }]\end{array}$ & & & & & $\begin{array}{c}2.510 \\
(3.170)\end{array}$ & $\begin{array}{c}2.381 \\
(3.121)\end{array}$ \\
\hline Female & $\begin{array}{c}0.431 \\
(3.680)\end{array}$ & $\begin{array}{c}0.486 \\
(3.805)\end{array}$ & $\begin{array}{c}3.696 \\
(3.496)\end{array}$ & $\begin{array}{c}3.677 \\
(3.671)\end{array}$ & $\begin{array}{c}-1.443 \\
(1.913)\end{array}$ & $\begin{array}{l}-1.424 \\
(1.908)\end{array}$ \\
\hline Herd size $[\mathrm{TLU}]$ & $\begin{array}{l}-0.013 \\
(0.051)\end{array}$ & $\begin{array}{l}-0.014 \\
(0.053)\end{array}$ & $\begin{array}{c}0.020 \\
(0.058)\end{array}$ & $\begin{array}{c}0.020 \\
(0.060)\end{array}$ & $\begin{array}{c}0.049 \\
(0.086)\end{array}$ & $\begin{array}{c}0.046 \\
(0.085)\end{array}$ \\
\hline Household size & $\begin{array}{c}1.212^{* * *} \\
(0.377)\end{array}$ & $\begin{array}{c}1.214^{* * * *} \\
(0.393)\end{array}$ & $\begin{array}{l}-0.158 \\
(0.540)\end{array}$ & $\begin{array}{l}-0.154 \\
(0.570)\end{array}$ & $\begin{array}{c}0.077 \\
(0.288)\end{array}$ & $\begin{array}{c}0.059 \\
(0.298)\end{array}$ \\
\hline Income [logged KSh] & $\begin{array}{c}-0.352^{*} \\
(0.194)\end{array}$ & $\begin{array}{c}-0.347 \\
(0.203)\end{array}$ & $\begin{array}{c}-0.494 \\
(0.590)\end{array}$ & $\begin{array}{c}-0.502 \\
(0.623)\end{array}$ & $\begin{array}{c}-0.542^{* *} \\
(0.249)\end{array}$ & $\begin{array}{c}-0.504^{*} \\
(0.259)\end{array}$ \\
\hline Village size [100 people] & $\begin{array}{c}-0.909^{* *} \\
(0.425)\end{array}$ & $\begin{array}{l}-0.903^{*} \\
(0.441)\end{array}$ & $\begin{array}{c}0.283 \\
(0.317)\end{array}$ & $\begin{array}{c}0.287 \\
(0.336)\end{array}$ & $\begin{array}{c}0.642 \\
(0.458)\end{array}$ & $\begin{array}{c}0.597 \\
(0.458)\end{array}$ \\
\hline $\begin{array}{l}\text { Years of owning a } \\
\text { mobile phone }\end{array}$ & $\begin{array}{l}0.648^{*} \\
(0.389)\end{array}$ & $\begin{array}{c}0.646 \\
(0.406)\end{array}$ & $\begin{array}{c}0.673^{* *} \\
(0.336)\end{array}$ & $\begin{array}{l}0.668^{*} \\
(0.355)\end{array}$ & $\begin{array}{l}-1.513^{*} \\
(0.778)\end{array}$ & $\begin{array}{l}-1.376^{*} \\
(0.765)\end{array}$ \\
\hline Constant & $\begin{array}{c}35.484^{* * *} \\
(7.727)\end{array}$ & $\begin{array}{c}35.411^{* * *} \\
(8.062)\end{array}$ & $\begin{array}{c}32.841^{* * *} \\
(9.760)\end{array}$ & $\begin{array}{c}32.900 * * * \\
(10.204)\end{array}$ & $\begin{array}{c}16.229 \\
(11.059)\end{array}$ & $\begin{array}{c}17.351 \\
(10.698)\end{array}$ \\
\hline $\ln (\sigma)$ & 2.697 & & 2.689 & & 2.785 & \\
\hline $\begin{array}{l}R^{2} \\
\text { Observations: }\end{array}$ & & 0.146 & & 0.149 & & 0.122 \\
\hline total & 142 & 142 & 120 & 120 & 132 & 132 \\
\hline left-censored & 7 & & 6 & & 21 & \\
\hline right-censored & 1 & & 0 & & 0 & \\
\hline interval & 134 & & 114 & & 111 & \\
\hline
\end{tabular}

Notes: Standard errors shown in parentheses are robust and clustered at the village level. CIR $=$ Censored Interval Regression. CRRA $=$ Constant relative risk aversion coefficient. KSh $=$ Kenyan Shilling. OLS $=$ Ordinary Least Squares. TLU $=$ Tropical Livestock Unit. ${ }^{* *} p<0.01,{ }^{* *} p<0.05,{ }^{* *} p<0.1$.

a Elicitation with an incentivized Eckel and Grossman (2002) task (see Table A3). Higher values imply higher risk aversion.

Source: Own elaboration. 
group send more on average and - independent of the amount sent - also expect higher returns compared to non-users. We therefore confirm both Hypothesis 1 and Hypothesis 2. Other than mobile phone use, one of the few variables that is consistently statistically significant in both Table 3.2 and Table 3.3 is the years of owning a mobile phone for the group of people paired with a city dweller. This effect is however negative. This could suggest that positive effect of mobile phone use may be driven by recent users; more experienced users have lower net trust gains. As suggested by case studies of mobile phone use in Eastern Africa, information transmitted via phones can also be misleading or deceiving (Molony, 2006; Butt, 2015; Debsu et al., 2016; Djohy et al., 2017). Too many negative experiences with the mobile phone could then induce a reduction of trust. Our finding puts a question mark to the sustainability of the positive effect of mobile phone use on trust towards city dwellers. If we assume a linear relationship between the years of ownership and trust, back-of-the-envelope calculation based on the regression coefficient estimates of column (6) in Table 3.2 suggest that a mobile phone user with ten years of ownership is projected to send less in the trust game than someone who neither owns nor uses a mobile phone. Coefficient estimates of column (5) in Table 3.3 suggest that a negative net effect on the expected return could already occur after the sixth year of mobile phone ownership. Nevertheless, since $87 \%$ of the respondent in the sample own a mobile phone for five years or less, and $92 \%$ own a phone for nine years or less, such negative net effects occur rarely. It is noteworthy that neither family ties, nor friendship ties have any statistically significant effect on the amount sent or the expected return concerning people from a neighboring village or towards city dwellers.

\subsection{Conclusion}

Mobile phones bear an enormous potential for economic development in low-income countries as well as for several household welfare domains. In this paper, we analyzed if mobile phone use can increase social trust among communities of semi-nomadic pastoralists in Northern Kenya. Trust-based relationships are particularly important in this region (Mahmoud, 2008; Roba et al., 2018). More specifically, we analyzed the effect of mobile phone use on trust towards three distinct groups: trust towards fellow villagers, trust towards people from a neighboring village, and trust towards city dwellers. Since trust is assumed to be a prerequisite for efficient economic exchange, higher levels of trust can help expanding economic activities beyond already existing familiar relations. Increases in trust towards people from any of these three groups can therefore be particularly valuable.

Using an incentivized trust game, we find that mobile phone use increases trust towards city dwellers from the county capital. We do not find that respondents' mobile phone use however affects their trust towards people from either their own village or neighboring villages. We suspect that this heterogeneous effect is mostly driven by the concept that mobile phones increase communication especially between people that are spatially distant 
Table 3.3: Determinants of the share expected to be returned by Player B

\begin{tabular}{|c|c|c|c|c|c|c|}
\hline & \multicolumn{2}{|c|}{$\begin{array}{l}\text { Trust towards } \\
\text { fellow villagers }\end{array}$} & \multicolumn{2}{|c|}{$\begin{array}{c}\text { Trust towards } \\
\text { people from a } \\
\text { neighboring village }\end{array}$} & \multicolumn{2}{|c|}{$\begin{array}{l}\text { Trust towards city } \\
\text { dwellers from the } \\
\text { county capital }\end{array}$} \\
\hline & $\begin{array}{l}\text { OLS } \\
(1)\end{array}$ & $\begin{array}{l}\text { Tobit } \\
(2)\end{array}$ & $\begin{array}{l}\text { OLS } \\
(3)\end{array}$ & $\begin{array}{l}\text { Tobit } \\
(4)\end{array}$ & $\begin{array}{l}\text { OLS } \\
(5)\end{array}$ & $\begin{array}{l}\text { Tobit } \\
(6)\end{array}$ \\
\hline Mobile phone user $[1=$ yes $]$ & $\begin{array}{c}2.838 \\
(5.626)\end{array}$ & $\begin{array}{c}2.788 \\
(6.720)\end{array}$ & $\begin{array}{c}4.384 \\
(5.928)\end{array}$ & $\begin{array}{c}4.652 \\
(6.418)\end{array}$ & $\begin{array}{l}10.290^{*} \\
(5.828)\end{array}$ & $\begin{array}{c}16.474^{* *} \\
(7.586)\end{array}$ \\
\hline Age [years] & $\begin{array}{c}0.151 \\
(0.223)\end{array}$ & $\begin{array}{c}0.149 \\
(0.254)\end{array}$ & $\begin{array}{l}-0.311^{*} \\
(0.176)\end{array}$ & $\begin{array}{l}-0.347^{*} \\
(0.205)\end{array}$ & $\begin{array}{l}-0.133 \\
(0.163)\end{array}$ & $\begin{array}{l}-0.152 \\
(0.206)\end{array}$ \\
\hline $\begin{array}{l}\text { Constant relative risk av- } \\
\text { ersion coefficient (CRRA) }\end{array}$ & $\begin{array}{l}1.689^{*} \\
(0.921)\end{array}$ & $\begin{array}{l}1.993^{*} \\
(1.038)\end{array}$ & $\begin{array}{l}-0.579 \\
(1.231)\end{array}$ & $\begin{array}{l}-0.738 \\
(1.315)\end{array}$ & $\begin{array}{l}-1.011 \\
(1.807)\end{array}$ & $\begin{array}{l}-1.234 \\
(2.326)\end{array}$ \\
\hline $\begin{array}{l}\text { Distance to next road } \\
\text { [log of walking minutes] }\end{array}$ & $\begin{array}{l}-1.313 \\
(1.986)\end{array}$ & $\begin{array}{l}-1.931 \\
(2.358)\end{array}$ & $\begin{array}{l}-0.585 \\
(1.525)\end{array}$ & $\begin{array}{l}-0.325 \\
(1.599)\end{array}$ & $\begin{array}{c}1.947 \\
(1.898)\end{array}$ & $\begin{array}{l}2.563 \\
(2.261)\end{array}$ \\
\hline Education [years] & $\begin{array}{l}-0.387 \\
(0.831)\end{array}$ & $\begin{array}{l}-0.398 \\
(0.957)\end{array}$ & $\begin{array}{l}-1.819^{*} \\
(0.919)\end{array}$ & $\begin{array}{c}-2.061^{* *} \\
(0.977)\end{array}$ & $\begin{array}{l}-0.515 \\
(0.931)\end{array}$ & $\begin{array}{l}-0.750 \\
(1.129)\end{array}$ \\
\hline $\begin{array}{l}\text { Having family in neigh- } \\
\text { boring villagers }[1=\text { yes }]\end{array}$ & & & $\begin{array}{l}-7.430 \\
(8.981)\end{array}$ & $\begin{array}{c}-7.634 \\
(10.280)\end{array}$ & & \\
\hline $\begin{array}{l}\text { Having family in the } \\
\text { county capital }[1=\text { yes }]\end{array}$ & & & & & $\begin{array}{l}-1.114 \\
(5.688)\end{array}$ & $\begin{array}{l}-1.787 \\
(7.292)\end{array}$ \\
\hline Female & $\begin{array}{c}0.058 \\
(5.157)\end{array}$ & $\begin{array}{c}0.388 \\
(5.808)\end{array}$ & $\begin{array}{l}-1.582 \\
(7.689)\end{array}$ & $\begin{array}{l}-2.322 \\
(8.475)\end{array}$ & $\begin{array}{l}-1.958 \\
(4.003)\end{array}$ & $\begin{array}{l}-1.643 \\
(5.225)\end{array}$ \\
\hline Herd size $[\mathrm{TLU}]$ & $\begin{array}{l}-0.031 \\
(0.070)\end{array}$ & $\begin{array}{l}-0.044 \\
(0.081)\end{array}$ & $\begin{array}{l}-0.019 \\
(0.067)\end{array}$ & $\begin{array}{l}-0.021 \\
(0.081)\end{array}$ & $\begin{array}{c}0.012 \\
(0.100)\end{array}$ & $\begin{array}{c}0.033 \\
(0.130)\end{array}$ \\
\hline Household size & $\begin{array}{l}-0.046 \\
(0.477)\end{array}$ & $\begin{array}{c}0.025 \\
(0.532)\end{array}$ & $\begin{array}{c}0.776 \\
(0.603)\end{array}$ & $\begin{array}{c}0.777 \\
(0.735)\end{array}$ & $\begin{array}{c}0.777 \\
(0.549)\end{array}$ & $\begin{array}{c}0.948 \\
(0.655)\end{array}$ \\
\hline Income [logged KSh] & $\begin{array}{c}1.007 \\
(0.629)\end{array}$ & $\begin{array}{l}1.187^{*} \\
(0.713)\end{array}$ & $\begin{array}{c}0.141 \\
(0.401)\end{array}$ & $\begin{array}{c}0.198 \\
(0.438)\end{array}$ & $\begin{array}{l}-0.785^{*} \\
(0.376)\end{array}$ & $\begin{array}{l}-0.913^{*} \\
(0.484)\end{array}$ \\
\hline Village size [100 people] & $\begin{array}{l}-0.283 \\
(0.389)\end{array}$ & $\begin{array}{l}-0.313 \\
(0.478)\end{array}$ & $\begin{array}{c}-1.265^{*} \\
(0.664)\end{array}$ & $\begin{array}{l}-1.345^{*} \\
(0.796)\end{array}$ & $\begin{array}{c}2.149 * * * \\
(0.641)\end{array}$ & $\begin{array}{c}2.800^{* * *} \\
(0.940)\end{array}$ \\
\hline $\begin{array}{l}\text { Years of owning a } \\
\text { mobile phone }\end{array}$ & $\begin{array}{c}0.469 \\
(0.630)\end{array}$ & $\begin{array}{c}0.589 \\
(0.772)\end{array}$ & $\begin{array}{c}0.416 \\
(0.483)\end{array}$ & $\begin{array}{c}0.536 \\
(0.518)\end{array}$ & $\begin{array}{l}-1.721^{*} \\
(0.911)\end{array}$ & $\begin{array}{c}-2.649^{* *} \\
(1.185)\end{array}$ \\
\hline Constant & $\begin{array}{c}40.389^{* * *} \\
(13.612)\end{array}$ & $\begin{array}{c}40.013^{* * *} \\
(14.536)\end{array}$ & $\begin{array}{c}73.044^{* * *} \\
(15.952)\end{array}$ & $\begin{array}{c}74.432^{* * *} \\
(17.780)\end{array}$ & $\begin{array}{l}33.838^{* *} \\
(14.407)\end{array}$ & $\begin{array}{c}24.804 \\
(18.972)\end{array}$ \\
\hline Observations & 142 & 142 & 120 & 120 & 132 & 132 \\
\hline $\begin{array}{l}R^{2} \\
\text { Pseudo } R^{2}\end{array}$ & 0.051 & 0.006 & 0.127 & 0.014 & 0.137 & 0.019 \\
\hline
\end{tabular}

Notes: : Standard errors shown in parentheses are robust and clustered at the village level. CRRA $=$ Constant relative risk aversion coefficient. KSh $=$ Kenyan Shilling. OLS $=$ Ordinary Least Squares. TLU $=$ Tropical Livestock Unit. ${ }^{* * *} p<0.01,{ }^{* *} p<0.05,{ }^{* *} p<0.1$.

a Elicitation with an incentivized Eckel and Grossman (2002) task (see Table A3). Higher values imply higher risk aversion.

Source: Own elaboration. 
from each other.

The size of the effect that mobile phone use has on trust towards city dwellers from the county capital is substantial (approximately 0.6 standard deviations) and robust to several specifications of the mobile phone use and trust variables. Given that trust towards people that live farther away is usually lower compared to people that live nearer (Karlan, 2005; Etang, 2010; Etang et al., 2011; Parlasca et al., 2019), such increases can be particularly valuable for people living in remote areas of sub-Saharan Africa. This finding therefore adds to the growing evidence that mobile phones are particularly useful in this context (Debsu et al., 2016; Parlasca et al., 2020). The positive effect of mobile phone use on trust towards city dwellers could enable pastoralists to engage in or increase efficiency of existing economic interactions with city dwellers such as selling livestock, petty trading, or purchasing goods from urban markets. While past research has emphasized the need for trust among actors in Northern Kenya's livestock sector (Roba et al., 2017, 2018), we encourage further research to confirm whether increases in trust among this population actually translate into higher welfare. Also beyond the mechanism of enabling economic interaction, higher levels of trust towards city dwellers might facilitate the implementation of development project that target remote Turkana villages. Well-intentioned projects can struggle with low acceptance by the targeted pastoralist population, if trust towards the implementing parties is low (see for example Rasmussen et al. (2015)). With higher levels of trust towards people from the city, such projects might become more successful.

However, we also find a robust negative effect of the years of mobile phone ownership on trust towards city dwellers. While we show that the short term effect of mobile phone use on trust towards city dwellers can be positive, the negative effect of the duration of mobile phone ownership could imply that positive effects diminish, disappear, or even turn negative in the middle to long run. Further research is therefore required to test if the positive effects of mobile phone use on trust are de facto sustainable. For this reason, we only derive cautious policy implications from this study. Mobile phones have shown to positively affect numerous important household welfare dimensions, and with the positive effect of mobile phone use on trust towards city dwellers that we find in this study, we generally agree with past studies that endorse policies that i) further enhance network coverage in rural areas and ii) maintain costs of communication low enough to keep mobile phone use affordable also for poor and marginalized households (Parlasca et al., 2020). However, since this is the first study to quantify the effects of mobile phone use on trust, we are hesitant in promoting mobile phones as a general tool to enhance trust until more insights of such effects have been gathered also for communities that have longer experience with the mobile phone technology. 


\title{
Chapter 4
}

\section{Can Mobile Phones Improve Nutrition among Pastoral Communities? Panel Data Evidence from Northern Kenya}

\begin{abstract}
The digital revolution and the ongoing dissemination of mobile phones carry several prospects for smallholder farmers in sub-Saharan Africa. Food insecurity remains a major issue among African smallholders. Mobile phones could potentially facilitate access to food markets and thus improve food security and nutrition, but research on such types of effects remains scarce. In this study we analyze whether mobile phones improve dietary quality of pastoralists in Northern Kenya. We use six rounds of household panel data covering the period between 2009 and 2015. During this period, mobile phone ownership in the sample increased from less than $30 \%$ to more than $70 \%$. Regression models with household fixed effects allow robust estimation while reducing potential issues of unobserved heterogeneity. The estimates show that mobile phone adoption has increased dietary diversity. The effect size increases with the frequency of mobile phone use. We also examine the underlying mechanisms. Mobile phones improve dietary diversity mainly through better access to purchased foods. These results encourage the promotion of mobile phone technologies as a valuable tool for nutritional improvements, especially in rural settings with poor access to food markets.
\end{abstract}

Keywords: mobile phones, dietary diversity, nutrition, pastoralism, Africa, Northern Kenya.

JEL Codes: I15, O12, O33.

This chapter is co-authored by Martin C. Parlasca (MP), Oliver Mußhoff (OM), and Matin Qaim (MQ). A slightly shortened version of this chapter has been published in Agricultural Economics. Data and code have been made available at https://doi.org/10.1111/agec.12566. The contributions of each author are as follows: MP, OM, and MQ developed the research design. MP analyzed and interpreted the data. OM and MQ assisted in the analyses and interpretation of the results. MP wrote the paper. OM and MQ provided continuous feedback and comments during writing. 


\subsection{Introduction}

Mobile phones are a promising tool to improve the livelihoods of smallholder farmers in developing countries (Aker and Ksoll, 2016; Nakasone et al., 2014; Aker and Mbiti, 2010). Following their rapid diffusion in sub-Saharan Africa over the last two decades, research has shown that mobile phones can positively influence a wide array of economic dimensions including market participation (Zanello, 2012), agricultural productivity (Lio and Liu, 2006), or livestock herding (Butt, 2015). Much less is known about the effects of mobile phones on different dimensions of household welfare.

Adequate nutrition is one of the welfare dimensions that deserve particular attention. Nutrition is one of the cornerstones of the Sustainable Development Goals and regarded as "infrastructure for economic development" (Development Initiatives, 2017, p. 12). Nutrition can enhance equality and inclusion and improve food security, peace, and stability (Development Initiatives, 2017). Despite the importance of mobile phones as a widely used information and communications technology (ICT) in Africa, and malnutrition as a major issue in that region (Akombi et al., 2017), empirical evidence that links these two aspects is scarce. Up till now, most studies that have addressed potential nutrition effects of mobile phones remain anecdotal; other studies suffer from limited data for robust impact evaluation. First indications for a potentially positive relationship between mobile phones and nutrition were presented by Beuermann et al. (2012), who found that regional mobile phone coverage can be associated with increased food expenditures in rural Peru. More recently, Sekabira and Qaim (2017) suggested that mobile phones are associated with improved diets in coffee-producing farm households in Uganda using two rounds of a panel survey. Comprehensive analysis of the effects of mobile phones on diets and nutrition over a longer timespan does not exist. This study aims at addressing this research gap.

Building on comprehensive panel data from Northern Kenya, covering the years 2009 to 2015 with six survey rounds, the objective of this study is to expand previous approaches and gain further insights into the links between mobile phones and nutrition. The study area in Northern Kenya belongs to the country's arid and semi-arid lands (ASAL) and is a particularly marginalized region (Commission on Revenue Allocation, 2012). Food insecurity and malnutrition still constitute relevant threats (Bauer and Mburu, 2017; Upton et al., 2016; Grace et al., 2014).

The pastoral setting in which the relationship between mobile phones and nutrition is analyzed here presents another important novelty addressed in this study. The potential of ICTs to increase food security is context-dependent (Nakasone and Torero, 2016), and pastoral communities exhibit several characteristics that are different from non-pastoral populations. Pastoralists are oftentimes not fully sedentary; they are generally less integrated in socioeconomic services and live farther away from food markets (Opiyo et al., 2014). To survive under harsh climate conditions, many pastoralist communities have adopted complex livelihood strategies and developed strong social bonds (Davies and Ben- 
nett, 2007). Malnutrition is often widespread in pastoral communities (Bauer and Mburu, 2017). The potential implications of mobile phones in a pastoral setting are therefore particularly interesting. We are not aware of previous studies that have analyzed links between mobile phones and nutrition in a pastoralist environment.

The remainder of this article is organized as follows. Section 4.2 reviews the relevant literature and develops concrete research hypotheses. Section 4.3 explains the data and the measurement of key variables. Section 4.4 describes the econometric approach to test the hypotheses. Results are presented and discussed in section 4.5, and section 4.6 concludes.

\subsection{Conceptual Framework}

Malnutrition is a global threat. About 2 billion people lack important micronutrients such as iron or vitamin A (Development Initiatives, 2018). Alongside individual health problems that can be triggered by malnutrition, the widespread nature of this problem can cause high economic and humanitarian costs for entire regions and countries. Dietary quality and diversity, which look beyond pure calorie consumption and account for nutritional aspects, are key factors to measure and improve nutrition in a comprehensive (Sibhatu and Qaim, 2018a).

Small-scale farmers in developing countries usually draw a substantial share of their food consumption from own production. A higher diversity in self-produced foods can therefore be associated with higher dietary diversity (Koppmair et al., 2017; Snapp and Fisher, 2015; Jones et al., 2014). However, recent research has shown that the association between farm production diversity and dietary diversity is often relatively small and that markets are more important for many smallholders to access food diversity (Sibhatu and Qaim, 2018a; Hirvonen and Hoddinott, 2017; Koppmair et al., 2017). This is especially true in very dry environments - such as Kenya's ASAL - where food crop production is limited (Mburu et al., 2017). Local communities in Kenya's ASAL mainly depend on pastoralism for food and income generation, so access to food markets is particularly important to increase dietary diversity. Unfortunately, market access and market participation are constrained due to long distances and poor road conditions (Commission on Revenue Allocation, 2013). Opiyo et al. (2014) found that $40 \%$ of the households in Northwestern Kenya live more than ten kilometers away from the next market. On average, households in Marsabit County need more than three hours to reach a market (Mude et al., 2012). In Samburu County, the average distance to the next urban market is even around 40 kilometers (Ng'ang'a et al., 2016). Hirvonen and Hoddinott (2017) suggested that - under typical infrastructure conditions in East Africa - a three kilometer distance may be a threshold for using markets on a daily basis.

However, geographic remoteness can also be a strategic decision of pastoral households. Less concentrated areas offer herders mobility and the possibility to move opportunistically in order to access more favorable grazing areas (Little et al., 2008). Physical closeness to 
and integration in markets and other forms of town-based services come with the drawback of reduced mobility which might outweigh the benefits of market access for certain households. Welfare maximizing behavior of pastoralists can therefore be heterogeneous (Little et al., 2008).

The difficulties in growing food and limited access to markets for food purchases constitute serious constraints for increasing dietary diversity in pastoral communities. Droughts present another, more seasonal threat to diets and nutrition. Lacking diversified livelihood options to fall back on during extreme weather events, pastoralists are particularly vulnerable to climate-induced risks (Mburu et al., 2017; Vigan et al., 2017; Upton et al., 2016). Reduction of food consumption is a problematic but widely practiced coping strategy among pastoralists during droughts (Opiyo et al., 2015; Silvestri et al., 2012). Adverse effects on both food quantity and diversity are the consequence.

How can mobile phones potentially mitigate these constraints and thus help improve household diets and nutrition? We identify three possible mechanisms. First, mobile phones can improve household income (Sekabira and Qaim, 2017; ?; Muto and Yamano, 2009). Income effects can result from better access to information, better access to production inputs and technologies, better access to output markets, and better prices (Debsu et al., 2016; Butt, 2015; Zanello, 2012; Aker and Mbiti, 2010). Higher incomes will likely result in higher food expenditures and improvements in household diets.

Second, mobile phones can present a valuable tool to smoothen income during shocks. The mobile money system M-Pesa, which offers a fast and easy way to send and receive money through mobile phones, is very widely used in Kenya (Kikulwe et al., 2014). Jack and Suri (2014) show that family members send remittances to each other using mobile money, thus sharing risks and reducing the need for reduced consumption during shocks.

Third, especially in the pastoral context mobile phones can increase nutrition through reducing transaction costs for everyday life activities. Sife et al. (2010) found that mobile phones help increase the efficiency of daily affairs, especially when geographically distant people interact with each other. As mentioned, better access to information and markets may improve income, but also beyond the income mechanism lower transaction costs may positively affect access to food quantity and variety. For instance, mobile phones can improve knowledge about the times and places of food aid distribution, which is not uncommon especially during drought periods. Mobile phones and mobile money can also facilitate coordination and collective action among members of pastoral communities for regular food purchases. Since the next market in the study area is on average more than three hours away (Mude et al., 2012), arrangements of reciprocal assistance and reachability through a mobile phone bear significant advantages for rural households. Better coordination allows more frequent market transactions without increasing transport costs for the individual. More frequent transactions may have particularly positive effects for the consumption of fresh and perishable foods, which are important for micronutrient supply. 
However, ownership and use of mobile phones is not costless. In our study, households spend on average 3,226 Kenyan shillings (KSh) (approximately USD32) on buying a mobile phone, which is equivalent to $150 \%$ of mean monthly per capita income. Consequently mobile phones are often shared between households. About one-third of the Kenyans interviewed in the FinAccess survey in 2009 mentioned sharing mobile phones with friends and relatives (Aker and Mbiti, 2010). A considerable degree of phone sharing was recently also observed in pastoral contexts of East Africa (Debsu et al., 2016; Butt, 2015). Looking at mobile phone ownership alone may therefore not fully capture the effects of mobile phone use (Tadesse and Bahiigwa, 2015; Zanello, 2012). In our analysis, we differentiate between the effects of mobile phone ownership and mobile phone use.

Given the mechanisms discussed, we expect that mobile phones contribute to improved dietary diversity and nutrition among pastoral communities in Kenya. This is analyzed by testing the following concrete hypotheses:

H1: Ownership of mobile phones has a positive effect on household nutrition.

H2: Using mobile phones has a positive effect on household nutrition.

Easier access to purchased food is one of the key arguments why we expect mobile phones to increase dietary diversity. This relationship has recently experienced increasing empirical support (Hirvonen and Hoddinott, 2017; Koppmair et al., 2017; Luckett et al., 2015). To shed light on this particular mechanism, we also test the following hypotheses:

H3: Ownership of mobile phones improves access to food purchases.

H4: Using a mobile phone improves access to food purchases.

\subsection{Data and Measurement of Key Variables}

\subsubsection{Data and Sampling}

This study uses panel data collected in Kenya's Marsabit County by the Index Based Livestock Insurance Project (IBLI). The data cover the years 2009, 2010, 2011, 2012, 2013, and 2015. In the first step of sampling, 16 out of 47 sub-locations in Marsabit County were chosen. These sub-locations were purposively selected to capture variability in various dimensions such as livestock production systems, agro-ecologies, market accessibility, and ethnic composition. The 16 sub-locations belong to five larger divisions. Within each sublocation, all households were categorized in three groups based on livestock holding size. Respondents were equally drawn from these three groups. Enumerators usually waited up 
to three days for households during data collection. In case sampled respondents moved away for a longer time period and could not be interviewed again, replacements were drawn from the same sub-location and herd size class. The average attrition rate is $3.4 \%$ per round. Some observations were dropped due to missing data of key variables. The final sample used in this study consists of 5,506 observations. The number of households that participated in all six survey rounds is 752. A more detailed description of the dataincluding sampling design, survey implementation, and attrition - can be found in Ikegami and Sheahan (2017).

\subsubsection{Measurements of Key Variables}

We use the Household Dietary Diversity Score (HDDS) to measure dietary diversity at the household level. The HDDS counts the number of food groups consumed by the household over a specific period of time, usually 24 hours (Swindale and Bilinksy, 2006), but longer recall periods have also become common in the recent literature (Sibhatu and Qaim, 2018a; Upton et al., 2016; Arimond et al., 2010). The HDDS is a common tool to assess food security and access to calories. It is not a very precise indicator of dietary quality, as it measures the diversity of the food consumed at the household level and therefore ignores issues of intra-household food distribution. More precise indicators of dietary quality, such as individual dietary diversity scores of particular target groups, would require individual-level dietary data, which we do not have in the data set. Recent studies in Kenya and other geographical contexts showed that household-level food consumption indicators are positively and significantly correlated with individual dietary diversity scores and micronutrient intakes of male and female adults and children (Fongar et al., 2019; Sibhatu and Qaim, 2018a; Koppmair et al., 2017). In other words, the HDDS can be used as a proxy of dietary quality in the absence of individual-level data, even though the results should be interpreted with some caution.

The data used in this study are based on a seven-day food consumption recall. The twelve food groups usually included in the HDDS are: cereals; white roots and tubers; legumes, nuts and seeds; vegetables; fruits; meat; eggs; fish and seafood; milk and milk products; sweets and sugars; oils and fats; and spices, condiments, and beverages (Swindale and Bilinksy, 2006). The number of food items in the survey's last round conducted in 2015 is smaller than in the previous rounds, since some foods that were previously disaggregated were combined. To keep consistency over all time periods we slightly alter the items included in two of the usual twelve food groups for the HDDS and do so consistently for all survey rounds. Instead of having one group for meat, poultry and offal, and one group for fish and seafood, we have one group for goat and sheep meat and one group for fish, seafood, offal and all other meat. Goat and sheep meat are the most-commonly consumed types of meat in the study area, while fish, offal, camel, donkey, or bush meat are eaten less frequently. The correlation of the HDDS using the original twelve food groups as 
defined by (Swindale and Bilinksy, 2006) and our modified version of the HDDS for the first five survey rounds is 0.995 . This close correlation suggests that our modification is very unlikely to reduce the validity of the indicator.

As an additional nutrition indicator we use a variation of the HDDS that does not include the three calorie-rich but micronutrient-poor food groups sweets and sugars, oils and fats, and spices, condiments, and beverages, as used for example by Sibhatu et al. (2015) and Arimond et al. (2010). This alternative indicator may be a better proxy of micronutrient consumption, but in the pastoral context of Northern Kenya calorie deficiency is also a widespread problem. Hence, both indicators are of interest here. In the following analysis, we refer to the two indicators as HDDS12 and HDDS9 to clarify the number of food groups included in each case.

Data for the HDDS were always collected in October or November, which is when the rainy season typically starts in Marsabit (Upton et al., 2016). The timespan of data collection never overlapped with Ramadan. Collecting data during the same season ensures comparability of HDDS over the survey rounds. However, one should be cautious not to over-interpret the HDDS as an indicator of food security during all periods of the year, because possible seasonal differences in food consumption are not captured. We are also interested in the main sources of food for sample households. We differentiate between selfproduction and purchases. This distinction is based on our expectation that income effects are not the only mechanism through which mobile phones can influence household dietary diversity. As discussed above, mobile phones facilitate communication and coordination and could thus improve access to food markets also without any income effects. For the HDDS calculations, we categorize a food group as self-produced (purchased) when the household consumed at least one food item belonging to this group from own production (purchase).

We consider two different outcome variables concerning the food source. First, we measure the relevance of self-produced foods by taking the sum over all self-produced food groups that the household consumed in the last seven days. This sum ranges from zero, if the household did not obtain any of the foods consumed from self-production, to twelve, if the household produced and consumed all twelve food groups. The sum of self-produced food groups is consequently always smaller or equal to the household's HDDS12. Second, we measure the relevance of purchased foods as the sum over all food groups consumed in the last seven days stemming from purchase. This second variable can also range from zero to twelve.

The main treatment variables in this study are mobile phone ownership and use. The survey contained questions about the number of mobile phones owned by each household and the frequency of mobile phone use. The frequency was captured as "never", "once a year", "once a month", "once a week", or "every day". Table 4.1 shows that ownership of a mobile phone is not a necessary condition for use. The proportion of people that used a mobile phone without owning one increased over time. Almost half of the respondents 
without a phone in 2015 mentioned using one at least once a month. This degree of phone sharing exceeds results reported in previous studies in similar settings (Debsu et al., 2016; Butt, 2015; Aker and Mbiti, 2010). Approximately 11\% of the respondents in our sample who stated that they own a mobile phone actually never used it during the twelve months prior to the survey. Potential reasons for owning but not using mobile phones are poor network coverage, weak electricity infrastructure, or insufficient mobile phone credit (Butt, 2015). In order not to dilute estimates by households that owned but never used a phone, we do not treat these households as owners in the impact analysis. However, the findings do not change much when including these households as mobile phone owners.

Table 4.1: Share of households that use MPs among households that do not own a MP

\begin{tabular}{lccccccc}
\hline \hline Usage... & Pooled & 2009 & 2010 & 2011 & 2012 & 2013 & 2015 \\
\cline { 2 - 8 } at least once a month & 27 & 20 & 20 & 25 & 27 & 36 & 48 \\
at least once a week & 17 & 9 & 11 & 16 & 18 & 23 & 42 \\
every day & 9 & 2 & 3 & 8 & 12 & 13 & 27 \\
$\mathrm{~N}$ & 3,012 & 654 & 618 & 553 & 477 & 443 & 257 \\
\hline
\end{tabular}

Notes: Own elaboration based on panel data from Northern Kenya. MP = Mobile phone.

To allow for differences in ownership and use frequencies and to increase the robustness of our estimations, we construct the following five mobile phone (MP) variables:

- MP ownership variable 1: unity if the household owns a MP and used it at least once during the twelve months prior to the survey, zero otherwise.

- MP ownership variable 2: unity if the household owns two or more mobile phones and used a mobile phone during the twelve months prior to the survey, zero otherwise

- MP utilization variable 1: unity if the household used a mobile phone every day, zero otherwise

- MP utilization variable 2: unity if the household used a mobile phone once a week excluding daily use, zero otherwise.

- MP utilization variable 3: unity if the household used a mobile phone at most once a month, zero otherwise.

We select suitable explanatory variables based on past research to control for several important variations in household characteristics. (Hirvonen and Hoddinott, 2017) find that the household's cooking source can influence its dietary diversity. We therefore control for the household's main cooking appliance by constructing a dummy variable that is zero if the household uses a traditional fire and unity if the household uses any form of 
advanced cooking appliance such as a jiko (local wood and charcoal stove) or some form of cooker. We also include the gender, age, and education of the household head as well as the household size. Income is measured as all income received by the household in the last four months including livestock sales, crop sales, cash transfers from family, friends and other people, salaried employment, casual labor and petty trading. To account for inflation, income is consistently measured in Kenyan Shilling (KSh) with 2015 as the base year (KSh $1 \approx$ USD 0.01). Moreover we include the nomadic status of the household as well as radio possession to control for an additional type of technology that can be used to access information.

The size of the land cultivated by the household measured in hectares is included as well. As mentioned in section 4.2, crop farming is rarely done in Northern Kenya. This is reflected in the data, where $81 \%$ of the observations have no land under cultivation and less than $7 \%$ farm more than one hectare. We also control for herd size measured in Tropical Livestock Units $(\mathrm{TLU})^{1}$. In the area of this study, camels form the largest proportion of the herds in terms of TLU, followed by cattle and goats (Mburu et al., 2017). Only 7.7\% of the households do not own any livestock at all. Herd size and agricultural land can be associated with higher household nutrition for two reasons. On the one hand, these are proxies for the households' wealth, and on the other hand they present assets that can directly supply the household with food.

\subsection{Econometric Strategy}

We use panel data regression models to analyze the effect of mobile phones on dietary diversity. We run separate regressions for the two dietary diversity scores explained above and for mobile phone ownership and mobile phone use. Since the analysis is based on observational data, self-selection of individuals into mobile phone ownership and use is probable. Hence, the estimated effects of mobile phones could suffer from selection bias. To remove selection bias resulting from unobserved time-invariant heterogeneity, we use panel data models with household fixed effects (FE) (Verbeek, 2004). The influence of factors such as physical market proximity is therefore eliminated.

A necessary condition for efficient FE estimates is the existence of sufficient data variability within groups over time. Figures 4.1 and 4.2 show that mobile phone ownership and use both show substantial variation over the timespan considered.

The following equation models the relationship between mobile phones and dietary diversity:

$$
H D D S_{i t}=\beta_{0}+\beta_{1}^{\prime} M P_{i t}+\beta_{2}^{\prime} X_{i t}+\beta_{3}^{\prime} T_{t}+\omega_{i}+\epsilon_{i t},
$$

where $H D D S_{i t}$ is the Household Dietary Diversity Score (with either twelve or nine food

\footnotetext{
${ }^{1}$ One tropical livestock unit refers to either 1 head of cattle, or 0.7 of a camel, or 10 goats, or 10 sheep (Mburu et al., 2017).
} 
Figure 4.1: Proportion of households owning at least one mobile phone in Marsabit, Kenya

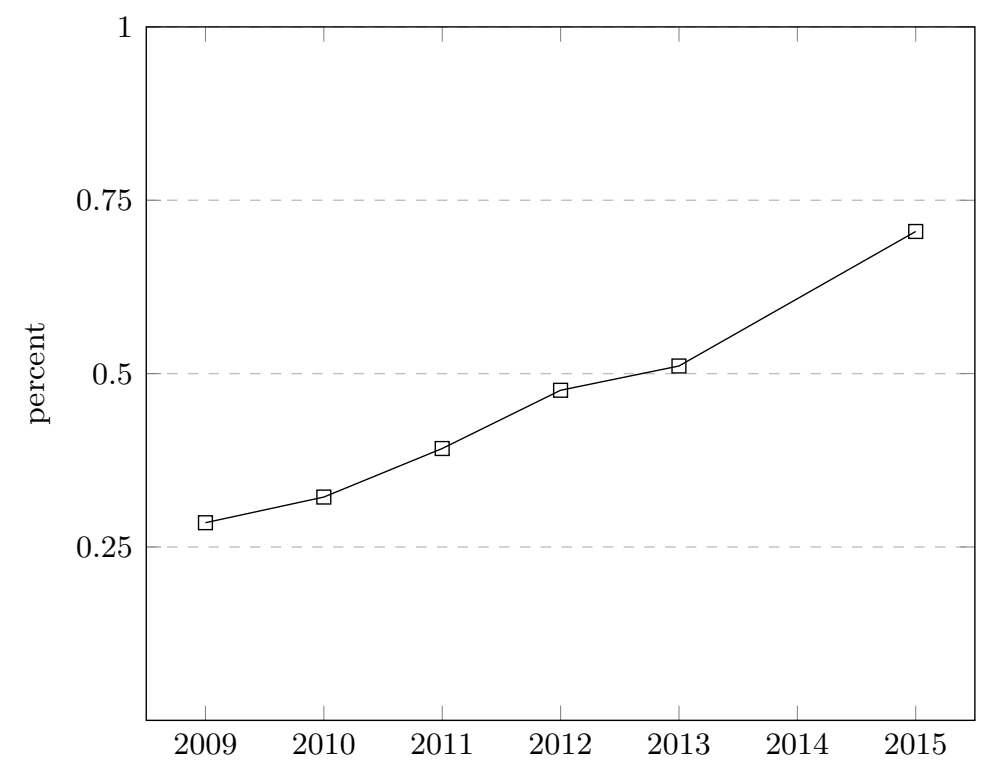

Source: Own presentation based on panel data from Marsabit, Kenya with 5,506 observations and 1,062 groups.

Figure 4.2: Development of mobile phone use in Marsabit, Kenya

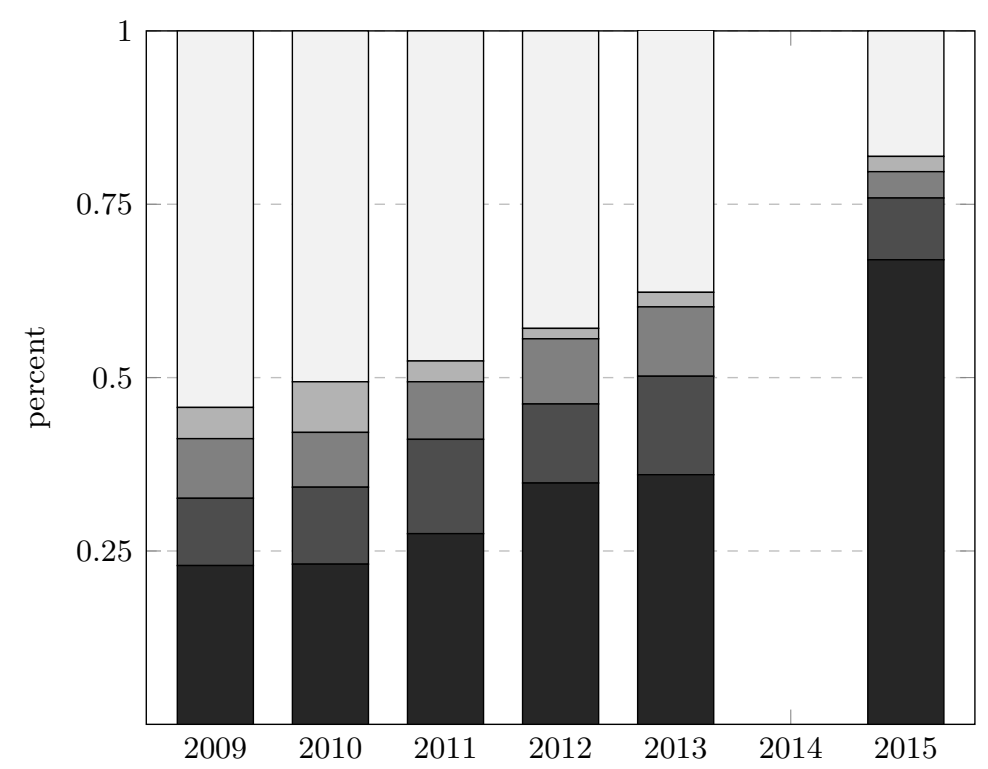

never $\square$ once a year $\square$ once a month $\square$ once a week $\square$ every day

Source: Own presentation based on panel data from Marsabit, Kenya with 5,506 observations and 1,062 groups. 
groups) of household $i$ at time $t . M P_{i t}$ is a vector of either three or two mobile phone variables that measure mobile phone use or mobile phone ownership of household $i . X_{i t}$ is a vector of time-variant household characteristics. Some of these characteristics, such as gender of the household head, are time-invariant for most but not all households. Higher income is one of the mechanisms through which mobile phones can positively influence nutrition. To better understand this and other mechanisms, we run each regression with and without controlling for income. $T_{t}$ is a vector of time dummies for the years 2009, 2010, 2011, 2012, and 2013, capturing all structural changes such as economic growth, overall expansion of network coverage, improvements of general infrastructure, or droughts. We have separate time dummies for each of the five geographical divisions to allow for heterogeneous structural change. $\omega_{i}$ is the household fixed effect. $\epsilon_{i t}$ is a normally distributed error term. The errors are robust and clustered at the sub-location level to account for possible heteroskedasticity and serial correlation of errors within sub-locations.

The dependent variables $H D D S 12_{i t}$ and $H D D S 9_{i t}$ are censored with a lower limit of zero and an upper limit of twelve or nine respectively. Using a tobit estimator could be more appropriate than a linear specification. However, maximum likelihood estimations of non-linear models with group and/or time fixed effects suffer from the incidental parameter problem (Greene, 2004; Neyman and Scott, 1948) and are thus biased and inconsistent. Potential corrections always lead to a trade-off between bias arising either through incidental parameters or through misspecification of unobserved heterogeneity (Bester and Hansen, 2016). In the data at hand there are only very few observations around the upper and lower limits. That is, very few households consume zero or all twelve (or nine) food groups. It therefore seems more reasonable to employ a linear model that captures time-invariant heterogeneity consistently rather than using a biased maximum likelihood estimator. We are mostly interested in $\beta_{1}$, since positive and statistically significant coefficients would imply a positive effect of mobile phone ownership and use on household dietary diversity (hypotheses 1 and 2).

The relatively large number of time periods covered by the data allows further analyses of both the persistence of potential benefits as well as controlling if any anticipatory effects occur. Similar to Beuermann et al. (2012) we also consider the following model with differential time trends for each individual household:

$$
H D D S_{i t}=\beta_{0}+\sum_{\tau=-5}^{5} \delta_{\tau} D_{i \tau}+\beta_{2}^{\prime} X_{i t}+\beta_{3}^{\prime} T_{t}+\omega_{i}+\epsilon_{i t}
$$

where where $\tau$ is the year of first mobile phone access normalized to $\tau=0$ for the first round of access. $D_{i \tau}$ is a dummy that equals unity for the $\tau$ th year of mobile phone access. We omit the dummy $D_{i,-1}$ from the analyses, so that $\delta_{-2}$ can be interpreted as the mean of the dietary diversity two rounds before first mobile phone access relative to the round before first access. 
Given that the three identification assumptions of parallel trends in the baseline outcomes, absence of anticipatory behavior in the periods before treatment, and treatment effect homogeneity hold, we can interpret $\delta_{0}$ as the mean of dietary diversity in the round of first access relative to the round before first access (Abraham and Sun, 2019). $\delta_{1}$ can be interpreted as the mean of dietary diversity in the round after first access etc. If our identification strategy is valid, none of the $\delta_{\tau}$ coefficients for $\tau<0$ should be positive and statistically significant, since significant positive coefficients would imply that mobile phones led to improved nutrition already before households actually had access to them.

To test hypotheses 3 and 4, we analyze whether mobile phones influence the primary household food sources. As explained above, we decompose HDDS12 $i t$ into two components, namely the number of consumed food groups from self-production and the number of food groups from purchases. To explain these two variables $\left(Y_{i t}\right)$ we employ the following linear fixed effect model similar to equation (4.1):

$$
Y_{i t}=\beta_{0}+\beta_{1}^{\prime} M P_{i t}+\beta_{2}^{\prime} X_{i t}+\beta_{3}^{\prime} T_{t}+\omega_{i}+\epsilon_{i t},
$$

\subsection{Results and Discusssion}

\subsubsection{Descriptive Statistics}

Ownership of a mobile phone increased from less than 30\% in 2009 to over $70 \%$ in 2015 (Figure 1). Actual use of mobile phones follows a similar structure. About $55 \%$ of the respondents never used a phone in 2009 , and only $22 \%$ used a mobile phone on a daily basis. In 2015, 65\% used a mobile phone daily, while the proportion of households that never used a mobile phone dropped to $18 \%$ (Figure 2).

Figure 4.3 shows the development of average household dietary diversity. The cumulative density function has shifted to the right over time, which implies a general improvement of dietary diversity. Compared to other household dietary diversity scores using seven-day recall data (Fongar et al., 2019; Sibhatu and Qaim, 2018a), the average HDDS in the study region is quite low. This points at high food insecurity and low nutritional quality in the pastoral communities.

Table 4.3 shows mean socioeconomic characteristics for all six survey rounds. Differences between households owning and not owning mobile phones are tested for statistical significance. Households that own mobile phones have higher dietary diversity scores and are more likely to own other assets. Mobile phone owners also have higher incomes. For most of the variables, the differences between households owning and not owning mobile phones are largest in 2009 and get smaller over the years with more households owning mobile phones. Beyond dietary diversity scores, we also compare the expenditures for selected food groups between households with and without mobile phones. Households with mobile phones consume significantly more fresh foods, such as fruits, vegetables, and animal source products, also pointing at higher dietary quality. 
Figure 4.3: Cumulative distribution of the Household Dietary Diversity Score in Marsabit, Kenya

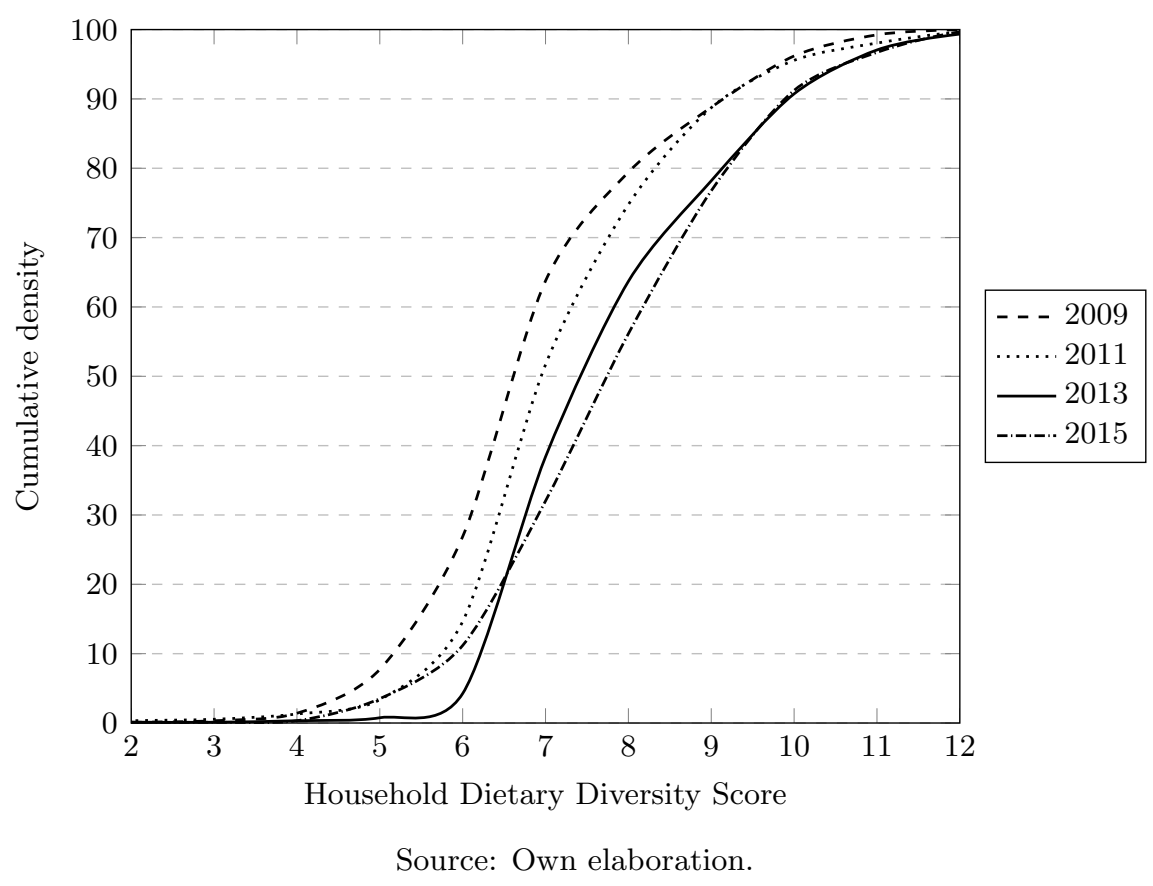

Table 4.2: Correlations between income, dietary diversity, and mobile phones $(\mathrm{N}=5,506)$

\begin{tabular}{lcccc}
\hline \hline & Income & $\begin{array}{c}\text { MP use at } \\
\text { least once } \\
\text { a month }\end{array}$ & $\begin{array}{c}\text { Owning at } \\
\text { least one MP }\end{array}$ & HDDS12 \\
\hline $\begin{array}{l}\text { MP use at least } \\
\text { once a month }\end{array}$ & $0.206^{* * *}$ & & & \\
$\begin{array}{l}\text { Owning at least } \\
\text { one MP }\end{array}$ & $0.235^{* * *}$ & $0.607^{* * *}$ & & \\
HDDS12 & $0.304^{* * *}$ & $0.380^{* * *}$ & $0.396^{* * *}$ & \\
HDDS9 & $0.296^{* * *}$ & $0.364^{* * *}$ & $0.386^{* * *}$ & $0.947^{* * *}$ \\
\hline
\end{tabular}

Notes: HDDS $=$ Household Dietary Diversity Score. $\mathrm{MP}=$ mobile phone.

${ }^{*},{ }^{* *},{ }^{* * *}$ denote statistical significance at the $10 \%, 5 \%, 1 \%$ level respectively. Significance levels are Bonferroni-adjusted. 
Table 4.3: Socioeconomic characteristics by mobile phone ownership

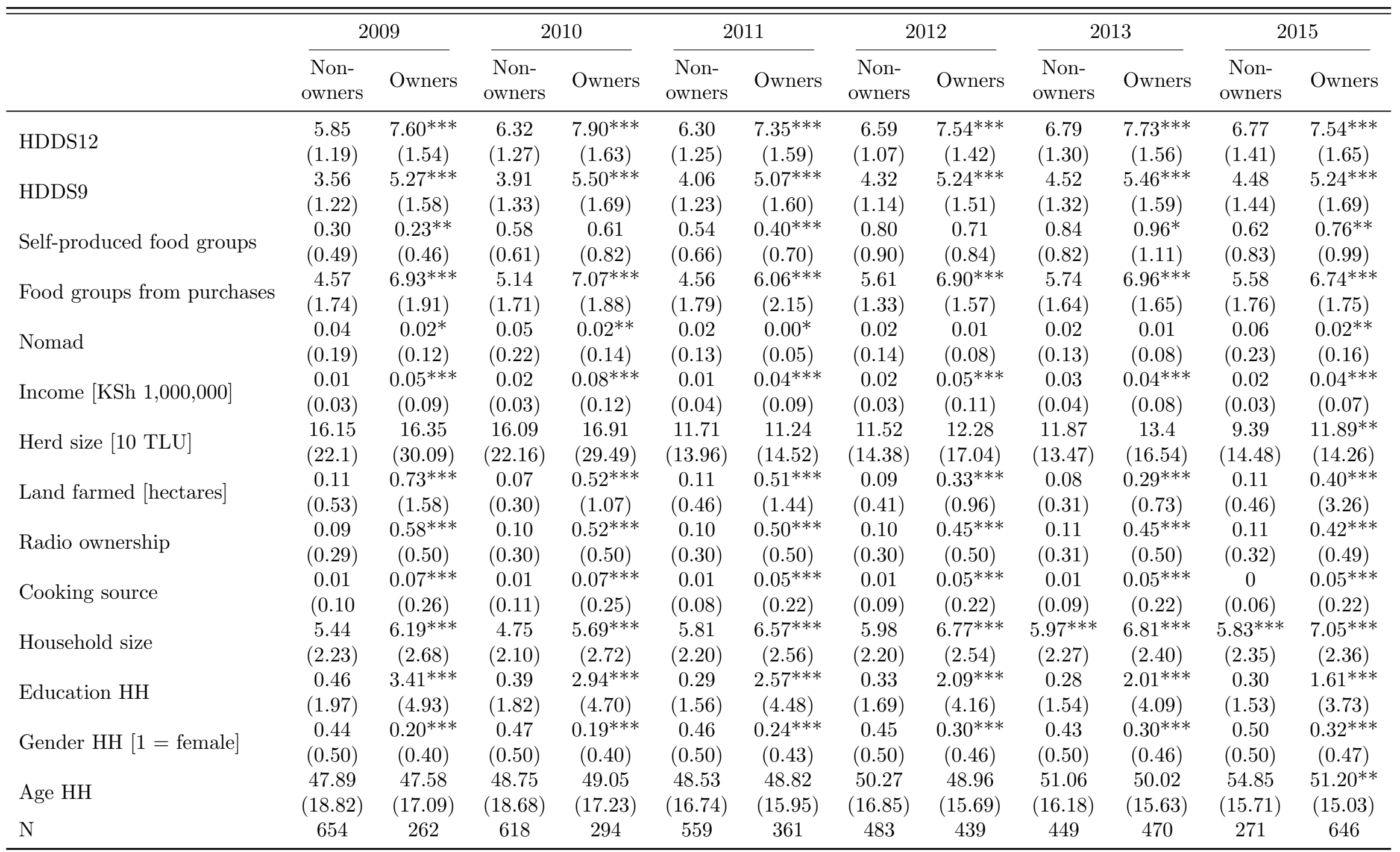

Notes: Mean values are shown. Standard errors are in parentheses. Differences in means between owners and non-owners are tested for statistical significance using the t-test. HDDS $=$ Household Dietary Diversity Score. HH= household head. TLU $=$ Tropical Livestock Unit. ${ }^{* * *} p<0.01,{ }^{* *} p<0.05,{ }^{*} p<0.1$. 
The relationships between income, mobile phones, and dietary diversity deserve particular attention. Richer households are more likely to use or own mobile phones and are also more likely to have higher dietary quality. A positive association between mobile phones and dietary quality could therefore emerge simply as a by-product of these latent mechanisms. To better understand these relationships, we present correlation coefficients in Table 4.2. All coefficients are positive and statistically significant, yet with some differences in terms of their magnitude. The correlations between income and mobile phone ownership/use are relatively small. The correlations between income and dietary diversity are slightly larger, and the largest correlation coefficients are observed between the mobile phone variables and dietary diversity. Since the correlation coefficients are based on the pooled sample and do not account for any confounding factors, interpretation should be made with caution. Nevertheless, the relatively weak linear relationship between income and mobile phone use suggests that a positive association between mobile phone use and dietary diversity may not be driven by the income mechanism alone, as predicted in our conceptual framework. This will be further analyzed with the econometric models below.

\subsubsection{Regression Results}

In Table 4.4, we present estimation results for the models in equation 4.1. Columns (1) to (4) show results for mobile phone use as the treatment variable. The dependent variable for columns (1) and (2) is the HDDS12 and for columns (3) and (4) the HDDS9. Coefficient estimates for daily mobile phone use are positive and statistically significant for both dietary diversity scores. Less frequent mobile phone use is only statistically significant for HDDS12. A coefficient of 0.3 for daily MP use (column 1) means that those who use mobile phones on a daily basis consume 0.3 food groups more compared to those who do not use mobile phones. This average effect size is larger than that of many agricultural interventions, such as increasing the diversity of farm production among African smallholders (Sibhatu and Qaim, 2018b).

Using the estimates in columns (2) and (4) of Table 4.4, we can also approximate the proportion of the improvements in average dietary diversity that can be attributed to increased mobile phone use. Multiplying the mobile phone regression coefficients of column (2) with the average increase in mobile phone use and dividing this number by the average increase in HDDS12 reveals that considering the time span analyzed here, mobile phones contributed to roughly $12 \%$ of the improvement in HDDS12. Similarly, the mobile phone regression coefficients of column (4) imply that increases in mobile phone use contributed to $10 \%$ of improvements in HDDS9.

Columns (5) and (6) of Table 4.4 show that both owning at least one phone and owning two or more mobile phones have a positive and statistically significant effect on HDDS12. When the HDDS with nine food groups is considered (columns 7 and 8), only owning two 
Table 4.4: Full Table for the effects of mobile phones on household dietary diversity scores (fixed effects panel model)

\begin{tabular}{|c|c|c|c|c|c|c|c|c|}
\hline & \multicolumn{4}{|c|}{ Mobile phone use } & \multicolumn{4}{|c|}{ Mobile phone ownership } \\
\hline & \multicolumn{2}{|c|}{ HDDS12 } & \multicolumn{2}{|c|}{ HDDS9 } & \multicolumn{2}{|c|}{ HDDS12 } & \multicolumn{2}{|c|}{ HDDS9 } \\
\hline & (1) & $(2)$ & (3) & (4) & $(5)$ & (6) & (7) & (8) \\
\hline Daily MP use & $\begin{array}{c}0.306^{* * *} \\
(0.075)\end{array}$ & $\begin{array}{c}0.289^{* * *} \\
(0.075)\end{array}$ & $\begin{array}{c}0.261^{* * *} \\
(0.077)\end{array}$ & $\begin{array}{c}0.243^{* * *} \\
(0.078)\end{array}$ & & & & \\
\hline Weekly MP use (excluding daily use) & $\begin{array}{c}0.021 \\
(0.070)\end{array}$ & $\begin{array}{c}0.011 \\
(0.068)\end{array}$ & $\begin{array}{l}-0.060 \\
(0.063)\end{array}$ & $\begin{array}{l}-0.071 \\
(0.061)\end{array}$ & & & & \\
\hline At most monthly MP use & $\begin{array}{l}0.142^{*} \\
(0.071)\end{array}$ & $\begin{array}{l}0.138^{*} \\
(0.069)\end{array}$ & $\begin{array}{c}0.122 \\
(0.077)\end{array}$ & $\begin{array}{c}0.118 \\
(0.075)\end{array}$ & & & & \\
\hline Owning at least one MP & & & & & $\begin{array}{l}0.192^{*} \\
(0.097)\end{array}$ & $\begin{array}{l}0.186^{*} \\
(0.096)\end{array}$ & $\begin{array}{c}0.120 \\
(0.103)\end{array}$ & $\begin{array}{c}0.115 \\
(0.102)\end{array}$ \\
\hline Owning two or more MPs & & & & & $\begin{array}{c}0.248^{* *} \\
(0.111)\end{array}$ & $\begin{array}{l}0.233^{*} \\
(0.111)\end{array}$ & $\begin{array}{l}0.211^{*} \\
(0.107)\end{array}$ & $\begin{array}{l}0.195^{*} \\
(0.109)\end{array}$ \\
\hline Income $[\mathrm{KSh} 1,000,000]$ & & $\begin{array}{c}2.321^{* * *} \\
(0.438)\end{array}$ & & $\begin{array}{c}2.484^{* * *} \\
(0.447)\end{array}$ & & $\begin{array}{c}2.362^{* * *} \\
(0.434)\end{array}$ & & $\begin{array}{r}2.515^{* * *} \\
(0.444)\end{array}$ \\
\hline Control Variables & YES & YES & YES & YES & YES & YES & YES & YES \\
\hline Division $\times$ years dummies & YES & YES & YES & YES & YES & YES & YES & YES \\
\hline $\begin{array}{l}\text { Model statistics } \\
R^{2}\end{array}$ & 0.587 & 0.591 & 0.584 & 0.589 & 0.567 & 0.572 & 0.565 & 0.570 \\
\hline
\end{tabular}

Notes: Estimates are based on an unbalanced panel data set with 5,506 observations and 1,062 groups. Standard errors shown in parentheses are robust and clustered at the sub-location level. HDDS = household dietary diversity score. MP = mobile phone. Control variables are: nomadic status, radio possession, cooking source, land farmed, herd size, education, gender, age, household size. Full results with all control variables are shown in Table C2 in the online Appendix. ${ }^{*},{ }^{* *},{ }^{* * *}$ denote statistical significance at the $10 \%, 5 \%$, $1 \%$ level respectively. 
or more mobile phones approaches statistical significance; the coefficient for owning at least one mobile phone is positive but insignificant ${ }^{2}$.

A possible explanation for the difference in significance levels between HDDS12 and HDDS9 for low utilization frequencies lies in the food groups not included in HDDS9. HDDS9 does not contain the food groups sweets and sugars, oils and fats, and spices, condiments, and beverages. These food groups contain foods that are generally less perishable than most of the foods in the other food groups. HDDS9 therefore mostly consists of foods that perish relatively fast such as meat, milk, vegetables, fruit, or eggs. While rare mobile phone use might induce better access to foods that last longer, it might not be frequent enough to increase access to more perishable foods. The same argument can be made to explain the insignificant effect of owning one mobile phone on HDDS9: if households only own a single mobile phone, the device might be used otherwise or by other household members and does not help procure more perishable food groups.

Columns (1), (3), (5), and (7) in Table 4.4 show the estimation results without income included as a control variable. As expected, the mobile phone effects are larger, supporting the hypothesis that income gains are one of the mechanisms through which mobile phones improve dietary diversity. However, the differences in the estimates between the models with and without income included are relatively small. This, together with the fact that the mobile phone coefficients are significant in columns (2), (4), (6), and (8) even after controlling for income, suggests that income gains are not the only mechanism of the mobile phone effects on dietary diversity.

Given the positive and statistically significant effects of the mobile phone variables in Table 4.4, we confirm Hypothesis 1 and Hypothesis 2. The partially different results for HDDS12 and HDDS9 imply that the effects of mobile phones may depend on the food group classification. To deepen the analysis we now look at the effects of mobile phones on the households' food sources. Table 4.5 shows regression results of the two models explained in equation 4.3. Columns (2) and (4) show that all specifications for the mobile phone ownership and use variables have positive and statistically significant effects on the number of food groups consumed from purchases. This confirms that mobile phones facilitate the acquisition of food through markets. Columns (1) and (3) of Table 4.5 show the same models with the number of food groups from self-production as dependent variable. All mobile phone coefficient estimates are statistically insignificant. This suggests that improved access to purchased foods is indeed the main mechanism how mobile phones improve diets and nutrition in the pastoral communities. We therefore also confirm Hypothesis 3 and Hypothesis 4.

\footnotetext{
${ }^{2}$ To understand how sensitive the results are with regard to attrition, we ran the same models but only including those households for whom we have complete observations for all six rounds $(\mathrm{N}=4,512)$. The results are shown in Table C1 in the online Appendix; they are nearly identical to those in Table 4.4. While these estimates with the balanced panel do not provide a perfect counterfactual for the scenario without non-random attrition, the similarity of the results suggests that the magnitude of any potential attrition bias is small.
} 
Table 4.5: Effects of mobile phones on dietary diversity obtained from self-production and food purchases (fixed effects panel model)

\begin{tabular}{|c|c|c|c|c|}
\hline & \multicolumn{2}{|c|}{ Mobile phone use } & \multicolumn{2}{|c|}{ Mobile phone ownership } \\
\hline & $\begin{array}{l}\text { Food groups } \\
\text { from self- } \\
\text { production } \\
\text { (1) }\end{array}$ & $\begin{array}{l}\text { Food groups } \\
\text { from purchase } \\
\text { (2) }\end{array}$ & $\begin{array}{l}\text { Food groups } \\
\text { from self- } \\
\text { production } \\
(3)\end{array}$ & $\begin{array}{l}\text { Food groups } \\
\text { from purchase } \\
\text { (4) }\end{array}$ \\
\hline Daily MP use & $\begin{array}{l}-0.019 \\
(0.047)\end{array}$ & $\begin{array}{c}0.384^{* * *} \\
(0.089)\end{array}$ & & \\
\hline $\begin{array}{l}\text { Weekly MP use } \\
\text { (excluding daily use) }\end{array}$ & $\begin{array}{l}-0.072 \\
(0.042)\end{array}$ & $\begin{array}{c}0.235^{* *} \\
(0.093)\end{array}$ & & \\
\hline At most monthly MP use & $\begin{array}{l}-0.013 \\
(0.040)\end{array}$ & $\begin{array}{c}0.236^{* *} \\
(0.090)\end{array}$ & & \\
\hline Owning at least one MP & & & $\begin{array}{l}0.008 \\
(0.050)\end{array}$ & $\begin{array}{c}0.307^{* * *} \\
(0.092)\end{array}$ \\
\hline Owning two or more MPs & & & $\begin{array}{c}0.042 \\
(0.070)\end{array}$ & $\begin{array}{c}0.276^{* * *} \\
(0.086)\end{array}$ \\
\hline Income $[$ KSh1,000,000] & $\begin{array}{c}0.568^{* *} \\
(0.231)\end{array}$ & $\begin{array}{c}2.302^{* * *} \\
(0.465)\end{array}$ & $\begin{array}{c}0.556^{* *} \\
(0.233)\end{array}$ & $\begin{array}{c}2.366^{* * *} \\
(0.472)\end{array}$ \\
\hline Control Variables & YES & YES & YES & YES \\
\hline Division $\times$ years dummies & YES & YES & YES & YES \\
\hline $\begin{array}{l}\text { Model statistics: } \\
R^{2}\end{array}$ & 0.443 & 0.607 & 0.442 & 0.606 \\
\hline
\end{tabular}

Notes: Estimates are based on an unbalanced panel data set with 5,506 observations and 1,062 groups. The dependent variable for columns (1) and (3) is the number of food groups that the household consumed coming from self-production. The dependent variable for the columns (2) and (4) is the number of food groups that the household consumed coming from food purchases. Standard errors shown in parentheses are robust and clustered at the sub-location level. MP $=$ mobile phone. Control variables are: nomadic status, radio possession, cooking source, land farmed, income, herd size, education, gender, age, household size. Full results with all control variables are shown in Table C3 in the online Appendix. ${ }^{*},{ }^{* *},{ }^{* * *}$ denote statistical significance at the $10 \%, 5 \%, 1 \%$ level respectively.

As a robustness check, we now look at the individual time trends in the years before, during, and after mobile phone adoption, as explained in equation (4.2). We consider the three outcome variables for which we found statistically significant effects of mobile phones, namely HDDS12, HDDS9, and the number of food groups coming from purchases. Table 4.6 shows that none of the 24 coefficients for the years prior to first mobile phone access is statistically significant. This supports the validity of our identification strategy and suggests that households adopting mobile phones were not already on a different trajectory than other households before they adopted.

The coefficients concerned with the years after first access to a mobile phone give insights on the duration of the positive effects on dietary diversity. Mobile phone use has a positive effect from the very first round for all three nutritional indicators. These 
effects last at least as long as the time span covered by the data. Mobile phone ownership approaches statistical significance when HDDS12 is considered, but only in the very first year of access. Treatment effects for later rounds are not statistically different from the round prior to first access. Ownership does not have a positive effect on HDDS9. The positive effect of mobile phone ownership on the food groups from purchases is more sustainable.

This analysis with individual time trends has certain limitations that deserve further discussion. Since the data cover six rounds, we can only estimate the before 5 coefficient based on the households that adopted mobile phones in the last survey round. Similarly, the before 4 coefficient can only be identified from households that adopted in the last or second to last survey round and so on. The before coefficients are therefore not representative of the respective pre-trend of all mobile phone adopters, but only capture households that adopted mobile phones later during the period. This does not render the results in Table 4.6 invalid, but means that the finding of absence of pre-trends is restricted to certain groups. We cannot rule out potential pre-trends of households that adopted relatively early. Similarly, the after coefficients can only be based on relatively early adopters and are therefore also not representative of the entire sample ${ }^{3}$.

That said, if we assume that potential pre-trends would become apparent especially in the years directly preceding the adoption decision, the before 1, before 2 , and before 3 coefficients would be the ones particularly important for this analysis. These coefficients are identified by a large share of the sample and therefore more representative. As a robustness check, we estimate equation (4.2) only with dummies for the time span from three years before individual mobile phone adoption to three years after mobile phone adoption. These additional estimates, which are shown in Table C5 in the online Appendix, do also not produce any negative and statistically significant coefficients that would indicate the existence of pre-trends.

One of the three identification assumptions formalized by Abraham and Sun (2019) requires treatment effect homogeneity across different cohorts. In the context of this study, it is plausible that cohorts react differently to the treatment. For example, early adopters might be wealthier than late adopters and therefore benefit more from easier access to food purchases. However, Abraham and Sun (2019) show that a violation of this assumption does not invalidate the estimation, but rather complicates the interpretation of the coefficients ${ }^{4}$.

Since we do not have data for the year of adoption before 2009, we do not know in which year households that already owned/used mobile phones in the first survey round had actually adopted the technology. Consequently we cannot assign proper after dummies

\footnotetext{
${ }^{3}$ This could explain why some of the after 5 coefficients are particularly large in Table 4.6 .

${ }^{4}$ Under effect heterogeneity across cohorts, the lead fixed effect estimators can be affected by variation in post-treatment. As a result, non-zero coefficient estimates for before variables do not provide evidence for the existence of pre-trends (Abraham and Sun, 2019).
} 
Table 4.6: Effect duration of mobile phone access on dietary outcomes (fixed effects panel model)

\begin{tabular}{|c|c|c|c|c|c|c|}
\hline & \multicolumn{3}{|c|}{ Mobile phone usage } & \multicolumn{3}{|c|}{ Mobile phone ownership } \\
\hline & $\begin{array}{l}\text { HDDS12 } \\
\text { (1) }\end{array}$ & $\begin{array}{c}\text { HHDS9 } \\
\text { (2) }\end{array}$ & $\begin{array}{l}\text { Food } \\
\text { groups } \\
\text { from } \\
\text { purchase } \\
\quad(3)\end{array}$ & HDDS12 & $\begin{array}{c}\text { HHDS9 } \\
\text { (5) }\end{array}$ & $\begin{array}{c}\text { Food } \\
\text { groups } \\
\text { from } \\
\text { purchase } \\
\quad(6)\end{array}$ \\
\hline Before 5 & $\begin{array}{c}0.162 \\
(0.162)\end{array}$ & $\begin{array}{c}0.199 \\
(0.146)\end{array}$ & $\begin{array}{c}0.127 \\
(0.218)\end{array}$ & $\begin{array}{c}0.022 \\
(0.102)\end{array}$ & $\begin{array}{c}0.084 \\
(0.118)\end{array}$ & $\begin{array}{l}-0.280 \\
(0.225)\end{array}$ \\
\hline Before 4 & $\begin{array}{c}0.116 \\
(0.143)\end{array}$ & $\begin{array}{c}0.132 \\
(0.143)\end{array}$ & $\begin{array}{c}0.121 \\
(0.201)\end{array}$ & $\begin{array}{l}-0.070 \\
(0.107)\end{array}$ & $\begin{array}{l}-0.004 \\
(0.096)\end{array}$ & $\begin{array}{l}-0.180 \\
(0.129)\end{array}$ \\
\hline Before 3 & $\begin{array}{c}0.089 \\
(0.093)\end{array}$ & $\begin{array}{c}0.113 \\
(0.095)\end{array}$ & $\begin{array}{l}-0.013 \\
(0.115)\end{array}$ & $\begin{array}{l}0.006 \\
(0.101)\end{array}$ & $\begin{array}{c}0.039 \\
(0.113)\end{array}$ & $\begin{array}{c}0.082 \\
(0.107)\end{array}$ \\
\hline Before 2 & $\begin{array}{c}0.058 \\
(0.059)\end{array}$ & $\begin{array}{c}0.073 \\
(0.079)\end{array}$ & $\begin{array}{c}0.013 \\
(0.089)\end{array}$ & $\begin{array}{c}0.055 \\
(0.074)\end{array}$ & $\begin{array}{c}0.100 \\
(0.070)\end{array}$ & $\begin{array}{c}0.063 \\
(0.090)\end{array}$ \\
\hline Before 1 & & & -Referenc & Year- & & \\
\hline After 0 & $\begin{array}{c}0.214^{* *} \\
(0.076)\end{array}$ & $\begin{array}{c}0.188^{* *} \\
(0.077)\end{array}$ & $\begin{array}{c}0.258^{* * *} \\
(0.087)\end{array}$ & $\begin{array}{l}0.136^{*} \\
(0.073)\end{array}$ & $\begin{array}{c}0.094 \\
(0.084)\end{array}$ & $\begin{array}{c}0.264^{* * *} \\
(0.085)\end{array}$ \\
\hline After 1 & $\begin{array}{l}0.192^{*} \\
(0.095)\end{array}$ & $\begin{array}{c}0.112 \\
(0.095)\end{array}$ & $\begin{array}{c}0.197 \\
(0.135)\end{array}$ & $\begin{array}{c}0.077 \\
(0.072)\end{array}$ & $\begin{array}{c}0.035 \\
(0.086)\end{array}$ & $\begin{array}{c}0.252^{* *} \\
(0.096)\end{array}$ \\
\hline After 2 & $\begin{array}{c}0.226^{* *} \\
(0.102)\end{array}$ & $\begin{array}{c}0.229^{* * *} \\
(0.071)\end{array}$ & $\begin{array}{c}0.337^{* *} \\
(0.127)\end{array}$ & $\begin{array}{c}0.042 \\
(0.145)\end{array}$ & $\begin{array}{l}-0.040 \\
(0.157)\end{array}$ & $\begin{array}{l}0.243^{*} \\
(0.134)\end{array}$ \\
\hline After 3 & $\begin{array}{c}0.252^{* *} \\
(0.087)\end{array}$ & $\begin{array}{c}0.234^{* *} \\
(0.080)\end{array}$ & $\begin{array}{c}0.330^{* * *} \\
(0.104)\end{array}$ & $\begin{array}{l}-0.080 \\
(0.210)\end{array}$ & $\begin{array}{l}-0.112 \\
(0.199)\end{array}$ & $\begin{array}{c}0.233 \\
(0.154)\end{array}$ \\
\hline After 4 & $\begin{array}{c}0.289^{* *} \\
(0.124)\end{array}$ & $\begin{array}{c}0.262 \\
(0.174)\end{array}$ & $\begin{array}{c}0.393 \\
(0.314)\end{array}$ & $\begin{array}{c}0.019 \\
(0.267)\end{array}$ & $\begin{array}{c}0.024 \\
(0.299)\end{array}$ & $\begin{array}{c}0.094 \\
(0.389)\end{array}$ \\
\hline After 5 & $\begin{array}{c}0.433^{* *} \\
(0.169)\end{array}$ & $\begin{array}{c}0.467^{* *} \\
(0.178)\end{array}$ & $\begin{array}{c}0.818^{* * *} \\
(0.216)\end{array}$ & $\begin{array}{l}-0.010 \\
(0.253)\end{array}$ & $\begin{array}{c}0.109 \\
(0.228)\end{array}$ & $\begin{array}{l}0.375^{*} \\
(0.204)\end{array}$ \\
\hline Control Variables & YES & YES & YES & YES & YES & YES \\
\hline Division $\times$ years dummies & YES & YES & YES & YES & YES & YES \\
\hline $\begin{array}{l}\text { Model statistics: } \\
R^{2}\end{array}$ & 0.443 & 0.607 & 0.442 & 0.606 & & \\
\hline
\end{tabular}

Notes: Estimates are based on an unbalanced panel data set with 5,506 observations and 1,062 groups. The dependent variable for columns (1) and (4) is household dietary diversity score with twelve food groups. The dependent variable for columns (2) and (5) is the dietary diversity score with nine food groups. The dependent variable for columns (3) and (6) is the number of food groups that the household consumed coming from food purchases. The independent variables shown here refer to the number of rounds before or after a household first gained access to a mobile phone relative to the year before first access. Standard errors shown in parentheses are robust and clustered at the sublocation level. Full results with all control variables are shown in Table C4 in the online Appendix. Control variables are: nomadic status, radio possession, cooking source, income, land farmed, herd size, education, gender, age, household size. ${ }^{*},{ }^{* *},{ }^{* * *}$ denote statistical significance at the $10 \%, 5 \%$, $1 \%$ level respectively. 
for these households. For the estimations in Table 4.6, all of the after and before dummies for these households were attributed a value of zero. Since we are mostly interested in pre-trends, this simplified assumption should be acceptable. It does however mean that the after coefficients in general should be interpreted with some caution.

To further analyze the effects of mobile phones on dietary quality from food purchases, we split HDDS12 into its twelve food groups and estimate a linear probability model for each of these groups. The dependent variable indicates whether or not a household consumed a certain food group in the seven days prior to the survey and mentioned purchase as the main source of acquirement. Different degrees of mobile phone use are the treatment variables in these models. Table 4.7 shows that daily mobile phone use helps procure foods that are particularly perishable such as white roots and tubers, vegetables, meat, eggs, and fish. These products spoil relatively fast, especially in the absence of cooling devices. Statistically significant coefficient estimates lie between 0.02 and 0.08 . Daily mobile phone users are therefore $2 \%$ to $8 \%$ more likely to have consumed such food groups in the last seven days with purchase being the main source than non-users.

Less frequent mobile phone use increases the probability to purchase foods that can typically be bought at markets such as cereals, milk 85 milk products, sweets and sugars, and spices, condiments, and beverages. These findings are in line with our argument that mobile phones help better coordinate procurement of foods from distant markets. For instance, mobile phones allow people in the local setting to organize alternating travels to the market, which reduces transport and transaction costs significantly. The rather odd negative effect of weekly mobile phone use on the probability to have consumed fruits from purchase is difficult to explain.

We also analyzed whether mobile phones helped smoothen income during shocks by interacting the mobile phone variables with a dummy variable taking the value of unity in case the household head died in the last year or was sick for more than 45 days in the three months prior to the survey. Neither the shock variable itself nor the shock variable interacted with the mobile phone variable is significantly different from zero in any of the models analyzed in this study. The inability to capture such effects with the data at hand could be due to the relatively long time periods in-between the survey rounds and presents an interesting topic for further research. 
Table 4.7: Linear Probability Models for the consumption of each food groups when purchase was the main source

\begin{tabular}{|c|c|c|c|c|c|c|c|c|c|c|c|c|}
\hline & 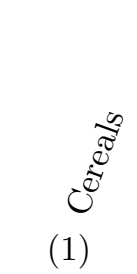 & 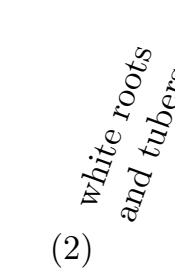 & (3) & 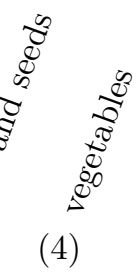 & $\begin{array}{c}: \underset{5}{5} \\
(5) \\
(5)\end{array}$ & $\underset{(6)}{\stackrel{\mathbb{E}}{\rightleftarrows}}$ & $\begin{array}{l}k^{20} \\
(7)\end{array}$ & 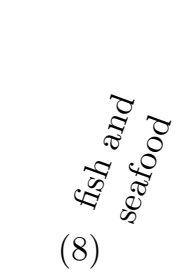 & 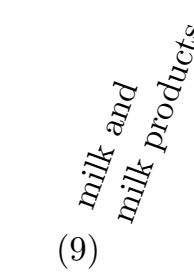 & 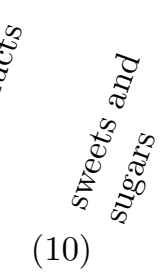 & 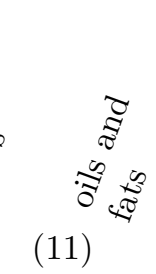 & 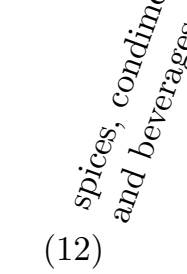 \\
\hline Daily MP use & $\begin{array}{c}0.000 \\
(0.016)\end{array}$ & $\begin{array}{c}0.054^{* *} \\
(0.021)\end{array}$ & $\begin{array}{c}0.039 \\
(0.030)\end{array}$ & $\begin{array}{l}0.048^{*} \\
(0.025)\end{array}$ & $\begin{array}{c}0.004 \\
(0.006)\end{array}$ & $\begin{array}{c}0.081^{* *} \\
(0.030)\end{array}$ & $\begin{array}{c}0.020^{* *} \\
(0.009)\end{array}$ & $\begin{array}{c}0.043^{* * *} \\
(0.013)\end{array}$ & $\begin{array}{c}0.035 \\
(0.029)\end{array}$ & $\begin{array}{c}0.028 * * \\
(0.012)\end{array}$ & $\begin{array}{c}0.018 \\
(0.026)\end{array}$ & $\begin{array}{c}0.013 \\
(0.009)\end{array}$ \\
\hline $\begin{array}{l}\text { Weekly MP use } \\
\text { (excl. daily use) }\end{array}$ & $\begin{array}{c}0.034^{* *} \\
(0.014)\end{array}$ & $\begin{array}{l}-0.019 \\
(0.022)\end{array}$ & $\begin{array}{c}0.019 \\
(0.030)\end{array}$ & $\begin{array}{l}-0.022 \\
(0.023)\end{array}$ & $\begin{array}{c}-0.020^{* *} \\
(0.008)\end{array}$ & $\begin{array}{c}0.043^{* *} \\
(0.019)\end{array}$ & $\begin{array}{c}0.013 \\
(0.010)\end{array}$ & $\begin{array}{c}0.012 \\
(0.013)\end{array}$ & $\begin{array}{c}0.101^{* * *} \\
(0.022)\end{array}$ & $\begin{array}{c}0.034^{* *} \\
(0.014)\end{array}$ & $\begin{array}{c}0.014 \\
(0.032)\end{array}$ & $\begin{array}{c}0.025^{* * *} \\
(0.007)\end{array}$ \\
\hline $\begin{array}{l}\text { At most monthly } \\
\text { MP use }\end{array}$ & $\begin{array}{c}0.022 \\
(0.019)\end{array}$ & $\begin{array}{c}0.030 \\
(0.020)\end{array}$ & $\begin{array}{c}0.029 \\
(0.019)\end{array}$ & $\begin{array}{c}0.011 \\
(0.022)\end{array}$ & $\begin{array}{c}0.001 \\
(0.009)\end{array}$ & $\begin{array}{c}0.047^{* *} \\
(0.021)\end{array}$ & $\begin{array}{c}0.004 \\
(0.009)\end{array}$ & $\begin{array}{c}0.013 \\
(0.013)\end{array}$ & $\begin{array}{c}0.026^{* *} \\
(0.011)\end{array}$ & $\begin{array}{c}0.019 \\
(0.011)\end{array}$ & $\begin{array}{c}0.019 \\
(0.020)\end{array}$ & $\begin{array}{c}0.014 \\
(0.009)\end{array}$ \\
\hline Control Variables & YES & YES & YES & YES & YES & YES & YES & YES & YES & YES & YES & YES \\
\hline $\begin{array}{l}\text { Division } \times \text { years } \\
\text { dummies }\end{array}$ & YES & YES & YES & YES & YES & YES & YES & YES & YES & YES & YES & YES \\
\hline
\end{tabular}

Notes: Estimates are based on an unbalanced panel data set with 5,506 observations and 1,062 groups. It is important to note that the items included in the two food groups meat and fish and seafood are slightly altered. Instead of having one group for meat, poultry and offal, and one group for fish and seafood, we have one group for goat and sheep meat and one group for fish, seafood, offal and all other meat. Standard errors shown in parentheses are robust and clustered at the sub-location level. $\mathrm{MP}=$ mobile phone. TLU $=$ Tropical Livestock Unit. Control variables are: nomadic status, radio possession, cooking source, income, land farmed, herd size, education, gender, age, household size. Full results with all control variables are shown in Table C6 in the online Appendix. ${ }^{* * *},{ }^{* * *}$ denote statistical significance at the $10 \%, 5 \%, 1 \%$ level respectively. 


\subsection{Conclusion}

Mobile phones are widely seen as an important technology for enhancing economic development. Communication without ICTs is associated with high opportunity costs especially in rural areas of developing countries. Mobile phones thus present a promising instrument to improve social welfare in such areas. This article has focused on nutrition as one essential social welfare dimension. We have analyzed whether and how mobile phone technology translates into improved dietary diversity among pastoral communities in Kenya. In particular, we used panel data from households in Northern Kenya covering six rounds from 2009 to 2015 to assess the effects of mobile phones on dietary diversity. We considered both mobile phone ownership and use. Dietary diversity was measured at the household level using two dietary diversity indicators. We further analyzed how mobile phones affect the number of food groups acquired through food purchases as well as the duration of the effects.

The results indicate that mobile phones are associated with higher levels of dietary diversity for households living in Kenya's arid and semi-arid lands and are therefore likely to contribute to improved nutrition in these areas. We argue that easier access to purchased foods, resulting from easier communication and coordination, could represent an important mechanism through which mobile phones improve dietary diversity.

When dietary diversity is measured using the household dietary diversity score with twelve food groups, mobile phone use is associated with higher dietary diversity for high and low usage frequencies. However, when dietary diversity is measured with a score that excludes three calorie-rich but micronutrient-poor food groups, only daily mobile phone use seems to improve dietary diversity. Results also show that mobile phones do not affect the consumption of self-produced foods, but are associated with increased consumption of foods obtained from purchases. This effect can be seen for all usage frequencies. The interpretation that dietary diversity is improved through easier communication and better access to purchased food is supported by the data and consistent with economic theory. We were able to control for a wide range of economic and social factors and self-selection of households based on time-invariant characteristics. This suggests that a causal relationship between mobile phones and household nutrition could be plausible.

We further looked into the duration of the positive effects that mobile phones have on dietary diversity. While dietary improvements based on mobile phone use seem to be sustainable and can be traced back at least five years after first access to mobile phones, the effects of mobile phone ownership on dietary diversity are weaker and much less sustainable.

Nevertheless, there are some limitations to our study, three of which deserve particular attention. First, we were not able to control for possible bias due to unobserved time-variant heterogeneity. Also, we could not analyze in more detail how and by whom mobile phones are actually used within the sample households, because such information 
is not available in the data set. Hence, causal interpretation should be made with some caution, although the effects described are plausible and cannot easily be explained by factors other than mobile phone use. Second, the relationships observed in the pastoral setting in Northern Kenya may be typical for pastoral communities with relatively poor market access, but should not be generalized to settings with very dissimilar conditions. In locations with more food crop production and better market access the effects of mobile phones on dietary diversity and nutrition may potentially be different. Third, the analyses are based on an unbalanced panel, since some observations dropped out of the survey. However, the attrition rate is relatively low, so we do not expect strong attrition bias in the estimates, which was also supported by an additional robustness check.

The lack of information regarding who uses mobile phones within the household calls for further scientific investigation in the future. While past research has started to address questions of intra-household phone usage (Sekabira and Qaim, 2017), more in-depth analysis could be worthwhile from a gender perspective. Further research on how mobile phones can be used to improve nutrition would be interesting as well, especially because mobile phones and smartphones also enable the dissemination of various other technologies and services.

Malnutrition is a relevant challenge in Northern Kenya. From the finding that mobile phones could help improve diets and nutrition in such areas, we draw several policy implications. First, we recommend policy makers to further facilitate the use of mobile phones in rural areas. Beyond helping to improve nutrition, mobile phones can have many other positive effects to spur rural development, as earlier research showed (Kikulwe et al., 2014; Aker and Mbiti, 2010). While many of the direct investments in ICT infrastructure are made by the private sector, public policies can facilitate access to mobile phones through enabling infrastructure (e.g., electricity) and conducive regulation. The households living farthest away from urban areas are the ones with the highest opportunity costs of reaching markets and thus can benefit most from mobile phone use. Second, policy makers should continue to develop methods to utilize mobile phones in order to reach and inform households about nutritious foods, balanced diets, and healthy lifestyles more generally. Third, it is crucial that costs for phone calls or text messages remain low and affordable. Many households in Kenya's ASAL are poor (Mburu et al., 2017), so that increases in communication costs could quickly diminish the benefits. Policies or interventions that keep such costs low could thus be beneficial to many households in pastoral communities. Although we cannot provide any estimates for the cost-effectiveness of such policies, we are confident that they could be justified, given the widespread food insecurity and poverty in the study region. 


\section{Chapter 5}

\section{General Conclusion}

\subsection{Main Findings}

The pastoralist communities in Northern Kenya are among the country's poorest and most vulnerable populations. Several challenges slow down the economic development in the region and cause social welfare of the pastoralist communities to remain low. In this thesis, we have analyzed two of these challenges in more detail, namely low levels of social trust among pastoralist communities and poor nutrition.

Playing the trust game by Berg et al. (1995) with nearly 400 members of a pastoralist community, we first demonstrated that social trust in general is low among this population. In addition, we also aimed at capturing the extent to which pastoralists grant trust towards other people by measuring levels of trust towards fellow villagers, towards people from a neighboring village, and towards people from the county capital. Behavior in the trust game suggested that social trust among pastoralists is low. Trust towards people from the county capital was found to be particularly limited, while fellow villagers and people from a neighboring village seemed to face somewhat higher levels of trust. Trust between fellow villagers and people from a neighboring was not significantly different. The concept of the radius of trust provides a possible explanation for this behavior.

In a second step, we then demonstrated that mobile phones are a particularly promising technology for pastoralist communities. We showed that mobile phone use can be associated with higher levels of social trust towards people from the county capital. This is beneficial, since pastoralsits' trust towards city dwellers is limited. However, the sustainability of these positive effects remains unclear. Lastly, we analyzed the effects of mobile phones on dietary diversity among pastoralist communities. We found that mobile phone ownership and use can be associated with higher dietary diversity. This effect seems to be partly driven by improved access of households to purchased foods.

\subsection{Limitations and Scope for Further Research}

Some limitations of the research presented in this thesis deserve further attention and should be addressed in future research. Both chapters concerned with social trust are 
based on the results of an incentivized trust game. This trust game measured trust towards fellow villagers, people from a neighboring village, and trust towards city dwellers from the county capital. While these levels of social distance represent groups of people with whom pastoralists engage regularly in economic activities, both studies could benefit from a higher number of social groups to be included in the experiment. With regard to the tribal tensions that exist in Northern Kenya, it seems worthwhile to have measurements of trust towards pastoralists from rivaling tribe as well. Whether mobile phones might actually increase or decrease trust towards this group is particularly interesting in the light of ongoing peace negotiations between the pastoralist tribes in Northern Kenya (Schilling et al., 2012; Noonan and Kevlihan, 2018).

Disentangling the aspects of social distance presents another challenge with the three treatments in the experiment. While interaction frequency is declining across the three treatments, other dimensions of social distance such as physical distance or group identity may also play a role. It would thus be interesting to see if levels of trust towards city dwellers and people from a village differ, when frequencies of interaction with both groups are identical. For the concept of the radius of trust it is not necessarily important if several dimension(s) of social distance are at play, as long as social distance is strictly monotonously increasing. Yet, having less dimensions of social distance at once would help better understand the relationship between social distance and trust.

The analyses of chapter 3 are based on cross-sectional data. The inability to appropriately capture a time dimension is particularly regrettable for research on the formation of trust, since trust and trustworthiness are developed in an iterative process (Woolcock and Narayan, 2000). The decisions of whether or not someone trusts another person is likely to be formed through a continuous updating of beliefs regarding the other person's trustworthiness and therefore rather dynamic than static. The cross-sectional nature of the data makes it difficult to assess the durability of the effects of mobile phones on trust towards city dwellers. Since the sustainability of the effects influences the practical implications that can be drawn from the research, we see the here-presented research mainly as a foundation for further research in this domain.

It is widely assumed that trust increases economic development (Knack and Keefer, 1997; Algan and Cahuc, 2010; Bjørnskov, 2012). Previous research has also shown that higher levels of trust have the potential to create efficiency gains in Northern Kenya's pastoral meat supply chain (Mahmoud, 2008; Roba et al., 2018). However, higher levels of trust are not per se beneficial for every person in every situation. If one's trust is not honored, higher levels of trust can also be disadvantageous for individuals in the short run. Pastoralists that increase their trust towards other city dwellers from the county capital, for example, might be worse off than pastoralists who do not increase their trust, if city dwellers are in fact untrustworthy and take advantage of a trusting person. How social trust relates to household income or welfare in the short- to medium-run is therefore unclear and should be further examined in future research. 
Both analyses in chapter 3 and chapter 4 are based on observational data. This makes any strong claims regarding the causality of mobile phone use on social trust and dietary diversity difficult. While we aim at identifying the effects with an instrumental variable approach and fixed effects panel estimations in the two studies respectively, full causality cannot be established in either case. We therefore highly encourage validations of our claims through experimental data, for example through the use of a randomized control trial (RCT). Gathering long run data based on RCTs is cumbersome and requires substantial time and capital investments by the researchers. It is however in principle feasible with regard to mobile phones in an African context (Aker et al., 2016). Further research in this domain based on experimental data is therefore encouraged.

\subsection{Policy Recommendations}

The research in this thesis highlights the potential of mobile phones for pastoralist communities. We therefore add to a growing body of literature emphasizing the benefits of this technology for pastoralists (Debsu et al., 2016; Djohy et al., 2017) and, more generally, for smallholders in rural Africa (Aker and Mbiti, 2010; ?; Sekabira and Qaim, 2017). The policy recommendations that we draw from this thesis thus focus on policies or projects that increase households' access to mobile phones and the utility that households can draw from this technology.

Pastoralists in rural Africa frequently mention low network coverage as the main barrier to mobile phone use (Rasmussen et al., 2015; Lewis et al., 2016; Vidal-González and Nahhass, 2018). Increasing the extent and strength of network signal can therefore impose an effective strategy to foster mobile phone use. Many of the direct investments needed to expand or improve network coverage are however not made by the government itself but by the private sector. To ensure that the private sector is able and willing to make the necessary investments, we see two promising strategies for governments.

As a first strategy, governments should ensure a healthy degree of competition in their mobile phone sector: the number of competitors should be small enough, so that each company is still sufficiently strong to stem the necessary investments for network expansion. At the same time the number of competitors should be large enough so that companies cannot exert market power. Providers are in that case more likely to compete for new customers, therefor extending network coverage into rural areas.

As an additional strategy, governments could impose license conditions for mobile phone operators when licenses are renewed or when additional spectrum is awarded. These conditions could for example set specific targets for the percentage of a country's population to be covered by a mobile phone network. This second strategy is more invasive than the first strategy and therefore more advisable for governments of countries with particularly weak network coverage in rural areas.

Another factor that can limit mobile phone use even in the presence of sufficient 
network coverage is insufficient electrical infrastructure. In remote villages without access to grid electricity, diesel generators are often used to enable mobile phone recharges (see for example Debsu et al. (2016)). During field work in 2018, we also observed pastoralists carrying portable solar panels to recharge their phones with them as they grazed the livestock. These alternative electricity sources enable mobile phone recharges even in the most remote areas, but usually come at a much higher price than electricity from the grid. We therefore advise governments to expand the electricity grid and/or subsidize portable solar panels.

High operating costs represent another barrier to mobile phone use. If prices for calling or text messaging are high, mobile phone use can quickly become too expensive for the relatively poor pastoralist households. Again, we advise governments to ensure a healthy degree of competition and sufficient antitrust legislation so that mobile phone operators are required to compete against one another with low prices. More invasive regulation such as maximal prices for airtime could in principle also be put in place if needed.

The above-mentioned policy recommendations relate to network coverage and mobile phone use quite broadly. They are therefore supported by the analyses of both chapter 3 and 4. The latter allows additional policy recommendation regarding mobile phones' specific potential to improve nutrition. One of the ways through which mobile phones can affect nutrition of rural households is mobile technology-driven capacity development. Through the use of agriculture and health mobile phone platforms, mobile phones can be used to deliver nutrition messages to rural and remote households. To increase knowledge and understanding of nutritious food and balanced diets, the mNutrition project for example targets marginalized and often poorly educated households in Kenya by providing service-ready mobile messages in form of factsheets, voice messages, or text messages. While challenges still exist, for example related to of content quality assurance and appropriate learning methods (Wandera et al., 2015), the approach seems promising. Crucial components of establishing and operating such technology-driven capacity development services are the identification of suitable local partners who create content that is accurate and fits to the population's nutritional needs, the assurance of training continuity of content creators, as well as the development of suitable learning methods (Wandera et al., 2015; Centre for Agriculture and Biosciences International, 2017b,a). We therefore encourage governments of both high- and low-income countries to devote resources to these components, so that the design and impact of mobile phone based nutrition services may be improved further. 


\section{Bibliography}

Abraham, S. and Sun, L. (2019). Estimating dynamic treatment effects in event studies with heterogeneous treatment effects. Working Paper Available at SSRN $315874 \%$.

Adriansen, H. K. (2008). Understanding pastoral mobility: the case of Senegalese Fulani. The Geographical Journal, 174(3):207-222.

Aker, J. C., Boumnijel, R., McClelland, A., and Tierney, N. (2016). Payment mechanisms and antipoverty programs: Evidence from a mobile money cash transfer experiment in Niger. Economic Development and Cultural Change, 65(1):1-37.

Aker, J. C. and Ksoll, C. (2016). Can mobile phones improve agricultural outcomes? evidence from a randomized experiment in Niger. Food Policy, 60:44-51.

Aker, J. C. and Mbiti, I. M. (2010). Mobile phones and economic development in Africa. Journal of Economic Perspectives, 24(3):207-232.

Akerlof, G. A. (1997). Social distance and social decisions. Econometrica, 65(5):1005-1027.

Akombi, B. J., Agho, K. E., Merom, D., Renzaho, A. M., and Hall, J. J. (2017). Child malnutrition in sub-Saharan Africa: A meta-analysis of demographic and health surveys (2006-2016). PLoS ONE, 12(5):e0177338.

Algan, Y. and Cahuc, P. (2010). Inherited trust and growth. The American Economic Review, 100(5):2060-2092.

Amwata, D. A., Nyariki, D. M., and Musimba, N. R. K. (2016). Factors influencing pastoral and agropastoral household vulnerability to food insecurity in the drylands of Kenya: A case study of Kajiado and Makueni Counties. Journal of International Development, 28(5):771-787.

Ansink, E., Tesfaye, A., Bouma, J., and Brouwer, R. (2017). Cooperation in watershed management: A field experiment on location, trust, and enforcement. Resource and Energy Economics, 50:91-104.

Arimond, M. and Ruel, M. (2004). Dietary diversity is associated with child nutritional status: Evidence from 11 demographic and health surveys. The Journal of Nutrition, 134(10):2579-2585. 
Arimond, M., Wiesmann, D., Becquey, E., Carriquiry, A., Daniels, M. C., Deitchler, M., Fanou-Fogny, N., Joseph, M. L., Kennedy, G., Martin-Prevel, Y., and Torheim, L. E. (2010). Simple food group diversity indicators predict micronutrient adequacy of women's diets in 5 diverse, resource-poor settings. The Journal of Nutrition, 140(11):2059S-69S.

Arrow, K. J. (1972). Gifts and exchanges. Philosophy \& Public Affairs, 1(4):343-362.

Asaka, J. O. and Smucker, T. A. (2016). Assessing the role of mobile phone communication in drought-related mobility patterns of Samburu pastoralists. Journal of Arid Environments, 128:12-16.

Balehegn, M., Balehey, S., Fu, C., and Liang, W. (2019). Indigenous weather and climate forecasting knowledge among Afar pastoralists of north eastern Ethiopia: Role in adaptation to weather and climate variability. Pastoralism: Research, Policy and Practice, 9(1):114.

Barr, A. (2003). Trust and expected trustworthiness: Experimental evidence from Zimbabwean villages. The Economic Journal, 113:614-630.

Bauer, J. M. and Mburu, S. (2017). Effects of drought on child health in Marsabit District, Northern Kenya. Economics and Human Biology, 24:74-79.

Bauer, P. C. and Freitag, M. (2018). Measuring trust. In Uslaner, E. M., editor, The Oxford Handbook of Social and Political Trust, pages 15-36. Oxford University Press.

Ben-Ner, A. and Putterman, L. (2009). Trust, communication and contracts: An experiment. Journal of Economic Behavior \& Organization, 70(1-2):106-121.

Berg, J., Dickhaut, J., and McCabe, K. (1995). Trust, reciprocity, and social history. Games and Economic Behavior, 10:122-142.

Bester, C. A. and Hansen, C. B. (2016). Grouped effects estimators in fixed effects models. Journal of Econometrics, 190(1):197-208.

Beuermann, D. W., McKelvey, C., and Vakis, R. (2012). Mobile phones and economic development in rural Peru. Journal of Development Studies, 48(11):1617-1628.

Binzel, C. and Fehr, D. (2013). Social distance and trust: Experimental evidence from a slum in Cairo. Journal of Development Economics, 103:99-106.

Bjørnskov, C. (2012). How does social trust affect economic growth? Southern Economic Journal, 78(4):1346-1368.

Bjørnskov, C. and Méon, P.-G. (2015). The productivity of trust. World Development, 70:317-331. 
Bond, J. and Mkutu, K. A. (2018). A patchwork for peace: institutions and activities in Kenya's Northern drylands. Local Environment, 23(3):239-315.

Bonfoh, B., Fokou, G., Crump, L., Zinsstag, J., and Schelling, E. (2016). Institutional development and policy frameworks for pastoralism: From local to regional perspectives. Revue scientifique et technique (International Office of Epizootics), 35(2):499-509.

Bouma, J., Soest, D. v., and Bulte, E. (2008). Trust and cooperation: social capital and community resource management. Journal of Environmental Economics and Management, 56(2).

Brülhart, M. and Usunier, J.-C. (2012). Does the trust game measure trust? Economics Letters, 115(1):20-23.

Buchan, N. R., Johnson, E. J., and Croson, R. T. (2006). Let's get personal: An international examination of the influence of communication, culture and social distance on other regarding preferences. Journal of Economic Behavior \& 3 Organization, 60(3):373-398.

Burns, J. (2012). Race, diversity and pro-social behavior in a segmented society. Journal of Economic Behavior \& Organization, 81(2):366-378.

Butt, B. (2015). Herding by mobile phone: Technology, social networks and the "transformation" of pastoral herding in East Africa. Human Ecology, 43(1):1-14.

Cárdenas, J. C. and Carpenter, J. (2008). Behavioural development economics: Lessons from field labs in the developing world. The Journal of Development Studies, $44(3): 311-338$.

Cárdenas, J. C., Chong, A., and Ñopo, H. (2013). Stated social behavior and revealed actions: Evidence from six Latin American countries. Journal of Development Economics, 104:16-33.

Centre for Agriculture and Biosciences International (2017a). Lessons learned from the content development stream of the mNutrition initiative: How to set up the right content creation model, processes and structures to achieve maximum project efficiency and quality outputs. mNutrition Brief, 1.

Centre for Agriculture and Biosciences International (2017b). Lessons learned from the content development stream of the mNutrition initiative: Key recommendations for content creation. CABI, Oxford, UK.

Chetty, R., Hofmeyr, A., Kincaid, H., and Monroe, B. (2020). The trust game does not (only) measure trust: The risk-trust confound revisited. Journal of Behavioral and Experimental Economics, page 101520. 
Cissé, J. D. and Barrett, C. B. (2018). Estimating development resilience: A conditional moments-based approach. Journal of Development Economics, 135:272-284.

Collier, P. (2002). Social capital and poverty: A microeconomic perspective. In Grootaert, C. and van Bastelaer, T., editors, The Role of Social Capital in Development, pages 19-41. Cambridge University Press, Cambridge.

Commission on Revenue Allocation (2012). Survey report in marginalized areas/ Counties in Kenya. CRA Working Paper, 3.

Commission on Revenue Allocation (2013). Kenya: County fact sheet.

Cronk, L. (2007). The influence of cultural framing on play in the trust game: A Maasai example. Evolution and Human Behavior, 28(5):352-358.

Crump, L., Béchir, M., Ngandolo, B. N. R., Daugla, D. M., Hattendorf, J., and Zinsstag, J. (2017). Seasonal dynamics of human retinol status in mobile pastoralists in Chad. Acta tropica, 166:280-286.

Danielson, A. J. and Holm, H. J. (2007). Do you trust your brethren? Journal of Economic Behavior \& Organization, 62(2):255-271.

Davies, J. and Bennett, R. (2007). Livelihood adaptation to risk: Constraints and opportunities for pastoral development in Ethiopia's Afar region. The Journal of Development Studies, 43(3):490-511.

de Bruijn, M., Amadou, A., Lewa Doksala, E., and Sangaré, B. (2016). Mobile pastoralists in Central and West Africa: Between conflict, mobile telephony and (im)mobility. Revue scientifique et technique (International Office of Epizootics), 35(2):649-657.

Debsu, D. N., Little, P. D., Tiki, W., Guagliardo, S. A. J., and Kitron, U. (2016). Mobile phones for mobile people: The role of information and communication technology (ICT) among livestock traders and Borana pastoralists of Southern Ethiopia. Nomadic Peoples, 20(1):35-61.

Delhey, J., Newton, K., and Welzel, C. (2011). How general is trust in "most people"? solving the radius of trust problem. American Sociological Review, 76(5):786-807.

Development Initiatives (2017). Global Nutrition Report 2017: Nourishing the SDGs. Development Initiatives, Bristol, UK.

Development Initiatives (2018). 2018 Global Nutrition Report: Shining a light to spur action on nutrition. Development Initiatives, Bristol, UK.

Djohy, G., Edja, H., and Schareika, N. (2017). Mobile phones and socio-economic transformation among Fulani pastoralists in northern Benin. Nomadic Peoples, 21(1):111-135. 
Eckel, C. C. and Grossman, P. J. (2002). Sex differences and statistical stereotyping in attitudes toward financial risk. Evolution and Human Behavior, 23(4):281-295.

Ensminger, J. (2001). Reputations, trust, and the principal agent problem. In Cook, K. S., editor, Trust in Society, pages 185-201. Russell Sage Foundation, New York, N.Y.

Etang, A. (2010). Analysing the radius of trust in rural Cameroon. Journal of African Economies, 19(5):691-717.

Etang, A., Fielding, D., and Knowles, S. (2011). Does trust extend beyond the village? Experimental trust and social distance in Cameroon. Experimental Economics, $14(1): 15-35$.

Etang, A., Fielding, D., and Knowles, S. (2012). Are survey measures of trust correlated with experimental trust? evidence from Cameroon. Journal of Development Studies, 48(12):1813-1827.

Fafchamps, M. (1996). The enforcement of commercial contracts in Ghana. World Development, 24(3):427-448.

Fafchamps, M. (2006). Development and social capital. Journal of Development Studies, 42(7):1180-1198.

Fafchamps, M. and Minten, B. (2002). Returns to social network capital among traders. Oxford Economic Papers, 54(54):173-206.

FAO (2016). Free prior and informed consent. an indigenous people's right and a good practice for local communities: Manual for project practicioners.

Financial Sector Deepening Kenya (2019). 2019 FinAcces Household Survey.

Fongar, A., Gödecke, T., Aseta, A., and Qaim, M. (2019). How well do different dietary and nutrition assessment tools match? insights from rural Kenya. Public Health Nutrition, 22(3):391-403.

Freitag, M. and Bauer, P. C. (2013). Testing for measurement equivalence in surveys. Public opinion quarterly, 77(S1):24-44.

Freitag, M. and Traunmüller, R. (2009). Spheres of trust: An empirical analysis of the foundations of particularised and generalised trust. European Journal of Political Research, 48(6):782-803.

Fukuyama, F. (2000). Social capital and civil society. IMF Working Paper, 74.

Gambetta, D. (2000a). Can we trust trust. In Gambetta, D., editor, Trust, pages 213-227. University of Oxford, Oxford. 
Gambetta, D., editor (2000b). Trust: Making and Breaking Cooperative Relations. University of Oxford, Oxford.

Gesare, A., Chelanga, P., and Banerjee, R. (2017). Feasibility of establishing a market information system in the Horn of Africa: Insights from Northern Kenya. ILRI Research Brief, 79:1-4.

Glaeser, E. L., Laibson, D., Scheinkman, J., and Soutter, C. (2000). Measuring trust. Quarterly Journal of Economics, pages 811-846.

Glanville, J. and Paxton, P. (2007). How do we learn to trust? A confirmatory tetrad analysis of the sources of generalized trust. Social Psychology Quarterly, 70(3):230242.

Gourieroux, C., Monfort, A., Renault, E., and Trognon, A. (1987). Generalised residuals. Journal of Econometrics, 34:5-32.

Grace, K., Brown, M., and McNally, A. (2014). Examining the link between food prices and food insecurity: A multi-level analysis of maize price and birthweight in Kenya. Food Policy, 46:56-65.

Greene, W. (2004). The behaviour of the maximum likelihood estimator of limited dependent variable models in the presence of fixed effects. The Econometrics Journal, $7(1): 98-119$.

Greenland, S., Senn, S. J., Rothman, K. J., Carlin, J. B., Poole, C., Goodman, S. N., and Altman, D. G. (2016). Statistical tests, p values, confidence intervals, and power: A guide to misinterpretations. European Journal of Epidemiology, 31(4):337-350.

Grillos, T. (2018). Women's participation in environmental decision-making: Quasiexperimental evidence from Northern Kenya. World Development, 108:115-130.

Gupta, G., Mahmud, M., Maitra, P., Mitra, S., and Neelim, A. (2018). Religion, minority status, and trust: Evidence from a field experiment. Journal of Economic Behavior E) Organization, 146:180-205.

Harrison, L. E. (1985). Underdevelopment is a State of Mind: The Latin American Case. Madison Books, New York, N.Y.

Herrero, M., Addison, J., Bedelian, C., Carabine, E., Havlík, P., Henderson, B., van de Steeg, J., and Thornton, P. K. (2016). Climate change and pastoralism: impacts, consequences and adaptation. Revue scientifique et technique (International Office of Epizootics), 35(2):417-433. 
Hirschauer, N., Grüner, S., Mußhoff, O., and Becker, C. (2018). Pitfalls of significance testing and p-value variability: An econometrics perspective. Statistics Surveys, 12(0):136-172.

Hirvonen, K. and Hoddinott, J. (2017). Agricultural production and children's diets: Evidence from rural Ethiopia. Agricultural Economics, 48(4):469-480.

Hoddinott, J., Behrman, J. R., Maluccio, J. A., Melgar, P., Quisumbing, A. R., RamirezZea, M., Stein, A. D., Yount, K. M., and Martorell, R. (2013). Adult consequences of growth failure in early childhood. The American journal of clinical nutrition, 98(5):1170-1178.

Hoffman, E., McCabe, K., and Smith, V. L. (1996). Social distance and other-regarding behavior in dictator games. American Economic Review, 86(3):654-660.

Houser, D., Schunk, D., and Winter, J. (2010). Distinguishing trust from risk: An anatomy of the investment game. Journal of Economic Behavior \& Organization, 74(1-2):7281.

Iannotti, L. and Lesorogol, C. (2014). Dietary intakes and micronutrient adequacy related to the changing livelihoods of two pastoralist communities in Samburu, Kenya. Current Anthropology, 55(4):475-482.

Ikegami, M. and Sheahan, M. (2017). Index Based Livestock Insurance (IBLI) Marsabit Household Survey Codebook.

Jack, W. and Suri, T. (2014). Risk sharing and transactions costs: Evidence from Kenya's mobile money revolution. American Economic Review, 104(1):183-223.

Johansson-Stenman, O., Mahmud, M., and Martinsson, P. (2013). Trust, trust games and stated trust: Evidence from rural Bangladesh. Journal of Economic Behavior \& Organization, 95:286-298.

Johnson, N. D. and Mislin, A. A. (2011). Trust games: A meta-analysis. Journal of Economic Psychology, 32(5):865-889.

Jones, A. D., Shrinivas, A., and Bezner-Kerr, R. (2014). Farm production diversity is associated with greater household dietary diversity in Malawi: Findings from nationally representative data. Food Policy, 46:1-12.

Kadushin, C. (1962). Social distance between client and professional. American Journal of Sociology, 67(5):517-531.

Karakayali, N. (2009). Social distance and affective orientations. Sociological Forum, $24(3): 538-562$. 
Karlan, D. (2005). Using experimental economics to measure social capital and predict financial decisions. The American Economic Review, 95(5):1688-1699.

Kikulwe, E. M., Fischer, E., and Qaim, M. (2014). Mobile money, smallholder farmers, and household welfare in Kenya. PLoS ONE, 9(10):1-13.

Knack, S. and Keefer, P. (1997). Does social capital have an economic payoff? a crosscountry investigation. The Quarterly Journal of Economics, 112(4):1251-1288.

Knack, S. and Zak, P. (2003). Building trust: Public policy, interpersonal trust, and economic development. Supreme Court Economic Review, 10:91-107.

Koppmair, S., Kassie, M., and Qaim, M. (2017). Farm production, market access and dietary diversity in Malawi. Public Health Nutrition, 20(2):325-335.

Labonne, J. and Chase, R. S. (2009). The power of information: The impact of mobile phones on farmers' welfare in the Philippines. World Bank Policy Research Working Paper, 4996.

Labonne, J. and Chase, R. S. (2010). A road to trust. Journal of Economic Behavior \&6 Organization, 74(3):253-261.

Lewicki, R. J., Tomlinson, E. C., and Gillespie, N. (2006). Models of interpersonal trust development: Theoretical approaches, empirical evidence, and future directions. Journal of Management, 32(6):991-1022.

Lewis, A. L., Baird, T. D., and Sorice, M. G. (2016). Mobile phone use and human-wildlife conflict in northern tanzania. Environmental management, 58(1):117-129.

Lio, M. and Liu, M.-C. (2006). ICT and agricultural productivity: evidence from crosscountry data. Agricultural Economics, 34:221-228.

Little, P. D., McPeak, J., Barrett, C. B., and Kristjanson, P. (2008). Challenging orthodoxies: Understanding poverty in pastoral areas of East Africa. Development and Change, 39(4):587-611.

Mahmoud, H. (2008). Risky trade, resilient traders: Trust and livestock marketing in Northern Kenya. Africa, 78(4):561-581.

Manski, C. F. and Tamer, E. (2002). Inference on regressions with interval data on a regressor or outcome. Econometrica, 70(2):519-546.

Mattes, R. and Moreno, A. (2018). Social and political trust in developing countries: Sub-Saharan and Latin America. In Uslaner, E. M., editor, The Oxford Handbook of Social and Political Trust, pages 357-381. Oxford University Press. 
Mburu, S., Otterbach, S., Sousa-Poza, A., and Mude, A. (2017). Income and asset poverty among pastoralists in Northern Kenya. The Journal of Development Studies, 53(6):971-986.

McCloskey, D. N. and Ziliak, S. T. (1996). The standard error of regressions. Journal of Economic Literature, 34(1):97-114.

Mertz, O., Rasmussen, K., and Rasmussen, L. V. (2016). Weather and resource information as tools for dealing with farmer-pastoralist conflicts in the Sahel. Earth System Dynamics, 7(4):969-976.

Molony, T. (2006). 'I don't trust the phone; it always lies': Trust and information and communication technologies in Tanzanian micro- and small enterprises. Information Technologies and International Development, 3(4):67-83.

Molony, T. (2009). Carving a niche: ICT, social capital, and trust in the shift from personal to impersonal trading in Tanzania. Information Technology for Development, 15(4):283-301.

Mude, A., Ouma, R., and Lentz, E. (2012). Responding to food insecurity: Employing the market information and food insecurity response analysis framework in rural Northern Kenya. Journal of Development Studies, 48(12):1731-1749.

Muto, M. and Yamano, T. (2009). The impact of mobile phone coverage expansion on market participation: Panel data evidence from Uganda. World Development, 37(12):1887-1896.

Nakasone, E. and Torero, M. (2016). A text message away: ICTs as a tool to improve food security. Agricultural Economics, 47(S1):49-59.

Nakasone, E., Torero, M., and Minten, B. (2014). The power of information: The ICT revolution in agricultural development. Annual Review of Resource Economics, 6(1):533550 .

Newton, K. (2001). Trust, social capital, civil society, and democracy. International Political Science Review, 22(2):201-214.

Newton, K. and Zmerli, S. (2011). Three forms of trust and their association. European Political Science Review, 3(02):169-200.

Neyman, J. and Scott, E. (1948). Consistent estimates based on partially consistent observations. Econometrica, 16(1):1-32. 
Ng'ang'a, S. K., Bulte, E. H., Giller, K. E., Ndiwa, N. N., Kifugo, S. C., McIntire, J. M., Herrero, M., and Rufino, M. C. (2016). Livestock wealth and social capital as insurance against climate risk: A case study of Samburu County in Kenya. Agricultural Systems, 146:44-54.

Nilsson, J. and Salazar, N. B. (2017). Embedded and re-purposed technologies: Human mobility practices in Maasailand. Mobilities, 12(3):445-461.

Noonan, O. and Kevlihan, R. (2018). Managing conflict in north-west Kenya: The siege of Loregon and its aftermath. Conflict, Security $\&$ Development, 18(2):137-157.

Nyaradi, A., Li, J., Hickling, S., Foster, J., and Oddy, W. H. (2013). The role of nutrition in children's neurocognitive development, from pregnancy through childhood. Frontiers in human neuroscience, 7:97.

Odhiambo, M. O. (2013). The Asal Policy of Kenya: Releasing the full potential of arid and semi-arid lands - an analytical review. Nomadic Peoples, 17(1):158-165.

O’Doherty, K., Rao, S., and Maio Mackay, M. (2007). Young Australians' perceptions of mobile phone content and information services: An analysis of the motivations behind usage. Young Consumers, 8(4):257-268.

Onyango, A., Koski, K. G., and Tucker, K. L. (1998). Food diversity versus breastfeeding choice in determining anthropometric status in rural Kenyan toddlers. International journal of epidemiology, 27(3):484-489.

Opiyo, F., Wasonga, O., and Nyangito, M. (2014). Measuring household vulnerability to climate-induced stresses in pastoral rangelands of Kenya: Implications for resilience programming. Pastoralism: Research, Policy and Practice, 4(10):1-15.

Opiyo, F., Wasonga, O., Nyangito, M., Schilling, J., and Munang, R. (2015). Drought adaptation and coping strategies among the turkana pastoralists of Northern Kenya. International Journal of Disaster Risk Science, 6(3):295-309.

Ostrom, E., Walker, J., and Gardner, R. (1992). Covenants with and without a sword: Self-governance is possible. American Political Science Review, 86(2):404-417.

Overå, R. (2006). Networks, distance, and trust: Telecommunications development and changing trading practices in Ghana. World Development, 34(7):1301-1315.

Parlasca, M. C., Hermann, D., and Mußhoff, O. (2019). A radius of trust? Contrasting insights from experiments and survey data. cege disucssion paper, 383.

Parlasca, M. C., Mußhoff, O., and Qaim, M. (2020). Can mobile phones improve nutrition among pastoral communities? Panel data evidence from Northern Kenya. Agricultural Economics, 51(3):475-488. 
Paul, C. J., Weinthal, E. S., Bellemare, M. F., and Jeuland, M. A. (2016). Social capital, trust, and adaptation to climate change: Evidence from rural Ethiopia. Global Environmental Change, 36:124-138.

Pavanello, S. (2010). Livestock marketing in Kenya-Ethiopia border areas: A baseline study. HPG Working Papers.

Platteau, J.-P., de Bock, O., and Gelade, W. (2017). The demand for microinsurance: A literature review. World Development, 94:139-156.

Putnam, R. D., Leonardi, R., and Nanetti, R. Y. (1993). Making Democracy Work: Civic Traditions in Modern Italy. Princton University Press, Princton.

Rasmussen, L. V., Mertz, O., Rasmussen, K., and Nieto, H. (2015). Improving how meteorological information is used by pastoralists through adequate communication tools. Journal of Arid Environments, 121:52-58.

Rasmussen, L. V., Mertz, O., Rasmussen, K., Nieto, H., Ali, A., and Maiga, I. (2014). Weather, climate, and resource information should meet the needs of Sahelian pastoralists. Weather, Climate, and Society, 6(4):482-494.

Reeskens, T. (2013). But who are those "most people" that can be trusted? evaluating the radius of trust across 29 European societies. Social Indicators Research, 114(2):703722 .

Reeskens, T. and Hooghe, M. (2008). Cross-cultural measurement equivalence of generalized trust. evidence from the European social survey (2002 and 2004). Social Indicators Research, 85(3):515-532.

Roba, G. M., Lelea, M. A., Hensel, O., and Kaufmann, B. (2018). Making decisions without reliable information: The struggle of local traders in the pastoral meat supply chain. Food Policy, 76:33-43.

Roba, G. M., Lelea, M. A., and Kaufmann, B. (2017). Manoeuvring through difficult terrain: How local traders link pastoralists to markets. Journal of Rural Studies, 54:85-97.

Sanfey, A., Rilling, J., Aronson, J., Nystrom, L., and Cohen, J. (2003). The neural basis of economic decision-making in the ultimatum game. Science, 300:1755-1758.

Sapienza, P., Toldra-Simats, A., and Zingales, L. (2013). Understanding trust. The Economic Journal, 123(573):1313-1332.

Schechter, L. (2007). Traditional trust measurement and the risk confound: An experiment in rural Paraguay. Journal of Economic Behavior \& Organization, 62(2):272-292. 
Schilling, J., Opiyo, F., and Scheffran, J. (2012). Raiding pastoral livelihoods: Motives and effects of violent conflict in North-Western Kenya. Pastoralism: Research, Policy and Practice, 2(25).

Seid, M. A., Yoseph, L. W., Befekadu, U. W., Muhammed, A., and Fikre, T. Z. (2016). Communication for the development of pastoralism. Revue scientifique et technique (International Office of Epizootics), 35(2):639-648.

Sekabira, H. and Qaim, M. (2017). Can mobile phones improve gender equality and nutrition? panel data evidence from farm households in Uganda. Food Policy, 73:95103.

Sibhatu, K. T., Krishna, V. V., and Qaim, M. (2015). Production diversity and dietary diversity in smallholder farm households. Proceedings of the National Academy of Sciences of the United States of America, 112(34):10657-10662.

Sibhatu, K. T. and Qaim, M. (2018a). Farm production diversity and dietary quality: Linkages and measurement issues. Food Security, 10(1):47-59.

Sibhatu, K. T. and Qaim, M. (2018b). Review: Meta-analysis of the association between production diversity, diets, and nutrition in smallholder farm households. Food Policy, $77: 1-18$.

Sife, A. S., Kiondo, E., and Lyimo-Macha, J. (2010). Contribution of mobile phones to rural livelihoods and poverty reduction in Morogoro Region, Tanzania. The Electronic Journal on Information Systems in Developing Countries, 42(3):1-15.

Silvestri, S., Bryan, E., Ringler, C., Herrero, M., and Okoba, B. (2012). Climate change perception and adaptation of agro-pastoral communities in Kenya. Regional Environmental Change, 12(4):791-802.

Snapp, S. S. and Fisher, M. (2015). "Filling the maize basket" supports crop diversity and quality of household diet in Malawi. Food Security, 7(1):83-96.

Stolle, D. (2002). Trusting strangers: The concept of generalized trust in perspective. Austrian Journal of Political Science, 31(4):397-412.

Swindale, A. and Bilinksy, P. (2006). Household Dietary Diversity Score (HDDS) for measurement of household food access: Indicator guide.

Tadesse, G. and Bahiigwa, G. (2015). Mobile phones and farmers' marketing decisions in Ethiopia. World Development, 68:296-307.

Takahashi, K., Ikegami, M., Sheahan, M., and Barrett, C. B. (2016). Experimental evidence on the drivers of Index-Based Livestock Insurance demand in Southern Ethiopia. World Development, 78:324-340. 
Tanis, M. and Postmes, T. (2005). A social identity approach to trust: Interpersonal perception, group membership and trusting behaviour. European Journal of Social Psychology, 35(3):413-424.

Terza, J. V., Basu, A., and Rathouz, P. J. (2008). Two-stage residual inclusion estimation: Addressing endogeneity in health econometric modeling. Journal of Health Economics, 27(3):531-543.

Torpe, L. and Lolle, H. (2011). Identifying social trust in cross-country analysis: Do we really measure the same? Social Indicators Research, 103(3):481-500.

Turkana County Government (2014). Turkana county second annual development plan $2015 / 2016$.

Turner, M. D. and Schlecht, E. (2019). Livestock mobility in sub-Saharan Africa: A critical review. Pastoralism, 9(1):207.

Upton, J. B., Cissé, J. D., and Barrett, C. B. (2016). Food security as resilience: Reconciling definition and measurement. Agricultural Economics, 47(S1):135-147.

Uslaner, E. M. (2002). The Moral Foundations of Trust. Cambridge University Press, Cambridge, UK.

van Hoorn, A. (2014). Trust radius versus trust level. American Sociological Review, $79(6): 1256-1259$.

Verbeek, M. (2004). A Guide to Modern Econometrics. John Wiley \& Sons, Ltd, Chichester, England, 2 edition.

Vidal-González, P. and Nahhass, B. (2018). The use of mobile phones as a survival strategy amongst nomadic populations in the Oriental region (Morocco). GeoJournal, 83(5):1079-1090.

Vigan, A., Lasseur, J., Benoit, M., Mouillot, F., Eugène, M., Mansard, L., Vigne, M., Lecomte, P., and Dutilly, C. (2017). Evaluating livestock mobility as a strategy for climate change mitigation: Combining models to address the specificities of pastoral systems. Agriculture, Ecosystems \& Environment, 242:89-101.

Wandera, B., Kang'ethe, E., and Davies, B. (2015). Mobile technology-driven capacity development: lessons from the mnutrition and ibli projects. ILRI Capacity development brief, $3: 1-4$.

Weiss, C. H. (1995). Nothing as practical as good theory: Exploring theory-based evaluation for comprehensive community initiatives for children and families. In Connell, J. P., editor, New approaches to evaluating community initiatives, pages 65-92. Aspen Institute, Queenstown, Md. 
Welch, M. R., Sikkink, D., and Loveland, M. T. (2007). The radius of trust: Religion, social embeddedness and trust in strangers. Social Forces, 86(1):23-46.

Wilson, R. K. (2018). Trust experiments, trust games, and surveys. In Uslaner, E. M., editor, The Oxford Handbook of Social and Political Trust, pages 279-304. Oxford University Press.

Woolcock, M. and Narayan, D. (2000). Social capital: Implications for development theory, research, and policy. The World Bank Research Observer, 15(2):225-249.

Wooldridge, J. M. (2010). Econometric Analysis of Cross Section and Panel Data. MIT Press, Cambridge, MA, 2 edition.

Wooldridge, J. M. (2014). Quasi-maximum likelihood estimation and testing for nonlinear models with endogenous explanatory variables. Journal of Econometrics, 182(1):226234 .

Wooldridge, J. M. (2015). Control function methods in applied econometrics. Journal of Human Resources, 50(2):420-445.

Yamagishi, T. and Yamagishi, M. (1994). Trust and commitment in the United States and Japan. Motivation and Emotion, 18(2):129-166.

Zak, P. and Knack, S. (2001). Trust and growth. The Economic Journal, 111:295-321.

Zanello, G. (2012). Mobile phones and radios: Effects on transactions costs and market participation for households in Northern Ghana. Journal of Agricultural Economics, 63(3):694-714. 
Appendices 



\section{Appendix A}

\section{Radius of Trust}

\section{A.1 Game Protocol and Assingment of Strategies}

\section{A.1.1 Game Protocol}

The protocol used for the field experiment of this study is very closely related to a game protocol employed by Schechter (2007). She in turn builds up on the project "The Roots of Human Sociality: an Ethno-Experimental Exploration of the Foundations of Economic Norms in 16 Small-Scale Societies" by Barr, Barrett, Bolyanatz, Cardenas, de la Pena, Ensminger, Gil-White, Gurven, Gwako, Henrich, Johnson, Marlowe, McElreath, Lesorogol, Patton, and Tracer.

\section{A.1.1.1 Opening Instructions}

Thank you all for taking the time to come today. We are here with you today to play a game with you and to ask you some questions. We will first start with a game and afterwards conduct interviews with each one of you. We invited you here today, because you were randomly selected from this village to participate in this activity. Only those people that were selected can participate. The decision of who was to be selected was not made by us, but by chance. We did not influence the selection and cannot change it.

The game that we will be playing now and the interviews will take approximately 4 hours, so if you think you will not be able to stay that long without leaving please let us know now. Before we begin I want to make some general comments about what we are doing here today and explain some rules that we need to follow. We will be playing a game for real money that you can take home. You should understand that this is not our own money. It is money given to us by a university to use to do a research study. This research will eventually be part of a book. It is not part of a development project of any sort. There are many researchers who are carrying out the same kind of games all around the world.

Before we proceed any further, let me stress something that is very important. Many of you were invited here without understanding very much about what we are planning to do today. If at any time you find that this is something that you do not wish to participate 
in for any reason, you are of course free to leave whether we have started the game or not. We are about to begin the game. It is important that you listen as carefully as possible, because only people who understand the game will actually be able to play it. We will run through some examples here while we are all together. You cannot ask questions or talk about the game while we are here together. This is very important and please be sure that you obey this rule, because it is possible for one person to spoil the game for everyone, in which case we would not be able to play the game today. Do not worry if you do not completely understand the game as we go through the examples here in the group. Each of you will have a chance to ask questions in private with [Name of enumerator and field assistant] to be sure that you understand how to play.

This game is played by two people, which we call player 1 and player 2 . All of you will first play this game as player 1. But each of you will have a different partner, with whom you play the game. For some of you player 2 will be someone from this village. For some of you player 2 will be a pastoralist from a neighboring village and for some of you player 2 will be a city dweller from Lodwar. We will later tell each of you individually if you will play the game with someone from your village, or with a pastoralist from a neighboring village, or with a city dweller from Lodwar. However, none of you will know the name of the person with whom you are playing. Only [name of corresponding author] knows who is to play with whom and he will never tell anyone else. You will only know if it is a person from your village, or a pastoralist from a neighboring village or a city dweller from Lodwar.

Let me explain the game. We will soon talk with each of you in private and we will give each one of you 500 Kenyan Shillings and an envelope to play with. Then we will tell you if you play this game with someone from this village or someone from a pastoralist from a neighboring village or a city dweller from Lodwar. You then have the opportunity to send any portion of that money to the person you are paired with by putting it into the envelope. Whatever amount you put into the envelope will be tripled by the research team and then the envelope will be passed to the other player. Whatever amount you do not put into the envelope can be kept by you. We triple the amount of money that you put into the envelope and pass the envelope to the player 2. That player has the option of returning any portion of this tripled amount to you. You must know that all the other players also played this game before in the role of player 1. At the end of today, when everyone here played the game, you will receive the envelope back from your partner. At the end of the game you can keep all the money you did not put into the envelope plus anything that was returned to you by player 2 .

Then, the game is over.

You see that there is no person here from Lodwar and no person from a neighboring village. So you will ask yourself, how we know if your partner wants to send something back to you and if yes, how much your partner wants to send back to you. So let me explain. We have played this game before in Lodwar and also in neighboring villages with 
other pastoralists and we have asked them to write down how much they want to send back to you. So we have a list where people told us if they want to send something back and if yes, how much they want to send to you. Only [name of corresponding author] has this list and he will not show it to anyone or talk with anyone about it.

Let us now go through some examples how the game could be played together:

1. Imagine that we start the game and it is your turn to play. You come to us and we tell you that you are playing with another pastoralist from this village. Remember, you will never know who exactly that person is. Now you can decide how much you want to send to that person. For example, you can decide to send all 500 shillings to the other player. We triple this amount, so that we will give 1500 shillings to the person with whom you play (3 times 500 shillings equals 1500 shillings). At this point, you have nothing and player 2 has 1500 shillings. Then we ask player 2 if he or she wishes to give anything back to you, and if so, how much. Suppose player 2 decides to return 200 shillings to you. At the end of the game you will go home with 200 shillings and the other player will go home with 1300 shillings.

2. Now let's try another example. Imagine that it is your turn and we tell you that you play with another pastoralist from a neighboring village. Again, you will never know who that person is. Now for example you decide to send 200 shillings to that player 2, and keep the remaining $300 \mathrm{KSh}$. We triple the amount so that we will give 600 shillings ( 3 times 200 shillings equals 600 shillings) to the player 2. At this point, you have 300 shillings and player 2 has 600 shillings. Then player 2 has to decide whether he wishes to give anything back you, and if so, how much. Suppose player 2 decides to return zero shillings to you. At the end of the game you will go home with 300 shillings and player 2 will go home with 600 shillings.

3. Now let's try another example. Imagine that you are paired with a city dweller from Lodwar and you decide to send 100 shillings to that player 2. Again, you will never know the exact identity of the player. We triple this amount, so player 2 gets 300 shillings (3 times 100 equals 300). At this point, you have 400 shillings and player 2 has 300 shillings. Then player 2 has to decide whether he wishes to give anything back to player 1, and if so, how much. Suppose player 2 decides to return 200 shillings to player 1 . At the end of the game you will go home with 600 shillings and player 2 will go home with 100 shillings. 4. Now let's try another example. Imagine that you give 400 shillings to player 2 . We triple this amount, so player 2 gets 1200 (3 times 400 equals 1200). At this point, you have 100 and player 2 has 1200 . Then player 2 has to decide whether they wish to give anything back to you, and if so, how much. Suppose player 2 decides to return 500 shillings to you. At the end of the game you will go home with 600 and player 2 will go home with 700 . 5. Now let's try another example. Imagine that you give nothing to player 2. There is nothing for us to triple. Player 2 has nothing to give back and the game ends here. You go home with 500 and player 2 goes home with 0 .

Note that the larger the amount that you give to player 2 , the greater the amount that 
can be taken away by you and player 2 together. However, it is entirely up to player 2 to decide what he should give back to you. You could end up with more than 500 shillings or less than 500 shillings as a result.

Remember that all of your actions are treated confidentially by us. Only we will know if and how much money you put back into the envelope and we promise to never tell anyone about this. We will go through more examples with each of you individually when you come to play the game. In the meantime, do not talk to anyone about the game. Even if you are not sure that you understand the game, do not talk to anyone about it. This is very important. [Name of enumerator] will wait together with you and if we see that you are talking to anyone about the game while you are waiting to play, we must disqualify you from playing.

\section{A.1.1.2 Individual Explanation}

Hello, [name of the respondent] it is now your turn to play. Before you can make your decision, we want to ask you some questions, to make sure that you understood the game correctly. Let's suppose you decide to send 100 shillings to player 2. How much money will player 2 receive?

[Now we checked if the respondent gave the correct answer. If she/he did not, we again explained and physically showed the process of tripling the money.]

Let's assume that your player 2 decides to return 100 shillings. With how much money will he or she go home?

[We again checked if the respondent gave the correct answer. If she/he did not, we explained and physically showed what happens to the 300 KSh if 100 KSh are sent back.]

With how much money will you go home?

[We again checked if the respondent gave the correct answer. If she/he did not, we explained and physically showed what happens to the 400 KSh that were kept plus the 100 KSh that were returned by player 2.]

Now let's try another example. Let's suppose you decide to send 300 shillings to player 2. How much money will player 2 receive?

[Now we checked if the respondent gave the correct answer. If he did not, we again explained and physically showed the process of tripling the money.]

Let's assume that your player 2 decides to return 500 shillings. With how much money will he or she go home?

[We again checked if the respondent gave the correct answer. If he did not, we explained and physically showed what happens to the 900 KSh if 500 KSh are sent back.]

With how much money will you go home?

[We again checked if the respondent gave the correct answer. If he did not, we explained and physically showed what happens to the 200 KSh that were kept plus the 500 KSh that were returned by player. 
We continued with these examples up to the point where respondents answered two scenarios in a row correctly. Most people needed three examples. Two respondents required five examples.

After the respondent answered two scenarios in a row correctly, we continued.]

Do you want us to give more examples about the game?

If the respondent wanted more examples, we continued until the respondent did not ask for more examples.]

We have randomly chosen, that you will be playing with [a pastoralist from this village OR a pastoralist from a neighboring village OR a city dweller from Lodwar.] That means that you can now decide if and how much you want to send to [a pastoralist from this village OR a pastoralist from a neighboring village OR a city dweller from Lodwar]. On this table are your 500 shillings and the envelope. You can give that player 2 nothing, 100 shillings, 200 shillings, 300 shillings, 400 shillings, or 500 shillings. Simply put all the money that you want to send to him or her in the envelope.

We will triple this amount and send it to that player. Later today we will pass onto you whatever he or she decides to return. Before you make your decision we want to ask you, if you have any questions about the game?

Do you want any assistance in handling the bank notes or the envelope? [This question was only asked, when respondents showed signs of reduced dexterity.]

\section{A.1.2 Assignemnt of Strategies I}

All 402 pastoralists in our sample also played the trust game in the role of player B, after they played the game as player A. 133 respondents played the game as player B and received money from a pastoralist from a neighboring village. We used the actual decisions of how much pastoralists sent to a pastoralist from a neighboring village revealed in previous sessions to determine how much that player B would have at her disposal. Her strategy could later be used in subsequent sessions to determine how much a player A that is paired with a pastoralist from a neighboring village would get back from a neighboring pastoralist. From having 133 strategies for returning money to a pastoralist from a neighboring village and 128 respondents that sent money to pastoralist from a neighboring village it follows that each inter-village return strategy was used a little less than once on average. However, returning strategies derived in early sessions are probabilistically used more than once in the course of the data collection, while strategies from later session are less likely to actually have been put into effect. The returning strategies for being paired with a pastoralist from a neighboring village derived in the last session were never employed, as there were no subsequent sessions. The returning strategies from the very first session were taken from the pretest.

From trust games played with city dwellers that are not further analyzed in this study, 
we derived 62 strategies of how much city dwellers would return to pastoralists living in Turkana villages. Out of the 402 pastoralists analyzed here, 132 were paired with a city dweller. Each of the 132 respondents paired with a city dweller was randomly matched with one of these 62 strategies. Each returning strategy from a city dweller was therefore used on average a little more than twice.

Table A1: Assignment of strategies II

\begin{tabular}{|c|c|c|c|c|c|c|c|}
\hline $\begin{array}{l}\text { Ele- } \\
\text { ment }\end{array}$ & Day & Location & BDM Players & $\begin{array}{l}\text { pairing } \\
\text { with }\end{array}$ & $\begin{array}{c}\text { SD used } \\
\text { for elements }\end{array}$ & $\begin{array}{c}\mathrm{RS} \\
\text { taken from } \\
\text { elements }\end{array}$ & $\begin{array}{l}\text { part of } \\
\text { analysis }\end{array}$ \\
\hline \multirow{3}{*}{ A } & \multirow{3}{*}{1} & \multirow{3}{*}{$\begin{array}{l}\text { pre-test in } \\
\text { a village }\end{array}$} & \multirow{3}{*}{ pastoralists } & $\mathrm{SV}$ & $\mathrm{A}$ & $\mathrm{A}$ & $\mathrm{No}$ \\
\hline & & & & NV & $\mathrm{C}, \mathrm{E}, \mathrm{F}$ & Simulated & No \\
\hline & & & & $\mathrm{CD}$ & $\mathrm{B}, \mathrm{D}, \mathrm{G}$ & Simulated & No \\
\hline \multirow{2}{*}{ B } & \multirow{2}{*}{$2-3$} & county & \multirow{2}{*}{ city dwellers } & $\mathrm{CD}$ & $\mathrm{B}$ & B & No \\
\hline & & capital & & NV & $\mathrm{C}, \mathrm{E}, \mathrm{F}$ & A & No \\
\hline \multirow{3}{*}{$\mathrm{C}$} & \multirow{3}{*}{$4-12$} & \multirow{3}{*}{ villages } & \multirow{3}{*}{ pastoralists } & $\mathrm{SV}$ & $\mathrm{C}$ & $\mathrm{C}$ & Yes \\
\hline & & & & NV & $\mathrm{C}^{*} \mathrm{E}, \mathrm{F}$ & $\mathrm{A}, \mathrm{C}^{\dagger}$ & Yes \\
\hline & & & & $\mathrm{CD}$ & $\mathrm{D}, \mathrm{G}$ & $\mathrm{B}$ & Yes \\
\hline \multirow{2}{*}{$\mathrm{D}$} & \multirow{2}{*}{$13-16$} & \multirow{2}{*}{$\begin{array}{l}\text { county } \\
\text { capital }\end{array}$} & \multirow{2}{*}{ city dwellers } & $\mathrm{CD}$ & $\mathrm{D}$ & $\mathrm{D}$ & No \\
\hline & & & & NV & $\mathrm{E}, \mathrm{F}$ & $\mathrm{A}, \mathrm{C}$ & No \\
\hline \multirow{3}{*}{$\mathrm{E}$} & \multirow{3}{*}{$17-23$} & \multirow{3}{*}{ villages } & \multirow{3}{*}{ pastoralists } & $\mathrm{SV}$ & $E$ & $\mathrm{E}$ & Yes \\
\hline & & & & NV & $\mathrm{E}^{*} \mathrm{~F}$ & $\mathrm{~A}, \mathrm{C}, \mathrm{E}^{\dagger}$ & Yes \\
\hline & & & & $\mathrm{CD}$ & $\mathrm{G}$ & $\mathrm{B}, \mathrm{D}$ & Yes \\
\hline \multirow{3}{*}{$\mathrm{F}$} & \multirow{3}{*}{24} & \multirow{3}{*}{ village } & \multirow{3}{*}{ pastoralists } & $\mathrm{SV}$ & $\mathrm{F}$ & $\mathrm{F}$ & Yes \\
\hline & & & & NV & n.a. & $\mathrm{A}, \mathrm{C}, \mathrm{E}$ & No \\
\hline & & & & $\mathrm{CD}$ & $\mathrm{G}$ & $\mathrm{B}, \mathrm{D}$ & Yes \\
\hline \multirow{2}{*}{ G } & \multirow{2}{*}{25} & \multirow{2}{*}{$\begin{array}{l}\text { county } \\
\text { capital }\end{array}$} & \multirow{2}{*}{ city dwellers } & $\mathrm{CD}$ & $G$ & $G$ & $\mathrm{No}$ \\
\hline & & & & NV & n.a. & $\mathrm{A}, \mathrm{C}, \mathrm{E}, \mathrm{F}$ & No \\
\hline
\end{tabular}

Notes: $\mathrm{BDM}=$ Trust game by Berg et al. (1995). SV = pastoralists from the same village. NV = pastoralists from a neighboring village. $\mathrm{CD}=$ city dwellers from the county capital. $\mathrm{SD}=$ sending decision. $\mathrm{RS}=$ Returning strategy.

* sending decisions only used for subsequent sessions.

$\dagger$ strategies only taken from preceding sessions.

Source: Own elaboration. 
Table A2: Sequence of data collection

\begin{tabular}{|c|c|c|}
\hline Element & Element description & $\begin{array}{l}\text { Conditional } \\
\text { on element }\end{array}$ \\
\hline 1 & $\begin{array}{l}\text { Introduction and opening instructions for playing the game } \\
\text { as player A }\end{array}$ & - \\
\hline 2 & Random assignment of a player B & - \\
\hline 3 & Individual Instruction and decision as player A & 2 \\
\hline 4 & Potential payout to player A of the money not sent to player B & 2,3 \\
\hline 5 & Household survey including: & \\
\hline $5 \mathrm{a}$ & Expected return to player B & 2,3 \\
\hline $5 b$ & Socio-economic characteristics & - \\
\hline $5 \mathrm{c}$ & $\begin{array}{l}\text { Either: context independent trust question }->\text { context } \\
\text { dependent trust question } \\
\text { Or: context dependent trust question }->\text { context } \\
\text { independent trust question }\end{array}$ & - \\
\hline 6 & Repeating general instructions for playing the game as player B & - \\
\hline 7 & Random assignment of a player A & - \\
\hline 8 & Individual instructions and decisions as player B & 7 \\
\hline 9 & Potential payout to player B of the money not returned to player $\mathrm{A}$ & 7,8 \\
\hline 10 & $\begin{array}{l}\text { Non-incentivized Discrete Choice Experiment regarding livestock } \\
\text { index insurance }\end{array}$ & - \\
\hline 11 & Decision regarding incentivized Eckel-Grossman task & - \\
\hline 12 & Payout Eckel-Grossman task & - \\
\hline 13 & Potential payout to player A of amount returned by player B & 2,3 \\
\hline
\end{tabular}


Table A3: Risk preference elicitation

\begin{tabular}{|c|c|c|c|c|c|c|c|}
\hline \multirow{2}{*}{$\begin{array}{c}\text { Gamble } \\
\text { choice }\end{array}$} & \multicolumn{4}{|c|}{ Payoff } & \multicolumn{2}{|c|}{ CRRA range } & \multirow{2}{*}{$\begin{array}{c}\text { Averages } \\
\text { used in } \\
\text { analyses }\end{array}$} \\
\hline & High & Low & $\begin{array}{c}\text { Expected } \\
\text { Value }\end{array}$ & $\begin{array}{l}\text { Standard } \\
\text { Deviation }\end{array}$ & $\begin{array}{l}\text { Lower } \\
\text { bound }\end{array}$ & $\begin{array}{l}\text { Upper } \\
\text { bound }\end{array}$ & \\
\hline 1 & 100 & 100 & 100 & 0 & 5 & $\infty$ & 5 \\
\hline 2 & 120 & 90 & 105 & 15 & 1.64 & 5 & 3.32 \\
\hline 3 & 140 & 80 & 110 & 30 & 1 & 1.64 & 1.32 \\
\hline 4 & 160 & 70 & 115 & 45 & 0.72 & 1 & 0.86 \\
\hline 5 & 180 & 60 & 120 & 60 & 0 & 0.72 & 0.36 \\
\hline 6 & 200 & 40 & 120 & 80 & $-\infty$ & 0 & 0 \\
\hline
\end{tabular}

Notes: CRRA $=$ Constant relative risk aversion.

Source: Method based on Eckel and Grossman (2002). 


\section{A.2 Additional Statistical Information}

Table A4: Summary statistics by treatment

\begin{tabular}{lcccc}
\hline \hline Variable & $\begin{array}{c}\text { Pairing with } \\
\text { someone from } \\
\text { the same village } \\
(\mathrm{N}=142)\end{array}$ & $\begin{array}{c}\text { Pairing with } \\
\text { someone from a } \\
\text { neighboring } \\
\text { village } \\
(\mathrm{N}=120)\end{array}$ & $\begin{array}{c}\text { Pairing with a } \\
\text { city dweller } \\
\text { from the county } \\
\text { capital } \\
(\mathrm{N}=132)\end{array}$ & $\begin{array}{c}\text { Kruskal- } \\
\text { Wallis } \\
\text { test }\end{array}$ \\
\hline $\begin{array}{l}\text { Age [years] } \\
\text { Constant relative risk av- } \\
\text { ersion coefficient (CRRA) }\end{array}$ & 40.345 & 40.512 & 38.076 & \\
$\begin{array}{l}\text { Distance to the next pav- } \\
\text { ed road [walking minutes] }\end{array}$ & 2.221 & 2.092 & 28.644 & \\
$\begin{array}{l}\text { Education [years] } \\
\text { Female }\end{array}$ & 1.063 & 25.75 & 28.644 & $*$ \\
Herd size [TLU] & 0.430 & 0.783 & 1.538 & \\
Household size & 32.822 & 31.549 & 33.913 & \\
$\begin{array}{l}\text { Income [1,000 KSh] } \\
\text { Mobile phone user }\end{array}$ & 8.401 & 8.333 & 7.583 & \\
Village size [100 people] & 5.575 & 5.608 & 5.475 & \\
Years lived in the village & 0.824 & 0.775 & 0.818 & \\
[percentage of lifetime] & 5.677 & 5.904 & 5.326 & \\
\hline
\end{tabular}

Notes: Mean values are shown. Variables are compared using the Kruskal-Wallis test. ${ }^{* * *} p<$ $0.01,{ }^{* *} p<0.05,{ }^{*} p<0.1$. 
Table A5: Multivariate regression analyses with explicit control variables

\begin{tabular}{|c|c|c|c|c|}
\hline & 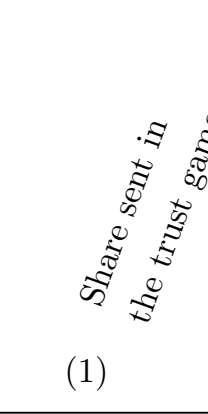 & (2) & 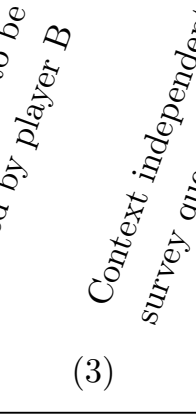 & (4) \\
\hline $\begin{array}{l}\text { Trust towards people from a } \\
\text { neighboring village }\end{array}$ & $\begin{array}{c}1.167 \\
(1.886)\end{array}$ & $\begin{array}{c}0.197 \\
(2.778)\end{array}$ & $\begin{array}{c}-0.305^{* * *} \\
(0.099)\end{array}$ & $\begin{array}{c}-0.186^{* *} \\
(0.082)\end{array}$ \\
\hline $\begin{array}{l}\text { Trust towards city dwellers } \\
\text { from the county capital }\end{array}$ & $\begin{array}{c}-7.889^{* * *} \\
(2.742)\end{array}$ & $\begin{array}{c}-8.361^{* *} \\
(3.661)\end{array}$ & $\begin{array}{c}-1.626^{* * *} \\
(0.142)\end{array}$ & $\begin{array}{c}-1.023^{* * *} \\
(0.104)\end{array}$ \\
\hline Age [years] & $\begin{array}{c}0.050 \\
(0.077)\end{array}$ & $\begin{array}{l}-0.143 \\
(0.146)\end{array}$ & $\begin{array}{c}0.022^{* * *} \\
(0.006)\end{array}$ & $\begin{array}{c}-0.017^{* * *} \\
(0.006)\end{array}$ \\
\hline $\begin{array}{l}\text { Constant relative risk aver- } \\
\text { sion coefficient (CRRA) }\end{array}$ & $\begin{array}{l}-0.785 \\
(0.541)\end{array}$ & $\begin{array}{l}-0.010 \\
(0.870)\end{array}$ & $\begin{array}{l}-0.050 \\
(0.035)\end{array}$ & $\begin{array}{l}-0.046 \\
(0.038)\end{array}$ \\
\hline $\begin{array}{l}\text { Distance to the next paved } \\
\text { road [log of walking minutes] }\end{array}$ & $\begin{array}{l}-0.743 \\
(0.635)\end{array}$ & $\begin{array}{c}0.290 \\
(1.207)\end{array}$ & $\begin{array}{c}-0.195^{* * *} \\
(0.063)\end{array}$ & $\begin{array}{l}-0.029 \\
(0.068)\end{array}$ \\
\hline Education [years] & $\begin{array}{c}0.083 \\
(0.387)\end{array}$ & $\begin{array}{c}-1.081^{* *} \\
(0.495)\end{array}$ & $\begin{array}{c}-0.085^{* * *} \\
(0.024)\end{array}$ & $\begin{array}{l}-0.003 \\
(0.029)\end{array}$ \\
\hline Female & $\begin{array}{c}0.455 \\
(1.659)\end{array}$ & $\begin{array}{l}-2.013 \\
(3.892)\end{array}$ & $\begin{array}{c}0.167 \\
(0.158)\end{array}$ & $\begin{array}{c}0.237 \\
(0.157)\end{array}$ \\
\hline Herd size $[\mathrm{TLU}]$ & $\begin{array}{c}0.022 \\
(0.050)\end{array}$ & $\begin{array}{l}-0.024 \\
(0.047)\end{array}$ & $\begin{array}{c}0.008^{* * *} \\
(0.002)\end{array}$ & $\begin{array}{c}0.006^{* * *} \\
(0.002)\end{array}$ \\
\hline Household size & $\begin{array}{c}0.299 \\
(0.286)\end{array}$ & $\begin{array}{c}0.267 \\
(0.500)\end{array}$ & $\begin{array}{c}-0.050^{* * *} \\
(0.019)\end{array}$ & $\begin{array}{l}0.037^{*} \\
(0.022)\end{array}$ \\
\hline Income $[1,000 \mathrm{KSh}]$ & $\begin{array}{c}-0.501^{* *} \\
(0.214)\end{array}$ & $\begin{array}{c}0.107 \\
(0.335)\end{array}$ & $\begin{array}{c}0.005 \\
(0.005)\end{array}$ & $\begin{array}{c}0.003 \\
(0.009)\end{array}$ \\
\hline Mobile phone user & $\begin{array}{l}5.053^{*} \\
(2.646)\end{array}$ & $\begin{array}{c}3.919 \\
(3.853)\end{array}$ & $\begin{array}{c}0.611^{* * *} \\
(0.184)\end{array}$ & $\begin{array}{l}-0.320 \\
(0.195)\end{array}$ \\
\hline Village size & $\begin{array}{c}0.126 \\
(0.342)\end{array}$ & $\begin{array}{c}0.269 \\
(0.515)\end{array}$ & $\begin{array}{c}-0.041^{*} \\
(0.023)\end{array}$ & $\begin{array}{l}-0.002 \\
(0.020)\end{array}$ \\
\hline $\begin{array}{l}\text { Years lived in village [per- } \\
\text { centage of lifetime] }\end{array}$ & $\begin{array}{l}-1.438 \\
(2.923)\end{array}$ & $\begin{array}{l}-5.026 \\
(3.937)\end{array}$ & $\begin{array}{c}0.762 \\
(0.215)\end{array}$ & $\begin{array}{c}0.322 \\
(0.220)\end{array}$ \\
\hline Constant & $\begin{array}{l}31.089 \\
(4.877)\end{array}$ & $\begin{array}{c}56.776^{* * *} \\
(8.571)\end{array}$ & & \\
\hline Total observations & 394 & 394 & 1,182 & 1,182 \\
\hline
\end{tabular}

Table A5 - continued on next page - 
Left-censored observations

34

46

Table A5 - continued from previous page -

\begin{tabular}{lcc}
\hline Uncensored observations & n.a. & 320 \\
Interval observations & 359 & n.a. \\
Right-censored observations & 1 & 28
\end{tabular}

Notes: Estimates in column (1) are based on censored interval regression. Estimates in column (2) are based on a tobit model. Estimates in column (3) and (4) are ordered log-odds estimates from ordered logistic regression. Standard errors shown in parentheses are robust and clustered at the village level for columns (1) and (2), and clustered at the individual level for columns (3) and (4). ${ }^{* * *} p<0.01,{ }^{* *} p<0.05,{ }^{*} p<0.1$.

Source: Own elaboration. 
Figure A1: Context independent survey trust $(\mathrm{N}=394)$

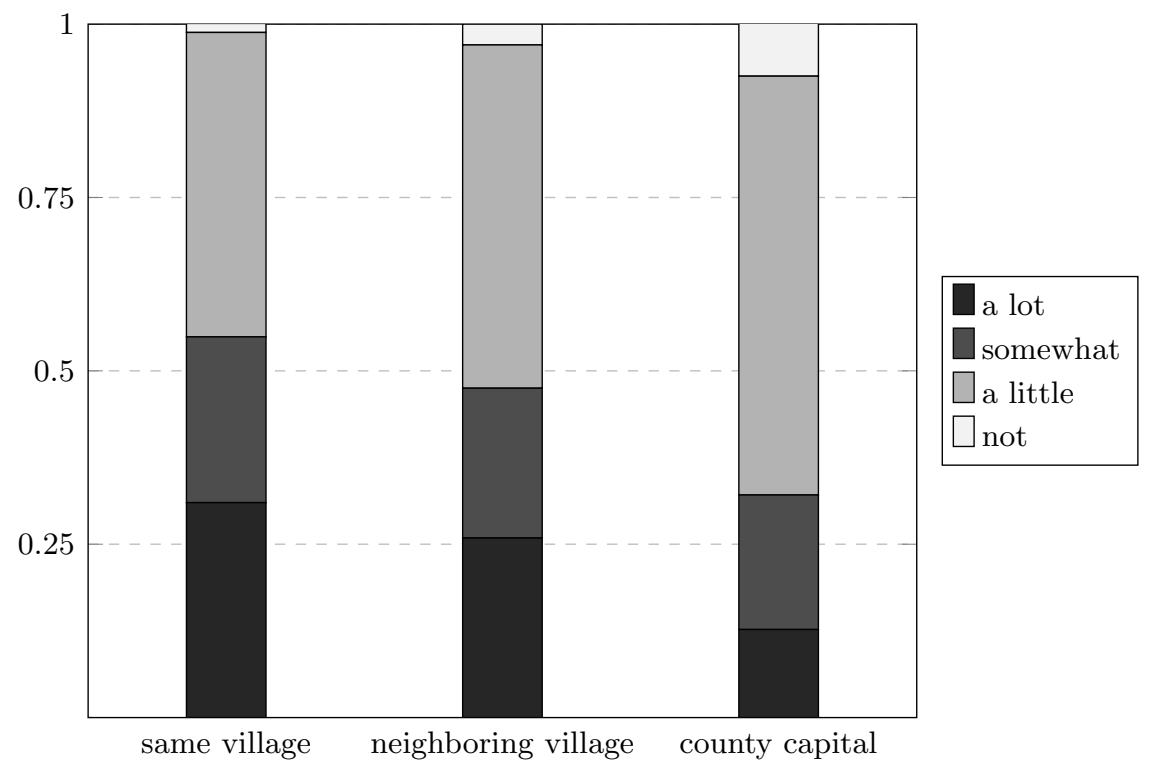

Source: Own elaboration.

Figure A2: Context dependent survey trust $(\mathrm{N}=394)$

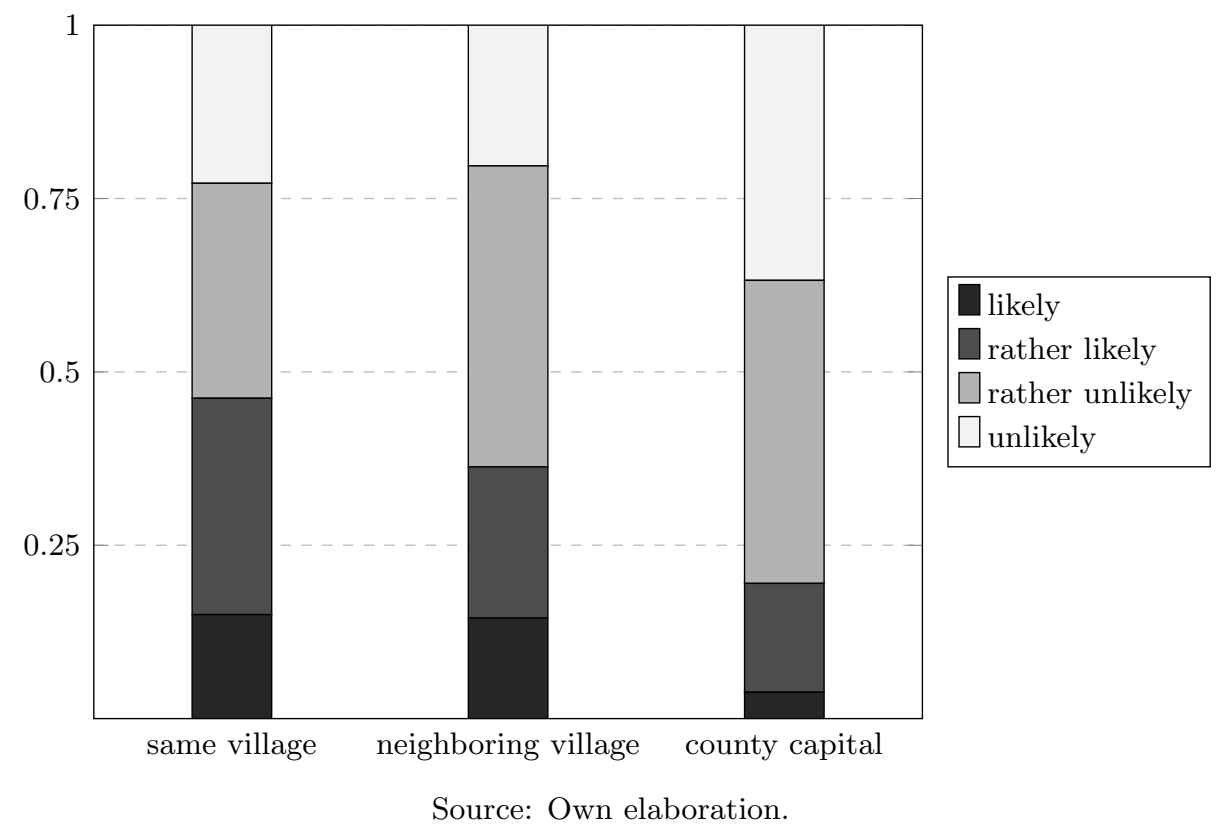




\section{Appendix B}

\section{Can Mobile Phones Build Social Trust?}

Table B1: Deviations from the original trust game

\begin{tabular}{lcc}
\hline \hline Aspect of experimental protocol & This Study & Original BDM \\
\hline Subjects & Non-students & Students \\
Amount at stake & 500KSh (approx. $5 \$)$ & $10 \$$ \\
Receiver endowment & 0 & $10 \$$ \\
Each subject played the role of sender and receiver & Yes & No \\
Strategy method used for amounts returned & Yes & No \\
Anonymity of choices & Single-blind $^{\mathrm{a}}$ & Double-blind $^{\mathrm{b}}$ \\
\hline
\end{tabular}

Notes: BDM = Trust game according to Berg et al. (1995).

a Single-blind refers to anonymity of choices with regards to other players.

b Double-blind refers to anonymity of choices with regards to other players and the experimeter. 
Table B2: First Stage Regressions

\begin{tabular}{|c|c|c|c|}
\hline & $\begin{array}{l}\text { Pairing with a } \\
\text { fellow villager } \\
\text { (1) }\end{array}$ & $\begin{array}{c}\text { Pairing with } \\
\text { person from a } \\
\text { neighboring village } \\
(2)\end{array}$ & $\begin{array}{c}\text { Pairing with } \\
\text { city dweller } \\
\text { (3) }\end{array}$ \\
\hline $\begin{array}{l}\text { Network reception at } \\
\text { homestead }[1=\text { yes }]\end{array}$ & $\begin{array}{c}4.161^{* * *} \\
(0.916)\end{array}$ & $\begin{array}{c}2.033^{* * *} \\
(0.303)\end{array}$ & $\begin{array}{c}2.229^{* * *} \\
(0.503)\end{array}$ \\
\hline Age & $\begin{array}{c}-0.042^{* *} \\
(0.018)\end{array}$ & $\begin{array}{l}-0.016 \\
(0.010)\end{array}$ & $\begin{array}{l}-0.008 \\
(0.011)\end{array}$ \\
\hline $\begin{array}{l}\text { Constant relative risk } \\
\text { aversion coefficient (CRRA) }\end{array}$ & $\begin{array}{c}-0.250^{* *} \\
(0.127)\end{array}$ & $\begin{array}{c}0.021 \\
(0.091)\end{array}$ & $\begin{array}{l}-0.020 \\
(0.078)\end{array}$ \\
\hline $\begin{array}{l}\text { Distance to next paved road } \\
\text { [log of walking minutes] }\end{array}$ & $\begin{array}{l}-0.192 \\
(0.161)\end{array}$ & $\begin{array}{l}-0.037 \\
(0.083)\end{array}$ & $\begin{array}{l}-0.116 \\
(0.080)\end{array}$ \\
\hline Education & $\begin{array}{c}0.011 \\
(0.080)\end{array}$ & $\begin{array}{c}0.248^{* * *} \\
(0.068)\end{array}$ & $\begin{array}{c}0.066 \\
(0.043)\end{array}$ \\
\hline $\begin{array}{l}\text { Having family in } \\
\text { neighboring villagers }\end{array}$ & & $\begin{array}{c}0.236 \\
(0.428)\end{array}$ & \\
\hline $\begin{array}{l}\text { Having family in } \\
\text { the county capital }\end{array}$ & & & $\begin{array}{c}0.006 \\
(0.342)\end{array}$ \\
\hline Female & $\begin{array}{c}-0.362 \\
(0.358)\end{array}$ & $\begin{array}{c}0.266 \\
(0.341)\end{array}$ & $\begin{array}{l}-0.157 \\
(0.253)\end{array}$ \\
\hline Herd size $[\mathrm{TLU}]$ & $\begin{array}{c}0.020^{* * *} \\
(0.006)\end{array}$ & $\begin{array}{c}0.004 \\
(0.004)\end{array}$ & $\begin{array}{c}-0.012^{* * *} \\
(0.003)\end{array}$ \\
\hline Household size & $\begin{array}{c}0.062 \\
(0.038)\end{array}$ & $\begin{array}{c}0.048 \\
(0.030)\end{array}$ & $\begin{array}{c}0.023 \\
(0.054)\end{array}$ \\
\hline Income [logged KSh] & $\begin{array}{c}0.004 \\
(0.040)\end{array}$ & $\begin{array}{c}0.051 \\
(0.046)\end{array}$ & $\begin{array}{l}-0.001 \\
(0.036)\end{array}$ \\
\hline Village size [100 people] & $\begin{array}{c}0.159^{* * *} \\
(0.050)\end{array}$ & $\begin{array}{c}0.018 \\
(0.029)\end{array}$ & $\begin{array}{l}-0.034 \\
(0.044)\end{array}$ \\
\hline Constant & $\begin{array}{l}-1.562 \\
(1.388)\end{array}$ & $\begin{array}{l}-1.299 \\
(1.001)\end{array}$ & $\begin{array}{c}0.177 \\
(0.619)\end{array}$ \\
\hline$\chi^{2}$ & $73.16^{* * *}$ & $112.74^{* * *}$ & $66.47^{* * *}$ \\
\hline Pseudo $R^{2}$ & 0.49 & 0.40 & 0.34 \\
\hline Observations & 142 & 120 & 132 \\
\hline
\end{tabular}

Notes: Coefficients estimates are based on a probit model. Standard errors shown in parentheses are robust and clustered at the village level. CRRA $=$ Constant relative risk aversion coefficient. KSh $=$ Kenyan Shilling. TLU $=$ Tropical Livestock Unit. ${ }^{* * *} p<0.01,{ }^{* *} p<0.05,{ }^{*} p<0.1$. 
Table B3: Control function estimates for the amount sents

\begin{tabular}{|c|c|c|c|c|c|c|}
\hline & \multicolumn{2}{|c|}{$\begin{array}{l}\text { Trust towards } \\
\text { fellow villagers }\end{array}$} & \multicolumn{2}{|c|}{$\begin{array}{c}\text { Trust towards people } \\
\text { from a neighboring } \\
\text { village }\end{array}$} & \multicolumn{2}{|c|}{$\begin{array}{l}\text { Trust towards city } \\
\text { dwellers from the } \\
\text { county capital }\end{array}$} \\
\hline & $\begin{array}{l}\text { CIR } \\
(1)\end{array}$ & $\begin{array}{l}\text { OLS } \\
(2)\end{array}$ & $\begin{array}{l}\text { CIR } \\
(3)\end{array}$ & $\begin{array}{l}\text { OLS } \\
(4)\end{array}$ & $\begin{array}{c}\text { CIR } \\
(5)\end{array}$ & $\begin{array}{l}\text { OLS } \\
(6)\end{array}$ \\
\hline Mobile phone user & $\begin{array}{l}-0.809 \\
(4.590)\end{array}$ & $\begin{array}{l}-0.687 \\
(4.776)\end{array}$ & $\begin{array}{c}6.373 \\
(6.240)\end{array}$ & $\begin{array}{c}6.280 \\
(6.499)\end{array}$ & $\begin{array}{c}14.927^{* *} \\
(7.233)\end{array}$ & $\begin{array}{l}14.134^{*} \\
(7.039)\end{array}$ \\
\hline First stage residuals & $\begin{array}{c}1.935 \\
(3.610)\end{array}$ & $\begin{array}{c}1.806 \\
(3.688)\end{array}$ & $\begin{array}{l}-0.172 \\
(3.039)\end{array}$ & $\begin{array}{l}-0.160 \\
(3.196)\end{array}$ & $\begin{array}{l}-4.902 \\
(3.629)\end{array}$ & $\begin{array}{l}-4.688 \\
(3.479)\end{array}$ \\
\hline Age & $\begin{array}{c}0.045 \\
(0.118)\end{array}$ & $\begin{array}{c}0.046 \\
(0.123)\end{array}$ & $\begin{array}{c}0.063 \\
(0.097)\end{array}$ & $\begin{array}{c}0.065 \\
(0.102)\end{array}$ & $\begin{array}{l}-0.007 \\
(0.142)\end{array}$ & $\begin{array}{l}-0.012 \\
(0.139)\end{array}$ \\
\hline Risk aversion & $\begin{array}{c}-1.733^{* *} \\
(0.740)\end{array}$ & $\begin{array}{c}-1.726^{* *} \\
(0.765)\end{array}$ & $\begin{array}{l}-0.101 \\
(0.711)\end{array}$ & $\begin{array}{l}-0.108 \\
(0.743)\end{array}$ & $\begin{array}{l}-0.752 \\
(1.343)\end{array}$ & $\begin{array}{l}-0.725 \\
(1.332)\end{array}$ \\
\hline $\begin{array}{l}\text { Distance to next } \\
\text { paved road }\end{array}$ & $\begin{array}{l}-2.126^{*} \\
(1.235)\end{array}$ & $\begin{array}{l}-2.084 \\
(1.264)\end{array}$ & $\begin{array}{c}-2.672^{* *} \\
(1.062)\end{array}$ & $\begin{array}{c}-2.688^{* *} \\
(1.110)\end{array}$ & $\begin{array}{c}1.601 \\
(1.297)\end{array}$ & $\begin{array}{c}1.550 \\
(1.300)\end{array}$ \\
\hline Education & $\begin{array}{c}0.952^{* *} \\
(0.424)\end{array}$ & $\begin{array}{c}0.944^{* *} \\
(0.441)\end{array}$ & $\begin{array}{c}0.195 \\
(0.900)\end{array}$ & $\begin{array}{c}0.196 \\
(0.946)\end{array}$ & $\begin{array}{l}-0.638 \\
(0.586)\end{array}$ & $\begin{array}{l}-0.598 \\
(0.569)\end{array}$ \\
\hline $\begin{array}{l}\text { Having family in } \\
\text { neighboring villages }\end{array}$ & & & $\begin{array}{c}2.671 \\
(6.093)\end{array}$ & $\begin{array}{c}2.661 \\
(6.336)\end{array}$ & & \\
\hline $\begin{array}{l}\text { Having family in the } \\
\text { county capital }\end{array}$ & & & & & $\begin{array}{l}1.740 \\
(2.832)\end{array}$ & $\begin{array}{c}1.560 \\
(2.863)\end{array}$ \\
\hline Female & $\begin{array}{l}-0.523 \\
(3.438)\end{array}$ & $\begin{array}{l}-0.463 \\
(3.550)\end{array}$ & $\begin{array}{c}4.513 \\
(3.547)\end{array}$ & $\begin{array}{c}4.485 \\
(3.723)\end{array}$ & $\begin{array}{l}-1.020 \\
(2.044)\end{array}$ & $\begin{array}{l}-1.074 \\
(2.020)\end{array}$ \\
\hline Herd size & $\begin{array}{l}-0.011 \\
(0.052)\end{array}$ & $\begin{array}{l}-0.012 \\
(0.054)\end{array}$ & $\begin{array}{c}0.027 \\
(0.056)\end{array}$ & $\begin{array}{c}0.027 \\
(0.059)\end{array}$ & $\begin{array}{c}0.069 \\
(0.076)\end{array}$ & $\begin{array}{c}0.065 \\
(0.075)\end{array}$ \\
\hline Household size & $\begin{array}{c}1.218^{* * * *} \\
(0.381)\end{array}$ & $\begin{array}{c}1.218^{* * *} \\
(0.398)\end{array}$ & $\begin{array}{l}-0.084 \\
(0.561)\end{array}$ & $\begin{array}{l}-0.079 \\
(0.592)\end{array}$ & $\begin{array}{l}-0.232 \\
(0.341)\end{array}$ & $\begin{array}{l}-0.228 \\
(0.346)\end{array}$ \\
\hline Income & $\begin{array}{c}-0.372^{* *} \\
(0.185)\end{array}$ & $\begin{array}{l}-0.365^{*} \\
(0.194)\end{array}$ & $\begin{array}{l}-0.616 \\
(0.597)\end{array}$ & $\begin{array}{l}-0.623 \\
(0.629)\end{array}$ & $\begin{array}{l}-0.461 \\
(0.305)\end{array}$ & $\begin{array}{l}-0.431 \\
(0.313)\end{array}$ \\
\hline Village size & $\begin{array}{c}-0.846^{* *} \\
(0.424)\end{array}$ & $\begin{array}{l}-0.840^{*} \\
(0.439)\end{array}$ & $\begin{array}{c}0.307 \\
(0.341)\end{array}$ & $\begin{array}{c}0.310 \\
(0.361)\end{array}$ & $\begin{array}{c}0.787^{*} \\
(0.453)\end{array}$ & $\begin{array}{c}0.736 \\
(0.453)\end{array}$ \\
\hline Constant & $\begin{array}{c}38.273^{* * *} \\
(8.988)\end{array}$ & $\begin{array}{c}38.059^{* * *} \\
(9.385)\end{array}$ & $\begin{array}{c}30.837^{* * *} \\
(9.631)\end{array}$ & $\begin{array}{c}30.938^{* * *} \\
(10.082)\end{array}$ & $\begin{array}{c}9.739 \\
(11.334)\end{array}$ & $\begin{array}{c}11.349 \\
(10.608)\end{array}$ \\
\hline $\ln (\sigma)$ & 2.697 & & 2.686 & & 2.785 & \\
\hline$R^{2}$ & & 0.146 & & 0.153 & & 0.123 \\
\hline \multicolumn{7}{|l|}{ Observations } \\
\hline total & 142 & 142 & 120 & 120 & 132 & 132 \\
\hline left censored & 7 & & 6 & & 21 & \\
\hline right-censored & 1 & & 0 & & 0 & \\
\hline interval & 134 & & 114 & & 111 & \\
\hline
\end{tabular}

Notes: Standard errors shown in parentheses are robust and clustered at the village level. CIR $=$ Censored Interval Regression. OLS $=$ Ordinary Least Squares. ${ }^{* * *} p<0.01,{ }^{* *} p<0.05,{ }^{*} p<$ 0.1 . 
Table B4: Determinants of the amount sent in the trust game if only daily MP use is considered MP use

\begin{tabular}{|c|c|c|c|c|c|c|}
\hline & \multicolumn{2}{|c|}{$\begin{array}{l}\text { Trust towards } \\
\text { fellow villagers }\end{array}$} & \multicolumn{2}{|c|}{$\begin{array}{c}\text { Trust towards } \\
\text { people from a } \\
\text { neighboring village }\end{array}$} & \multicolumn{2}{|c|}{$\begin{array}{l}\text { Trust towards city } \\
\text { dwellers from the } \\
\text { county capital }\end{array}$} \\
\hline & $\begin{array}{c}\text { CIR } \\
(1)\end{array}$ & $\begin{array}{c}\text { OLS } \\
(2)\end{array}$ & $\begin{array}{c}\text { CIR } \\
(3)\end{array}$ & $\begin{array}{c}\text { OLS } \\
(4)\end{array}$ & $\begin{array}{c}\mathrm{CIR} \\
(5)\end{array}$ & $\begin{array}{c}\text { OLS } \\
(6)\end{array}$ \\
\hline MP user & $\begin{array}{l}-0.379 \\
(3.125)\end{array}$ & $\begin{array}{l}-0.354 \\
(3.244)\end{array}$ & $\begin{array}{c}3.932 \\
(4.551)\end{array}$ & $\begin{array}{c}3.890 \\
(4.757)\end{array}$ & $\begin{array}{c}12.816^{* *} \\
(5.343)\end{array}$ & $\begin{array}{c}11.873^{* *} \\
(5.380)\end{array}$ \\
\hline Age & $\begin{array}{c}0.060 \\
(0.116)\end{array}$ & $\begin{array}{c}0.060 \\
(0.121)\end{array}$ & $\begin{array}{c}0.067 \\
(0.092)\end{array}$ & $\begin{array}{c}0.070 \\
(0.097)\end{array}$ & $\begin{array}{l}-0.016 \\
(0.135)\end{array}$ & $\begin{array}{l}-0.020 \\
(0.133)\end{array}$ \\
\hline Risk aversion & $\begin{array}{c}-1.585^{* *} \\
(0.702)\end{array}$ & $\begin{array}{c}-1.583^{* *} \\
(0.728)\end{array}$ & $\begin{array}{l}-0.137 \\
(0.731)\end{array}$ & $\begin{array}{l}-0.143 \\
(0.765)\end{array}$ & $\begin{array}{l}-1.127 \\
(1.390)\end{array}$ & $\begin{array}{l}-1.063 \\
(1.380)\end{array}$ \\
\hline $\begin{array}{l}\text { Distance to } \\
\text { next paved road }\end{array}$ & $\begin{array}{l}-1.931 \\
(1.213)\end{array}$ & $\begin{array}{l}-1.894 \\
(1.245)\end{array}$ & $\begin{array}{c}-2.876^{* * *} \\
(1.003)\end{array}$ & $\begin{array}{c}-2.888^{* *} \\
(1.050)\end{array}$ & $\begin{array}{c}1.132 \\
(1.156)\end{array}$ & $\begin{array}{c}1.160 \\
(1.150)\end{array}$ \\
\hline Education & $\begin{array}{c}0.926^{* *} \\
(0.390)\end{array}$ & $\begin{array}{c}0.920^{* *} \\
(0.406)\end{array}$ & $\begin{array}{c}0.017 \\
(0.861)\end{array}$ & $\begin{array}{c}0.018 \\
(0.903)\end{array}$ & $\begin{array}{l}-0.374 \\
(0.579)\end{array}$ & $\begin{array}{l}-0.348 \\
(0.560)\end{array}$ \\
\hline $\begin{array}{l}\text { Having family in } \\
\text { neighboring villagers }\end{array}$ & & & $\begin{array}{c}1.732 \\
(5.987)\end{array}$ & $\begin{array}{c}1.747 \\
(6.226)\end{array}$ & & \\
\hline $\begin{array}{l}\text { Having family in } \\
\text { the county capital }\end{array}$ & & & & & $\begin{array}{c}2.988 \\
(2.976)\end{array}$ & $\begin{array}{c}2.813 \\
(2.939)\end{array}$ \\
\hline Female & $\begin{array}{c}0.395 \\
(3.701)\end{array}$ & $\begin{array}{c}0.448 \\
(3.828)\end{array}$ & $\begin{array}{c}3.670 \\
(3.506)\end{array}$ & $\begin{array}{c}3.652 \\
(3.682)\end{array}$ & $\begin{array}{l}-1.118 \\
(1.990)\end{array}$ & $\begin{array}{l}-1.119 \\
(1.995)\end{array}$ \\
\hline Herd size & $\begin{array}{l}-0.015 \\
(0.050)\end{array}$ & $\begin{array}{l}-0.016 \\
(0.052)\end{array}$ & $\begin{array}{c}0.018 \\
(0.058)\end{array}$ & $\begin{array}{c}0.018 \\
(0.061)\end{array}$ & $\begin{array}{c}0.046 \\
(0.087)\end{array}$ & $\begin{array}{c}0.042 \\
(0.086)\end{array}$ \\
\hline Household size & $\begin{array}{c}1.196^{* * *} \\
(0.378)\end{array}$ & $\begin{array}{c}1.198^{* * *} \\
(0.395)\end{array}$ & $\begin{array}{l}-0.171 \\
(0.536)\end{array}$ & $\begin{array}{l}-0.167 \\
(0.565)\end{array}$ & $\begin{array}{c}0.087 \\
(0.286)\end{array}$ & $\begin{array}{c}0.070 \\
(0.296)\end{array}$ \\
\hline Income & $\begin{array}{r}-0.350^{*} \\
(0.193)\end{array}$ & $\begin{array}{l}-0.345 \\
(0.202)\end{array}$ & $\begin{array}{l}-0.484 \\
(0.577)\end{array}$ & $\begin{array}{l}-0.492 \\
(0.609)\end{array}$ & $\begin{array}{c}-0.573^{* *} \\
(0.246)\end{array}$ & $\begin{array}{l}-0.532^{*} \\
(0.256)\end{array}$ \\
\hline Village size & $\begin{array}{c}-0.911^{* *} \\
(0.418)\end{array}$ & $\begin{array}{l}-0.904^{*} \\
(0.433)\end{array}$ & $\begin{array}{c}0.266 \\
(0.327)\end{array}$ & $\begin{array}{c}0.270 \\
(0.346)\end{array}$ & $\begin{array}{c}0.599 \\
(0.472)\end{array}$ & $\begin{array}{c}0.558 \\
(0.473)\end{array}$ \\
\hline $\begin{array}{l}\text { Years of owning } \\
\text { a MP }\end{array}$ & $\begin{array}{c}0.590 \\
(0.412)\end{array}$ & $\begin{array}{c}0.588 \\
(0.430)\end{array}$ & $\begin{array}{c}0.660^{* *} \\
(0.325)\end{array}$ & $\begin{array}{l}0.654^{*} \\
(0.343)\end{array}$ & $\begin{array}{l}-1.518^{*} \\
(0.791)\end{array}$ & $\begin{array}{l}-1.376^{*} \\
(0.774)\end{array}$ \\
\hline Constant & $\begin{array}{c}34.670^{* * *} \\
(7.644)\end{array}$ & $\begin{array}{c}34.588^{* * *} \\
(7.975)\end{array}$ & $\begin{array}{c}32.936^{* * *} \\
(9.697)\end{array}$ & $\begin{array}{c}32.978^{* * *} \\
(10.138)\end{array}$ & $\begin{array}{c}17.506 \\
(10.793)\end{array}$ & $\begin{array}{c}18.521^{*} \\
(10.482)\end{array}$ \\
\hline $\ln (\sigma)$ & 2.698 & & 2.687 & & 2.788 & \\
\hline$R^{2}$ & & 0.146 & & 0.151 & & 0.116 \\
\hline \multicolumn{7}{|l|}{ Observations: } \\
\hline left-censored & 7 & & 6 & & 21 & \\
\hline right-censored & 1 & & 0 & & 0 & \\
\hline interval & 134 & & 114 & & 111 & \\
\hline
\end{tabular}

Notes: Standard errors shown in parentheses are robust and clustered at the village level. CIR = Censored Interval Regression. OLS $=$ Ordinary Least Squares. $* * * p<0.01, * * p<0.05, * p<0.1$. Source: Own elaboration. 
Table B5: Determinants of the amount sent in the trust game if any positive MP use is considered MP use

\begin{tabular}{|c|c|c|c|c|c|c|}
\hline & \multicolumn{2}{|c|}{$\begin{array}{l}\text { Trust towards } \\
\text { fellow villagers }\end{array}$} & \multicolumn{2}{|c|}{$\begin{array}{c}\text { Trust towards } \\
\text { people from a } \\
\text { neighboring village }\end{array}$} & \multicolumn{2}{|c|}{$\begin{array}{l}\text { Trust towards city } \\
\text { dwellers from the } \\
\text { county capital }\end{array}$} \\
\hline & $\begin{array}{l}\text { CIR } \\
(1)\end{array}$ & $\begin{array}{l}\text { OLS } \\
(2)\end{array}$ & $\begin{array}{l}\text { CIR } \\
(3)\end{array}$ & $\begin{array}{l}\text { OLS } \\
(4)\end{array}$ & $\begin{array}{l}\text { CIR } \\
(5)\end{array}$ & $\begin{array}{c}\text { OLS } \\
(6)\end{array}$ \\
\hline MP user & $\begin{array}{l}-1.136 \\
(3.537)\end{array}$ & $\begin{array}{l}-1.128 \\
(3.665)\end{array}$ & $\begin{array}{c}3.550 \\
(4.606)\end{array}$ & $\begin{array}{c}3.491 \\
(4.812)\end{array}$ & $\begin{array}{c}12.204^{* *} \\
(5.723)\end{array}$ & $\begin{array}{l}11.387^{*} \\
(5.742)\end{array}$ \\
\hline Age & $\begin{array}{c}0.056 \\
(0.115)\end{array}$ & $\begin{array}{c}0.056 \\
(0.119)\end{array}$ & $\begin{array}{c}0.057 \\
(0.091)\end{array}$ & $\begin{array}{c}0.060 \\
(0.096)\end{array}$ & $\begin{array}{l}-0.033 \\
(0.143)\end{array}$ & $\begin{array}{l}-0.036 \\
(0.140)\end{array}$ \\
\hline Risk aversion & $\begin{array}{c}-1.602^{* *} \\
(0.696)\end{array}$ & $\begin{array}{c}-1.601^{* *} \\
(0.721)\end{array}$ & $\begin{array}{l}-0.094 \\
(0.699)\end{array}$ & $\begin{array}{l}-0.100 \\
(0.731)\end{array}$ & $\begin{array}{l}-0.970 \\
(1.378)\end{array}$ & $\begin{array}{l}-0.916 \\
(1.366)\end{array}$ \\
\hline $\begin{array}{l}\text { Distance to next } \\
\text { paved road }\end{array}$ & $\begin{array}{l}-1.917 \\
(1.228)\end{array}$ & $\begin{array}{l}-1.881 \\
(1.261)\end{array}$ & $\begin{array}{c}-2.862^{* * * *} \\
(1.006)\end{array}$ & $\begin{array}{c}-2.875^{* *} \\
(1.052)\end{array}$ & $\begin{array}{c}1.322 \\
(1.243)\end{array}$ & $\begin{array}{c}1.324 \\
(1.234)\end{array}$ \\
\hline Education & $\begin{array}{c}0.931^{* *} \\
(0.398)\end{array}$ & $\begin{array}{c}0.925^{* *} \\
(0.414)\end{array}$ & $\begin{array}{c}0.030 \\
(0.861)\end{array}$ & $\begin{array}{c}0.032 \\
(0.903)\end{array}$ & $\begin{array}{l}-0.390 \\
(0.582)\end{array}$ & $\begin{array}{l}-0.363 \\
(0.563)\end{array}$ \\
\hline $\begin{array}{l}\text { Having family in } \\
\text { neighboring villages }\end{array}$ & & & $\begin{array}{c}1.972 \\
(5.896)\end{array}$ & $\begin{array}{c}1.982 \\
(6.132)\end{array}$ & & \\
\hline $\begin{array}{l}\text { Having family in } \\
\text { the county capital }\end{array}$ & & & & & $\begin{array}{c}2.516 \\
(3.158)\end{array}$ & $\begin{array}{c}2.356 \\
(3.133)\end{array}$ \\
\hline Female & $\begin{array}{c}0.446 \\
(3.697)\end{array}$ & $\begin{array}{c}0.501 \\
(3.825)\end{array}$ & $\begin{array}{c}3.696 \\
(3.496)\end{array}$ & $\begin{array}{c}3.677 \\
(3.671)\end{array}$ & $\begin{array}{l}-1.764 \\
(1.987)\end{array}$ & $\begin{array}{l}-1.733 \\
(1.969)\end{array}$ \\
\hline Herd size & $\begin{array}{l}-0.014 \\
(0.051)\end{array}$ & $\begin{array}{l}-0.015 \\
(0.053)\end{array}$ & $\begin{array}{c}0.020 \\
(0.058)\end{array}$ & $\begin{array}{c}0.020 \\
(0.060)\end{array}$ & $\begin{array}{c}0.049 \\
(0.087)\end{array}$ & $\begin{array}{c}0.045 \\
(0.086)\end{array}$ \\
\hline Household size & $\begin{array}{c}1.206^{* * *} \\
(0.380)\end{array}$ & $\begin{array}{c}1.208^{* * *} \\
(0.397)\end{array}$ & $\begin{array}{l}-0.158 \\
(0.540)\end{array}$ & $\begin{array}{c}-0.154 \\
(0.570)\end{array}$ & $\begin{array}{c}0.075 \\
(0.290)\end{array}$ & $\begin{array}{c}0.060 \\
(0.300)\end{array}$ \\
\hline Income & $\begin{array}{c}-0.350^{*} \\
(0.194)\end{array}$ & $\begin{array}{l}-0.345 \\
(0.203)\end{array}$ & $\begin{array}{l}-0.494 \\
(0.590)\end{array}$ & $\begin{array}{c}-0.502 \\
(0.623)\end{array}$ & $\begin{array}{c}-0.543^{* *} \\
(0.243)\end{array}$ & $\begin{array}{c}-0.506^{*} \\
(0.253)\end{array}$ \\
\hline Village size & $\begin{array}{c}-0.910^{* *} \\
(0.423)\end{array}$ & $\begin{array}{c}-0.903^{*} \\
(0.439)\end{array}$ & $\begin{array}{c}0.283 \\
(0.317)\end{array}$ & $\begin{array}{c}0.287 \\
(0.336)\end{array}$ & $\begin{array}{c}0.667 \\
(0.460)\end{array}$ & $\begin{array}{c}0.623 \\
(0.461)\end{array}$ \\
\hline Years of owning a MP & $\begin{array}{c}0.633 \\
(0.404)\end{array}$ & $\begin{array}{c}0.631 \\
(0.421)\end{array}$ & $\begin{array}{c}0.673^{* *} \\
(0.336)\end{array}$ & $\begin{array}{c}0.668^{*} \\
(0.355)\end{array}$ & $\begin{array}{c}-1.411^{*} \\
(0.746)\end{array}$ & $\begin{array}{r}-1.285^{*} \\
(0.733)\end{array}$ \\
\hline Constant & $\begin{array}{c}35.177^{* * *} \\
(7.617)\end{array}$ & $\begin{array}{l}35.108^{* * *} \\
(7.949)\end{array}$ & $\begin{array}{l}32.841^{* * *} \\
(9.760)\end{array}$ & $\begin{array}{c}32.900^{* * *} \\
(10.204)\end{array}$ & $\begin{array}{c}17.380 \\
(11.337)\end{array}$ & $\begin{array}{r}18.385 \\
(10.965)\end{array}$ \\
\hline $\ln (\sigma)$ & 2.697 & & 2.689 & & 2.793 & \\
\hline$R^{2}$ & & 0.146 & & 0.149 & & 0.109 \\
\hline \multicolumn{7}{|l|}{ Observations: } \\
\hline total & 142 & 142 & 120 & 120 & 132 & 132 \\
\hline left-censored & 7 & & 6 & & 21 & \\
\hline right-censored & 1 & & 0 & & 0 & \\
\hline interval & 134 & & 114 & & 111 & \\
\hline
\end{tabular}

Notes:Standard errors shown in parentheses are robust and clustered at the village level. CIR $=$ Censored Interval Regression. OLS $=$ Ordinary Least Squares. $* * * p<0.01, * * p<0.05, * p<0.1$.

Source: Own elaboration. 
Table B6: Summary statistics by treatment

\begin{tabular}{|c|c|c|c|c|}
\hline Variable & $\begin{array}{l}\text { Pairing with } \\
\text { someone from } \\
\text { the same village } \\
\qquad(\mathrm{N}=142)\end{array}$ & $\begin{array}{l}\text { Pairing with } \\
\text { someone from a } \\
\text { neighboring } \\
\text { village } \\
(\mathrm{N}=120)\end{array}$ & $\begin{array}{l}\text { Pairing with a } \\
\text { city dweller } \\
\text { from the county } \\
\text { capital } \\
(\mathrm{N}=132)\end{array}$ & $\begin{array}{c}\text { Kruskal- } \\
\text { Wallis } \\
\text { test }\end{array}$ \\
\hline Age [years] & 40.345 & 40.512 & 38.076 & \\
\hline $\begin{array}{l}\text { Constant relative risk } \\
\text { aversion coefficient (CRRA) }\end{array}$ & 2.221 & 2.092 & 2.214 & \\
\hline $\begin{array}{l}\text { Distance to the next paved } \\
\text { road [walking minutes ] }\end{array}$ & 27.732 & 25.75 & 28.644 & \\
\hline Education [years] & 1.063 & 0.783 & 1.538 & \\
\hline Female & 0.430 & 0.575 & 0.522 & * \\
\hline Herd size [TLU] & 32.822 & 31.549 & 33.913 & \\
\hline Household size & 8.401 & 8.333 & 7.583 & \\
\hline Income $[1000 \mathrm{KSh}]$ & 5.575 & 5.608 & 5.475 & \\
\hline Mobile phone use daily & 0.810 & 0.741 & 0.803 & \\
\hline Mobile phone ownership & 0.831 & 0.775 & 0.826 & \\
\hline $\begin{array}{l}\text { Number of mobile } \\
\text { phones owned }\end{array}$ & 1.211 & 1.258 & 1.167 & \\
\hline $\begin{array}{l}\text { Years of mobile } \\
\text { phone ownership }\end{array}$ & 3.465 & 3.725 & 3.174 & \\
\hline Smartphone ownership & 0.028 & 0.008 & 0.045 & \\
\hline $\begin{array}{l}\text { Number of smartphones } \\
\text { owned }\end{array}$ & 0.028 & 0.008 & 0.061 & \\
\hline $\begin{array}{l}\text { Years of smartphone } \\
\text { ownership }\end{array}$ & 0.141 & 0.046 & 0.098 & \\
\hline $\begin{array}{l}\text { Network reception } \\
\text { at homestead }\end{array}$ & 0.908 & 0.825 & 0.902 & \\
\hline $\begin{array}{l}\text { Having relatives in } \\
\text { neighboring villages }\end{array}$ & 0.944 & 0.900 & 0.955 & \\
\hline $\begin{array}{l}\text { Having relatives in } \\
\text { the County Capital }\end{array}$ & 0.585 & 0.600 & 0.667 & \\
\hline Village size [100 people] & 5.677 & 5.904 & 5.326 & \\
\hline $\begin{array}{l}\text { Years lived in the village } \\
\text { [percentage of lifetime] }\end{array}$ & 0.765 & 0.759 & 0.771 & \\
\hline
\end{tabular}

Notes: Mean values are shown. Variables are compared using the Kruskal-Wallis test. CRRA = Constant relative risk aversion coefficient. KSh $=$ Kenyan Shilling. TLU $=$ Tropical Livestock Unit. ${ }^{* * *} p<0.01,{ }^{* *} p<0.05,{ }^{*} p<0.1$. 
Table B7: Two-way table of frequency counts for mobile phone use and network reception at homestead

\begin{tabular}{|c|c|c|}
\hline \multirow[t]{2}{*}{ Network reception } & \multicolumn{2}{|c|}{ Mobile phone use } \\
\hline & No & Yes \\
\hline No & 40 & 7 \\
\hline Yes & 36 & 311 \\
\hline $\begin{array}{l}\text { Pearson } \chi^{2}: 148.49^{* * *} \\
\mathrm{~N}=394\end{array}$ & & \\
\hline
\end{tabular}

Notes: ${ }^{* * *},{ }^{* * *}$ denote statistical significance at the $10 \%, 5 \%, 1 \%$ level respectively.

Table B8: Correlations between network coverage and access to infrastructure $(\mathrm{N}=394)$

\begin{tabular}{lcc}
\hline \hline Variables [log of walking minutes] & $\begin{array}{c}\text { Correlation } \\
\text { coefficient }\end{array}$ & $p$-value \\
\hline Distance to next paved road & -0.067 & 0.182 \\
Distance to next source of potable water & -0.006 & 0.899 \\
Distance to next local food market & -0.041 & 0.423 \\
Distance to next urban food market & -0.006 & 0.900 \\
\hline
\end{tabular}

Notes: ${ }^{*},{ }^{* *},{ }^{* * *}$ denote statistical significance at the $10 \%, 5 \%, 1 \%$ level respectively. 
Table B9: Correlations between amounts sent in the trust game and network coverage for non-users of MP

\begin{tabular}{lccc}
\hline \hline Group & $\mathrm{N}$ & $\begin{array}{c}\text { Correlation } \\
\text { coefficient }\end{array}$ & $p$-value \\
\hline Total sample & 76 & 0.010 & 0.930 \\
Paired with fellow villager & 25 & 0.020 & 0.924 \\
Paired with person from neighboring village & 27 & -0.115 & 0.567 \\
Paired with city dweller from county capital & 24 & 0.211 & 0.322 \\
\hline
\end{tabular}

Notes: $: \mathrm{MP}=$ Mobile phone. ${ }^{*},{ }^{* *},{ }^{* * *}$ denote statistical significance at the $10 \%, 5 \%, 1 \%$ level respectively. 
Appendix $\mathrm{C}$

Can Mobile Phones Improve Nutrition? 
Table C1: Effects of mobile phones on household dietary diversity scores (fixed effects balanced panel model)

\begin{tabular}{|c|c|c|c|c|c|c|c|c|}
\hline & \multicolumn{4}{|c|}{ Mobile phone use } & \multicolumn{4}{|c|}{ Mobile phone ownership } \\
\hline & \multicolumn{2}{|c|}{ HDDS12 } & \multicolumn{2}{|c|}{ HDDS9 } & \multicolumn{2}{|c|}{ HDDS12 } & \multicolumn{2}{|c|}{ HDDS9 } \\
\hline & (1) & (2) & (3) & (4) & (5) & (6) & (7) & (8) \\
\hline Daily MP use & $\begin{array}{c}0.316^{* * *} \\
(0.082)\end{array}$ & $\begin{array}{c}0.301^{* * *} \\
(0.082)\end{array}$ & $\begin{array}{c}0.251^{* * *} \\
(0.082)\end{array}$ & $\begin{array}{c}0.237^{* *} \\
(0.083)\end{array}$ & & & & \\
\hline Weekly MP use (excluding daily use) & $\begin{array}{c}0.000 \\
(0.074)\end{array}$ & $\begin{array}{l}-0.007 \\
(0.072)\end{array}$ & $\begin{array}{l}-0.109 \\
(0.074)\end{array}$ & $\begin{array}{l}-0.117 \\
(0.072)\end{array}$ & & & & \\
\hline At most monthly MP use & $\begin{array}{l}0.146^{*} \\
(0.074)\end{array}$ & $\begin{array}{l}0.142^{*} \\
(0.073)\end{array}$ & $\begin{array}{c}0.107 \\
(0.082)\end{array}$ & $\begin{array}{c}0.103 \\
(0.081)\end{array}$ & & & & \\
\hline Owning at least one MP & & & & & $\begin{array}{c}0.211^{* *} \\
(0.095)\end{array}$ & $\begin{array}{c}0.209 * * \\
(0.094)\end{array}$ & $\begin{array}{c}0.148 \\
(0.101)\end{array}$ & $\begin{array}{c}0.146 \\
(0.099)\end{array}$ \\
\hline Owning two or more MPs & & & & & $\begin{array}{l}0.259^{*} \\
(0.124)\end{array}$ & $\begin{array}{c}0.248^{*} \\
(0.129)\end{array}$ & $\begin{array}{l}0.231^{*} \\
(0.125)\end{array}$ & $\begin{array}{l}0.219 \\
(0.130)\end{array}$ \\
\hline Income $[\mathrm{KSh} 1,000,000]$ & & $\begin{array}{c}2.592^{* * *} \\
(0.465)\end{array}$ & & $\begin{array}{c}2.690^{* * *} \\
(0.461)\end{array}$ & & $\begin{array}{c}2.637^{* * *} \\
(0.463)\end{array}$ & & $\begin{array}{c}2.720^{* * *} \\
(0.461)\end{array}$ \\
\hline Nomadic status & $\begin{array}{l}-0.009 \\
(0.256)\end{array}$ & $\begin{array}{l}-0.002 \\
(0.259)\end{array}$ & $\begin{array}{l}-0.022 \\
(0.260)\end{array}$ & $\begin{array}{l}-0.015 \\
(0.262)\end{array}$ & $\begin{array}{l}-0.024 \\
(0.254)\end{array}$ & $\begin{array}{l}-0.016 \\
(0.256)\end{array}$ & $\begin{array}{l}-0.037 \\
(0.258)\end{array}$ & $\begin{array}{l}-0.029 \\
(0.260)\end{array}$ \\
\hline Radio ownership & $\begin{array}{l}-0.151 \\
(0.146)\end{array}$ & $\begin{array}{l}-0.156 \\
(0.138)\end{array}$ & $\begin{array}{l}-0.176 \\
(0.142)\end{array}$ & $\begin{array}{l}-0.181 \\
(0.134)\end{array}$ & $\begin{array}{l}-0.172 \\
(0.149)\end{array}$ & $\begin{array}{l}-0.176 \\
(0.141)\end{array}$ & $\begin{array}{l}-0.191 \\
(0.148)\end{array}$ & $\begin{array}{l}-0.195 \\
(0.140)\end{array}$ \\
\hline Cooking source & $\begin{array}{c}0.456^{* *} \\
(0.161)\end{array}$ & $\begin{array}{c}0.450^{* *} \\
(0.193)\end{array}$ & $\begin{array}{c}0.340^{* *} \\
(0.137)\end{array}$ & $\begin{array}{l}0.334^{*} \\
(0.167)\end{array}$ & $\begin{array}{c}0.464^{* *} \\
(0.166)\end{array}$ & $\begin{array}{c}0.458^{* *} \\
(0.198)\end{array}$ & $\begin{array}{c}0.348^{* *} \\
(0.140)\end{array}$ & $\begin{array}{l}0.341^{*} \\
(0.172)\end{array}$ \\
\hline Land farmed [hectares] & $\begin{array}{c}0.023 \\
(0.030)\end{array}$ & $\begin{array}{c}0.026 \\
(0.026)\end{array}$ & $\begin{array}{l}0.029 \\
(0.029)\end{array}$ & $\begin{array}{c}0.031 \\
(0.026)\end{array}$ & $\begin{array}{c}0.026 \\
(0.030)\end{array}$ & $\begin{array}{c}0.028 \\
(0.027)\end{array}$ & $\begin{array}{c}0.031 \\
(0.030)\end{array}$ & $\begin{array}{c}0.033 \\
(0.027)\end{array}$ \\
\hline Herd size $[\mathrm{TLU}]$ & $\begin{array}{c}0.005^{* * *} \\
(0.001)\end{array}$ & $\begin{array}{c}0.004^{* *} \\
(0.001)\end{array}$ & $\begin{array}{c}0.005^{* * *} \\
(0.001)\end{array}$ & $\begin{array}{c}0.004^{* * *} \\
(0.001)\end{array}$ & $\begin{array}{c}0.005^{* * *} \\
(0.001)\end{array}$ & $\begin{array}{c}0.004^{* *} \\
(0.001)\end{array}$ & $\begin{array}{c}0.005^{* * *} \\
(0.001)\end{array}$ & $\begin{array}{c}0.004^{* * *} \\
(0.001)\end{array}$ \\
\hline Education HH [years] & -0.017 & -0.021 & $-0.072^{*}$ & $-0.075^{* *}$ & -0.029 & -0.033 & $-0.086^{*}$ & $-0.090^{* *}$ \\
\hline
\end{tabular}


Table C1 - continued from previous page -

\begin{tabular}{|c|c|c|c|c|c|c|c|c|}
\hline & $(0.080)$ & $(0.075)$ & $(0.040)$ & $(0.034)$ & $(0.083)$ & $(0.078)$ & $(0.046)$ & $(0.041)$ \\
\hline Gender HH & $\begin{array}{c}0.190 \\
(0.119)\end{array}$ & $\begin{array}{c}0.195 \\
(0.120)\end{array}$ & $\begin{array}{c}0.243^{* *} \\
(0.109)\end{array}$ & $\begin{array}{c}0.248^{* *} \\
(0.110)\end{array}$ & $\begin{array}{c}0.198 \\
(0.118)\end{array}$ & $\begin{array}{c}0.203 \\
(0.117)\end{array}$ & $\begin{array}{c}0.248^{* *} \\
(0.105)\end{array}$ & $\begin{array}{c}0.253^{* *} \\
(0.105)\end{array}$ \\
\hline Age HH & $\begin{array}{c}0.001 \\
(0.003)\end{array}$ & $\begin{array}{c}0.001 \\
(0.003)\end{array}$ & $\begin{array}{c}0.002 \\
(0.003)\end{array}$ & $\begin{array}{c}0.002 \\
(0.003)\end{array}$ & $\begin{array}{c}0.001 \\
(0.003)\end{array}$ & $\begin{array}{c}0.001 \\
(0.003)\end{array}$ & $\begin{array}{c}0.002 \\
(0.003)\end{array}$ & $\begin{array}{c}0.002 \\
(0.003)\end{array}$ \\
\hline Household size & $\begin{array}{c}0.079^{* * *} \\
(0.022)\end{array}$ & $\begin{array}{c}0.076^{* * *} \\
(0.022)\end{array}$ & $\begin{array}{c}0.085^{* * *} \\
(0.019)\end{array}$ & $\begin{array}{c}0.082^{* * *} \\
(0.019)\end{array}$ & $\begin{array}{c}0.081 * * * \\
(0.023)\end{array}$ & $\begin{array}{c}0.078^{* * *} \\
(0.022)\end{array}$ & $\begin{array}{c}0.087^{* * *} \\
(0.019)\end{array}$ & $\begin{array}{c}0.084^{* * *} \\
(0.019)\end{array}$ \\
\hline Division 1 round 1 & $\begin{array}{c}-0.953^{* * *} \\
(0.234)\end{array}$ & $\begin{array}{c}-0.943^{* * *} \\
(0.241)\end{array}$ & $\begin{array}{c}-0.984^{* * *} \\
(0.216)\end{array}$ & $\begin{array}{c}-0.974^{* * *} \\
(0.222)\end{array}$ & $\begin{array}{c}-0.997^{* * *} \\
(0.248)\end{array}$ & $\begin{array}{c}-0.986^{* * *} \\
(0.254)\end{array}$ & $\begin{array}{c}-1.023^{* * *} \\
(0.227)\end{array}$ & $\begin{array}{c}-1.012^{* * *} \\
(0.232)\end{array}$ \\
\hline Division 1 round 2 & $\begin{array}{l}-0.142 \\
(0.259)\end{array}$ & $\begin{array}{l}-0.185 \\
(0.217)\end{array}$ & $\begin{array}{l}-0.235 \\
(0.293)\end{array}$ & $\begin{array}{l}-0.280 \\
(0.249)\end{array}$ & $\begin{array}{l}-0.179 \\
(0.273)\end{array}$ & $\begin{array}{l}-0.220 \\
(0.229)\end{array}$ & $\begin{array}{l}-0.264 \\
(0.306)\end{array}$ & $\begin{array}{l}-0.307 \\
(0.261)\end{array}$ \\
\hline Division 1 round 3 & $\begin{array}{c}-0.786^{* * *} \\
(0.107)\end{array}$ & $\begin{array}{c}-0.810^{* * *} \\
(0.095)\end{array}$ & $\begin{array}{c}-0.562^{* * *} \\
(0.089)\end{array}$ & $\begin{array}{c}-0.587^{* * *} \\
(0.077)\end{array}$ & $\begin{array}{c}-0.835^{* * *} \\
(0.123)\end{array}$ & $\begin{array}{c}-0.858^{* * *} \\
(0.109)\end{array}$ & $\begin{array}{c}-0.605^{* * *} \\
(0.100)\end{array}$ & $\begin{array}{c}-0.628^{* * *} \\
(0.087)\end{array}$ \\
\hline Division 1 round 4 & $\begin{array}{c}-0.583^{* * *} \\
(0.029)\end{array}$ & $\begin{array}{c}-0.657^{* * *} \\
(0.040)\end{array}$ & $\begin{array}{c}-0.522^{* * *} \\
(0.050)\end{array}$ & $\begin{array}{c}-0.599^{* * *} \\
(0.034)\end{array}$ & $\begin{array}{c}-0.621^{* * *} \\
(0.046)\end{array}$ & $\begin{array}{c}-0.694^{* * *} \\
(0.031)\end{array}$ & $\begin{array}{c}-0.554^{* * *} \\
(0.071)\end{array}$ & $\begin{array}{c}-0.630^{* * *} \\
(0.043)\end{array}$ \\
\hline Division 1 round 5 & $\begin{array}{l}-0.058 \\
(0.045)\end{array}$ & $\begin{array}{l}-0.053 \\
(0.046)\end{array}$ & $\begin{array}{l}-0.066 \\
(0.066)\end{array}$ & $\begin{array}{l}-0.061 \\
(0.068)\end{array}$ & $\begin{array}{c}-0.094^{*} \\
(0.046)\end{array}$ & $\begin{array}{c}-0.087^{*} \\
(0.046)\end{array}$ & $\begin{array}{l}-0.100 \\
(0.068)\end{array}$ & $\begin{array}{l}-0.093 \\
(0.068)\end{array}$ \\
\hline Division 2 round 1 & $\begin{array}{c}-0.270^{* * *} \\
(0.082)\end{array}$ & $\begin{array}{c}-0.264^{* * *} \\
(0.078)\end{array}$ & $\begin{array}{c}-0.245^{*} \\
(0.126)\end{array}$ & $\begin{array}{c}-0.239^{*} \\
(0.122)\end{array}$ & $\begin{array}{c}-0.301^{* * *} \\
(0.088)\end{array}$ & $\begin{array}{c}-0.296^{* * *} \\
(0.085)\end{array}$ & $\begin{array}{c}-0.275^{*} \\
(0.143)\end{array}$ & $\begin{array}{c}-0.269^{*} \\
(0.140)\end{array}$ \\
\hline Division 2 round 2 & $\begin{array}{c}0.326 \\
(0.577)\end{array}$ & $\begin{array}{c}0.289 \\
(0.576)\end{array}$ & $\begin{array}{c}0.238 \\
(0.570)\end{array}$ & $\begin{array}{c}0.199 \\
(0.568)\end{array}$ & $\begin{array}{c}0.268 \\
(0.590)\end{array}$ & $\begin{array}{c}0.232 \\
(0.588)\end{array}$ & $\begin{array}{c}0.185 \\
(0.583)\end{array}$ & $\begin{array}{c}0.147 \\
(0.580)\end{array}$ \\
\hline Division 2 round 3 & $\begin{array}{c}0.162^{* * *} \\
(0.053)\end{array}$ & $\begin{array}{c}0.157^{* * *} \\
(0.050)\end{array}$ & $\begin{array}{c}0.189^{* *} \\
(0.065)\end{array}$ & $\begin{array}{c}0.183^{* * *} \\
(0.062)\end{array}$ & $\begin{array}{c}0.127^{* *} \\
(0.047)\end{array}$ & $\begin{array}{c}0.122^{* *} \\
(0.044)\end{array}$ & $\begin{array}{c}0.142^{* *} \\
(0.065)\end{array}$ & $\begin{array}{c}0.136^{* *} \\
(0.062)\end{array}$ \\
\hline Division 2 round 4 & $\begin{array}{l}-0.017 \\
(0.033)\end{array}$ & $\begin{array}{c}-0.061^{*} \\
(0.034)\end{array}$ & $\begin{array}{c}0.035 \\
(0.029)\end{array}$ & $\begin{array}{l}-0.011 \\
(0.032)\end{array}$ & $\begin{array}{l}-0.054 \\
(0.032)\end{array}$ & $\begin{array}{c}-0.099^{* * *} \\
(0.032)\end{array}$ & $\begin{array}{l}-0.010 \\
(0.029)\end{array}$ & $\begin{array}{l}-0.056^{*} \\
(0.032)\end{array}$ \\
\hline Division 2 round 5 & $\begin{array}{c}0.522^{* * *} \\
(0.082)\end{array}$ & $\begin{array}{c}0.487^{* * *} \\
(0.082)\end{array}$ & $\begin{array}{c}0.589^{* * *} \\
(0.105)\end{array}$ & $\begin{array}{c}0.553^{* * *} \\
(0.105)\end{array}$ & $\begin{array}{c}0.506^{* * *} \\
(0.080)\end{array}$ & $\begin{array}{c}0.471^{* * *} \\
(0.081)\end{array}$ & $\begin{array}{c}0.571^{* * *} \\
(0.106)\end{array}$ & $\begin{array}{c}0.534^{* * *} \\
(0.106)\end{array}$ \\
\hline
\end{tabular}


Table C1 - continued from previous page -

\begin{tabular}{|c|c|c|c|c|c|c|c|c|}
\hline Division 3 round 1 & $\begin{array}{c}-0.569^{* * *} \\
(0.136)\end{array}$ & $\begin{array}{c}-0.544^{* * *} \\
(0.121)\end{array}$ & $\begin{array}{c}-0.592^{* * *} \\
(0.135)\end{array}$ & $\begin{array}{c}-0.565^{* * *} \\
(0.119)\end{array}$ & $\begin{array}{c}-0.623^{* * *} \\
(0.111)\end{array}$ & $\begin{array}{c}-0.595^{* * *} \\
(0.099)\end{array}$ & $\begin{array}{c}-0.633^{* * *} \\
(0.115)\end{array}$ & $\begin{array}{c}-0.603^{* * *} \\
(0.101)\end{array}$ \\
\hline Division 3 round 2 & $\begin{array}{l}-0.346 \\
(0.316)\end{array}$ & $\begin{array}{l}-0.357 \\
(0.305)\end{array}$ & $\begin{array}{l}-0.516^{*} \\
(0.259)\end{array}$ & $\begin{array}{c}-0.528^{* *} \\
(0.246)\end{array}$ & $\begin{array}{l}-0.391 \\
(0.335)\end{array}$ & $\begin{array}{l}-0.400 \\
(0.324)\end{array}$ & $\begin{array}{l}-0.549^{*} \\
(0.274)\end{array}$ & $\begin{array}{c}-0.558^{* *} \\
(0.261)\end{array}$ \\
\hline Division 3 round 3 & $\begin{array}{c}-0.525^{* * *} \\
(0.067)\end{array}$ & $\begin{array}{c}-0.505^{* * *} \\
(0.063)\end{array}$ & $\begin{array}{c}-0.555^{* * *} \\
(0.077)\end{array}$ & $\begin{array}{c}-0.534^{* * *} \\
(0.078)\end{array}$ & $\begin{array}{c}-0.572^{* * *} \\
(0.056)\end{array}$ & $\begin{array}{c}-0.550^{* * *} \\
(0.050)\end{array}$ & $\begin{array}{c}-0.594^{* * *} \\
(0.059)\end{array}$ & $\begin{array}{c}-0.571^{* * *} \\
(0.059)\end{array}$ \\
\hline Division 3 round 4 & $\begin{array}{c}-0.306^{*} \\
(0.153)\end{array}$ & $\begin{array}{l}-0.281^{*} \\
(0.134)\end{array}$ & $\begin{array}{l}-0.333^{*} \\
(0.179)\end{array}$ & $\begin{array}{l}-0.306^{*} \\
(0.161)\end{array}$ & $\begin{array}{c}-0.336^{* *} \\
(0.133)\end{array}$ & $\begin{array}{c}-0.308^{* *} \\
(0.112)\end{array}$ & $\begin{array}{c}-0.356^{* *} \\
(0.157)\end{array}$ & $\begin{array}{c}-0.328^{* *} \\
(0.138)\end{array}$ \\
\hline Division 3 round 5 & $\begin{array}{c}-0.225^{* * *} \\
(0.038)\end{array}$ & $\begin{array}{c}-0.212^{* * *} \\
(0.039)\end{array}$ & $\begin{array}{c}-0.190^{* * *} \\
(0.039)\end{array}$ & $\begin{array}{c}-0.177^{* * *} \\
(0.035)\end{array}$ & $\begin{array}{c}-0.270^{* * *} \\
(0.053)\end{array}$ & $\begin{array}{c}-0.255^{* * *} \\
(0.057)\end{array}$ & $\begin{array}{c}-0.236^{* * *} \\
(0.052)\end{array}$ & $\begin{array}{c}-0.222^{* * *} \\
(0.053)\end{array}$ \\
\hline Division 4 round 1 & $\begin{array}{c}-0.763^{*} \\
(0.407)\end{array}$ & $\begin{array}{l}-0.733^{*} \\
(0.409)\end{array}$ & $\begin{array}{c}-0.838^{* *} \\
(0.368)\end{array}$ & $\begin{array}{c}-0.806^{* *} \\
(0.370)\end{array}$ & $\begin{array}{l}-0.769^{*} \\
(0.399)\end{array}$ & $\begin{array}{l}-0.736^{*} \\
(0.403)\end{array}$ & $\begin{array}{c}-0.829^{* *} \\
(0.354)\end{array}$ & $\begin{array}{c}-0.795^{* *} \\
(0.357)\end{array}$ \\
\hline Division 4 round 2 & $\begin{array}{l}-0.184 \\
(0.254)\end{array}$ & $\begin{array}{l}-0.192 \\
(0.257)\end{array}$ & $\begin{array}{l}-0.293 \\
(0.235)\end{array}$ & $\begin{array}{l}-0.301 \\
(0.238)\end{array}$ & $\begin{array}{l}-0.194 \\
(0.234)\end{array}$ & $\begin{array}{l}-0.199 \\
(0.237)\end{array}$ & $\begin{array}{l}-0.297 \\
(0.217)\end{array}$ & $\begin{array}{l}-0.302 \\
(0.221)\end{array}$ \\
\hline Division 4 round 3 & $\begin{array}{l}-0.351 \\
(0.252)\end{array}$ & $\begin{array}{l}-0.322 \\
(0.248)\end{array}$ & $\begin{array}{l}-0.338^{*} \\
(0.184)\end{array}$ & $\begin{array}{l}-0.308 \\
(0.179)\end{array}$ & $\begin{array}{l}-0.387 \\
(0.250)\end{array}$ & $\begin{array}{l}-0.355 \\
(0.246)\end{array}$ & $\begin{array}{c}-0.365^{*} \\
(0.178)\end{array}$ & $\begin{array}{l}-0.332^{*} \\
(0.174)\end{array}$ \\
\hline Division 4 round 4 & $\begin{array}{c}0.265 \\
(0.228)\end{array}$ & $\begin{array}{c}0.266 \\
(0.232)\end{array}$ & $\begin{array}{c}0.247 \\
(0.214)\end{array}$ & $\begin{array}{c}0.248 \\
(0.220)\end{array}$ & $\begin{array}{c}0.228 \\
(0.198)\end{array}$ & $\begin{array}{c}0.232 \\
(0.202)\end{array}$ & $\begin{array}{c}0.221 \\
(0.190)\end{array}$ & $\begin{array}{c}0.225 \\
(0.196)\end{array}$ \\
\hline Division 4 round 5 & $\begin{array}{c}0.519^{* * *} \\
(0.168)\end{array}$ & $\begin{array}{c}0.518^{* * *} \\
(0.164)\end{array}$ & $\begin{array}{c}0.529^{* * *} \\
(0.173)\end{array}$ & $\begin{array}{c}0.528^{* * *} \\
(0.170)\end{array}$ & $\begin{array}{c}0.491^{* * *} \\
(0.140)\end{array}$ & $\begin{array}{c}0.492^{* * *} \\
(0.136)\end{array}$ & $\begin{array}{c}0.506^{* * *} \\
(0.147)\end{array}$ & $\begin{array}{c}0.507^{* * *} \\
(0.143)\end{array}$ \\
\hline Division 5 round 1 & $\begin{array}{c}-1.410^{* * *} \\
(0.232)\end{array}$ & $\begin{array}{c}-1.397^{* * *} \\
(0.224)\end{array}$ & $\begin{array}{c}-1.419 * * * \\
(0.251)\end{array}$ & $\begin{array}{c}-1.405^{* * *} \\
(0.243)\end{array}$ & $\begin{array}{c}-1.439^{* * *} \\
(0.232)\end{array}$ & $\begin{array}{c}-1.422^{* * *} \\
(0.225)\end{array}$ & $\begin{array}{c}-1.433^{* * *} \\
(0.248)\end{array}$ & $\begin{array}{c}-1.416^{* * *} \\
(0.241)\end{array}$ \\
\hline Division 5 round 2 & $\begin{array}{c}-0.833^{* *} \\
(0.317)\end{array}$ & $\begin{array}{c}-0.833^{* *} \\
(0.311)\end{array}$ & $\begin{array}{c}-0.918^{* *} \\
(0.318)\end{array}$ & $\begin{array}{c}-0.918^{* * *} \\
(0.311)\end{array}$ & $\begin{array}{c}-0.855^{* *} \\
(0.304)\end{array}$ & $\begin{array}{c}-0.852^{* *} \\
(0.298)\end{array}$ & $\begin{array}{c}-0.927^{* * *} \\
(0.306)\end{array}$ & $\begin{array}{c}-0.924^{* * *} \\
(0.299)\end{array}$ \\
\hline Division 5 round 3 & $\begin{array}{c}-0.753^{* * *} \\
(0.074)\end{array}$ & $\begin{array}{c}-0.725^{* * *} \\
(0.071)\end{array}$ & $\begin{array}{c}-0.704^{* * *} \\
(0.062)\end{array}$ & $\begin{array}{c}-0.675^{* * *} \\
(0.060)\end{array}$ & $\begin{array}{c}-0.787^{* * *} \\
(0.062)\end{array}$ & $\begin{array}{c}-0.755^{* * *} \\
(0.060)\end{array}$ & $\begin{array}{c}-0.725^{* * *} \\
(0.060)\end{array}$ & $\begin{array}{c}-0.691^{* * *} \\
(0.058)\end{array}$ \\
\hline Division 5 round 4 & $-0.569^{* * *}$ & $-0.566^{* * *}$ & $-0.546^{* * *}$ & $-0.543^{* * *}$ & $-0.601^{* * *}$ & $-0.595^{* * *}$ & $-0.563^{* * *}$ & $-0.556^{* * *}$ \\
\hline
\end{tabular}


Table C1 - continued from previous page -

\begin{tabular}{|c|c|c|c|c|c|c|c|c|}
\hline & $(0.178)$ & $(0.173)$ & $(0.183)$ & $(0.178)$ & $(0.192)$ & $(0.186)$ & $(0.190)$ & $(0.185)$ \\
\hline Division 5 round 5 & $\begin{array}{c}-0.507^{* * *} \\
(0.138)\end{array}$ & $\begin{array}{c}-0.518^{* * *} \\
(0.137)\end{array}$ & $\begin{array}{c}-0.446^{* * *} \\
(0.144)\end{array}$ & $\begin{array}{c}-0.457^{* * *} \\
(0.142)\end{array}$ & $\begin{array}{c}-0.529 * * * \\
(0.160)\end{array}$ & $\begin{array}{c}-0.536^{* * *} \\
(0.158)\end{array}$ & $\begin{array}{c}-0.454^{* *} \\
(0.161)\end{array}$ & $\begin{array}{c}-0.462^{* *} \\
(0.159)\end{array}$ \\
\hline Constant & $\begin{array}{c}6.485^{* * *} \\
(0.295)\end{array}$ & $\begin{array}{c}6.437^{* * *} \\
(0.285)\end{array}$ & $\begin{array}{c}4.154^{* * *} \\
(0.272)\end{array}$ & $\begin{array}{c}4.104^{* * *} \\
(0.262)\end{array}$ & $\begin{array}{c}6.555^{* * *} \\
(0.294)\end{array}$ & $\begin{array}{c}6.500 * * * \\
(0.283)\end{array}$ & $\begin{array}{c}4.204^{* * *} \\
(0.264)\end{array}$ & $\begin{array}{c}4.148^{* * *} \\
(0.254)\end{array}$ \\
\hline \multicolumn{9}{|l|}{ Model statistics } \\
\hline$R^{2}$ & 0.574 & 0.580 & 0.557 & 0.563 & 0.572 & 0.577 & 0.555 & 0.560 \\
\hline
\end{tabular}

Notes: Estimates are based on a balanced panel data set with 4,512 observations and 752 groups. Errors shown in parentheses are robust and clustered at the sub-location level. HDDS = household dietary diversity score. HH = household head. MP $=$ mobile phone. $\mathrm{TLU}=$ Tropical Livestock Unit. ${ }^{*},{ }^{* *},{ }^{* * *}$ denote statistical significance at the $10 \%, 5 \%, 1 \%$ level respectively. 
Table C2: Full Table for the effects of mobile phones on household dietary diversity scores (fixed effects panel model)

\begin{tabular}{|c|c|c|c|c|c|c|c|c|}
\hline & \multicolumn{4}{|c|}{ Mobile phone use } & \multicolumn{4}{|c|}{ Mobile phone ownership } \\
\hline & \multicolumn{2}{|c|}{ HDDS12 } & \multicolumn{2}{|c|}{ HDDS9 } & \multicolumn{2}{|c|}{ HDDS12 } & \multicolumn{2}{|c|}{ HDDS9 } \\
\hline & (1) & $(2)$ & (3) & (4) & (5) & (6) & (7) & (8) \\
\hline Daily MP use & $\begin{array}{c}0.306^{* * *} \\
(0.075)\end{array}$ & $\begin{array}{c}0.289^{* * *} \\
(0.075)\end{array}$ & $\begin{array}{c}0.261^{* * *} \\
(0.077)\end{array}$ & $\begin{array}{c}0.243^{* * *} \\
(0.078)\end{array}$ & & & & \\
\hline Weekly MP use (excluding daily use) & $\begin{array}{c}0.021 \\
(0.070)\end{array}$ & $\begin{array}{c}0.011 \\
(0.068)\end{array}$ & $\begin{array}{l}-0.060 \\
(0.063)\end{array}$ & $\begin{array}{l}-0.071 \\
(0.061)\end{array}$ & & & & \\
\hline At most monthly MP use & $\begin{array}{l}0.142^{*} \\
(0.071)\end{array}$ & $\begin{array}{l}0.138^{*} \\
(0.069)\end{array}$ & $\begin{array}{c}0.122 \\
(0.077)\end{array}$ & $\begin{array}{c}0.118 \\
(0.075)\end{array}$ & & & & \\
\hline Owning at least one MP & & & & & $\begin{array}{l}0.192^{*} \\
(0.097)\end{array}$ & $\begin{array}{l}0.186^{*} \\
(0.096)\end{array}$ & $\begin{array}{c}0.120 \\
(0.103)\end{array}$ & $\begin{array}{c}0.115 \\
(0.102)\end{array}$ \\
\hline Owning two or more MPs & & & & & $\begin{array}{c}0.248^{* *} \\
(0.111)\end{array}$ & $\begin{array}{l}0.233^{*} \\
(0.111)\end{array}$ & $\begin{array}{l}0.211^{*} \\
(0.107)\end{array}$ & $\begin{array}{l}0.195^{*} \\
(0.109)\end{array}$ \\
\hline Income $[\mathrm{KSh} 1,000,000]$ & & $\begin{array}{c}2.321^{* * *} \\
(0.438)\end{array}$ & & $\begin{array}{c}2.484^{* * *} \\
(0.447)\end{array}$ & & $\begin{array}{c}2.362^{* * *} \\
(0.434)\end{array}$ & & $\begin{array}{c}2.515^{* * *} \\
(0.444)\end{array}$ \\
\hline Nomadic status & $\begin{array}{l}-0.021 \\
(0.224)\end{array}$ & $\begin{array}{l}-0.015 \\
(0.226)\end{array}$ & $\begin{array}{c}0.024 \\
(0.224)\end{array}$ & $\begin{array}{c}0.030 \\
(0.226)\end{array}$ & $\begin{array}{l}-0.030 \\
(0.220)\end{array}$ & $\begin{array}{l}-0.024 \\
(0.222)\end{array}$ & $\begin{array}{c}0.014 \\
(0.221)\end{array}$ & $\begin{array}{c}0.021 \\
(0.223)\end{array}$ \\
\hline Radio ownership & $\begin{array}{l}-0.124 \\
(0.153)\end{array}$ & $\begin{array}{l}-0.131 \\
(0.147)\end{array}$ & $\begin{array}{l}-0.131 \\
(0.158)\end{array}$ & $\begin{array}{l}-0.139 \\
(0.152)\end{array}$ & $\begin{array}{l}-0.140 \\
(0.156)\end{array}$ & $\begin{array}{l}-0.146 \\
(0.150)\end{array}$ & $\begin{array}{l}-0.138 \\
(0.164)\end{array}$ & $\begin{array}{l}-0.145 \\
(0.157)\end{array}$ \\
\hline Cooking source & $\begin{array}{c}0.202 \\
(0.195)\end{array}$ & $\begin{array}{c}0.199 \\
(0.220)\end{array}$ & $\begin{array}{c}0.032 \\
(0.170)\end{array}$ & $\begin{array}{l}0.029 \\
(0.194)\end{array}$ & $\begin{array}{c}0.205 \\
(0.201)\end{array}$ & $\begin{array}{c}0.202 \\
(0.226)\end{array}$ & $\begin{array}{c}0.037 \\
(0.174)\end{array}$ & $\begin{array}{c}0.034 \\
(0.199)\end{array}$ \\
\hline Land farmed [hectares] & $\begin{array}{c}0.017^{* * *} \\
(0.005)\end{array}$ & $\begin{array}{c}0.017^{* * *} \\
(0.004)\end{array}$ & $\begin{array}{c}0.018^{* * *} \\
(0.004)\end{array}$ & $\begin{array}{c}0.018^{* * *} \\
(0.004)\end{array}$ & $\begin{array}{c}0.015^{* *} \\
(0.005)\end{array}$ & $\begin{array}{c}0.015^{* * *} \\
(0.005)\end{array}$ & $\begin{array}{c}0.017^{* * *} \\
(0.005)\end{array}$ & $\begin{array}{c}0.017^{* * *} \\
(0.004)\end{array}$ \\
\hline Herd size $[\mathrm{TLU}]$ & $\begin{array}{c}0.005^{* * *} \\
(0.001)\end{array}$ & $\begin{array}{c}0.005^{* * *} \\
(0.001)\end{array}$ & $\begin{array}{c}0.006^{* * *} \\
(0.002)\end{array}$ & $\begin{array}{c}0.005^{* * *} \\
(0.002)\end{array}$ & $\begin{array}{c}0.005^{* * *} \\
(0.001)\end{array}$ & $\begin{array}{c}0.005^{* * *} \\
(0.001)\end{array}$ & $\begin{array}{c}0.006^{* * *} \\
(0.002)\end{array}$ & $\begin{array}{c}0.005^{* * *} \\
(0.002)\end{array}$ \\
\hline
\end{tabular}


Table C2 - continued from previous page -

\begin{tabular}{|c|c|c|c|c|c|c|c|c|}
\hline Education HH [years] & $\begin{array}{l}-0.052 \\
(0.075)\end{array}$ & $\begin{array}{l}-0.049 \\
(0.071)\end{array}$ & $\begin{array}{l}-0.088 \\
(0.082)\end{array}$ & $\begin{array}{l}-0.085 \\
(0.079)\end{array}$ & $\begin{array}{l}-0.055 \\
(0.073)\end{array}$ & $\begin{array}{l}-0.052 \\
(0.069)\end{array}$ & $\begin{array}{l}-0.092 \\
(0.079)\end{array}$ & $\begin{array}{l}-0.088 \\
(0.077)\end{array}$ \\
\hline Gender $\mathrm{HH}$ & $\begin{array}{l}0.206^{*} \\
(0.106)\end{array}$ & $\begin{array}{l}0.215^{*} \\
(0.106)\end{array}$ & $\begin{array}{c}0.238^{* *} \\
(0.094)\end{array}$ & $\begin{array}{c}0.248^{* *} \\
(0.095)\end{array}$ & $\begin{array}{l}0.211^{*} \\
(0.104)\end{array}$ & $\begin{array}{l}0.220^{*} \\
(0.104)\end{array}$ & $\begin{array}{c}0.240^{* *} \\
(0.092)\end{array}$ & $\begin{array}{l}0.250^{* *} \\
(0.092)\end{array}$ \\
\hline Age $\mathrm{HH}$ & $\begin{array}{l}-0.000 \\
(0.003)\end{array}$ & $\begin{array}{l}-0.000 \\
(0.003)\end{array}$ & $\begin{array}{c}0.001 \\
(0.003)\end{array}$ & $\begin{array}{c}0.001 \\
(0.003)\end{array}$ & $\begin{array}{l}-0.000 \\
(0.003)\end{array}$ & $\begin{array}{l}-0.000 \\
(0.003)\end{array}$ & $\begin{array}{c}0.001 \\
(0.003)\end{array}$ & $\begin{array}{c}0.001 \\
(0.003)\end{array}$ \\
\hline Household size & $\begin{array}{c}0.077^{* * *} \\
(0.019)\end{array}$ & $\begin{array}{c}0.075^{* * *} \\
(0.019)\end{array}$ & $\begin{array}{c}0.080^{* * *} \\
(0.018)\end{array}$ & $\begin{array}{c}0.078^{* * *} \\
(0.018)\end{array}$ & $\begin{array}{c}0.078^{* * *} \\
(0.020)\end{array}$ & $\begin{array}{c}0.076^{* * *} \\
(0.020)\end{array}$ & $\begin{array}{c}0.081^{* * *} \\
(0.019)\end{array}$ & $\begin{array}{c}0.079^{* * *} \\
(0.019)\end{array}$ \\
\hline Division 1 round 1 & $\begin{array}{c}-0.933^{* * *} \\
(0.230)\end{array}$ & $\begin{array}{c}-0.923^{* * *} \\
(0.238)\end{array}$ & $\begin{array}{c}-0.936^{* * *} \\
(0.201)\end{array}$ & $\begin{array}{c}-0.926^{* * *} \\
(0.209)\end{array}$ & $\begin{array}{c}-0.971^{* * *} \\
(0.240)\end{array}$ & $\begin{array}{c}-0.960^{* * *} \\
(0.247)\end{array}$ & $\begin{array}{c}-0.974^{* * *} \\
(0.212)\end{array}$ & $\begin{array}{c}-0.963^{* * *} \\
(0.220)\end{array}$ \\
\hline Division 1 round 2 & $\begin{array}{c}-0.193 \\
(0.287)\end{array}$ & $\begin{array}{c}-0.228 \\
(0.249)\end{array}$ & $\begin{array}{c}-0.280 \\
(0.324)\end{array}$ & $\begin{array}{c}-0.317 \\
(0.284)\end{array}$ & $\begin{array}{l}-0.228 \\
(0.297)\end{array}$ & $\begin{array}{l}-0.261 \\
(0.257)\end{array}$ & $\begin{array}{l}-0.312 \\
(0.336)\end{array}$ & $\begin{array}{l}-0.348 \\
(0.294)\end{array}$ \\
\hline Division 1 round 3 & $\begin{array}{c}-0.893^{* * *} \\
(0.150)\end{array}$ & $\begin{array}{c}-0.917^{* * *} \\
(0.140)\end{array}$ & $\begin{array}{c}-0.669^{* * *} \\
(0.128)\end{array}$ & $\begin{array}{c}-0.694^{* * *} \\
(0.118)\end{array}$ & $\begin{array}{c}-0.937^{* * *} \\
(0.165)\end{array}$ & $\begin{array}{c}-0.958^{* * *} \\
(0.153)\end{array}$ & $\begin{array}{c}-0.711^{* * *} \\
(0.143)\end{array}$ & $\begin{array}{c}-0.734^{* * *} \\
(0.131)\end{array}$ \\
\hline Division 1 round 4 & $\begin{array}{c}-0.604^{* * *} \\
(0.052)\end{array}$ & $\begin{array}{c}-0.669^{* * *} \\
(0.032)\end{array}$ & $\begin{array}{c}-0.527^{* * *} \\
(0.086)\end{array}$ & $\begin{array}{c}-0.597^{* * *} \\
(0.057)\end{array}$ & $\begin{array}{c}-0.640^{* * *} \\
(0.073)\end{array}$ & $\begin{array}{c}-0.703^{* * *} \\
(0.042)\end{array}$ & $\begin{array}{c}-0.562^{* * *} \\
(0.108)\end{array}$ & $\begin{array}{c}-0.629^{* * *} \\
(0.073)\end{array}$ \\
\hline Division 1 round 5 & $\begin{array}{l}-0.093 \\
(0.066)\end{array}$ & $\begin{array}{l}-0.097 \\
(0.068)\end{array}$ & $\begin{array}{l}-0.080 \\
(0.079)\end{array}$ & $\begin{array}{l}-0.083 \\
(0.080)\end{array}$ & $\begin{array}{c}-0.127^{*} \\
(0.069)\end{array}$ & $\begin{array}{c}-0.128^{*} \\
(0.069)\end{array}$ & $\begin{array}{l}-0.113 \\
(0.083)\end{array}$ & $\begin{array}{l}-0.114 \\
(0.083)\end{array}$ \\
\hline Division 2 round 1 & $\begin{array}{c}-0.186 \\
(0.130)\end{array}$ & $\begin{array}{l}-0.180 \\
(0.128)\end{array}$ & $\begin{array}{l}-0.181 \\
(0.166)\end{array}$ & $\begin{array}{l}-0.175 \\
(0.163)\end{array}$ & $\begin{array}{l}-0.214 \\
(0.137)\end{array}$ & $\begin{array}{l}-0.208 \\
(0.135)\end{array}$ & $\begin{array}{l}-0.208 \\
(0.178)\end{array}$ & $\begin{array}{l}-0.202 \\
(0.176)\end{array}$ \\
\hline Division 2 round 2 & $\begin{array}{c}0.430 \\
(0.599)\end{array}$ & $\begin{array}{c}0.401 \\
(0.600)\end{array}$ & $\begin{array}{c}0.314 \\
(0.590)\end{array}$ & $\begin{array}{c}0.282 \\
(0.590)\end{array}$ & $\begin{array}{c}0.371 \\
(0.612)\end{array}$ & $\begin{array}{c}0.343 \\
(0.612)\end{array}$ & $\begin{array}{c}0.256 \\
(0.604)\end{array}$ & $\begin{array}{c}0.225 \\
(0.603)\end{array}$ \\
\hline Division 2 round 3 & $\begin{array}{c}0.268^{* * *} \\
(0.088)\end{array}$ & $\begin{array}{c}0.265^{* * *} \\
(0.086)\end{array}$ & $\begin{array}{c}0.272^{* *} \\
(0.106)\end{array}$ & $\begin{array}{c}0.269^{* *} \\
(0.104)\end{array}$ & $\begin{array}{c}0.231^{* *} \\
(0.086)\end{array}$ & $\begin{array}{c}0.228^{* *} \\
(0.085)\end{array}$ & $\begin{array}{l}0.226^{*} \\
(0.108)\end{array}$ & $\begin{array}{l}0.223^{*} \\
(0.107)\end{array}$ \\
\hline Division 2 round 4 & $\begin{array}{c}0.015 \\
(0.043)\end{array}$ & $\begin{array}{l}-0.024 \\
(0.047)\end{array}$ & $\begin{array}{c}0.026 \\
(0.037)\end{array}$ & $\begin{array}{l}-0.016 \\
(0.041)\end{array}$ & $\begin{array}{l}-0.021 \\
(0.030)\end{array}$ & $\begin{array}{l}-0.061 \\
(0.035)\end{array}$ & $\begin{array}{l}-0.016 \\
(0.028)\end{array}$ & $\begin{array}{l}-0.059^{*} \\
(0.033)\end{array}$ \\
\hline Division 2 round 5 & $0.668^{* * *}$ & $0.641^{* * *}$ & $0.714^{* * *}$ & $0.686^{* * *}$ & $0.646^{* * *}$ & $0.619^{* * *}$ & $0.689^{* * *}$ & $0.660^{* * *}$ \\
\hline
\end{tabular}


Table C2 - continued from previous page -

\begin{tabular}{|c|c|c|c|c|c|c|c|c|}
\hline & $(0.145)$ & $(0.145)$ & $(0.158)$ & $(0.158)$ & $(0.146)$ & $(0.146)$ & $(0.160)$ & $(0.160)$ \\
\hline Division 3 round 1 & $\begin{array}{c}-0.600^{* * *} \\
(0.123)\end{array}$ & $\begin{array}{c}-0.575^{* * *} \\
(0.109)\end{array}$ & $\begin{array}{c}-0.620^{* * *} \\
(0.116)\end{array}$ & $\begin{array}{c}-0.593^{* * *} \\
(0.101)\end{array}$ & $\begin{array}{c}-0.652^{* * *} \\
(0.100)\end{array}$ & $\begin{array}{c}-0.625^{* * *} \\
(0.089)\end{array}$ & $\begin{array}{c}-0.669^{* * *} \\
(0.091)\end{array}$ & $\begin{array}{c}-0.640^{* * *} \\
(0.080)\end{array}$ \\
\hline Division 3 round 2 & $\begin{array}{l}-0.304 \\
(0.320)\end{array}$ & $\begin{array}{l}-0.316 \\
(0.316)\end{array}$ & $\begin{array}{l}-0.465^{*} \\
(0.264)\end{array}$ & $\begin{array}{c}-0.479^{*} \\
(0.258)\end{array}$ & $\begin{array}{l}-0.347 \\
(0.339)\end{array}$ & $\begin{array}{l}-0.358 \\
(0.334)\end{array}$ & $\begin{array}{l}-0.507^{*} \\
(0.282)\end{array}$ & $\begin{array}{l}-0.519^{*} \\
(0.276)\end{array}$ \\
\hline Division 3 round 3 & $\begin{array}{c}-0.514^{* * *} \\
(0.067)\end{array}$ & $\begin{array}{c}-0.491^{* * *} \\
(0.062)\end{array}$ & $\begin{array}{c}-0.518^{* * *} \\
(0.090)\end{array}$ & $\begin{array}{c}-0.493^{* * *} \\
(0.086)\end{array}$ & $\begin{array}{c}-0.556^{* * *} \\
(0.058)\end{array}$ & $\begin{array}{c}-0.532^{* * *} \\
(0.053)\end{array}$ & $\begin{array}{c}-0.560^{* * *} \\
(0.068)\end{array}$ & $\begin{array}{c}-0.534^{* * *} \\
(0.065)\end{array}$ \\
\hline Division 3 round 4 & $\begin{array}{c}-0.282^{* *} \\
(0.105)\end{array}$ & $\begin{array}{c}-0.259^{* *} \\
(0.090)\end{array}$ & $\begin{array}{c}-0.296^{* *} \\
(0.116)\end{array}$ & $\begin{array}{c}-0.271^{* *} \\
(0.101)\end{array}$ & $\begin{array}{c}-0.305^{* * *} \\
(0.099)\end{array}$ & $\begin{array}{c}-0.281^{* * *} \\
(0.084)\end{array}$ & $\begin{array}{c}-0.320^{* * *} \\
(0.095)\end{array}$ & $\begin{array}{c}-0.295^{* * *} \\
(0.079)\end{array}$ \\
\hline Division 3 round 5 & $\begin{array}{c}-0.221^{* * *} \\
(0.064)\end{array}$ & $\begin{array}{c}-0.207^{* * *} \\
(0.070)\end{array}$ & $\begin{array}{c}-0.215^{* * *} \\
(0.039)\end{array}$ & $\begin{array}{c}-0.200^{* * *} \\
(0.047)\end{array}$ & $\begin{array}{c}-0.262^{* * *} \\
(0.084)\end{array}$ & $\begin{array}{c}-0.247^{* *} \\
(0.090)\end{array}$ & $\begin{array}{c}-0.260^{* * *} \\
(0.064)\end{array}$ & $\begin{array}{c}-0.244^{* * *} \\
(0.073)\end{array}$ \\
\hline Division 4 round 1 & $\begin{array}{c}-0.800^{*} \\
(0.448)\end{array}$ & $\begin{array}{l}-0.778 \\
(0.452)\end{array}$ & $\begin{array}{l}-0.864^{*} \\
(0.411)\end{array}$ & $\begin{array}{l}-0.840^{*} \\
(0.415)\end{array}$ & $\begin{array}{l}-0.814^{*} \\
(0.444)\end{array}$ & $\begin{array}{l}-0.789 \\
(0.450)\end{array}$ & $\begin{array}{c}-0.875^{* *} \\
(0.406)\end{array}$ & $\begin{array}{l}-0.849^{*} \\
(0.411)\end{array}$ \\
\hline Division 4 round 2 & $\begin{array}{l}-0.235 \\
(0.249)\end{array}$ & $\begin{array}{l}-0.249 \\
(0.253)\end{array}$ & $\begin{array}{l}-0.372 \\
(0.241)\end{array}$ & $\begin{array}{l}-0.387 \\
(0.245)\end{array}$ & $\begin{array}{l}-0.249 \\
(0.230)\end{array}$ & $\begin{array}{l}-0.262 \\
(0.234)\end{array}$ & $\begin{array}{l}-0.391 \\
(0.225)\end{array}$ & $\begin{array}{l}-0.404^{*} \\
(0.230)\end{array}$ \\
\hline Division 4 round 3 & $\begin{array}{l}-0.405 \\
(0.238)\end{array}$ & $\begin{array}{l}-0.381 \\
(0.234)\end{array}$ & $\begin{array}{c}-0.400^{* *} \\
(0.175)\end{array}$ & $\begin{array}{c}-0.374^{* *} \\
(0.172)\end{array}$ & $\begin{array}{l}-0.446^{*} \\
(0.236)\end{array}$ & $\begin{array}{l}-0.418^{*} \\
(0.233)\end{array}$ & $\begin{array}{c}-0.441^{* *} \\
(0.168)\end{array}$ & $\begin{array}{c}-0.412^{* *} \\
(0.166)\end{array}$ \\
\hline Division 4 round 4 & $\begin{array}{c}0.225 \\
(0.236)\end{array}$ & $\begin{array}{c}0.211 \\
(0.236)\end{array}$ & $\begin{array}{c}0.222 \\
(0.216)\end{array}$ & $\begin{array}{c}0.208 \\
(0.218)\end{array}$ & $\begin{array}{c}0.190 \\
(0.208)\end{array}$ & $\begin{array}{c}0.179 \\
(0.208)\end{array}$ & $\begin{array}{c}0.192 \\
(0.193)\end{array}$ & $\begin{array}{c}0.181 \\
(0.194)\end{array}$ \\
\hline Division 4 round 5 & $\begin{array}{l}0.359^{*} \\
(0.175)\end{array}$ & $\begin{array}{l}0.350^{*} \\
(0.177)\end{array}$ & $\begin{array}{l}0.378^{*} \\
(0.189)\end{array}$ & $\begin{array}{l}0.368^{*} \\
(0.192)\end{array}$ & $\begin{array}{c}0.330^{* *} \\
(0.150)\end{array}$ & $\begin{array}{l}0.323^{*} \\
(0.152)\end{array}$ & $\begin{array}{l}0.349^{*} \\
(0.167)\end{array}$ & $\begin{array}{l}0.341^{*} \\
(0.171)\end{array}$ \\
\hline Division 5 round 1 & $\begin{array}{c}-1.418^{* * *} \\
(0.225)\end{array}$ & $\begin{array}{c}-1.408^{* * *} \\
(0.216)\end{array}$ & $\begin{array}{c}-1.375^{* * *} \\
(0.243)\end{array}$ & $\begin{array}{c}-1.365^{* * *} \\
(0.234)\end{array}$ & $\begin{array}{c}-1.448^{* * *} \\
(0.225)\end{array}$ & $\begin{array}{c}-1.436^{* * *} \\
(0.217)\end{array}$ & $\begin{array}{c}-1.405^{* * *} \\
(0.241)\end{array}$ & $\begin{array}{c}-1.392^{* * *} \\
(0.233)\end{array}$ \\
\hline Division 5 round 2 & $\begin{array}{c}-0.866^{* *} \\
(0.299)\end{array}$ & $\begin{array}{c}-0.867^{* * *} \\
(0.294)\end{array}$ & $\begin{array}{c}-0.943^{* * *} \\
(0.296)\end{array}$ & $\begin{array}{c}-0.944^{* * *} \\
(0.290)\end{array}$ & $\begin{array}{c}-0.891^{* * *} \\
(0.289)\end{array}$ & $\begin{array}{c}-0.889^{* * *} \\
(0.284)\end{array}$ & $\begin{array}{c}-0.968^{* * *} \\
(0.287)\end{array}$ & $\begin{array}{c}-0.966^{* * *} \\
(0.281)\end{array}$ \\
\hline Division 5 round 3 & $\begin{array}{c}-0.742^{* * *} \\
(0.090)\end{array}$ & $\begin{array}{c}-0.726^{* * *} \\
(0.082)\end{array}$ & $\begin{array}{c}-0.652^{* * *} \\
(0.082)\end{array}$ & $\begin{array}{c}-0.634^{* * *} \\
(0.075)\end{array}$ & $\begin{array}{c}-0.781^{* * *} \\
(0.079)\end{array}$ & $\begin{array}{c}-0.761^{* * *} \\
(0.074)\end{array}$ & $\begin{array}{c}-0.691^{* * *} \\
(0.077)\end{array}$ & $\begin{array}{c}-0.670^{* * *} \\
(0.073)\end{array}$ \\
\hline
\end{tabular}


Table C2 - continued from previous page -

\begin{tabular}{|c|c|c|c|c|c|c|c|c|}
\hline Division 5 round 4 & $\begin{array}{c}-0.605^{* * *} \\
(0.160)\end{array}$ & $\begin{array}{c}-0.604^{* * *} \\
(0.158)\end{array}$ & $\begin{array}{c}-0.567^{* * *} \\
(0.179)\end{array}$ & $\begin{array}{c}-0.566 * * * \\
(0.177)\end{array}$ & $\begin{array}{c}-0.642^{* * *} \\
(0.174)\end{array}$ & $\begin{array}{c}-0.637^{* * *} \\
(0.171)\end{array}$ & $\begin{array}{c}-0.602^{* * *} \\
(0.184)\end{array}$ & $\begin{array}{c}-0.598^{* * *} \\
(0.182)\end{array}$ \\
\hline Division 5 round 5 & $\begin{array}{c}-0.497^{* * *} \\
(0.122)\end{array}$ & $\begin{array}{c}-0.499 * * * \\
(0.119)\end{array}$ & $\begin{array}{c}-0.407^{* *} \\
(0.139)\end{array}$ & $\begin{array}{c}-0.410^{* * *} \\
(0.135)\end{array}$ & $\begin{array}{c}-0.521^{* * *} \\
(0.145)\end{array}$ & $\begin{array}{c}-0.521^{* * *} \\
(0.141)\end{array}$ & $\begin{array}{c}-0.431^{* *} \\
(0.156)\end{array}$ & $\begin{array}{c}-0.431^{* *} \\
(0.152)\end{array}$ \\
\hline Constant & $\begin{array}{c}6.555^{* * *} \\
(0.297)\end{array}$ & $\begin{array}{c}6.501^{* * *} \\
(0.288)\end{array}$ & $\begin{array}{c}4.235^{* * *} \\
(0.284)\end{array}$ & $\begin{array}{c}4.177^{* * *} \\
(0.275)\end{array}$ & $\begin{array}{c}6.629 * * * \\
(0.292)\end{array}$ & $\begin{array}{c}6.568^{* * *} \\
(0.282)\end{array}$ & $\begin{array}{c}4.308^{* * *} \\
(0.278)\end{array}$ & $\begin{array}{c}4.244^{* * *} \\
(0.270)\end{array}$ \\
\hline \multicolumn{9}{|l|}{ Model statistics } \\
\hline$R^{2}$ & 0.587 & 0.591 & 0.584 & 0.589 & 0.567 & 0.572 & 0.565 & 0.570 \\
\hline
\end{tabular}

Notes: Estimates are based on an unbalanced panel data set with 5,506 observations and 1,062 groups. Errors shown in parentheses are robust and clustered at the sub-location level. HDDS = household dietary diversity score. HH = household head. MP $=$ mobile phone. TLU $=$ Tropical Livestock Unit. ${ }^{*},{ }^{* *},{ }^{* * *}$ denote statistical significance at the $10 \%, 5 \%, 1 \%$ level respectively. 
Table C3: Full Table for the effects of mobile phones on dietary diversity obtained from self-production and food purchases (fixed effects panel model)

\begin{tabular}{|c|c|c|c|c|}
\hline & \multicolumn{2}{|c|}{ Mobile phone use } & \multicolumn{2}{|c|}{ Mobile phone ownership } \\
\hline & $\begin{array}{l}\text { Food groups } \\
\text { from self- } \\
\text { production } \\
\quad(1)\end{array}$ & $\begin{array}{l}\text { Food groups } \\
\text { from purchase } \\
(2)\end{array}$ & $\begin{array}{l}\text { Food groups } \\
\text { from self- } \\
\text { production } \\
\quad(3)\end{array}$ & $\begin{array}{c}\text { Food groups } \\
\text { from purchase } \\
\text { (4) }\end{array}$ \\
\hline Daily MP use & $\begin{array}{l}-0.019 \\
(0.047)\end{array}$ & $\begin{array}{c}0.384^{* * *} \\
(0.089)\end{array}$ & & \\
\hline $\begin{array}{l}\text { Weekly MP use } \\
\text { (excluding daily use) }\end{array}$ & $\begin{array}{l}-0.072 \\
(0.042)\end{array}$ & $\begin{array}{c}0.235^{* *} \\
(0.093)\end{array}$ & & \\
\hline At most monthly MP use & $\begin{array}{l}-0.013 \\
(0.040)\end{array}$ & $\begin{array}{c}0.236^{* *} \\
(0.090)\end{array}$ & & \\
\hline Owning at least one MP & & & $\begin{array}{c}0.008 \\
(0.050)\end{array}$ & $\begin{array}{c}0.307^{* * *} \\
(0.092)\end{array}$ \\
\hline Owning two or more MPs & & & $\begin{array}{c}0.042 \\
(0.070)\end{array}$ & $\begin{array}{c}0.276^{* * *} \\
(0.086)\end{array}$ \\
\hline Income $[\mathrm{KSh} 1,000,000]$ & $\begin{array}{c}0.568^{* *} \\
(0.231)\end{array}$ & $\begin{array}{c}2.302^{* * *} \\
(0.465)\end{array}$ & $\begin{array}{c}0.556^{* *} \\
(0.233)\end{array}$ & $\begin{array}{c}2.366^{* * *} \\
(0.472)\end{array}$ \\
\hline Nomadic status & $\begin{array}{c}0.207 \\
(0.135)\end{array}$ & $\begin{array}{l}-0.291 \\
(0.187)\end{array}$ & $\begin{array}{c}0.209 \\
(0.138)\end{array}$ & $\begin{array}{l}-0.301 \\
(0.189)\end{array}$ \\
\hline Radio ownership & $\begin{array}{l}-0.078 \\
(0.070)\end{array}$ & $\begin{array}{l}-0.165 \\
(0.149)\end{array}$ & $\begin{array}{l}-0.082 \\
(0.071)\end{array}$ & $\begin{array}{l}-0.193 \\
(0.151)\end{array}$ \\
\hline Cooking source & $\begin{array}{l}-0.190 \\
(0.148)\end{array}$ & $\begin{array}{c}0.073 \\
(0.430)\end{array}$ & $\begin{array}{l}-0.193 \\
(0.149)\end{array}$ & $\begin{array}{c}0.077 \\
(0.442)\end{array}$ \\
\hline Land farmed [hectares] & $\begin{array}{c}0.005 \\
(0.008)\end{array}$ & $\begin{array}{c}0.003 \\
(0.016)\end{array}$ & $\begin{array}{c}0.005 \\
(0.008)\end{array}$ & $\begin{array}{c}0.001 \\
(0.016)\end{array}$ \\
\hline Herd size $[\mathrm{TLU}]$ & $\begin{array}{c}0.002^{* *} \\
(0.001)\end{array}$ & $\begin{array}{l}0.003^{*} \\
(0.002)\end{array}$ & $\begin{array}{c}0.002^{* *} \\
(0.001)\end{array}$ & $\begin{array}{l}0.003^{*} \\
(0.002)\end{array}$ \\
\hline Education [years] & $\begin{array}{c}0.051 \\
(0.035)\end{array}$ & $\begin{array}{c}-0.198^{*} \\
(0.102)\end{array}$ & $\begin{array}{c}0.051 \\
(0.036)\end{array}$ & $\begin{array}{c}-0.200^{*} \\
(0.099)\end{array}$ \\
\hline Gender & $\begin{array}{l}-0.051 \\
(0.064)\end{array}$ & $\begin{array}{c}0.250 \\
(0.175)\end{array}$ & $\begin{array}{l}-0.050 \\
(0.065)\end{array}$ & $\begin{array}{c}0.258 \\
(0.178)\end{array}$ \\
\hline Age & $\begin{array}{c}0.000 \\
(0.002)\end{array}$ & $\begin{array}{l}-0.002 \\
(0.005)\end{array}$ & $\begin{array}{c}0.000 \\
(0.002)\end{array}$ & $\begin{array}{l}-0.002 \\
(0.005)\end{array}$ \\
\hline Household size & $\begin{array}{c}0.025^{* * *} \\
(0.008)\end{array}$ & $\begin{array}{r}0.053^{* *} \\
(0.023)\end{array}$ & $\begin{array}{c}0.024^{* * *} \\
(0.008)\end{array}$ & $\begin{array}{r}0.053^{* *} \\
(0.023)\end{array}$ \\
\hline Division 1 round 1 & $\begin{array}{c}-0.728^{* * *} \\
(0.158)\end{array}$ & $\begin{array}{l}-1.240^{*} \\
(0.656)\end{array}$ & $\begin{array}{c}-0.718^{* * *} \\
(0.162)\end{array}$ & $\begin{array}{l}-1.282^{*} \\
(0.671)\end{array}$ \\
\hline Division 1 round 2 & $\begin{array}{c}0.041 \\
(0.220)\end{array}$ & $\begin{array}{l}-0.939 \\
(0.602)\end{array}$ & $\begin{array}{c}0.054 \\
(0.225)\end{array}$ & $\begin{array}{l}-0.981 \\
(0.612)\end{array}$ \\
\hline & $-0.517^{*}$ & $-0.802^{* * *}$ & $-0.509^{*}$ & $-0.845^{* * *}$ \\
\hline
\end{tabular}


Table C3 - continued from previous page -

\begin{tabular}{|c|c|c|c|c|}
\hline & $(0.256)$ & $(0.167)$ & $(0.262)$ & $(0.185)$ \\
\hline Division 1 round 4 & $\begin{array}{l}-0.026 \\
(0.018)\end{array}$ & $\begin{array}{c}-0.506 * * * \\
(0.046)\end{array}$ & $\begin{array}{l}-0.015 \\
(0.014)\end{array}$ & $\begin{array}{c}-0.547^{* * *} \\
(0.065)\end{array}$ \\
\hline Division 1 round 5 & $\begin{array}{c}0.501^{* * *} \\
(0.109)\end{array}$ & $\begin{array}{c}-0.182^{*} \\
(0.089)\end{array}$ & $\begin{array}{c}0.510^{* * *} \\
(0.100)\end{array}$ & $\begin{array}{c}-0.210^{* *} \\
(0.092)\end{array}$ \\
\hline Division 2 round 1 & $\begin{array}{c}-1.222^{* * *} \\
(0.162)\end{array}$ & $\begin{array}{l}-0.196 \\
(0.311)\end{array}$ & $\begin{array}{c}-1.217^{* * *} \\
(0.143)\end{array}$ & $\begin{array}{l}-0.220 \\
(0.293)\end{array}$ \\
\hline Division 2 round 2 & $\begin{array}{c}-0.951^{* * *} \\
(0.031)\end{array}$ & $\begin{array}{c}0.763 \\
(0.451)\end{array}$ & $\begin{array}{c}-0.946^{* * *} \\
(0.037)\end{array}$ & $\begin{array}{c}0.705 \\
(0.449)\end{array}$ \\
\hline Division 2 round 3 & $\begin{array}{c}-1.297 * * * \\
(0.107)\end{array}$ & $\begin{array}{c}0.476^{* * *} \\
(0.106)\end{array}$ & $\begin{array}{c}-1.303^{* * *} \\
(0.095)\end{array}$ & $\begin{array}{c}0.470 * * * \\
(0.094)\end{array}$ \\
\hline Division 2 round 4 & $\begin{array}{l}-0.356 \\
(0.243)\end{array}$ & $\begin{array}{c}0.162 \\
(0.094)\end{array}$ & $\begin{array}{l}-0.361 \\
(0.234)\end{array}$ & $\begin{array}{l}0.146^{*} \\
(0.076)\end{array}$ \\
\hline Division 2 round 5 & $\begin{array}{l}0.240^{*} \\
(0.132)\end{array}$ & $\begin{array}{c}0.739 * * * \\
(0.095)\end{array}$ & $\begin{array}{l}0.240^{*} \\
(0.122)\end{array}$ & $\begin{array}{c}0.728^{* * *} \\
(0.084)\end{array}$ \\
\hline Division 3 round 1 & $\begin{array}{c}-0.242^{* * *} \\
(0.049)\end{array}$ & $\begin{array}{l}-0.248 \\
(0.205)\end{array}$ & $\begin{array}{c}-0.219^{* * *} \\
(0.049)\end{array}$ & $\begin{array}{l}-0.313 \\
(0.185)\end{array}$ \\
\hline Division 3 round 2 & $\begin{array}{c}0.015 \\
(0.073)\end{array}$ & $\begin{array}{l}-0.238 \\
(0.276)\end{array}$ & $\begin{array}{c}0.034 \\
(0.074)\end{array}$ & $\begin{array}{l}-0.292 \\
(0.300)\end{array}$ \\
\hline Division 3 round 3 & $\begin{array}{c}-0.207^{* *} \\
(0.085)\end{array}$ & $\begin{array}{c}-1.458^{* * *} \\
(0.185)\end{array}$ & $\begin{array}{c}-0.194^{* *} \\
(0.086)\end{array}$ & $\begin{array}{c}-1.502^{* * *} \\
(0.189)\end{array}$ \\
\hline Division 3 round 4 & $\begin{array}{c}-0.077 \\
(0.058)\end{array}$ & $\begin{array}{c}0.226 \\
(0.133)\end{array}$ & $\begin{array}{l}-0.066 \\
(0.058)\end{array}$ & $\begin{array}{c}0.202 \\
(0.126)\end{array}$ \\
\hline Division 3 round 5 & $\begin{array}{c}0.106 \\
(0.076)\end{array}$ & $\begin{array}{c}-0.123^{* *} \\
(0.054)\end{array}$ & $\begin{array}{c}0.110 \\
(0.075)\end{array}$ & $\begin{array}{c}-0.152^{* *} \\
(0.056)\end{array}$ \\
\hline Division 4 round 1 & $\begin{array}{c}-0.301^{* * *} \\
(0.034)\end{array}$ & $\begin{array}{c}-1.632^{* * *} \\
(0.427)\end{array}$ & $\begin{array}{c}-0.276^{* * *} \\
(0.029)\end{array}$ & $\begin{array}{c}-1.658^{* * *} \\
(0.437)\end{array}$ \\
\hline Division 4 round 2 & $\begin{array}{c}0.061 \\
(0.175)\end{array}$ & $\begin{array}{l}-0.733 \\
(0.463)\end{array}$ & $\begin{array}{c}0.079 \\
(0.176)\end{array}$ & $\begin{array}{l}-0.745 \\
(0.456)\end{array}$ \\
\hline Division 4 round 3 & $\begin{array}{c}0.125 \\
(0.099)\end{array}$ & $\begin{array}{c}-1.266^{* * *} \\
(0.361)\end{array}$ & $\begin{array}{c}0.143 \\
(0.094)\end{array}$ & $\begin{array}{c}-1.310^{* * *} \\
(0.375)\end{array}$ \\
\hline Division 4 round 4 & $\begin{array}{c}0.222^{* *} \\
(0.097)\end{array}$ & $\begin{array}{l}-0.093 \\
(0.212)\end{array}$ & $\begin{array}{c}0.237^{* *} \\
(0.098)\end{array}$ & $\begin{array}{l}-0.138 \\
(0.198)\end{array}$ \\
\hline Division 4 round 5 & $\begin{array}{c}0.226^{*} \\
(0.116)\end{array}$ & $\begin{array}{c}0.193^{* *} \\
(0.084)\end{array}$ & $\begin{array}{c}0.236^{* *} \\
(0.107)\end{array}$ & $\begin{array}{l}0.166^{*} \\
(0.079)\end{array}$ \\
\hline Division 5 round 1 & $\begin{array}{l}-0.187 \\
(0.120)\end{array}$ & $\begin{array}{c}-1.468^{* * *} \\
(0.191)\end{array}$ & $\begin{array}{l}-0.167 \\
(0.119)\end{array}$ & $\begin{array}{c}-1.517^{* * *} \\
(0.195)\end{array}$ \\
\hline Division 5 round 2 & $\begin{array}{l}-0.071 \\
(0.125)\end{array}$ & $\begin{array}{c}-1.065^{* * *} \\
(0.167)\end{array}$ & $\begin{array}{l}-0.053 \\
(0.123)\end{array}$ & $\begin{array}{c}-1.101^{* * *} \\
(0.161)\end{array}$ \\
\hline Division 5 round 3 & $\begin{array}{c}0.167 \\
(0.127)\end{array}$ & $\begin{array}{c}-1.660^{* * *} \\
(0.171)\end{array}$ & $\begin{array}{c}0.186 \\
(0.129)\end{array}$ & $\begin{array}{c}-1.714^{* * *} \\
(0.175)\end{array}$ \\
\hline Division 5 round 4 & $\begin{array}{c}0.269 \\
(0.186)\end{array}$ & $\begin{array}{c}-0.658^{* * *} \\
(0.108)\end{array}$ & $\begin{array}{c}0.290 \\
(0.186)\end{array}$ & $\begin{array}{c}-0.715^{* * *} \\
(0.095)\end{array}$ \\
\hline
\end{tabular}


Table C3 - continued from previous page -

\begin{tabular}{lcccc}
\hline Division 5 round 5 & 0.064 & $-0.417^{* *}$ & 0.086 & $-0.456^{* *}$ \\
& $(0.058)$ & $(0.160)$ & $(0.060)$ & $(0.172)$ \\
Constant & $0.496^{* * *}$ & $5.951^{* * *}$ & $0.465^{* * *}$ & $6.053^{* * *}$ \\
Model statistics: & $(0.146)$ & $(0.434)$ & $(0.145)$ & $(0.433)$ \\
$R^{2}$ & & & & \\
\hline
\end{tabular}

Notes: Estimates are based on an unbalanced panel data set with 5,506 observations and 1,062 groups. The dependent variable for columns (1) and (3) is the number of food groups that the household consumed coming from self-production. The dependent variable for the columns (2) and (4) is the number of food groups that the household consumed coming from food purchases. Errors shown in parentheses are robust and clustered at the sublocation level. HDDS = household dietary diversity score. $\mathrm{HH}=$ household head. $\mathrm{MP}=$ mobile phone. TLU $=$ Tropical Livestock Unit. ${ }^{* * *},{ }^{* * *}$ denote statistical significance at the $10 \%, 5 \%, 1 \%$ level respectively. 
Table C4: Full Table for the effect duration of mobile phone access on dietary outcomes (5 year time span)

\begin{tabular}{|c|c|c|c|c|c|c|}
\hline & \multicolumn{3}{|c|}{ Mobile phone usage } & \multicolumn{3}{|c|}{ Mobile phone ownership } \\
\hline & $\begin{array}{c}\text { HDDS12 } \\
\text { (1) }\end{array}$ & $\begin{array}{c}\text { HHDS9 } \\
\text { (2) }\end{array}$ & $\begin{array}{c}\text { Food } \\
\text { groups } \\
\text { from } \\
\text { purchase } \\
(3)\end{array}$ & HDDS12 & $\begin{array}{l}\text { HHDS9 } \\
\text { (5) }\end{array}$ & $\begin{array}{c}\text { Food } \\
\text { groups } \\
\text { from } \\
\text { purchase } \\
\quad(6)\end{array}$ \\
\hline Before 5 & $\begin{array}{c}0.162 \\
(0.162)\end{array}$ & $\begin{array}{c}0.199 \\
(0.146)\end{array}$ & $\begin{array}{c}0.127 \\
(0.218)\end{array}$ & $\begin{array}{c}0.022 \\
(0.102)\end{array}$ & $\begin{array}{c}0.084 \\
(0.118)\end{array}$ & $\begin{array}{l}-0.280 \\
(0.225)\end{array}$ \\
\hline Before 4 & $\begin{array}{c}0.116 \\
(0.143)\end{array}$ & $\begin{array}{c}0.132 \\
(0.143)\end{array}$ & $\begin{array}{c}0.121 \\
(0.201)\end{array}$ & $\begin{array}{l}-0.070 \\
(0.107)\end{array}$ & $\begin{array}{l}-0.004 \\
(0.096)\end{array}$ & $\begin{array}{l}-0.180 \\
(0.129)\end{array}$ \\
\hline Before 3 & $\begin{array}{c}0.089 \\
(0.093)\end{array}$ & $\begin{array}{c}0.113 \\
(0.095)\end{array}$ & $\begin{array}{l}-0.013 \\
(0.115)\end{array}$ & $\begin{array}{c}0.006 \\
(0.101)\end{array}$ & $\begin{array}{c}0.039 \\
(0.113)\end{array}$ & $\begin{array}{c}0.082 \\
(0.107)\end{array}$ \\
\hline Before 2 & $\begin{array}{c}0.058 \\
(0.059)\end{array}$ & $\begin{array}{c}0.073 \\
(0.079)\end{array}$ & $\begin{array}{c}0.013 \\
(0.089)\end{array}$ & $\begin{array}{c}0.055 \\
(0.074)\end{array}$ & $\begin{array}{c}0.100 \\
(0.070)\end{array}$ & $\begin{array}{c}0.063 \\
(0.090)\end{array}$ \\
\hline Before 1 & & & -Refere & ce Year- & & \\
\hline After 0 & $\begin{array}{c}0.214^{* *} \\
(0.076)\end{array}$ & $\begin{array}{c}0.188^{* *} \\
(0.077)\end{array}$ & $\begin{array}{c}0.258^{* * *} \\
(0.087)\end{array}$ & $\begin{array}{l}0.136^{*} \\
(0.073)\end{array}$ & $\begin{array}{c}0.094 \\
(0.084)\end{array}$ & $\begin{array}{c}0.264^{* * *} \\
(0.085)\end{array}$ \\
\hline After 1 & $\begin{array}{l}0.192^{*} \\
(0.095)\end{array}$ & $\begin{array}{c}0.112 \\
(0.095)\end{array}$ & $\begin{array}{c}0.197 \\
(0.135)\end{array}$ & $\begin{array}{c}0.077 \\
(0.072)\end{array}$ & $\begin{array}{c}0.035 \\
(0.086)\end{array}$ & $\begin{array}{l}0.252^{* *} \\
(0.096)\end{array}$ \\
\hline After 2 & $\begin{array}{c}0.226^{* *} \\
(0.102)\end{array}$ & $\begin{array}{c}0.229^{* * *} \\
(0.071)\end{array}$ & $\begin{array}{c}0.337^{* *} \\
(0.127)\end{array}$ & $\begin{array}{c}0.042 \\
(0.145)\end{array}$ & $\begin{array}{l}-0.040 \\
(0.157)\end{array}$ & $\begin{array}{l}0.243^{*} \\
(0.134)\end{array}$ \\
\hline After 3 & $\begin{array}{c}0.252^{* *} \\
(0.087)\end{array}$ & $\begin{array}{c}0.234^{* *} \\
(0.080)\end{array}$ & $\begin{array}{c}0.330^{* * *} \\
(0.104)\end{array}$ & $\begin{array}{l}-0.080 \\
(0.210)\end{array}$ & $\begin{array}{l}-0.112 \\
(0.199)\end{array}$ & $\begin{array}{c}0.233 \\
(0.154)\end{array}$ \\
\hline After 4 & $\begin{array}{c}0.289^{* *} \\
(0.124)\end{array}$ & $\begin{array}{c}0.262 \\
(0.174)\end{array}$ & $\begin{array}{c}0.393 \\
(0.314)\end{array}$ & $\begin{array}{c}0.019 \\
(0.267)\end{array}$ & $\begin{array}{c}0.024 \\
(0.299)\end{array}$ & $\begin{array}{c}0.094 \\
(0.389)\end{array}$ \\
\hline After 5 & $\begin{array}{c}0.433^{* *} \\
(0.169)\end{array}$ & $\begin{array}{c}0.467^{* *} \\
(0.178)\end{array}$ & $\begin{array}{c}0.818^{* * *} \\
(0.216)\end{array}$ & $\begin{array}{l}-0.010 \\
(0.253)\end{array}$ & $\begin{array}{c}0.109 \\
(0.228)\end{array}$ & $\begin{array}{l}0.375^{*} \\
(0.204)\end{array}$ \\
\hline Nomadic status & $\begin{array}{l}-0.031 \\
(0.228)\end{array}$ & $\begin{array}{c}0.017 \\
(0.230)\end{array}$ & $\begin{array}{l}-0.304 \\
(0.195)\end{array}$ & $\begin{array}{l}-0.037 \\
(0.227)\end{array}$ & $\begin{array}{c}0.008 \\
(0.227)\end{array}$ & $\begin{array}{l}-0.315 \\
(0.192)\end{array}$ \\
\hline Radio ownership & $\begin{array}{l}-0.108 \\
(0.150)\end{array}$ & $\begin{array}{l}-0.112 \\
(0.158)\end{array}$ & $\begin{array}{l}-0.142 \\
(0.150)\end{array}$ & $\begin{array}{l}-0.117 \\
(0.147)\end{array}$ & $\begin{array}{l}-0.108 \\
(0.156)\end{array}$ & $\begin{array}{l}-0.188 \\
(0.154)\end{array}$ \\
\hline Cooking source & $\begin{array}{c}0.212 \\
(0.205)\end{array}$ & $\begin{array}{c}0.031 \\
(0.179)\end{array}$ & $\begin{array}{c}0.085 \\
(0.416)\end{array}$ & $\begin{array}{c}0.218 \\
(0.225)\end{array}$ & $\begin{array}{c}0.049 \\
(0.196)\end{array}$ & $\begin{array}{c}0.091 \\
(0.449)\end{array}$ \\
\hline $\begin{array}{l}\text { Income } \\
{[\text { KSh1,000,000] }}\end{array}$ & $\begin{array}{c}2.370^{* * *} \\
(0.445)\end{array}$ & $\begin{array}{c}2.524^{* * *} \\
(0.448)\end{array}$ & $\begin{array}{c}2.384^{* * *} \\
(0.484)\end{array}$ & $\begin{array}{c}2.380^{* * *} \\
(0.446)\end{array}$ & $\begin{array}{c}2.534^{* * *} \\
(0.455)\end{array}$ & $\begin{array}{r}2.393^{\text {*** }} \\
(0.475)\end{array}$ \\
\hline $\begin{array}{l}\text { Land farmed } \\
\text { [hectares] }\end{array}$ & $\begin{array}{c}0.017^{* * *} \\
(0.004)\end{array}$ & $\begin{array}{c}0.019^{* * *} \\
(0.004)\end{array}$ & $\begin{array}{c}0.004 \\
(0.016)\end{array}$ & $\begin{array}{c}0.016^{* * *} \\
(0.004)\end{array}$ & $\begin{array}{c}0.018^{* * *} \\
(0.004)\end{array}$ & $\begin{array}{c}0.002 \\
(0.015)\end{array}$ \\
\hline Herd size $[\mathrm{TLU}]$ & $\begin{array}{c}0.005^{* * *} \\
(0.001)\end{array}$ & $\begin{array}{c}0.005^{* * *} \\
(0.002)\end{array}$ & $\begin{array}{l}0.003^{*} \\
(0.002)\end{array}$ & $\begin{array}{c}0.005^{* * *} \\
(0.001)\end{array}$ & $\begin{array}{c}0.005^{* * *} \\
(0.002)\end{array}$ & $\begin{array}{l}0.003^{*} \\
(0.002)\end{array}$ \\
\hline Education [years] & -0.051 & -0.086 & $-0.196^{*}$ & -0.061 & -0.093 & $-0.216^{*}$ \\
\hline
\end{tabular}


Table C4 - continued from previous page -

\begin{tabular}{|c|c|c|c|c|c|c|}
\hline & $(0.074)$ & $(0.083)$ & $(0.106)$ & $(0.072)$ & $(0.080)$ & $(0.102)$ \\
\hline Gender & $\begin{array}{l}0.211^{*} \\
(0.103)\end{array}$ & $\begin{array}{c}0.246^{* *} \\
(0.091)\end{array}$ & $\begin{array}{c}0.247 \\
(0.175)\end{array}$ & $\begin{array}{l}0.209^{*} \\
(0.103)\end{array}$ & $\begin{array}{c}0.238^{* *} \\
(0.091)\end{array}$ & $\begin{array}{c}0.252 \\
(0.178)\end{array}$ \\
\hline Age & $\begin{array}{l}-0.001 \\
(0.003)\end{array}$ & $\begin{array}{c}0.001 \\
(0.003)\end{array}$ & $\begin{array}{l}-0.002 \\
(0.005)\end{array}$ & $\begin{array}{l}-0.001 \\
(0.003)\end{array}$ & $\begin{array}{c}0.001 \\
(0.003)\end{array}$ & $\begin{array}{l}-0.002 \\
(0.005)\end{array}$ \\
\hline Household size & $\begin{array}{c}0.075^{* * *} \\
(0.019)\end{array}$ & $\begin{array}{c}0.079^{* * *} \\
(0.017)\end{array}$ & $\begin{array}{c}0.052^{* *} \\
(0.022)\end{array}$ & $\begin{array}{c}0.077^{* * *} \\
(0.020)\end{array}$ & $\begin{array}{c}0.080^{* * *} \\
(0.019)\end{array}$ & $\begin{array}{c}0.052^{* *} \\
(0.022)\end{array}$ \\
\hline Division 1 round 1 & $\begin{array}{c}-0.948^{* * *} \\
(0.307)\end{array}$ & $\begin{array}{c}-0.962^{* * *} \\
(0.286)\end{array}$ & $\begin{array}{l}-1.216 \\
(0.753)\end{array}$ & $\begin{array}{c}-0.995^{* * *} \\
(0.262)\end{array}$ & $\begin{array}{c}-1.008^{* * *} \\
(0.233)\end{array}$ & $\begin{array}{l}-1.247^{*} \\
(0.648)\end{array}$ \\
\hline Division 1 round 2 & $\begin{array}{l}-0.249 \\
(0.297)\end{array}$ & $\begin{array}{l}-0.336 \\
(0.340)\end{array}$ & $\begin{array}{l}-0.939 \\
(0.681)\end{array}$ & $\begin{array}{l}-0.286 \\
(0.265)\end{array}$ & $\begin{array}{l}-0.379 \\
(0.302)\end{array}$ & $\begin{array}{l}-0.974 \\
(0.597)\end{array}$ \\
\hline Division 1 round 3 & $\begin{array}{c}-0.927^{* * *} \\
(0.182)\end{array}$ & $\begin{array}{c}-0.704^{* * *} \\
(0.165)\end{array}$ & $\begin{array}{c}-0.753^{* * *} \\
(0.228)\end{array}$ & $\begin{array}{c}-0.981^{* * *} \\
(0.172)\end{array}$ & $\begin{array}{c}-0.759^{* * *} \\
(0.144)\end{array}$ & $\begin{array}{c}-0.866^{* * *} \\
(0.206)\end{array}$ \\
\hline Division 1 round 4 & $\begin{array}{c}-0.680^{* * *} \\
(0.061)\end{array}$ & $\begin{array}{c}-0.602^{* * *} \\
(0.095)\end{array}$ & $\begin{array}{c}-0.490^{* * *} \\
(0.104)\end{array}$ & $\begin{array}{c}-0.741^{* * *} \\
(0.063)\end{array}$ & $\begin{array}{c}-0.666^{* * *} \\
(0.092)\end{array}$ & $\begin{array}{c}-0.583^{* * *} \\
(0.092)\end{array}$ \\
\hline Division 1 round 5 & $\begin{array}{l}-0.092 \\
(0.085)\end{array}$ & $\begin{array}{l}-0.071 \\
(0.098)\end{array}$ & $\begin{array}{l}-0.155 \\
(0.133)\end{array}$ & $\begin{array}{l}-0.153^{*} \\
(0.086)\end{array}$ & $\begin{array}{l}-0.131 \\
(0.090)\end{array}$ & $\begin{array}{l}-0.232^{*} \\
(0.112)\end{array}$ \\
\hline Division 2 round 1 & $\begin{array}{l}-0.113 \\
(0.154)\end{array}$ & $\begin{array}{l}-0.133 \\
(0.194)\end{array}$ & $\begin{array}{l}-0.006 \\
(0.339)\end{array}$ & $\begin{array}{l}-0.236 \\
(0.148)\end{array}$ & $\begin{array}{l}-0.245 \\
(0.184)\end{array}$ & $\begin{array}{l}-0.171 \\
(0.326)\end{array}$ \\
\hline Division 2 round 2 & $\begin{array}{c}0.444 \\
(0.625)\end{array}$ & $\begin{array}{c}0.314 \\
(0.618)\end{array}$ & $\begin{array}{l}0.901^{*} \\
(0.499)\end{array}$ & $\begin{array}{c}0.304 \\
(0.636)\end{array}$ & $\begin{array}{c}0.181 \\
(0.619)\end{array}$ & $\begin{array}{c}0.709 \\
(0.492)\end{array}$ \\
\hline Division 2 round 3 & $\begin{array}{c}0.324^{* * *} \\
(0.101)\end{array}$ & $\begin{array}{c}0.316^{* *} \\
(0.127)\end{array}$ & $\begin{array}{c}0.658^{* * *} \\
(0.151)\end{array}$ & $\begin{array}{l}0.200^{*} \\
(0.102)\end{array}$ & $\begin{array}{c}0.193 \\
(0.119)\end{array}$ & $\begin{array}{c}0.474^{* * *} \\
(0.117)\end{array}$ \\
\hline Division 2 round 4 & $\begin{array}{c}0.014 \\
(0.049)\end{array}$ & $\begin{array}{c}0.024 \\
(0.051)\end{array}$ & $\begin{array}{c}0.296^{* *} \\
(0.120)\end{array}$ & $\begin{array}{l}-0.092^{*} \\
(0.043)\end{array}$ & $\begin{array}{c}-0.090^{* *} \\
(0.036)\end{array}$ & $\begin{array}{l}0.146 \\
(0.093)\end{array}$ \\
\hline Division 2 round 5 & $\begin{array}{c}0.668^{* * *} \\
(0.159)\end{array}$ & $\begin{array}{c}0.718^{* * *} \\
(0.176)\end{array}$ & $\begin{array}{c}0.823^{* * *} \\
(0.123)\end{array}$ & $\begin{array}{c}0.594^{* * *} \\
(0.150)\end{array}$ & $\begin{array}{c}0.642^{* * *} \\
(0.164)\end{array}$ & $\begin{array}{c}0.720^{* * *} \\
(0.097)\end{array}$ \\
\hline Division 3 round 1 & $\begin{array}{c}-0.587^{* * *} \\
(0.100)\end{array}$ & $\begin{array}{c}-0.609^{* * *} \\
(0.103)\end{array}$ & $\begin{array}{l}-0.171 \\
(0.193)\end{array}$ & $\begin{array}{c}-0.714^{* * *} \\
(0.085)\end{array}$ & $\begin{array}{c}-0.737^{* * *} \\
(0.092)\end{array}$ & $\begin{array}{l}-0.288 \\
(0.180)\end{array}$ \\
\hline Division 3 round 2 & $\begin{array}{l}-0.307 \\
(0.337)\end{array}$ & $\begin{array}{l}-0.466^{*} \\
(0.256)\end{array}$ & $\begin{array}{l}-0.151 \\
(0.261)\end{array}$ & $\begin{array}{l}-0.428 \\
(0.350)\end{array}$ & $\begin{array}{c}-0.590 * \\
(0.280)\end{array}$ & $\begin{array}{l}-0.291 \\
(0.309)\end{array}$ \\
\hline Division 3 round 3 & $\begin{array}{c}-0.478^{* * *} \\
(0.062)\end{array}$ & $\begin{array}{c}-0.470^{* * *} \\
(0.087)\end{array}$ & $\begin{array}{c}-1.352^{* * *} \\
(0.139)\end{array}$ & $\begin{array}{c}-0.602^{* * *} \\
(0.068)\end{array}$ & $\begin{array}{c}-0.598^{* * *} \\
(0.083)\end{array}$ & $\begin{array}{c}-1.537^{* * *} \\
(0.185)\end{array}$ \\
\hline Division 3 round 4 & $\begin{array}{c}-0.241^{* * *} \\
(0.080)\end{array}$ & $\begin{array}{c}-0.239^{* *} \\
(0.097)\end{array}$ & $\begin{array}{c}0.313^{* *} \\
(0.108)\end{array}$ & $\begin{array}{c}-0.347^{* * *} \\
(0.083)\end{array}$ & $\begin{array}{c}-0.350^{* * *} \\
(0.079)\end{array}$ & $\begin{array}{c}0.167 \\
(0.112)\end{array}$ \\
\hline Division 3 round 5 & $\begin{array}{c}-0.214^{* *} \\
(0.082)\end{array}$ & $\begin{array}{c}-0.195^{* * *} \\
(0.063)\end{array}$ & $\begin{array}{l}-0.067 \\
(0.104)\end{array}$ & $\begin{array}{c}-0.284^{* *} \\
(0.100)\end{array}$ & $\begin{array}{c}-0.262^{* * *} \\
(0.089)\end{array}$ & $\begin{array}{l}-0.174^{*} \\
(0.092)\end{array}$ \\
\hline Division 4 round 1 & $\begin{array}{l}-0.801 \\
(0.463)\end{array}$ & $\begin{array}{l}-0.861^{*} \\
(0.429)\end{array}$ & $\begin{array}{c}-1.622^{* * *} \\
(0.373)\end{array}$ & $\begin{array}{c}-0.870^{*} \\
(0.438)\end{array}$ & $\begin{array}{c}-0.941^{* *} \\
(0.400)\end{array}$ & $\begin{array}{c}-1.639^{* * *} \\
(0.406)\end{array}$ \\
\hline Division 4 round 2 & $\begin{array}{l}-0.261 \\
(0.251)\end{array}$ & $\begin{array}{l}-0.397 \\
(0.241)\end{array}$ & $\begin{array}{l}-0.705 \\
(0.429)\end{array}$ & $\begin{array}{l}-0.335 \\
(0.244)\end{array}$ & $\begin{array}{l}-0.484^{*} \\
(0.239)\end{array}$ & $\begin{array}{l}-0.755 \\
(0.446)\end{array}$ \\
\hline Division 4 round 3 & $\begin{array}{l}-0.405 \\
(0.234)\end{array}$ & $\begin{array}{c}-0.391^{* *} \\
(0.164)\end{array}$ & $\begin{array}{c}-1.243^{* * *} \\
(0.338)\end{array}$ & $\begin{array}{c}-0.498^{* *} \\
(0.227)\end{array}$ & $\begin{array}{c}-0.488^{* *} \\
(0.168)\end{array}$ & $\begin{array}{c}-1.353^{* * *} \\
(0.372)\end{array}$ \\
\hline
\end{tabular}


Table $\mathrm{C} 4$ - continued from previous page -

\begin{tabular}{lcccccc}
\hline \multirow{2}{*}{ Division 4 round 4 } & 0.214 & 0.221 & -0.060 & 0.109 & 0.113 & -0.169 \\
& $(0.230)$ & $(0.203)$ & $(0.212)$ & $(0.225)$ & $(0.211)$ & $(0.208)$ \\
Division 4 round 5 & $0.347^{*}$ & $0.379^{*}$ & $0.218^{* *}$ & 0.272 & $0.302^{*}$ & 0.140 \\
& $(0.175)$ & $(0.187)$ & $(0.084)$ & $(0.160)$ & $(0.172)$ & $(0.084)$ \\
Division 5 round 1 & $-1.487^{* * *}$ & $-1.445^{* * *}$ & $-1.566^{* * *}$ & $-1.474^{* * *}$ & $-1.448^{* * *}$ & $-1.438^{* * *}$ \\
& $(0.210)$ & $(0.223)$ & $(0.176)$ & $(0.221)$ & $(0.238)$ & $(0.208)$ \\
Division 5 round 2 & $-0.927^{* * *}$ & $-0.998^{* * *}$ & $-1.153^{* * *}$ & $-0.898^{* *}$ & $-0.993^{* * *}$ & $-1.055^{* * *}$ \\
& $(0.310)$ & $(0.298)$ & $(0.202)$ & $(0.305)$ & $(0.299)$ & $(0.188)$ \\
Division 5 round 3 & $-0.792^{* * *}$ & $-0.695^{* * *}$ & $-1.728^{* * *}$ & $-0.802^{* * *}$ & $-0.715^{* * *}$ & $-1.763^{* * *}$ \\
& $(0.075)$ & $(0.067)$ & $(0.159)$ & $(0.085)$ & $(0.086)$ & $(0.168)$ \\
Division 5 round 4 & $-0.659^{* * *}$ & $-0.613^{* * *}$ & $-0.733^{* * *}$ & $-0.694^{* * *}$ & $-0.662^{* * *}$ & $-0.760^{* * *}$ \\
& $(0.161)$ & $(0.178)$ & $(0.105)$ & $(0.174)$ & $(0.183)$ & $(0.077)$ \\
Division 5 round 5 & $-0.527^{* * *}$ & $-0.423^{* * *}$ & $-0.477^{* * *}$ & $-0.562^{* * *}$ & $-0.463^{* * *}$ & $-0.489^{* *}$ \\
& $(0.121)$ & $(0.135)$ & $(0.147)$ & $(0.141)$ & $(0.150)$ & $(0.170)$ \\
Constant & $6.556^{* * *}$ & $4.199^{* * *}$ & $6.042^{* * *}$ & $6.694^{* * *}$ & $4.334^{* * *}$ & $6.196^{* * *}$ \\
Model statistics: & $(0.314)$ & $(0.289)$ & $(0.443)$ & $(0.292)$ & $(0.267)$ & $(0.443)$ \\
$R^{2}$ & & & & & & \\
\hline
\end{tabular}

Notes: Estimates are based on an unbalanced panel data set with 5,506 observations and 1,062 groups. The dependent variable for columns (1) and (4) is household dietary diversity score with twelve food groups. The dependent variable for columns (2) and (5) is the dietary diversity score with nine food groups. The dependent variable for columns (3) and (6) is the number of food groups that the household consumed coming from food purchases. The independent variables shown here refer to the number of rounds before or after a household first gained access to a mobile phone relative to the year before first access. Errors shown in parentheses are robust and clustered at the sub-location level. HDDS $=$ household dietary diversity score. $\mathrm{HH}=$ household head. $\mathrm{MP}=$ mobile phone. $\mathrm{TLU}=$ Tropical Livestock Unit. ${ }^{*},{ }^{* *},{ }^{* * *}$ denote statistical significance at the $10 \%, 5 \%, 1 \%$ level respectively. 
Table C5: Full Table for the effect duration of mobile phone access on dietary outcomes (3 year time span)

\begin{tabular}{|c|c|c|c|c|c|c|}
\hline & \multicolumn{3}{|c|}{ Mobile phone usage } & \multicolumn{3}{|c|}{ Mobile phone ownership } \\
\hline & HDDS12 & HHDS9 & $\begin{array}{c}\text { Food } \\
\text { groups } \\
\text { from } \\
\text { purchase } \\
\quad(3)\end{array}$ & HDDS12 & $\begin{array}{l}\text { HHDS9 } \\
\text { (5) }\end{array}$ & $\begin{array}{c}\text { Food } \\
\text { groups } \\
\text { from } \\
\text { purchase } \\
\quad(6)\end{array}$ \\
\hline Before 3 & $\begin{array}{c}0.016 \\
(0.075)\end{array}$ & $\begin{array}{c}0.029 \\
(0.079)\end{array}$ & $\begin{array}{l}-0.084 \\
(0.071)\end{array}$ & $\begin{array}{c}0.019 \\
(0.099)\end{array}$ & $\begin{array}{c}0.020 \\
(0.105)\end{array}$ & $\begin{array}{c}0.180 \\
(0.107)\end{array}$ \\
\hline Before 2 & $\begin{array}{l}-0.020 \\
(0.058)\end{array}$ & $\begin{array}{l}-0.012 \\
(0.071)\end{array}$ & $\begin{array}{l}-0.075 \\
(0.078)\end{array}$ & $\begin{array}{c}0.066 \\
(0.071)\end{array}$ & $\begin{array}{c}0.082 \\
(0.071)\end{array}$ & $\begin{array}{c}0.138 \\
(0.099)\end{array}$ \\
\hline Before 1 & & & -Referer & ce Year- & & \\
\hline After 0 & $\begin{array}{c}0.112 \\
(0.072)\end{array}$ & $\begin{array}{c}0.082 \\
(0.068)\end{array}$ & $\begin{array}{c}0.115 \\
(0.073)\end{array}$ & $\begin{array}{l}0.144^{*} \\
(0.075)\end{array}$ & $\begin{array}{c}0.075 \\
(0.072)\end{array}$ & $\begin{array}{c}0.298^{* *} \\
(0.104)\end{array}$ \\
\hline After 1 & $\begin{array}{c}0.099 \\
(0.089)\end{array}$ & $\begin{array}{c}0.019 \\
(0.083)\end{array}$ & $\begin{array}{c}0.050 \\
(0.131)\end{array}$ & $\begin{array}{c}0.079 \\
(0.076)\end{array}$ & $\begin{array}{c}0.020 \\
(0.086)\end{array}$ & $\begin{array}{l}0.236^{*} \\
(0.126)\end{array}$ \\
\hline After 2 & $\begin{array}{c}0.103 \\
(0.112)\end{array}$ & $\begin{array}{c}0.106 \\
(0.072)\end{array}$ & $\begin{array}{c}0.141 \\
(0.088)\end{array}$ & $\begin{array}{c}0.046 \\
(0.139)\end{array}$ & $\begin{array}{l}-0.057 \\
(0.150)\end{array}$ & $\begin{array}{c}0.216 \\
(0.124)\end{array}$ \\
\hline After 3 & $\begin{array}{c}0.112 \\
(0.086)\end{array}$ & $\begin{array}{c}0.093 \\
(0.089)\end{array}$ & $\begin{array}{c}0.094 \\
(0.103)\end{array}$ & $\begin{array}{l}-0.078 \\
(0.202)\end{array}$ & $\begin{array}{l}-0.132 \\
(0.182)\end{array}$ & $\begin{array}{c}0.192 \\
(0.173)\end{array}$ \\
\hline Nomadic status & $\begin{array}{l}-0.042 \\
(0.225)\end{array}$ & $\begin{array}{c}0.005 \\
(0.227)\end{array}$ & $\begin{array}{l}-0.321 \\
(0.191)\end{array}$ & $\begin{array}{l}-0.038 \\
(0.226)\end{array}$ & $\begin{array}{c}0.006 \\
(0.227)\end{array}$ & $\begin{array}{l}-0.315 \\
(0.188)\end{array}$ \\
\hline Radio ownership & $\begin{array}{l}-0.111 \\
(0.148)\end{array}$ & $\begin{array}{l}-0.117 \\
(0.154)\end{array}$ & $\begin{array}{l}-0.143 \\
(0.154)\end{array}$ & $\begin{array}{l}-0.116 \\
(0.143)\end{array}$ & $\begin{array}{l}-0.108 \\
(0.151)\end{array}$ & $\begin{array}{l}-0.177 \\
(0.150)\end{array}$ \\
\hline Cooking source & $\begin{array}{c}0.233 \\
(0.215)\end{array}$ & $\begin{array}{c}0.055 \\
(0.191)\end{array}$ & $\begin{array}{c}0.120 \\
(0.421)\end{array}$ & $\begin{array}{c}0.218 \\
(0.223)\end{array}$ & $\begin{array}{c}0.050 \\
(0.194)\end{array}$ & $\begin{array}{c}0.089 \\
(0.441)\end{array}$ \\
\hline $\begin{array}{l}\text { Income } \\
{[\mathrm{KSh} 1,000,000]}\end{array}$ & $\begin{array}{c}2.378^{* * *} \\
(0.443)\end{array}$ & $\begin{array}{c}2.534^{* * *} \\
(0.449)\end{array}$ & $\begin{array}{c}2.389 * * * \\
(0.482)\end{array}$ & $\begin{array}{c}2.387^{* * *} \\
(0.445)\end{array}$ & $\begin{array}{c}2.536^{* * *} \\
(0.455)\end{array}$ & $\begin{array}{c}2.399^{* * *} \\
(0.476)\end{array}$ \\
\hline $\begin{array}{l}\text { Land farmed } \\
\text { [hectares] }\end{array}$ & $\begin{array}{c}0.017^{* * *} \\
(0.004)\end{array}$ & $\begin{array}{c}0.019^{* * *} \\
(0.004)\end{array}$ & $\begin{array}{c}0.004 \\
(0.015)\end{array}$ & $\begin{array}{c}0.016^{* * *} \\
(0.004)\end{array}$ & $\begin{array}{c}0.018^{* * *} \\
(0.004)\end{array}$ & $\begin{array}{c}0.002 \\
(0.015)\end{array}$ \\
\hline Herd size [TLU] & $\begin{array}{c}0.005^{* * *} \\
(0.001)\end{array}$ & $\begin{array}{c}0.005^{* * *} \\
(0.002)\end{array}$ & $\begin{array}{l}0.004^{* *} \\
(0.002)\end{array}$ & $\begin{array}{c}0.005^{* * *} \\
(0.001)\end{array}$ & $\begin{array}{c}0.005^{* * *} \\
(0.002)\end{array}$ & $\begin{array}{c}0.003^{* *} \\
(0.002)\end{array}$ \\
\hline Education [years] & $\begin{array}{l}-0.055 \\
(0.071)\end{array}$ & $\begin{array}{l}-0.089 \\
(0.078)\end{array}$ & $\begin{array}{l}-0.206^{*} \\
(0.099)\end{array}$ & $\begin{array}{l}-0.060 \\
(0.070)\end{array}$ & $\begin{array}{l}-0.095 \\
(0.077)\end{array}$ & $\begin{array}{c}-0.214^{* *} \\
(0.099)\end{array}$ \\
\hline Gender & $\begin{array}{l}0.205^{*} \\
(0.105)\end{array}$ & $\begin{array}{l}0.241^{* *} \\
(0.092)\end{array}$ & $\begin{array}{c}0.240 \\
(0.177)\end{array}$ & $\begin{array}{l}0.208^{*} \\
(0.104)\end{array}$ & $\begin{array}{c}0.237 * * \\
(0.092)\end{array}$ & $\begin{array}{c}0.242 \\
(0.178)\end{array}$ \\
\hline Age & $\begin{array}{l}-0.001 \\
(0.003)\end{array}$ & $\begin{array}{c}0.001 \\
(0.003)\end{array}$ & $\begin{array}{l}-0.002 \\
(0.005)\end{array}$ & $\begin{array}{l}-0.001 \\
(0.003)\end{array}$ & $\begin{array}{c}0.001 \\
(0.003)\end{array}$ & $\begin{array}{l}-0.002 \\
(0.005)\end{array}$ \\
\hline Household size & $\begin{array}{c}0.077^{* * *} \\
(0.020)\end{array}$ & $\begin{array}{c}0.079^{* * *} \\
(0.019)\end{array}$ & $\begin{array}{c}0.054^{* *} \\
(0.022)\end{array}$ & $\begin{array}{c}0.078^{* * *} \\
(0.020)\end{array}$ & $\begin{array}{c}0.080^{* * *} \\
(0.019)\end{array}$ & $\begin{array}{c}0.054^{* *} \\
(0.023)\end{array}$ \\
\hline Division 1 round 1 & $-0.972^{* * *}$ & $-0.977^{* * *}$ & $-1.293^{*}$ & $-0.992^{* * *}$ & $-1.000^{* * *}$ & $-1.300^{*}$ \\
\hline
\end{tabular}


Table C5 - continued from previous page -

\begin{tabular}{|c|c|c|c|c|c|c|}
\hline & $(0.259)$ & $(0.228)$ & (0.699) & ) & ) & 4) \\
\hline Division 1 round 2 & $\begin{array}{l}-0.284 \\
(0.263)\end{array}$ & $\begin{array}{l}-0.369 \\
(0.300)\end{array}$ & $\begin{array}{l}-1.014 \\
(0.626)\end{array}$ & $\begin{array}{l}-0.297 \\
(0.269)\end{array}$ & $\begin{array}{l}-0.385 \\
(0.305)\end{array}$ & $\begin{array}{l}-1.008 \\
(0.616)\end{array}$ \\
\hline Division 1 round 3 & $\begin{array}{c}-0.973^{* * *} \\
(0.158)\end{array}$ & $\begin{array}{c}-0.748^{* * *} \\
(0.136)\end{array}$ & $\begin{array}{c}-0.838^{* * *} \\
(0.189)\end{array}$ & $\begin{array}{c}-0.983^{* * *} \\
(0.171)\end{array}$ & $\begin{array}{c}-0.761^{* * *} \\
(0.144)\end{array}$ & $\begin{array}{c}-0.888^{* * *} \\
(0.220)\end{array}$ \\
\hline Division 1 round 4 & $\begin{array}{c}-0.720^{* * *} \\
(0.043)\end{array}$ & $\begin{array}{c}-0.641^{* * *} \\
(0.073)\end{array}$ & $\begin{array}{c}-0.563^{* * *} \\
(0.069)\end{array}$ & $\begin{array}{c}-0.743^{* * *} \\
(0.062)\end{array}$ & $\begin{array}{c}-0.668^{* * *} \\
(0.094)\end{array}$ & $\begin{array}{c}-0.598^{* * *} \\
(0.098)\end{array}$ \\
\hline Division 1 round 5 & $\begin{array}{c}-0.151^{*} \\
(0.075)\end{array}$ & & $\begin{array}{c}-0.246^{* *} \\
(0.112)\end{array}$ & & & $\begin{array}{c}-0.235^{*} \\
(0.112)\end{array}$ \\
\hline Division 2 round 1 & $\begin{array}{l}-0.1 \\
(0.1\end{array}$ & & & & & $\begin{array}{l}-0.224 \\
(0.311)\end{array}$ \\
\hline Division 2 round 2 & & & & & & \\
\hline Division 2 round 3 & $\begin{array}{l}0.22 \\
(0.0\end{array}$ & $\begin{array}{r}0.22 \\
(0.1\end{array}$ & $\begin{array}{c}0.499^{* * *} \\
(0.112)\end{array}$ & & & $\begin{array}{c}0.447^{* * *} \\
(0.105)\end{array}$ \\
\hline Division 2 round 4 & $\begin{array}{r}-0.0^{\prime} \\
(0.0\end{array}$ & & & & & \\
\hline Division $2 \mathrm{r}$ & $\begin{array}{c}0.589^{* * *} \\
(0.147)\end{array}$ & $\begin{array}{c}0.643^{* * *} \\
(0.158)\end{array}$ & $\begin{array}{r}0.70 \\
(0 .\end{array}$ & $\begin{array}{c}0.59 \\
(0 .\end{array}$ & *** & $\begin{array}{c}0.706^{* * *} \\
(0.088)\end{array}$ \\
\hline Division 3 round 1 & $\begin{array}{c}-0.677^{* * *} \\
(0.082)\end{array}$ & $\begin{array}{r}-0.68 \\
(0.0\end{array}$ & $\begin{array}{l}-0 .: \\
(0 .\end{array}$ & $\begin{array}{r}-0.71 \\
(0.0\end{array}$ & *** & $\begin{array}{c}-0.388^{* *} \\
(0.170)\end{array}$ \\
\hline Division 3 round 2 & $\begin{array}{l}-0.408 \\
(0.335)\end{array}$ & $\begin{array}{l}-0.5 \\
(0.2\end{array}$ & & & $\begin{array}{c}-0.6 \\
(0.8\end{array}$ & $\begin{array}{l}-0.363 \\
(0.294)\end{array}$ \\
\hline Division 3 round 3 & $\begin{array}{r}-0.581 \\
(0.0\end{array}$ & $\begin{array}{c}-0.570^{* * *} \\
(0.073)\end{array}$ & $\begin{array}{c}-1.531^{* * *} \\
(0.192)\end{array}$ & 4** & $\begin{array}{r}-0.60 \\
(0 .\end{array}$ & $\begin{array}{c}-1.590^{* * *} \\
(0.199)\end{array}$ \\
\hline Division 3 round 4 & $\begin{array}{c}-0.333^{* * *} \\
(0.077)\end{array}$ & $\begin{array}{c}-0.329^{* * *} \\
(0.092)\end{array}$ & & $\begin{array}{r}-0.35 \\
(0.0\end{array}$ & $\begin{array}{c}-0.358^{* * *} \\
(0.072)\end{array}$ & $\begin{array}{c}0.123 \\
(0.114)\end{array}$ \\
\hline Division 3 round 5 & $\begin{array}{c}-0.303^{* * *} \\
(0.072)\end{array}$ & $\begin{array}{c}-0.284^{* * *} \\
(0.057)\end{array}$ & $\begin{array}{c}-0.211^{* *} \\
(0.076)\end{array}$ & $\begin{array}{c}-0.284^{* * *} \\
(0.090)\end{array}$ & $\begin{array}{c}-0.272^{* * *} \\
(0.076)\end{array}$ & $\begin{array}{c}-0.201^{* *} \\
(0.074)\end{array}$ \\
\hline Division 4 round 1 & $\begin{array}{l}-0.829^{*} \\
(0.458)\end{array}$ & $\begin{array}{l}-0.879^{*} \\
(0.426)\end{array}$ & $\begin{array}{c}-1.708^{* * *} \\
(0.415)\end{array}$ & $\begin{array}{l}-0.872^{*} \\
(0.445)\end{array}$ & $\begin{array}{c}-0.935^{* *} \\
(0.412)\end{array}$ & $\begin{array}{c}-1.727^{* * *} \\
(0.433)\end{array}$ \\
\hline Division 4 round 2 & $\begin{array}{l}-0.302 \\
(0.254)\end{array}$ & -0.433 & $\begin{array}{l}-0.793^{*} \\
(0.452)\end{array}$ & $\begin{array}{l}-0.346 \\
(0.243)\end{array}$ & $\begin{array}{l}-0.491^{*} \\
(0.239)\end{array}$ & $\begin{array}{l}-0.814^{*} \\
(0.463)\end{array}$ \\
\hline Division 4 round 3 & $\begin{array}{l}-0.458^{*} \\
(0.236)\end{array}$ & $\begin{array}{c}-0.440^{* *} \\
(0.170)\end{array}$ & $\begin{array}{c}-1.341^{* * *} \\
(0.356)\end{array}$ & $\begin{array}{c}-0.500^{* *} \\
(0.226)\end{array}$ & $\begin{array}{c}-0.494^{* * *} \\
(0.167)\end{array}$ & $\begin{array}{c}-1.390^{* * *} \\
(0.373)\end{array}$ \\
\hline Division 4 round 4 & $\begin{array}{c}0.164 \\
(0.236)\end{array}$ & $\begin{array}{c}0.172 \\
(0.215)\end{array}$ & $\begin{array}{l}-0.148 \\
(0.223)\end{array}$ & $\begin{array}{c}0.107 \\
(0.227)\end{array}$ & $\begin{array}{c}0.109 \\
(0.215)\end{array}$ & $\begin{array}{l}-0.199 \\
(0.217)\end{array}$ \\
\hline Division 4 round 5 & $\begin{array}{c}0.294 \\
(0.180)\end{array}$ & $\begin{array}{c}0.325 \\
(0.196)\end{array}$ & $\begin{array}{c}0.132 \\
(0.092)\end{array}$ & $\begin{array}{c}0.272 \\
(0.160)\end{array}$ & $\begin{array}{c}0.295 \\
(0.176)\end{array}$ & $\begin{array}{c}0.127 \\
(0.080)\end{array}$ \\
\hline Division 5 round 1 & $\begin{array}{c}-1.472^{* * *} \\
(0.210)\end{array}$ & $\begin{array}{c}-1.419^{* * *} \\
(0.225)\end{array}$ & $\begin{array}{c}-1.578^{* * *} \\
(0.183)\end{array}$ & $\begin{array}{c}-1.466^{* * *} \\
(0.207)\end{array}$ & $\begin{array}{c}-1.429^{* * *} \\
(0.223)\end{array}$ & $\begin{array}{c}-1.524^{* * *} \\
(0.184)\end{array}$ \\
\hline Division : & $\begin{array}{c}-0.924^{* * *} \\
(0.292)\end{array}$ & $\begin{array}{c}-0.992^{* * *} \\
(0.285)\end{array}$ & $\begin{array}{c}-1.163^{* * *} \\
(0.173)\end{array}$ & $\begin{array}{c}-0.918^{* * *} \\
(0.290)\end{array}$ & $\begin{array}{c}-1.000^{* * *} \\
(0.283)\end{array}$ & $\begin{array}{c}-1.108^{* * *} \\
(0.169)\end{array}$ \\
\hline
\end{tabular}


Table C5 - continued from previous page -

\begin{tabular}{lcccccc}
\hline \multirow{2}{*}{ Division 5 round 3 } & $-0.806^{* * *}$ & $-0.707^{* * *}$ & $-1.759^{* * *}$ & $-0.804^{* * *}$ & $-0.715^{* * *}$ & $-1.790^{* * *}$ \\
& $(0.075)$ & $(0.070)$ & $(0.167)$ & $(0.078)$ & $(0.079)$ & $(0.171)$ \\
Division 5 round 4 & $-0.670^{* * *}$ & $-0.623^{* * *}$ & $-0.758^{* * *}$ & $-0.695^{* * *}$ & $-0.663^{* * *}$ & $-0.776^{* * *}$ \\
& $(0.163)$ & $(0.182)$ & $(0.105)$ & $(0.175)$ & $(0.185)$ & $(0.074)$ \\
Division 5 round 5 & $-0.565^{* * *}$ & $-0.463^{* * *}$ & $-0.532^{* * *}$ & $-0.560^{* * *}$ & $-0.469^{* * *}$ & $-0.480^{* *}$ \\
& $(0.137)$ & $(0.148)$ & $(0.162)$ & $(0.143)$ & $(0.150)$ & $(0.172)$ \\
Constant & $6.660^{* * *}$ & $4.306^{* * *}$ & $6.198^{* * *}$ & $6.688^{* * *}$ & $4.349^{* * *}$ & $6.191^{* * *}$ \\
Model statistics: & $(0.300)$ & $(0.271)$ & $(0.443)$ & $(0.285)$ & $(0.259)$ & $(0.443)$ \\
$R^{2}$ & & & & & & \\
\hline
\end{tabular}

Notes: Estimates are based on an unbalanced panel data set with 5,506 observations and 1,062 groups. The dependent variable for columns (1) and (4) is household dietary diversity score with twelve food groups. The dependent variable for columns (2) and (5) is the dietary diversity score with nine food groups. The dependent variable for columns (3) and (6) is the number of food groups that the household consumed coming from food purchases. The independent variables shown here refer to the number of rounds before or after a household first gained access to a mobile phone relative to the year before first access. Errors shown in parentheses are robust and clustered at the sub-location level. HDDS $=$ household dietary diversity score. $\mathrm{HH}=$ household head. $\mathrm{MP}=$ mobile phone. $\mathrm{TLU}=$ Tropical Livestock Unit. ${ }^{*},{ }^{* *},{ }^{* * *}$ denote statistical significance at the $10 \%, 5 \%, 1 \%$ level respectively. 
Table C6: Full Table for the Linear Probability Models for the consumption of each food groups when purchase was the main source

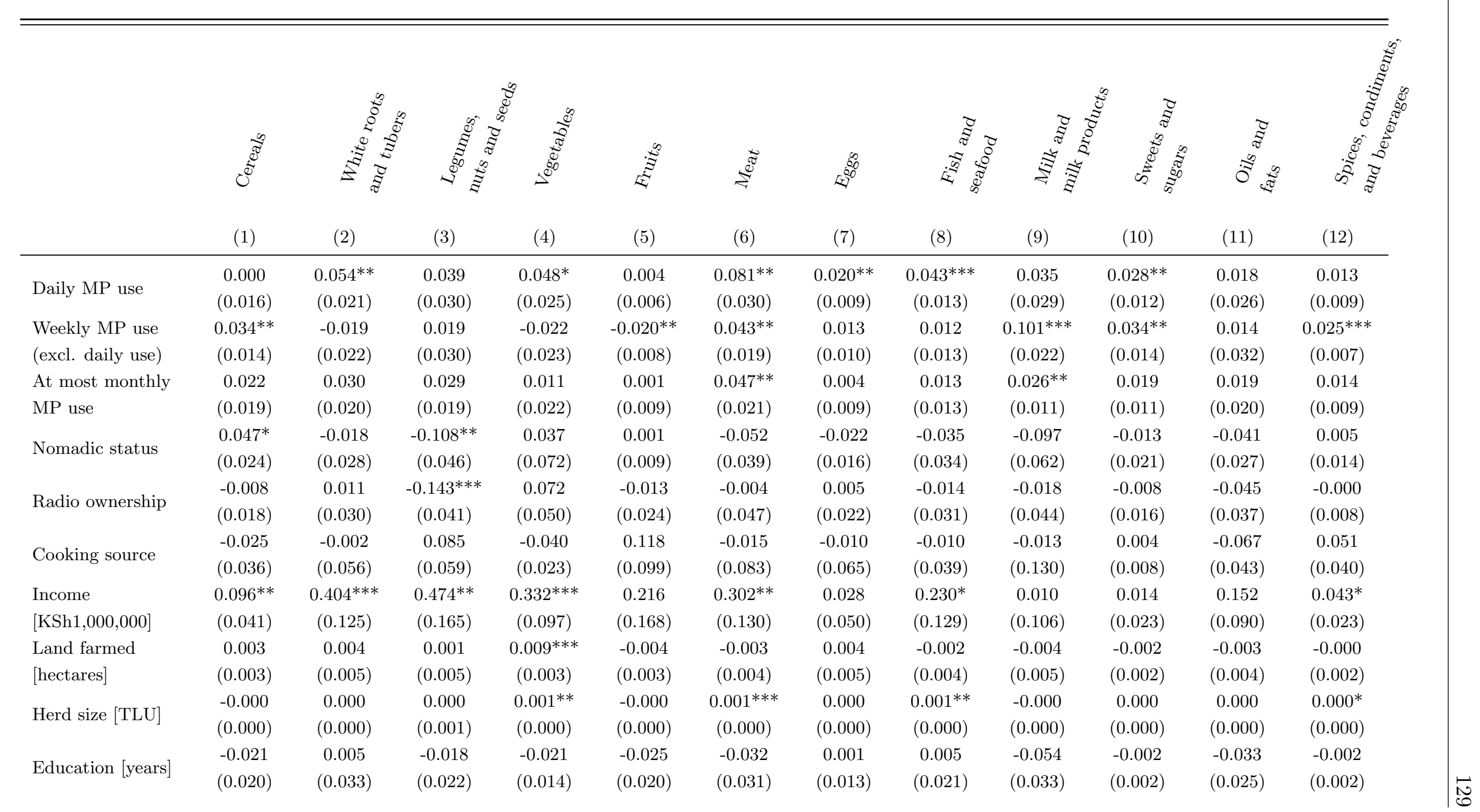


Table C6 - continued from previous page -

\begin{tabular}{|c|c|c|c|c|c|c|c|c|c|c|c|c|}
\hline Gender & $\begin{array}{l}-0.010 \\
(0.023)\end{array}$ & $\begin{array}{c}0.042 \\
(0.027)\end{array}$ & $\begin{array}{c}0.003 \\
(0.051)\end{array}$ & $\begin{array}{c}0.020 \\
(0.035)\end{array}$ & $\begin{array}{c}0.041^{* * *} \\
(0.013)\end{array}$ & $\begin{array}{c}0.060 \\
(0.044)\end{array}$ & $\begin{array}{c}0.003 \\
(0.016)\end{array}$ & $\begin{array}{c}0.024 \\
(0.029)\end{array}$ & $\begin{array}{c}0.042 \\
(0.058)\end{array}$ & $\begin{array}{l}-0.023 \\
(0.018)\end{array}$ & $\begin{array}{c}0.047 \\
(0.044)\end{array}$ & $\begin{array}{l}-0.000 \\
(0.018)\end{array}$ \\
\hline Age & $\begin{array}{l}-0.001 \\
(0.001)\end{array}$ & $\begin{array}{c}0.000 \\
(0.001)\end{array}$ & $\begin{array}{l}-0.001 \\
(0.001)\end{array}$ & $\begin{array}{l}-0.000 \\
(0.001)\end{array}$ & $\begin{array}{c}0.001^{*} \\
(0.000)\end{array}$ & $\begin{array}{c}0.002^{* *} \\
(0.001)\end{array}$ & $\begin{array}{l}0.000^{*} \\
(0.000)\end{array}$ & $\begin{array}{l}-0.001 \\
(0.000)\end{array}$ & $\begin{array}{c}0.000 \\
(0.001)\end{array}$ & $\begin{array}{l}-0.001 \\
(0.001)\end{array}$ & $\begin{array}{c}0.000 \\
(0.002)\end{array}$ & $\begin{array}{c}-0.002^{* *} \\
(0.001)\end{array}$ \\
\hline Household size & $\begin{array}{l}-0.001 \\
(0.004)\end{array}$ & $\begin{array}{c}0.016^{* *} \\
(0.006)\end{array}$ & $\begin{array}{c}0.002 \\
(0.004)\end{array}$ & $\begin{array}{c}0.005 \\
(0.005)\end{array}$ & $\begin{array}{c}0.001 \\
(0.003)\end{array}$ & $\begin{array}{c}0.012 \\
(0.008)\end{array}$ & $\begin{array}{c}0.007 \\
(0.004)\end{array}$ & $\begin{array}{l}-0.002 \\
(0.003)\end{array}$ & $\begin{array}{c}0.007 \\
(0.008)\end{array}$ & $\begin{array}{c}0.001 \\
(0.003)\end{array}$ & $\begin{array}{c}0.006 \\
(0.006)\end{array}$ & $\begin{array}{l}-0.001 \\
(0.002)\end{array}$ \\
\hline Division 1 round 1 & $\begin{array}{c}-0.188^{*} \\
(0.097)\end{array}$ & $\begin{array}{l}-0.203 \\
(0.126)\end{array}$ & $\begin{array}{l}-0.038 \\
(0.186)\end{array}$ & $\begin{array}{l}-0.280 \\
(0.167)\end{array}$ & $\begin{array}{l}-0.151 \\
(0.112)\end{array}$ & $\begin{array}{c}-0.196^{* *} \\
(0.082)\end{array}$ & $\begin{array}{c}0.068 \\
(0.083)\end{array}$ & $\begin{array}{c}0.169^{* * *} \\
(0.022)\end{array}$ & $\begin{array}{c}0.066^{* * *} \\
(0.011)\end{array}$ & $\begin{array}{c}-0.075^{* *} \\
(0.030)\end{array}$ & $\begin{array}{c}-0.319 * \\
(0.167)\end{array}$ & $\begin{array}{c}-0.094^{* * *} \\
(0.027)\end{array}$ \\
\hline Division 1 round 2 & $\begin{array}{l}-0.249 \\
(0.162)\end{array}$ & $\begin{array}{l}-0.118 \\
(0.113)\end{array}$ & $\begin{array}{c}-0.227^{* * *} \\
(0.065)\end{array}$ & $\begin{array}{l}-0.202 \\
(0.154)\end{array}$ & $\begin{array}{l}-0.062 \\
(0.055)\end{array}$ & $\begin{array}{l}-0.229 \\
(0.227)\end{array}$ & $\begin{array}{c}0.042^{* * *} \\
(0.014)\end{array}$ & $\begin{array}{c}0.375 \\
(0.229)\end{array}$ & $\begin{array}{l}-0.070 \\
(0.092)\end{array}$ & $\begin{array}{c}0.005 \\
(0.007)\end{array}$ & $\begin{array}{c}-0.191^{* *} \\
(0.067)\end{array}$ & $\begin{array}{l}-0.015^{*} \\
(0.007)\end{array}$ \\
\hline Division 1 round 3 & $\begin{array}{c}-0.077^{*} \\
(0.042)\end{array}$ & $\begin{array}{l}-0.103 \\
(0.113)\end{array}$ & $\begin{array}{l}-0.005 \\
(0.011)\end{array}$ & $\begin{array}{l}-0.155 \\
(0.111)\end{array}$ & $\begin{array}{l}-0.132 \\
(0.114)\end{array}$ & $\begin{array}{l}-0.107 \\
(0.097)\end{array}$ & $\begin{array}{c}-0.024^{* *} \\
(0.010)\end{array}$ & $\begin{array}{c}0.014^{* *} \\
(0.006)\end{array}$ & $\begin{array}{c}0.084 \\
(0.074)\end{array}$ & $\begin{array}{l}-0.029 \\
(0.018)\end{array}$ & $\begin{array}{c}-0.214^{* * *} \\
(0.011)\end{array}$ & $\begin{array}{l}-0.057 \\
(0.035)\end{array}$ \\
\hline Division 1 round 4 & $\begin{array}{l}-0.028 \\
(0.030)\end{array}$ & $\begin{array}{l}-0.143 \\
(0.115)\end{array}$ & $\begin{array}{c}0.151^{* * *} \\
(0.051)\end{array}$ & $\begin{array}{l}-0.115 \\
(0.100)\end{array}$ & $\begin{array}{l}-0.171 \\
(0.131)\end{array}$ & $\begin{array}{c}-0.345^{* *} \\
(0.141)\end{array}$ & $\begin{array}{l}-0.011 \\
(0.026)\end{array}$ & $\begin{array}{l}0.183^{*} \\
(0.097)\end{array}$ & $\begin{array}{c}0.015 \\
(0.058)\end{array}$ & $\begin{array}{c}0.015 \\
(0.012)\end{array}$ & $\begin{array}{c}-0.056^{*} \\
(0.030)\end{array}$ & $\begin{array}{l}-0.002 \\
(0.015)\end{array}$ \\
\hline Division 1 round 5 & $\begin{array}{c}0.008 \\
(0.025)\end{array}$ & $\begin{array}{l}-0.027 \\
(0.105)\end{array}$ & $\begin{array}{c}0.204^{* * *} \\
(0.018)\end{array}$ & $\begin{array}{l}-0.150 \\
(0.099)\end{array}$ & $\begin{array}{l}-0.078 \\
(0.051)\end{array}$ & $\begin{array}{l}-0.133 \\
(0.105)\end{array}$ & $\begin{array}{c}0.023 \\
(0.015)\end{array}$ & $\begin{array}{c}0.137^{* * *} \\
(0.040)\end{array}$ & $\begin{array}{c}-0.140 * * * \\
(0.008)\end{array}$ & $\begin{array}{l}-0.007 \\
(0.005)\end{array}$ & $\begin{array}{l}-0.011 \\
(0.012)\end{array}$ & $\begin{array}{l}-0.010 \\
(0.009)\end{array}$ \\
\hline Division 2 round 1 & $\begin{array}{c}-0.115^{* * *} \\
(0.023)\end{array}$ & $\begin{array}{c}0.081 \\
(0.050)\end{array}$ & $\begin{array}{c}0.030 \\
(0.108)\end{array}$ & $\begin{array}{c}0.073^{* *} \\
(0.027)\end{array}$ & $\begin{array}{c}-0.117^{* * *} \\
(0.033)\end{array}$ & $\begin{array}{c}-0.085^{* * *} \\
(0.027)\end{array}$ & $\begin{array}{c}-0.038^{* * *} \\
(0.010)\end{array}$ & $\begin{array}{c}0.069^{* * *} \\
(0.012)\end{array}$ & $\begin{array}{c}0.169 * * * \\
(0.033)\end{array}$ & $\begin{array}{c}0.002 \\
(0.019)\end{array}$ & $\begin{array}{c}-0.225^{* * *} \\
(0.029)\end{array}$ & $\begin{array}{l}-0.042 \\
(0.040)\end{array}$ \\
\hline Division 2 round 2 & $\begin{array}{l}0.035^{*} \\
(0.017)\end{array}$ & $\begin{array}{c}0.063 \\
(0.200)\end{array}$ & $\begin{array}{c}0.335^{* * *} \\
(0.072)\end{array}$ & $\begin{array}{c}0.148 \\
(0.150)\end{array}$ & $\begin{array}{l}-0.043 \\
(0.075)\end{array}$ & $\begin{array}{c}0.136 \\
(0.123)\end{array}$ & $\begin{array}{c}0.024^{* *} \\
(0.011)\end{array}$ & $\begin{array}{c}0.061 \\
(0.067)\end{array}$ & $\begin{array}{c}0.076 \\
(0.120)\end{array}$ & $\begin{array}{c}0.030^{* * *} \\
(0.009)\end{array}$ & $\begin{array}{c}-0.076^{* *} \\
(0.034)\end{array}$ & $\begin{array}{l}-0.030 \\
(0.041)\end{array}$ \\
\hline Division 2 round 3 & $\begin{array}{c}-0.059^{* * *} \\
(0.008)\end{array}$ & $\begin{array}{c}0.111^{* * *} \\
(0.015)\end{array}$ & $\begin{array}{c}0.046 \\
(0.087)\end{array}$ & $\begin{array}{c}0.231^{* * *} \\
(0.012)\end{array}$ & $\begin{array}{c}0.054 \\
(0.060)\end{array}$ & $\begin{array}{c}-0.029^{* *} \\
(0.013)\end{array}$ & $\begin{array}{c}-0.028^{* * *} \\
(0.007)\end{array}$ & $\begin{array}{l}-0.016 \\
(0.015)\end{array}$ & $\begin{array}{c}0.327^{* * *} \\
(0.030)\end{array}$ & $\begin{array}{c}0.018 \\
(0.014)\end{array}$ & $\begin{array}{c}-0.164^{* * *} \\
(0.034)\end{array}$ & $\begin{array}{c}-0.016^{* * *} \\
(0.004)\end{array}$ \\
\hline Division 2 round 4 & $\begin{array}{c}0.018 \\
(0.014)\end{array}$ & $\begin{array}{c}-0.048^{* * *} \\
(0.008)\end{array}$ & $\begin{array}{c}0.243^{* *} \\
(0.091)\end{array}$ & $\begin{array}{c}0.169^{* * *} \\
(0.009)\end{array}$ & $\begin{array}{c}-0.060^{* * *} \\
(0.014)\end{array}$ & $\begin{array}{c}-0.203^{* * *} \\
(0.011)\end{array}$ & $\begin{array}{c}-0.047^{* * *} \\
(0.008)\end{array}$ & $\begin{array}{c}0.095^{* * *} \\
(0.007)\end{array}$ & $\begin{array}{c}-0.052^{*} \\
(0.026)\end{array}$ & $\begin{array}{c}0.034^{* * *} \\
(0.008)\end{array}$ & $\begin{array}{c}0.020 \\
(0.017)\end{array}$ & $\begin{array}{c}-0.008^{* *} \\
(0.003)\end{array}$ \\
\hline Division 2 round 5 & $\begin{array}{c}0.015^{* * *} \\
(0.004)\end{array}$ & $\begin{array}{c}0.158^{* * *} \\
(0.027)\end{array}$ & $\begin{array}{c}0.086 \\
(0.136)\end{array}$ & $\begin{array}{c}0.257^{* * *} \\
(0.006)\end{array}$ & $\begin{array}{l}-0.014 \\
(0.018)\end{array}$ & $\begin{array}{l}-0.003 \\
(0.043)\end{array}$ & $\begin{array}{l}-0.001 \\
(0.004)\end{array}$ & $\begin{array}{c}0.238^{* * *} \\
(0.021)\end{array}$ & $\begin{array}{l}-0.052 \\
(0.083)\end{array}$ & $\begin{array}{c}0.038^{* * *} \\
(0.008)\end{array}$ & $\begin{array}{c}0.012 \\
(0.020)\end{array}$ & $\begin{array}{c}0.004 \\
(0.005)\end{array}$ \\
\hline Division 3 round 1 & $\begin{array}{c}-0.121^{* * *} \\
(0.018)\end{array}$ & $\begin{array}{c}-0.126^{* *} \\
(0.044)\end{array}$ & $\begin{array}{c}0.090^{* * *} \\
(0.021)\end{array}$ & $\begin{array}{c}-0.287^{* *} \\
(0.100)\end{array}$ & $\begin{array}{c}0.005 \\
(0.007)\end{array}$ & $\begin{array}{l}-0.025 \\
(0.072)\end{array}$ & $\begin{array}{c}0.008 \\
(0.012)\end{array}$ & $\begin{array}{c}0.071^{* *} \\
(0.028)\end{array}$ & $\begin{array}{c}0.159^{* * *} \\
(0.031)\end{array}$ & $\begin{array}{c}0.022 \\
(0.020)\end{array}$ & $\begin{array}{l}-0.032 \\
(0.048)\end{array}$ & $\begin{array}{l}-0.013 \\
(0.022)\end{array}$ \\
\hline & $-0.083^{* * *}$ & -0.029 & $0.123^{* * *}$ & $-0.226^{*}$ & -0.003 & 0.060 & 0.007 & 0.015 & -0.012 & 0.026 & $-0.132^{*}$ & 0.012 \\
\hline
\end{tabular}


Table C6 - continued from previous page -

\begin{tabular}{|c|c|c|c|c|c|c|c|c|c|c|c|c|}
\hline & $(0.021)$ & $(0.060)$ & $(0.034)$ & $(0.113)$ & $(0.009)$ & $(0.101)$ & $(0.013)$ & $(0.010)$ & $(0.094)$ & $(0.021)$ & $(0.064)$ & $(0.015)$ \\
\hline Division 3 round 3 & $\begin{array}{c}-0.156^{* * *} \\
(0.014)\end{array}$ & $\begin{array}{c}-0.204^{* * *} \\
(0.055)\end{array}$ & $\begin{array}{c}-0.262^{* * *} \\
(0.022)\end{array}$ & $\begin{array}{c}-0.236^{* * *} \\
(0.045)\end{array}$ & $\begin{array}{c}0.018 \\
(0.018)\end{array}$ & $\begin{array}{c}-0.089^{* *} \\
(0.038)\end{array}$ & $\begin{array}{c}0.007 \\
(0.011)\end{array}$ & $\begin{array}{c}0.020 * * \\
(0.008)\end{array}$ & $\begin{array}{c}0.058 \\
(0.057)\end{array}$ & $\begin{array}{c}-0.138^{* * *} \\
(0.006)\end{array}$ & $\begin{array}{c}-0.404^{* * *} \\
(0.024)\end{array}$ & $\begin{array}{c}-0.060^{* *} \\
(0.027)\end{array}$ \\
\hline Division 3 round 4 & $\begin{array}{c}0.026 \\
(0.018)\end{array}$ & $\begin{array}{c}-0.092^{* *} \\
(0.032)\end{array}$ & $\begin{array}{c}0.229^{* * *} \\
(0.030)\end{array}$ & $\begin{array}{c}-0.084^{* *} \\
(0.032)\end{array}$ & $\begin{array}{l}-0.007 \\
(0.007)\end{array}$ & $\begin{array}{c}-0.080^{* *} \\
(0.028)\end{array}$ & $\begin{array}{c}0.007 \\
(0.007)\end{array}$ & $\begin{array}{c}0.016^{* *} \\
(0.007)\end{array}$ & $\begin{array}{c}0.079 \\
(0.052)\end{array}$ & $\begin{array}{c}0.035^{* *} \\
(0.014)\end{array}$ & $\begin{array}{l}0.065^{*} \\
(0.031)\end{array}$ & $\begin{array}{c}0.030^{* *} \\
(0.013)\end{array}$ \\
\hline Division 3 round 5 & $\begin{array}{l}-0.029 \\
(0.022)\end{array}$ & $\begin{array}{c}0.033 \\
(0.045)\end{array}$ & $\begin{array}{c}0.195^{* * *} \\
(0.015)\end{array}$ & $\begin{array}{c}-0.204^{* * *} \\
(0.037)\end{array}$ & $\begin{array}{c}0.001 \\
(0.006)\end{array}$ & $\begin{array}{l}-0.020 \\
(0.049)\end{array}$ & $\begin{array}{c}0.009 \\
(0.010)\end{array}$ & $\begin{array}{c}0.015 \\
(0.011)\end{array}$ & $\begin{array}{l}-0.135 \\
(0.080)\end{array}$ & $\begin{array}{l}-0.016 \\
(0.017)\end{array}$ & $\begin{array}{c}0.030 \\
(0.018)\end{array}$ & $\begin{array}{l}-0.001 \\
(0.007)\end{array}$ \\
\hline Division 4 round 1 & $\begin{array}{c}-0.191^{* * *} \\
(0.054)\end{array}$ & $\begin{array}{c}-0.198^{* *} \\
(0.085)\end{array}$ & $\begin{array}{l}-0.099 \\
(0.109)\end{array}$ & $\begin{array}{c}-0.278^{* * *} \\
(0.064)\end{array}$ & $\begin{array}{c}-0.040^{* * *} \\
(0.013)\end{array}$ & $\begin{array}{c}-0.139^{* *} \\
(0.055)\end{array}$ & $\begin{array}{l}-0.069 \\
(0.043)\end{array}$ & $\begin{array}{c}0.055^{* *} \\
(0.024)\end{array}$ & $\begin{array}{l}-0.063 \\
(0.165)\end{array}$ & $\begin{array}{l}-0.038 \\
(0.045)\end{array}$ & $\begin{array}{c}-0.530 * * * \\
(0.075)\end{array}$ & $\begin{array}{l}-0.045 \\
(0.040)\end{array}$ \\
\hline Division 4 round 2 & $\begin{array}{l}-0.024 \\
(0.030)\end{array}$ & $\begin{array}{c}-0.162^{*} \\
(0.084)\end{array}$ & $\begin{array}{c}0.124 \\
(0.159)\end{array}$ & $\begin{array}{c}-0.227^{* * *} \\
(0.058)\end{array}$ & $\begin{array}{c}-0.022 * \\
(0.012)\end{array}$ & $\begin{array}{l}-0.084 \\
(0.070)\end{array}$ & $\begin{array}{l}-0.070 \\
(0.042)\end{array}$ & $\begin{array}{c}0.033 \\
(0.043)\end{array}$ & $\begin{array}{c}-0.083^{* *} \\
(0.032)\end{array}$ & $\begin{array}{c}0.028 \\
(0.029)\end{array}$ & $\begin{array}{l}-0.228 \\
(0.150)\end{array}$ & $\begin{array}{l}-0.022 \\
(0.040)\end{array}$ \\
\hline Division 4 round 3 & $\begin{array}{c}-0.236^{*} \\
(0.114)\end{array}$ & $\begin{array}{c}-0.162^{* *} \\
(0.057)\end{array}$ & $\begin{array}{c}-0.053 \\
(0.161)\end{array}$ & $\begin{array}{c}-0.229^{* * *} \\
(0.059)\end{array}$ & $\begin{array}{l}-0.004 \\
(0.024)\end{array}$ & $\begin{array}{c}-0.115^{* * *} \\
(0.038)\end{array}$ & $\begin{array}{l}-0.077 \\
(0.046)\end{array}$ & $\begin{array}{c}0.087 \\
(0.063)\end{array}$ & $\begin{array}{l}-0.066 \\
(0.040)\end{array}$ & $\begin{array}{l}-0.010 \\
(0.036)\end{array}$ & $\begin{array}{c}-0.393^{* * *} \\
(0.097)\end{array}$ & $\begin{array}{l}-0.010 \\
(0.032)\end{array}$ \\
\hline Division 4 round 4 & $\begin{array}{l}-0.009 \\
(0.012)\end{array}$ & $\begin{array}{c}-0.144^{* * *} \\
(0.044)\end{array}$ & $\begin{array}{c}0.344^{* * *} \\
(0.100)\end{array}$ & $\begin{array}{c}-0.141^{* *} \\
(0.056)\end{array}$ & $\begin{array}{c}-0.025^{* *} \\
(0.010)\end{array}$ & $\begin{array}{c}0.000 \\
(0.073)\end{array}$ & $\begin{array}{l}-0.074 \\
(0.053)\end{array}$ & $\begin{array}{c}0.085 \\
(0.064)\end{array}$ & $\begin{array}{l}-0.078 \\
(0.065)\end{array}$ & $\begin{array}{c}0.023 \\
(0.020)\end{array}$ & $\begin{array}{l}-0.093 \\
(0.064)\end{array}$ & $\begin{array}{c}0.018 \\
(0.012)\end{array}$ \\
\hline Division 4 round 5 & $\begin{array}{c}0.005 \\
(0.009)\end{array}$ & $\begin{array}{c}-0.105^{* *} \\
(0.049)\end{array}$ & $\begin{array}{c}0.418^{* * *} \\
(0.054)\end{array}$ & $\begin{array}{c}-0.137^{* * *} \\
(0.045)\end{array}$ & $\begin{array}{l}-0.012 \\
(0.017)\end{array}$ & $\begin{array}{l}-0.053 \\
(0.043)\end{array}$ & $\begin{array}{l}-0.075 \\
(0.045)\end{array}$ & $\begin{array}{c}0.075 \\
(0.065)\end{array}$ & $\begin{array}{c}0.041 \\
(0.048)\end{array}$ & $\begin{array}{c}0.025 \\
(0.019)\end{array}$ & $\begin{array}{l}-0.010 \\
(0.028)\end{array}$ & $\begin{array}{c}0.019 \\
(0.012)\end{array}$ \\
\hline Division 5 round 1 & $\begin{array}{l}-0.050 \\
(0.029)\end{array}$ & $\begin{array}{c}-0.341^{* * *} \\
(0.058)\end{array}$ & $\begin{array}{l}-0.120 \\
(0.156)\end{array}$ & $\begin{array}{c}-0.376^{* * *} \\
(0.031)\end{array}$ & $\begin{array}{l}-0.040 \\
(0.029)\end{array}$ & $\begin{array}{c}0.010 \\
(0.047)\end{array}$ & $\begin{array}{c}-0.040^{* * *} \\
(0.013)\end{array}$ & $\begin{array}{c}0.031^{* *} \\
(0.014)\end{array}$ & $\begin{array}{l}-0.105 \\
(0.067)\end{array}$ & $\begin{array}{c}-0.015^{* *} \\
(0.007)\end{array}$ & $\begin{array}{c}-0.356^{* * *} \\
(0.121)\end{array}$ & $\begin{array}{c}-0.068^{* * *} \\
(0.019)\end{array}$ \\
\hline Division 5 round 2 & $\begin{array}{c}-0.216^{*} \\
(0.119)\end{array}$ & $\begin{array}{c}-0.165^{* * *} \\
(0.021)\end{array}$ & $\begin{array}{c}0.011 \\
(0.141)\end{array}$ & $\begin{array}{c}-0.200^{* *} \\
(0.084)\end{array}$ & $\begin{array}{l}-0.041 \\
(0.028)\end{array}$ & $\begin{array}{c}0.045 \\
(0.065)\end{array}$ & $\begin{array}{c}-0.026^{*} \\
(0.014)\end{array}$ & $\begin{array}{c}0.013 \\
(0.009)\end{array}$ & $\begin{array}{c}-0.176^{* * *} \\
(0.047)\end{array}$ & $\begin{array}{l}-0.013 \\
(0.012)\end{array}$ & $\begin{array}{c}-0.285^{* *} \\
(0.109)\end{array}$ & $\begin{array}{l}-0.014 \\
(0.015)\end{array}$ \\
\hline Division 5 round 3 & $\begin{array}{c}-0.099^{* * *} \\
(0.024)\end{array}$ & $\begin{array}{c}-0.354^{* * *} \\
(0.052)\end{array}$ & $\begin{array}{c}-0.157^{* * *} \\
(0.038)\end{array}$ & $\begin{array}{c}-0.399^{* * *} \\
(0.036)\end{array}$ & $\begin{array}{l}-0.027 \\
(0.019)\end{array}$ & $\begin{array}{c}-0.059 * \\
(0.029)\end{array}$ & $\begin{array}{c}-0.039^{* * *} \\
(0.013)\end{array}$ & $\begin{array}{c}0.017^{* *} \\
(0.008)\end{array}$ & $\begin{array}{c}-0.176^{* * *} \\
(0.051)\end{array}$ & $\begin{array}{c}0.006 \\
(0.016)\end{array}$ & $\begin{array}{c}-0.375^{* * *} \\
(0.061)\end{array}$ & $\begin{array}{c}0.001 \\
(0.014)\end{array}$ \\
\hline Division 5 round 4 & $\begin{array}{c}-0.013 \\
(0.011)\end{array}$ & $\begin{array}{c}-0.319^{* * *} \\
(0.050)\end{array}$ & $\begin{array}{c}0.194^{* * *} \\
(0.046)\end{array}$ & $\begin{array}{c}-0.298^{* * *} \\
(0.027)\end{array}$ & $\begin{array}{l}-0.045 \\
(0.031)\end{array}$ & $\begin{array}{l}-0.063 \\
(0.042)\end{array}$ & $\begin{array}{l}-0.024 \\
(0.017)\end{array}$ & $\begin{array}{c}0.061^{* * *} \\
(0.017)\end{array}$ & $\begin{array}{c}-0.119 * * * \\
(0.033)\end{array}$ & $\begin{array}{l}0.013^{*} \\
(0.007)\end{array}$ & $\begin{array}{l}-0.042 \\
(0.038)\end{array}$ & $\begin{array}{l}-0.004 \\
(0.015)\end{array}$ \\
\hline Division 5 round 5 & $\begin{array}{l}-0.007 \\
(0.010)\end{array}$ & $\begin{array}{c}-0.332^{* * *} \\
(0.051)\end{array}$ & $\begin{array}{c}0.376^{* * *} \\
(0.024)\end{array}$ & $\begin{array}{c}-0.345^{* * *} \\
(0.033)\end{array}$ & $\begin{array}{l}-0.046 \\
(0.030)\end{array}$ & $\begin{array}{l}-0.042 \\
(0.031)\end{array}$ & $\begin{array}{c}-0.025^{*} \\
(0.013)\end{array}$ & $\begin{array}{c}0.035^{* * *} \\
(0.010)\end{array}$ & $\begin{array}{l}-0.031 \\
(0.042)\end{array}$ & $\begin{array}{c}0.006 \\
(0.006)\end{array}$ & $\begin{array}{l}-0.012 \\
(0.030)\end{array}$ & $\begin{array}{c}0.003 \\
(0.005)\end{array}$ \\
\hline Constant & $\begin{array}{c}1.073^{* * *} \\
(0.094)\end{array}$ & $\begin{array}{c}0.240^{* * *} \\
(0.069)\end{array}$ & $\begin{array}{c}0.621^{* * *} \\
(0.082)\end{array}$ & $\begin{array}{c}0.430^{* * *} \\
(0.080)\end{array}$ & $\begin{array}{c}0.049 \\
(0.033)\end{array}$ & $\begin{array}{c}0.074 \\
(0.092)\end{array}$ & $\begin{array}{c}-0.028 \\
(0.051)\end{array}$ & $\begin{array}{c}0.026 \\
(0.046)\end{array}$ & $\begin{array}{c}0.483^{* * *} \\
(0.117)\end{array}$ & $\begin{array}{c}0.990^{* * *} \\
(0.047)\end{array}$ & $\begin{array}{c}0.932^{* * *} \\
(0.134)\end{array}$ & $\begin{array}{c}1.072^{* * *} \\
(0.041)\end{array}$ \\
\hline
\end{tabular}


Table C6 - continued from previous page -

Model statistics:

$R^{2}$

0.304

0.574

0.367

0.607

0.350

0.368

0.301

0.369

0.412

0.247

0.389

0.242

Notes: Estimates are based on an unbalanced panel data set with 5,506 observations and 1,062 groups. It is important to note that the items included in the two food groups meat and fish and seafood and seafood are slightly altered. Instead of having one group for meat, poultry and offal, and one group for fish and seafood, we have one group for goat and sheep meat and one group for fish, seafood, offal and all other meat. Errors shown in parentheses are robust and clustered at the sub-location level. $\mathrm{MP}=$ mobile phone. TLU $=$ Tropical Livestock Unit. ${ }^{*},{ }^{* *},{ }^{* * *}$ denote statistical significance at the $10 \%, 5 \%, 1 \%$ level respectively. 


\section{Eidesstattliche Erklärung}

Hiermit erkläre ich eidesstattlich, dass

1. diese Arbeit weder in gleicher noch in ähnlicher Form bereits anderen Prüfungsbehörden vorgelegen hat.

2. ich mich an keiner anderen Hochschule um einen Doktorgrad beworben habe.

Göttingen, den 21.03.2020

(Unterschrift)

Hiermit erkläre ich eidesstattlich, dass diese Dissertation selbstständig und ohne unerlaubte Hilfe angefertigt wurde.

Göttingen, den 21.03.2020

(Unterschrift) 


\section{Martin C. Parlasca \\ Curriculum Vitae}

\section{COMPETENCY PROFILE}

- Profound analytical and quantitative methodological skills

- Communicative team player

- Several working positions in East Africa within multinational teams

- Experience in conducting household surveys and economic experiments

- Ability to write for a variety of audiences

\section{EDUCATION}

07/2017-03/2020

$10 / 2014-12 / 2016$

08/2012 - 12/2012

$10 / 2010-07 / 2014$

2000-2009

$08 / 2006-06 / 2007$

\section{Doctoral Candidate in Agricultural Economics}

Göttingen University, degree: Dr. rer. pol (05/2020)

Thesis: Essays on Trust, Phones, and Nutrition among Pastoralists in Northern Kenya.

\section{Agricultural and Food Economics M.Sc.}

Bonn University, Degree: Master of Science: 12/2016. $(1,2)$

Focus: Agricultural and Development Policies, and Agribusiness

Thesis: Motivation for Bilateral Development Assistance in the $21^{\text {st }}$ Century.

Exchange semester at Korea University in Seoul, Korea.

\section{Business Administration B.Sc.}

Cologne University, Degree: Bachelor of Science: 07/2014 (1,6).

Major: International Management, and Corporate Organization.

Thesis: Chances and Challenges of Employability Enhancement.

Otto Pankok Gymnasium in Mülheim an der Ruhr.

Degree: Secondary School Diploma 06/2009 $(1,7)$

Hargrave High School Huffman, TX, USA.

\section{WORK EXPERIENCE}

Since $04 / 2020$

$07 / 2017-03 / 2020$

$01 / 2017-06 / 2017$

$08 / 2016-11 / 2016$

05/2015 - 08/2016

\section{Post-doctoral Researcher}

Chair of International Food Economics and Rural Development,

Georg-August University Göttingen, Germany

\section{Research Associate}

Research Training Group: Transformation of Global Agri-Food Systems GlobalFood,

Chair of Farm Management, Georg-August University Göttingen, Germany

\section{Agricultural Trainer}

Arava Institute of Sustainable Development within the project Furrows in the Desert in Lobur, North Turkana, Kenya.

\section{Secondary level Teacher}

for the subjects Biology and Natural Phenomena, at the German Embassy School Addis Ababa, Ethiopia.

\section{Research assistant}

German Development Institute, Department of World Economics and Development Finance in Bonn, Germany. 


\section{Student research assistant}

Bonn University, Institute for Food and Resource Economics, Chair of Production Economics.

Project: Risk Preferences and Risk Management of Farmers in the Münsterland.

09/2014

\section{Freelance coach}

Starkmacher e.V., within the project "sICHtbar" about intercultural learning, conflict management and identity development in German schools.

07/2009 - 06/2010 Civil Service Abroad with the Focolare Movement e.V. at the International Youth Institution in Loppiano, Italy.

HONORARY WORK

10/2015 - 04/2016 City of Köln, Drehscheibe Köln/Bonn

Honorary staff member in the refugee work.

12/2014 - 04/2015 Starkmacher e.V., International Youth and Ecology Project PRESET

In Germany and Argentina as a participant and assistant to the project management.

\section{SCIENTIFIC PUBLICATIONS}

Parlasca, Martin C., Daniel Hermann, and Oliver Mußhoff. 2020. "Can mobile phones build social trust? Insights from rural Kenya." Journal of Rural Studies (forthcoming)

Parlasca, Martin C., Oliver Mußhoff, and Matin Qaim. 2020. "Can mobile phones improve nutrition among pastoral communities? Panel data evidence from Northern Kenya." Agricultural Economics, 51(3), 475-488.

Parlasca, Martin C., Daniel Hermann, and Oliver Mußhoff. 2019. "A Radius of trust? Contrasting insights from experiments and survey data." cege disucssion paper, 383.

\section{CONFERENCE PRESENTATIONS (ORAL)}

Parlasca, Martin C., Daniel Hermann, and Oliver Mußhoff. 2019. "Interactive social distance and trust. Different measuring approaches among semi-nomadic pastoralists in Northern Kenya." AAEA Annual Meeting July 21-23, Atlanta, GA, USA.

Parlasca, Martin C., Daniel Hermann, and Oliver Mußhoff. 2019. "Interactive social distance and trust. Different measuring approaches among semi-nomadic pastoralists in Northern Kenya." 93rd AES Annual Conference, April 15-17, 2019, Warwick University, Coventry, UK.

Parlasca, Martin C., Daniel Hermann, and Oliver Mußhoff. 2019. "Interactive social distance and trust. Different measuring approaches among semi-nomadic pastoralists in Northern Kenya." EAAE Seminar 168:

Behavioural Perspectives in Agricultural Economics and Management, February 06-07, Uppsala, Sweden.

\section{NON-SCIENTIFIC PUBLICATIONS AND OUTREACH}

Parlasca, Martin C., Video 2019. GlobalFood: Trust but verify: How mobile phones increase trust among pastoralists in rural Kenya. https://agrardebatten.blog/2019/03/25/globelfood-trust-but-verify-how-mobilephones-increase-trust-among-pastoralists-in-rural-kenya/

Parlasca, Martin C., 2020. Vielfältigere Ernährung durch Handynutzung? Wie Hirten in Kenia von Mobiltelefonen profitieren. https://agrardebatten.blog/2020/04/15/ernahrung-handynutzung-hirten-kenia/

Parlasca, Martin C., Lena Parlasca 2019. "Bittere Not, süßer Überfluss“, Neue Stadt, 2, 15-17

Parlasca, Martin C., Lena Parlasca 2017. "Ein schönes Land, aber kein gutes“, Neue Stadt, 1, 23-25. 